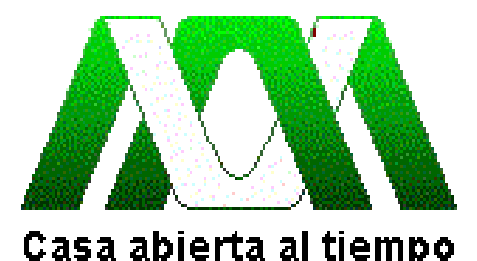

UNIVERSIDAD AUTÓNOMA METROPOLITANA

UNIDAD IZTAPALAPA

DIVISIÓN DE CIENCIAS SOCIALES Y HUMANIDADES

POSGRADO EN CIENCIAS ANTROPOLÓGICAS

Caminando por el arte y la cultura en la calle Francisco I. Madero del Centro Histórico de la Ciudad de México.

Ginna Alexandra Zabre Santamaría

Tesina de Maestría en Ciencias Antropológicas

Directora: Dra. Alba Elena Ávila González

Asesores: Dr. Miguel Ángel Aguilar Díaz

Dr. Eduardo Vicente Nivón Bolán 


\section{Caminando por el arte y la cultura en la calle Francisco I. Madero del Centro Histórico de la Ciudad de México.}

Contenido.

Introducción.

1.

Acercamiento al estudio de las políticas $\quad 1$

culturales.

Debate sobre la definición de cultura.

$1.4 \quad$ Paradigmas políticos de la acción cultural. 22

2. Importancia y acciones en Centros Históricos. 28

$2.1 \quad$ Declaraciones internacionales sobre los $\mathrm{CH}$. 29

2.2 Algunas características de los $\mathrm{CH}$ de América Latina y el 32

Caribe.

$2.3 \quad$ Análisis de los $\mathrm{CH}$. 35

a) Lo espacial. $\quad 37$

b) Lo temporal. $\quad 39$

c) Lo patrimonial. $\quad 40$

3. Revitalización del Centro Histórico de la 44

3.1 Aspectos generales del CH de la Ciudad de México. 45

3.2 Gestión en el CH de la Ciudad de México. 48

3.2.1 Consejo Consultivo para el Rescate del Centro Histórico 49 de la Ciudad de México.

3.2.2 Fideicomiso del Centro Histórico. 51

a) Apoyo al arte. $\quad 53$

3.2.3 Fundación del Centro Histórico de la Ciudad de México 54

A.C.

3.2.4 Autoridad del Centro Histórico. 57

a) Fachadas y Patrimonio cultural tangible. $\quad 58$

b) Peatonalización. $\quad 60$

3.3 Plan Estratégico para la Regeneración y Desarrollo 64

Integral del Centro Histórico de la Ciudad de México.

4. Expresiones artísticas en espacios públicos: $\quad 70$

4.1 Aproximaciones al arte en espacios públicos. 71

4.2 Del arte público al performance: estatuas vivientes. 79 
4.3 Estatuas humanas en México y el mundo.

a) Performance en la década de los setenta: escultura viva. 84

b) Estatuas humanas: teatro, pantomima y calle. 88

- Esbozo histórico de las estatuas humanas y su 90 escenario: la calle.

- Mensaje y público de las estatuas vivientes. 96

Galería: Estatuas humanas del mundo. 100

5.

Rehabilitación de la calle Francisco I. Madero: 101 El conflicto por el espacio público desde el arte.

Patrimonio cultural tangible: Museos y sus edificios emblemáticos.

a) Casa del Conde del Valle de Orizaba /Casa de los Azulejos.

b) Antiguo Palacio de Iturbide / Palacio de Cultura

Banamex.

c) Antigua Joyería La Esmeralda / Museo del Estanquillo. Peatonalización de la calle. Francisco I. Madero.

a) La necesidad y el arte confluyen en Madero.

b) La calle como escenario y el cambio de coordenadas en

el $\mathrm{CH}$.

c) Del comercio ambulante al artista callejero ¿Sólo hay 138 un paso?

5.5 Intentando regularizar el arte callejero en Madero.

a) Remitidos al Juez Cívico 33: Obstrucción de vía 141 pública.

b) Credenciales de la Secretaría del Trabajo: No asalariados.

c) Del Punto de Acuerdo del Diputado Arturo López

Candido a la creación de ES CULTURA VIVIENTE FUERA DE TIEMPO A.C.

- ES CULTURA VIVIENTE FUERA DE TIEMPO A.C.

d) Del Punto de Acuerdo a la intervención del Fideicomiso del $\mathrm{CH}$ y PRO DIANA A.C.

- Reunión realizada con el Fideicomiso del CH: 12 de enero de 2011.

- Reunión realizada con el Fideicomiso del CH: 18 de enero de 2011.

- Reunión realizada con el Fideicomiso del CH: 20 de enero de 2011.

Galería: Artistas de la calle Francisco I. Madero. 
Conclusiones

Fuentes consultadas 


\section{Agradecimientos.}

A la Universidad Autónoma Metropolitana por haberme dado la oportunidad de encontrar en la Antropología Social el conocimiento y las herramientas para llevar a cabo esta investigación, por abrirme los ojos hacia una realidad que no deja de asombrarme y me cautiva día a día.

A la Dra. Yanina Ávila por haberme mostrado un campo fértil de estudio, por cambiar mi mirada hacia el Centro Histórico y por enseñarme que en este espacio el corazón, la vida y la riqueza social están a cada paso que damos. Al Dr. Miguel Ángel Aguilar por apoyarme a lo largo de esta investigación, por compartir su experiencia de campo y de docencia, por el interés mostrado, el impulso y la confianza para realizar este análisis. Al Dr. Eduardo Nivón por todas las enseñanzas a lo largo de estos años, por ayudarme a navegar en las Políticas Culturales, por sus comentarios certeros y el apoyo teórico y de campo que me ha dado, por mostrarme terrenos de análisis como el arte. Sin su paciencia, guía y apoyo no hubiera sido posible realizar esta investigación.

A las estatuas vivientes, por permitirme estar a su lado estos meses, por mostrarme el lado humano, estético y fascinante del estatismo. Por permitirme ser parte de ese espacio, por compartir sus experiencias, sus sueños y sus historias en este tiempo. Gracias a todos los personajes, estatuas vivientes, músicos, payasos, por permitirme ser la voz que narra su historia en esta calle del Centro Histórico.

A las instituciones que me apoyaron con información y entrevistas para realizar esta investigación. Locatarios y visitantes que formaron parte de este análisis.

A mi mamá, Judith Santamaría Díaz que nunca ha dejado de confiar en mí. Por su cariño, apoyo, conocimientos a lo largo de mi vida, así como la paciencia y experiencia que tuvo con esta investigación, por la lectura detallada y los cuestionamientos constantes. Su tenacidad, consejos y ejemplo son motores para mi vida. A mi hermano Alfonso Zabre Santamaría, que con su cariño y ejemplo me impulsa a seguir adelante, a luchar por mis sueños. Gracias por apoyarme en mis decisiones. A Ponchito y Leo que aguantaron mis ausencias y estrés constante, pero siempre me dieron una sonrisa a cambio. 
A Hugo Martínez Aquino, por el apoyo incondicional durante casi siete años, por impulsarme a seguir adelante, por demostrarme que las metas se pueden alcanzar con trabajo constante. Por tu apoyo metodológico y de análisis. Gracias por tu amor y comprensión estos años, eres parte fundamental de mi vida.

A mis amigos por la paciencia, el tiempo compartido y el apoyo constante durante estos años.

A mi familia por el cariño, interés, apoyo y pláticas que me orientan en la vida. En especial al Huizachal, que siempre me impulsó a lograr mis sueños, por darme consejos de vida, por recibirme con los brazos abiertos a pesar de mis ausencias y porque ahora sé que es: "Todo lo mejor y sólo lo mejor".

Gracias a todos los que contribuyeron personal o académicamente para que esta tesis se llevara a cabo, por su apoyo, solidaridad, paciencia y consejos compartidos. 


\section{Introducción.}

La presente investigación es el resultado de dos años de estudios de Maestría en Ciencias Antropológicas en la Universidad Autónoma Metropolitana. Como parte de mi formación profesional desarrollé este estudio para culminar con mi Tesis de Maestría, para la cual realizo una discusión teórica sobre los temas a desarrollar, así como investigación de campo. En este caso, el trabajo de campo lo realicé en el Centro Histórico de la Ciudad de México, concretamente en Francisco I. Madero, calle recientemente peatonalizada y donde el arte no se encuentra solamente en foros establecidos, sino en el espacio público.

La elección del tema a desarrollar lo llevé a cabo por la asistencia continúa al Centro Histórico y las pláticas informales con los artistas callejeros. En un principio realizaría la investigación de políticas culturales y oferta cultural en tres calles peatonales de este espacio: Guatemala, Regina y Madero. Sin embargo, al encontrarme inmersa en el trabajo de campo comprendí la complejidad que existe en la calle Francisco I. Madero, así como la disposición (por momentos) de los artistas callejeros, lo cual me llevó a estudiar solamente esta calle. Dicha etapa de investigación comenzó el 12 de enero de 2011 y culminó el 20 de junio. Realicé alrededor de 50 entrevistas, entre artistas callejeros: a los cuales entrevisté a profundidad y por medio de observación participante. Funcionarios de algunas instancias de gobierno del Centro Histórico: mediante entrevistas a profundidad. Visitantes: a los cuales realicé entrevistas itinerantes. Encargados de Relaciones públicas de los museos establecidos en esta calle: por medio de entrevistas a profundidad. Así como algunos locatarios de la calle: por medio de entrevistas a profundidad. La decisión de tener contacto con distintos sectores surgió por la complejidad contenida en este espacio, debido al conflicto por el uso de la calle para manifestaciones artísticas. Consideré necesario entrevistar a diversos sectores involucrados en el uso y protección de la calle, así como a personas que tienen estrecha relación con el arte en los museos de Francisco I. Madero.

Dicha calle de estudio está ubicada en el Centro Histórico de la Ciudad de México y debido a la revitalización ocurrida en ella, se ha convertido en un espacio con características particulares, donde la historia y el arte callejero se encuentran a cada paso. Su ubicación en el Centro Histórico la convierten en un espacio hiper regulado, en 
donde el arte callejero no cuenta con políticas culturales acordes con estas manifestaciones.

Cabe aclarar que el Centro Histórico del DF no es un caso aislado de revitalización, ya que forma parte de un proyecto global que ocurre en diversas latitudes del mundo, en donde se busca mejorar las condiciones de edificios patrimoniales, vivienda y seguridad, pero en el caso de estudio se deja a un lado el apoyo para los artistas callejeros en este espacio.

Considero que como marco teórico para poder explicar y analizar este fenómeno de estudio, es importante precisar y profundizar en la teoría y práctica de las políticas culturales, por medio de los autores más representativos del tema, así como las características de la revitalización de los Centros Históricos en Iberoamérica. Debido a que el arte callejero en espacios como los Centros Históricos requiere de profundidad en el análisis de las políticas culturales y urbanas en la ciudad. Otro elemento teórico que consideré relevante presentar fue el arte público, para presentar claramente el caso de estudio, en donde los artistas callejeros pugnan por presentar Arte para todos, en un espacio libre como es la calle. Sin embargo, el apoyo institucional para estas actividades es casi nulo y eso ha generado conflictos dentro y fuera del grupo de estudio, lo cual muestra la complejidad del tema de estudio y el espacio específico en el que se analiza: Centro Histórico de la Ciudad de México.

La hipótesis de esta investigación es:

La revitalización del Centro Histórico y en particular de la calle de Madero como espacio público con vasto patrimonio cultural, en donde se encuentra la cultura y la historia, deja de lado manifestaciones y expresiones urbanas que van más allá de la cultura y arte en foros cerrados y/o patrimoniales. ¿Cómo lograr encuentros entre arte urbano-callejero (espacio público) y el patrimonio cultural en las políticas culturales del corredor Madero en el Centro Histórico?

Debido a las políticas culturales de revitalización del Centro Histórico, el patrimonio cultural tangible se ha convertido en eje conductor de acciones, se encuentra conservado y casi inmaculado ante el paso del tiempo. Sin embargo, en estas mismas calles se encuentran manifestaciones artísticas, que no cuentan con apoyo institucional para 
desarrollarse, por lo tanto, consideré relevante esta investigación en un espacio que denota identidad, memoria, historia, pero también un acercamiento con el arte a pie de calle, el cual es poco considerado desde las políticas culturales locales y federales. Si la revitalización de Centros Históricos se realiza considerando el patrimonio cultural tangible, expresado en edificaciones prehispánicas, virreinales o modernas, al parecer no se contemplan otras expresiones del patrimonio cultural. La hipótesis surge a raíz de las primeras observaciones en campo y el análisis teórico de la revitalización de Centros Históricos a nivel mundial.

Objetivo general de esta investigación:

Análisis de las políticas culturales en la revitalización del corredor Madero en el Centro Histórico de la Ciudad de México. Así como el uso, percepción de arte y cultura en este espacio público.

Objetivos específicos:

- Investigación y análisis del Plan Estratégico para la Regeneración y Desarrollo Integral del Centro Histórico de la Ciudad de México. Máximo documento para la denominada revitalización del Centro Histórico de la Ciudad de México.

- Análisis sobre la revitalización de la calle Madero del Centro Histórico de la Ciudad de México.

- Investigación con usuarios, artistas, instituciones de gobierno, asociaciones civiles y locatarios, sobre la transformación surgida de la peatonalización de la calle.

- Análisis sobre el conflicto por el uso del espacio público en esta calle, escenario en donde los artistas callejeros han encontrado una forma de vida y expresión, pero no han logrado acuerdos para tener políticas culturales que los apoyen, ni desarrollen estas actividades.

En el primer apartado titulado Acercamiento al estudio de las políticas culturales, considero la complejidad que existe en dichas políticas, desde el debate de la definición de cultura, ya que si no la tenemos clara, será difícil realizar políticas en este sentido. Consideré importante retomar lo presentado por García Canclini sobre lo cultural, como esa lucha de significados, ¿Quién define? ¿Desde dónde? ¿Para quién define?, ya que si 
las políticas culturales solamente son verticales pueden surgir conflictos desde la definición y acciones para el desarrollo humano y social por medio de la cultura. Para esta investigación, lo cultural, juega un rol fundamental, ya que desde algunos discursos de los funcionarios y representantes de los museos en esta calle, las actividades artísticas realizadas a pie de calle no cuentan con los cánones para ser considerado arte, así que éste es un primer obstáculo, ya que depende desde dónde se defina es la manera en que se proyectan algunas políticas culturales. En este mismo capítulo tengo un apartado sobre la función cultural del Estado, que en su momento era el encargado de todas las políticas culturales. En el caso de estudio, el Estado sigue siendo el eje que dicta las pautas a seguir, por el uso del espacio público y las restricciones en él para el arte sin formación profesional. Con la definición de política cultural de García Canclini, considero se da un giro, ya que el Estado no será el único agente que decida sobre dichas acciones, deberá existir mayor participación de la sociedad, esto es, si tenemos políticas culturales incluyentes, los resultados serán más favorecedores. Para concluir este apartado retomo los paradigmas de acción cultural presentados por García Canclini, ya que en ellos se marca la importancia del patrimonio cultural (Tradicionalismo patrimonialista, el cual considero es vigente en el Centro Histórico) y Democracia Participativa, como el ideal de políticas culturales, donde exista participación y diálogo entre diferentes expresiones artísticas y culturales, que en el caso de estudio no se ha dado de la manera adecuada, ni con los resultados esperados.

En el segundo apartado titulado Importancia y acciones en Centros Históricos, realizo un esbozo de la relevancia de estos espacios, como identitarios, históricos, de apropiación, de desarrollo de nuestras ciudades, ya que en su momento, eran la ciudad misma. Los Centros Históricos tienen estrecha relación con el patrimonio cultural tangible, como lo expreso en las declaraciones de protección de éste, así que no es de extrañar que se dé tanto apoyo a estas edificaciones, que como menciona Carrión, el patrimonio cultural es la síntesis de espacio y tiempo y genera relaciones sociales de apropiación. Por lo que, el apoyo para la conservación a ultranza no es una novedad, sino parte de políticas que buscan generar identidad y memoria en la población, no sólo de nuestro Centro Histórico, sino de todo el mundo. La revitalización de estos sitios se ha dado en diversas ciudades del globo, comenzó en Europa después de la segunda guerra mundial y se ha convertido en un modelo a seguir por el resto de los países en América Latina y el Caribe, aunque no es conveniente caer en modelos a copiar, sino en 
comprender la complejidad de cada Centro Histórico, ya que en nuestro continente, estos espacios tienen la dicotomía: riqueza histórica y pobreza económica. Por lo tanto, las acciones deberán generar desarrollo social e identitario, aunque la conservación del patrimonio cultural tangible es una constante en todo el mundo, como recuerdo de nuestra historia y cultura.

El tercer capítulo es sobre el Centro Histórico de la Ciudad de México, catalogado en 1980 como zona de monumentos por el Gobierno Federal, lo cual nos muestra una política cultural patrimonialista. En 1987 es incluido por UNESCO en la lista de Patrimonio Cultural de la Humanidad, lo cual genera una transformación sobre las acciones en este espacio que estaba en grave deterioro por el despoblamiento provocado por el terremoto de 1985, por la inseguridad y la violencia. La investigación sobre las acciones en este espacio decidí comenzarla en 1997, año en el cual se eligió por primera vez al Jefe de Gobierno de la Ciudad de México, quien desde un principio expresó la importancia de tener un Centro Histórico con vida, mejorando viviendas, áreas comerciales, culturales, etc., por lo tanto, es el inicio de las acciones en nuestro Centro Histórico. Este espacio comprende alrededor de veinte instancias que hacen la gestión, por lo tanto, es posible que los resultados no sean tan incluyentes y que existan intereses privados o políticos de por medio. Para demostrar este aspecto, decidí esbozar algunas instituciones creadas o reconfiguradas para la gestión del Centro Histórico, cada una con diferentes programas, pero trabajando en colaboración, algunas de manera local y otras federales como el Consejo Consultivo para el Rescate del Centro Histórico de la Ciudad de México (2001), en donde la iniciativa privada juega un rol fundamental para las acciones en este espacio. Por otra parte, el Fideicomiso del Centro Histórico, en la actualidad es público y apoya las actividades de diferentes instituciones, pero también propone acciones en este espacio. El apoyo al arte otorgado por esta instancia, pareciera que es para foros establecidos, asociaciones, etc., pero el arte callejero no está dentro de sus acciones específicas, aunque han tenido acercamiento con ellos, no se ha llegado a ningún acuerdo que genere el desarrollo de estas manifestaciones. Otra institución, que es meramente privada es la Fundación del Centro Histórico de la Ciudad de México A.C, la cual ha dado gran apoyo a dicho espacio, cuenta con diferentes programas, en donde el arte es apoyado con la creación de Casa Vecina y el Atrio de San Francisco (en la calle Francisco I. Madero), sin embargo, no existe apoyo, ni conocimiento del arte callejero. Por último, la recién creada (2007) Autoridad del Centro Histórico, que tiene 
mayores atribuciones que las anteriores, cuenta con el apoyo directo del Jefe de Gobierno del DF y ha realizado acciones sin precedentes en este espacio, como lo fue el quitar el comercio ambulante, algunos de sus programas más relevantes son el apoyo para conservación de fachadas y patrimonio cultural tangible, así como la peatonalización de algunas calles del Centro Histórico. Cabe destacar que, esta última instancia no cuenta con programas de apoyo al arte, por lo tanto, al ser la máxima autoridad de este espacio, no es de extrañar que existan conflictos por el uso del espacio público para el arte. Por último, presento el Plan Estratégico para la Regeneración y Desarrollo Integral del Centro Histórico de la Ciudad de México, en donde el rescate y uso del espacio público son ejes conductores de acciones, así como el fomento de la oferta cultural. Sin embargo, no hay mención sobre al arte en espacios públicos, por lo tanto, no cuentan con apoyo institucional para sus actividades. En este apartado quise destacar la complejidad institucional y de programas en la gestión del Centro Histórico, ya que en ocasiones no queda claro qué hace cada instancia, hay programas que se hacen en coordinación con otras instituciones, por lo tanto, la gestión en este espacio es compleja y eso genera que las acciones se tornen dispersas y sin líneas certeras.

En el cuarto capítulo titulado Expresiones artísticas en espacios públicos: Arte público y estatuas humanas. Realicé un recorrido teórico por el arte público, el cual comienza con las definiciones de arte, espacio público y arte en espacio público. Comencé con la definición clásica de arte público, que remite a monumentos, esculturas, etc. en espacios públicos, para así ampliar la definición hacia la performance como el uso de diferentes expresiones artísticas, donde la libertad creativa mezcla teatro, video, literatura, el cuerpo como lienzo, etc., para adentrarme al estudio de las estatuas vivientes, ya que en la calle de estudio existen alrededor de 30, por lo tanto, este es el comienzo del análisis sobre arte en espacios públicos. Desde la performance existen ejemplos ilustradores sobre el desarrollo del estatuismo viviente, como es el caso de Gilbert y George en Londres en la década de los setenta, en donde se promulgaba que el arte era para todos, máxima que retomo para el caso de estudio, donde las manifestaciones artísticas en la calle buscan que el arte no tenga restricciones académicas, de foros, ni de creatividad, sino relación directa con el público. Los últimos incisos de este capítulo están dedicados exclusivamente a las estatuas vivientes en el mundo, su historia remite al uso del teatro, pantomima y la calle, por lo tanto, realicé un esbozo histórico sobre la síntesis artística y sobre el uso de la calle como escenario de comunicación. Comenzando con la historia 
grecolatina, juglares, etruscos, cuadros vivientes, etc., en los cuales la calle se convirtió en el escenario ideal de comunicación y también un reto para lograr un estrecho contacto con el público. El último inciso es sobre el mensaje y público de las estatuas vivientes, ya que el arte siempre se realiza con base en la comunicación, por lo tanto, ambos elementos son vitales, con la salvedad de que las estatuas vivientes no emiten palabra, todo se hace a través de sus suaves movimientos, por lo tanto, es un reto histriónico, en un escenario no especializado y con público diverso, que no está preparado para ver un espectáculo de esta naturaleza en dicho espacio.

Por último, el capítulo cinco titulado Rehabilitación de la calle Francisco I. Madero: el conflicto por el espacio público desde el arte, se refiere a mi calle de estudio. Para comenzar, realizo una breve historia de ella, ya que desde la etapa novohispana fue una calle comercial, para el gremio platero, por lo tanto, su historia la marca como una de las más importantes del Centro Histórico. En ella se encuentran tres museos y diversos edificios emblemáticos, conservados como testigos de la historia. El patrimonio cultural tangible está inmaculado al paso del tiempo, por lo tanto, podría haberse caído en el tradicionalismo patrimonialista. Desarrollo brevemente la peatonalización de la calle y las acciones generadas en ella. En esta calle no sólo nos encontramos con edificios conservados y museos con propuestas diversas, sino con artistas callejeros, entre estatuas vivientes, personajes, payasos, cantantes, etc., que han estado en diversos plazas del Centro Histórico y llegaron a esta calle por presiones del Gobierno, ya que éste, dentro de sus políticas de revitalización de este espacio, limpió las calles de ambulantes, pero también de artistas callejeros, les permitieron colocarse en dos calles que hacen esquina con Madero y han estado en ellas desde hace cuatro años. La lucha por estos espacios, que les fueron otorgados momentáneamente ha sido larga y tensa, generando conflictos dentro del gremio por la inserción de ambulantes, al sector artístico, lo cual ha provocado incisiones en los artistas callejeros. Cabe aclarar que, en su gran mayoría, los artistas callejeros de esta zona no cuentan con estudios profesionales en arte, lo cual genera críticas desde el sector que cuenta con ellos, estos son algunos de los conflictos internos desarrollados. La gestión para colocarse en esta calle comenzó en 2007, aunque el argumento para no permitir que se expresen es obstrucción en vía pública, lo cual culmina con la remisión al Juez Cívico 33. Han tenido intentos de regularizar su situación, otorgando credenciales desde distintas dependencias, pero los resultados no han sido favorables, la lucha por el espacio es 
constante y en la actualidad se encuentran pagando por el uso de suelo a una asociación que apoya a los comerciantes ambulantes, que no son especialistas en arte, ni en políticas culturales, sino en el uso del espacio público. Esta es la realidad de los artistas callejeros de la calle Francisco I. Madero y aunque han tenido algunas gestiones para regularizar su situación en el Centro Histórico y el espacio público en él, existen diversos intereses económicos y políticos, en donde el arte en el espacio público se ha tomado como rehén de diversos sectores involucrados y las políticas culturales para el arte callejero son inexistentes.

Por último, presento las conclusiones de la investigación, tanto teórica como de campo, lo cual muestra la complejidad del Centro Histórico y de las políticas culturales en este espacio, donde la lucha por el arte para todos se torna cada vez más tensa, la creatividad y el autoempleo por medio del arte se enfrentan cada día con los diversos intereses que existen en el Centro Histórico. 


\section{Acercamiento al estudio de las políticas culturales.}

El tema que desarrollaré en este apartado es sobre políticas culturales y requiere de la reflexión sobre cultura, desarrollo, política e instituciones, entre otras. Dicho análisis también necesita tomar en cuenta el momento histórico en el cual se llevan a cabo estas políticas. En la actualidad, al encontrarnos inmersos en la globalización es importante acercarnos a ellas, tomando en cuenta su historicidad para analizar su desarrollo y las diferentes encrucijadas en las cuales han estado inmersas, así como las condiciones actuales. La presente investigación tiene como base a los autores más representativos y prolíficos del tema, éstos han realizado grandes esfuerzos por focalizar el estudio de las políticas culturales y ofrecer un análisis concienzudo de ellas.

\subsection{Debate sobre la definición de cultura.}

Considero que para realizar una investigación sobre políticas culturales es importante analizar las definiciones de cultura que se han presentado a partir del siglo XIX. Es fundamental retomar dichos conceptos como punto de partida para la investigación de políticas culturales. Debido al interés de instituciones internacionales a este respecto, se presentó en la Conferencia Mundial sobre Políticas Culturales. Declaración de México. UNESCO (1982):

"La cultura puede considerarse actualmente como el conjunto de rasgos distintivos, espirituales y materiales, intelectuales y afectivos que caracterizan a una sociedad o grupo social. Ella engloba, además de las artes y las letras, los modos de vida, los derechos fundamentales, al ser humano, los sistemas de valores, las tradiciones y las creencias."

La definición anterior cuenta con gran amplitud y complejidad, lo cual puede ser considerado una crítica, ya que no especifica campos de acción ni apoyo, aunque también he de destacar el reconocimiento de las artes y las letras como parte de la cultura. Sin embargo, pareciera que la cultura es todo lo producido por el hombre, como lo expresaba Edward B. Tylor en 1871: La cultura [...] es aquel todo complejo que incluye el conocimiento, las creencias, el arte, la moral, el derecho, las costumbres y cualesquiera otros hábitos y capacidades adquiridos por el hombre en cuanto miembro de la sociedad (Tylor en Kahn, 1975: 29). Con esta referencia no quiero anticipar que la definición de cultura propuesta por la UNESCO en el campo de las políticas 
culturales tenga rasgos decimonónicos sino que dentro de dichas políticas se requiere de una definición dinámica, heterogénea donde se expresen algunos rasgos específicos y de acción por parte de dichas políticas.

La discusión en torno a la definición de cultura ha sido larga y compleja, a su vez, ha requerido de diferentes acercamientos conceptuales. Como menciona García Canclini (2008a), ha habido diferentes laberintos del sentido alrededor de su definición. El autor menciona que se han presentado dos confrontaciones: la distinción naturaleza-cultura y sociedad-cultura. La primera quedará clara con la definición de Tylor (y otros autores, como Murdock), ya que cultura es todo lo relacionado y realizado por el hombre, dejando fuera la naturaleza. Esta oposición, para García Canclini (2008a) descarta que esas distinciones también cuentan con visiones etnocéntricas, en donde una cultura era superior a la otra, pero también se encontraba el riesgo de darle peso específico a cada cultura y terminar en un relativismo cultural, en donde la interculturalidad podría ser un elemento conflictivo. La segunda distinción sociedad-cultura fue desarrollada a mediados del siglo XX (Linton y Bourdieu), en donde:

"La sociedad es concebida como el conjunto de estructuras más o menos objetivas que organizan la distribución de los medios de producción y del poder entre los individuos y los grupos sociales, y que determinan las prácticas sociales, económicas y políticas [...] pero queda un residuo, una serie de actos que no parecen tener mucho sentido si se los analiza con una concepción pragmática, como realización del poder o administración de la economía." (García Canclini, 2008a: 32)

La definición de sociedad presentada por el autor y su señalamiento sobre los vacíos en la misma, es fundamental, ya que no podemos caer en una especie de economicismo ni racionalismo cultural al extremo, además de que se dejan de lado las producciones y reproducciones simbólicas.

Las revisiones constantes a la definición de cultura han sido del interés de diferentes investigadores, como Alejandro Grimson (2008) y José Teixeira (2008), quienes hacen una revisión crítica sobre las definiciones presentadas por Tylor y Boas, entre otros. Tanto Grimson como Teixeira (2008) consideran que tales definiciones tienen la concepción de las sociedades como homogéneas, territorializadas, cerradas, donde no existiera la pluralidad cultural ni el contacto entre culturas. Es así, como nos 
introducen a la complejidad y necesaria redefinición de cultura dentro de relaciones sociales globales, donde a pesar de que los territorios están definidos, las identidades no son estáticas. La heterogeneidad es una realidad fundamental para concebir la cultura como dinámica en el mundo actual.

Del mismo modo, García Canclini (2008a) presenta la siguiente definición de cultura: [...] abarca el conjunto de procesos sociales de significación, o, de un modo más complejo, la cultura abarca el conjunto de procesos sociales de producción, circulación y consumo de la significación de la vida social. (García Canclini, 2008a:34). Con dicha definición, el autor concibe la cultura como un proceso social, con vitalidades y heterogeneidades, ya que es producida, consumida, pero también circula. Dicha definición deja de lado las dicotomías material-espiritual, económico-simbólico, individual-colectivo. Sin embargo, el mismo autor comenta que es una definición que concibe a cada sociedad, pero que busca tener alcances universales, lo cual constituye un problema epistemológico para abordar el estudio de la cultura. Antes de continuar, quisiera aclarar que García Canclini (2008a) advierte que la multiculturalidad y la interculturalidad son relaciones que generan diferentes repertorios culturales, que son significados y resignificados, es decir, la cultura ya no se relaciona con identidades concretas, cerradas, sino con relaciones entre culturas. De esta forma, el autor nos acerca al estudio de la cultura imbricada en un conjunto de relaciones sociales, materiales y simbólicas. En otras palabras, con diferentes etapas, que son dinámicas y fundamentales, que cambia a través del tiempo, no es estática...está viva.

La cultura tiene diferentes significaciones, porque es resignificada constantemente, no es un todo monolítico y estático, ya que cada grupo le da significación y uso. Por ejemplo, un tapete artesanal puede convertirse en un cuadro kitsch al cambiar de una cultura a otra. En mi tema de investigación es importante mencionar que el arte realizado en la calle Francisco I. Madero, para unos es una forma de vida, de expresión, para otros la manifestación del desempleo. Sin embargo, se busca comunicar algo, que quizá desde las instituciones que definen la cultura y las políticas en este sentido no se ha contemplado. 
Después de haber presentado de manera breve el debate del concepto de cultura y de realizar algunas críticas a la definición presentada por la UNESCO en 1982, es necesario destacar el papel de estas instancias internacionales en la consideración de las políticas culturales y la cultura como ejes centrales de discusión y redefinición. Retomando la Conferencia Mundial sobre Políticas Culturales. Declaración de México. UNESCO (1982), en la que se llegó a una definición de cultura totalizadora, también se concibió el factor transformador que ésta tiene, con capacidad reflexiva sobre el hombre, en busca de significaciones.

"La cultura da al hombre la capacidad de reflexionar sobre sí mismo. Es ella la que hace que nosotros seres específicamente humanos, racionales, críticos y éticamente comprometidos. A través de ella discernimos los valores y efectuamos opciones. A través de ella el hombre se expresa, toma conciencia de sí mismo, se reconoce como un proyecto inacabado, pone en cuestión sus propias realizaciones, busca incansablemente nuevas significaciones, y crea obras que lo trascienden." (Conferencia Mundial sobre Políticas Culturales, 1982)

Dicho acercamiento por parte de la UNESCO es un gran cambio, ya que la cultura se concibe como reflexiva, transformadora y transformada. Lo cual me remite a la definición de cultura que presenta García Canclini (2002):

"Cultura se denomina a la producción de fenómenos que contribuyen, mediante la representación a la reelaboración simbólica de las estructuras materiales, a comprender, reproducir o transformar el sistema social, es decir, todas las prácticas e instituciones dedicadas a la administración, renovación y reestructuración del sentido.” (García Canclini, 2002:71)

De esta manera, la cultura no es inmóvil sino un proceso de resignificaciones, de transformaciones sociales e institucionales, en donde la sociedad, por medio de sus instituciones y cultura juegan un papel fundamental en las construcciones y significaciones. La reelaboración simbólica es un acercamiento a la forma de entender y abordar la cultura en la globalización, en donde las culturas se reinventan constantemente, sin perder de vista las instituciones generadoras de sentido. Diversidad y heterogeneidad están presentes en las últimas definiciones, donde la cultura ya no es estática como una representación museística, está en múltiples contactos con otras culturas, lo cual genera un diálogo cultural y de resignificación constante.

Respecto a la discusión sobre el concepto de cultura, García Canclini (2008a) retoma a 
Appadurai al exponer que la cultura no debe ser un "objeto o cosa". García Canclini argumenta, basado en Appadurai: lo cultural facilita hablar de la cultura como una dimensión que refiere a "diferencias, contrastes y comparaciones" (García Canclini, 2008a:39). Menciona que desde esta perspectiva, ya no será propiedad de individuos ni grupos sino como una forma para hablar de la diferencia. De esta manera, lo cultural es el conjunto de diferencias que marcan los límites entre una cultura y otra. Así, el estudio de lo cultural se basará en el choque de significados. De ese modo, lo cultural contempla la migración y los medios de comunicación para ver el cambio, que a su vez se expresa en esferas públicas en diáspora, como proceso político (Grimson, 2008: 13).

"Al proponernos estudiar lo cultural, abarcamos el conjunto de procesos a través de los cuales dos o más grupos representan e intuyen imaginariamente lo social, conciben y gestionan las relaciones con otros, o sea las diferencias, ordenan su dispersión y su inconmensurabilidad mediante una delimitación que fluctúa entre el orden que hace posible el funcionamiento de la sociedad, las zonas de disputa (local y global) y los actores que la abren a lo posible." (García Canclini, 2008a: 40)

Es así como el autor nos remite a la complejidad de hablar de la cultura, pero no sólo de ella como algo propio de ciertos grupos sociales, con características definidas, con fronteras, con estructuras impermeables, estáticas. Si bien, el mismo autor nos ha acercado a definiciones de cultura que son dinámicas, donde la pluralidad cultural juega un papel fundamental en el desarrollo de los grupos sociales, donde la significación, transformación y reapropiación son procesos clave en el desarrollo de las culturas; el acercamiento a lo cultural nos permite adentrarnos en el terreno de los conflictos por la lucha de significados, por las diferencias, entre otras. De esta manera, la globalización y la pluralidad cultural nos presentan al "otro" frente a "nosotros" y eso genera otra serie de relaciones, que se encuentran en el campo de lo que estos autores denominan "lo cultural". Siguiendo esta línea, es importante enfatizar que al existir una cierta lucha por las diferencias, por significados, se establecen (de manera consciente e inconsciente) relaciones de poder. Es importante destacar este aspecto de la cultura y de la política, que en este sentido, se da por la pluralidad cultural, que se hace más visible dentro de los procesos de globalización.

El acercamiento desde lo cultural permite concebir la cultura como relaciones sociales, que no son homogéneas, ni estáticas, sino cambiantes y donde existen conflictos. En mi 
tema de investigación, lo cultural me permite acercarme al conflicto que existe en la calle Francisco I. Madero por las expresiones artísticas, que no cuentan con ningún apoyo institucional, ya que no son considerados artistas urbanos sino desempleados que obstruyen la vía pública. Es así como lo cultural me permite expresar la complejidad de este tema, quizá para una estatua viviente de nuestro $\mathrm{CH}$ se está haciendo una labor cultural al entretener a las personas o al darles algún mensaje que genere reflexión. Sin embargo, desde las políticas culturales formales, no se contemplan estas expresiones, ¿Por qué ocurre esto? Porque la cultura debe de contemplar su análisis desde la complejidad que nos presenta el estudio de lo cultural y la lucha de significados.

García Canclini (2008a) nos presenta una discusión sobre la lucha de significados y de diferencias (remitiendo a lo cultural) en donde también es importante mencionar que enfatiza esta polémica por los significados, ¿Quién significa? ¿Quién da la pauta para el otro? Por supuesto, como mencioné, al estar enfrentadas diferentes significaciones se establecen relaciones de poder per se, pero es importante preguntarnos de dónde vienen éstas: de gobierno, mercados, movimientos sociales, etc. La manera en que está reorganizándose la producción, la circulación y consumo de los bienes culturales [...] instauran modos nuevos de entender qué es lo cultural y cuáles son sus desempeños sociales. (García Canclini, 2008a: 40). De esta manera, es importante retomar que lo cultural (con la argumentación expresada) requiere de reconfiguraciones que van más allá de lo político y lo mercantil, requiere de reinterpretaciones en todos los sectores sociales. De esta manera, las políticas culturales deben concebir la cultura y las acciones en este sentido, pero no debemos olvidar que es importante saber desde dónde se define, ya que es un proceso en el cual puede haber diferentes actores involucrados, como he mencionado: política, visión de especialistas en arte y cultura en museos, mercantilización, etc.

En el caso de estudio, es notable que en la calle de Madero existen diferentes intereses para legislar, apoyar, castigar y desarrollar la cultura y arte fuera de los foros establecidos. Así como una falta de definición sobre la actividad que realizan los “artistas callejeros”, como lo menciona Gilberto Ramírez (Comunicación Interna en Fomento Cultural Banamex, 25 de abril de 2011): Digamos, cultura es todo, pero no como una actividad artística, donde hay una serie de normas o de cánones a seguir, 
para que tenga estas características de actividad artística. De esta manera, un especialista en arte y cultura de la calle de estudio, restringe la actividad de estos artistas por no ser profesionales. Aunque habría que remitir a lo presentado por García Canclini (2010) Se produce un "giro etnográfico" en el estudio del arte y en la misma práctica de los artistas: ante la dificultad de arribar a respuestas universalizables [sobre la definición de arte], observamos qué hacen los que dicen hacer arte, cómo se organizan, con qué operaciones lo valoran y lo diferencian de otras actividades. (García Canclini, 2010: 40)

De esta manera, nos encontramos ante la problemática de buscar definiciones absolutas, cuando existen expresiones que no cumplen con los criterios formales, se decide aseverar que la actividad no es artística, ni cultural, ya que desde el espacio privado del Museo de Cultura Banamex: el crear un personaje, mantener una postura por horas, dar un mensaje a la población ....no es arte, ni cultura, ya que el arte y la cultura se aprende en la academia y no puede ser algo inherente a la creatividad, sino a las instituciones dedicadas a enseñar estas definiciones y actividades. Por lo tanto, la aproximación desde lo cultural nos presenta la lucha por significados, encuentros, desencuentros y donde existen relaciones de poder, como lo es el caso de estudio.

Después de presentar los aportes de los especialistas en el tema, me parece pertinente definir la cultura como la concibe el Diputado López Candido (Vicepresidente de la Comisión de cultura de la Asamblea Legislativa del DF), no porque coincida del todo con ella, sino porque nos puede mostrar de qué manera se gestionan las políticas culturales en el DF:

"Una definición de cultura, creo que es el acceso al conocimiento, el acceso a las costumbres, el acceso a las expresiones populares y a las expresiones de otras características más complejas, pero creo que tiene que ver mucho con conceptos universales de desarrollo del género humano que tiene que ver con su desarrollo intelectual, desarrollo físico. Entonces, el panorama de la cultura es muy amplio, pienso que la expresión artística: pintura, literatura, poesía, las artes manuales, con las expresiones populares y el lenguaje popular, todo es cultura." (Arturo López Candido, 6 de abril de 2011)

Desde mi percepción, lo aportado por el Diputado nos remite a la vieja dicotomía de alta y baja cultura, pero deja abierto el diálogo con el arte y la cultura popular como 
expresiones que deberán contribuir al desarrollo del hombre. Con lo cual, pareciera que no hay conflicto en contemplar como parte de la cultura expresiones que normalmente no se consideran, como el arte popular y en mi caso de estudio, el arte callejero en la calle Francisco I. Madero. Con esto no quiero caer en absolutismos sobre la cultura, regresando al postulado inicial de que todo es cultura, pero es conveniente detenernos a analizar las expresiones artísticas y culturales contemporáneas, donde lo cultural juega un rol fundamental en las definiciones y acciones en este campo.

Otra expresión de la importancia de la cultura es la planteada por el Gobierno del Distrito Federal en el Programa General de Desarrollo 2007-2012:

"La cultura y el arte son bienes públicos, cuyos beneficios se difunden por toda la sociedad y la impactan de manera profunda. Además de su valor intrínseco y del goce estético que producen, tienen sin duda una función formativa fundamental: fomentan una conciencia humanística, que promueve la valoración de las personas, la tolerancia y el respeto a las diferencias [...] Promover el arte y la cultura es devolver la ciudad a sus habitantes. Ambos aspectos tienen una función innegable en la formación de identidad y sentido de pertenencia comunitaria. Los ciudadanos hacen suya la ciudad cuando disfrutan de espacios públicos a través del arte y la cultura" (Gobierno del Distrito Federal: 50)

De esta manera, el Gobierno del DF no define la cultura, sino los alcances de ésta, como lo son la formación humanística, ciudadana e identitaria. Lo cual me remite a la función transformadora de la cultura (UNESCO). Siguiendo el Programa General de Desarrollo del DF, se busca el respeto a las diferencias, pero por lo analizado en mi investigación de campo, las diferencias estéticas y formativas que se dan en el arte urbano de la calle de Madero no cuentan con ningún apoyo, como lo expone el GDF. Así que habría qué preguntarnos ¿Qué tipo de arte y cultura es apoyado desde el Gobierno local? ¿De qué manera se devuelve la ciudad a los habitantes ante la poca tolerancia, respeto y apoyo de las manifestaciones artísticas fuera de los foros establecidos? Me quedan algunas interrogantes en este sentido, que son necesarias de reflexionar, porque aunque parezca que se tiene la voluntad política de apoyar el arte público, en mi caso de estudio, ese apoyo no ha llegado y el poco que han tenido se ha ido desvaneciendo. 


\subsection{Función cultural del Estado.}

Considero fundamental adentrarnos brevemente a las competencias culturales del Estado, para así comenzar el análisis de las políticas públicas en cultura (como algunos autores denominan a las políticas culturales).

Sobre la formación del Estado-Nación, quisiera retomar algunas propuestas presentadas por Gellner (1998), antropólogo de la escuela clásica inglesa, quien lo define como: [...] aquella institución o conjunto de instituciones específicamente relacionadas con la conservación del orden (aunque pueden estar relacionadas con muchas más cosas). (Gellner, 1998: 16-17). Para entender mejor el concepto de Nación, Gellner lo expone desde dos puntos de vista:

“1. Dos hombres son de la misma nación si y sólo si comparten la misma cultura, entendiendo por cultura un sistema de ideas y signos, de asociaciones y de pautas de conducta y comunicación. 2. Dos hombres son de la misma nación si y sólo si se reconocen como pertenecientes a la misma nación." (Gellner, 1998: 20)

¿Cómo lograr lo anteriormente enunciado? A través de la exoeducación, que consiste en que los conocimientos, actitudes, comportamientos, etc. deben ser responsabilidad del Estado, el cual impartirá una educación escolarizada y general. Este tipo de educación también permitirá la comunicación en forma clara y precisa en todos los niveles y en forma oral y escrita. Siguiendo a Gellner (1998), la sociedad industrial orientada al crecimiento, busca la homogeneidad cultural en cada unidad política, la cultura se convierte como símbolo de unidades políticas, la homogeneidad crea el sentido de solidaridad, movilidad y ausencia de barreras profundas. Siguiendo a este autor, y remitiendo a lo definido por cultura desde el Museo de Cultura Banamex, podemos darnos cuenta que la homogeneidad que marcan los cánones artísticos y culturales forman parte de un entramado mayor, el cual nos refiere la homogeneidad y a pautas sentadas. No propongo que se haga una revolución y deje de existir el respeto en la sociedad. Pero si Gellner nos propone que el Estado- Nación es un todo homogéneo, donde la educación es la forma de considerarnos parte de ella, ¿Qué ocurre con expresiones artísticas y culturales que no han sido contempladas cuando nos enseñaron arte en la escuela? ¿Si no fueron enseñadas en las instituciones educativas, su calidad es menor, dejan de existir, las rechazamos por antonomasia? 
Después de la propuesta teórica de Gellner (1998) sobre la formación del Estado nación puedo concluir brevemente, que éste se encarga de crear instituciones, programas (por ejemplo, educativos) que permitan (en el campo cultural) la unidad cultural, homogeneización y en teoría la facilitación de estrategias para que todos los grupos sociales se sumen al proyecto de nación y al desarrollo del Estado. Ahora bien, ¿De qué manera se puede tener diálogo entre Estado y cultura?

Como presenté en el apartado anterior, la cultura y lo cultural son procesos que requieren de reconceptualizaciones y redefiniciones, en donde se realicen acciones y programas en esta materia. A este respecto, Nivón (2006) presenta una revisión sobre la intervención pública en la cultura. Partiendo de Adorno y Horkheimer, quienes consideraban que la cultura y la administración se refieren a dos campos distantes pero convergentes. Sin embargo, en este sentido. Nivón (2006: 31) nos presenta la siguiente cita de Adorno (1972:76): La administración es extrínseca a lo administrado; lo subsume en lugar de comprenderlo; lo cual, incluso estriba en la esencia de la misma realidad administradora, que simplemente ordena y envuelve. De esta forma, Adorno también se encuentra con la disyuntiva de la necesidad de la administración de la cultura, pero advierte que muchas veces llega a tornarse lejana a lo administrado y es un gran obstáculo, sobre todo en el campo cultural. El mismo autor expresa que la mayor contradicción entre cultura y administración se da en el proceso de la planeación. En el caso de estudio de esta tesis, coincido con Adorno, la administración pública del arte y la cultura en el $\mathrm{CH}$ del DF se encuentra ajena (salvo algunas excepciones) a las expresiones artísticas de estatuas vivientes, músicos y personajes de la calle de Madero. Se sigue contemplando el foro establecido o los eventos realizados desde la administración como los aceptados y al resto de manifestaciones se dejan de lado: por no cumplir con los cánones, por estorbar el paso, por falta de comprensión y de interés en estas expresiones contemporáneas.

En el caso de México (presentado en Nivón, 2006), la cultura ha tenido gran interés por parte del Estado, desde el periodo de la Independencia, debido a la formación del Estado- nación y la homogeneidad cultural. Aunque como menciona García Canclini (1987), podríamos hablar de políticas culturales desde la época de la Colonia. Insisto, 
me estoy refiriendo al papel cultural del Estado para así adentrarme a las políticas culturales, en donde el Estado es un actor fundamental, pero no el único en ellas.

Tomando como punto de partida el período posterior a la Independencia, Nivón (2006) nos presenta algunos puntos relevantes en la relación Estado y cultura. Básicamente se establece la construcción de la nación con el principio de "progreso", en donde el objeto de estudio y preocupación era el indígena. Bajo esta premisa evolutiva, se buscaban (entre otros) mitos integradores de México, principalmente prehispánicos y de Independencia (lo cual tenemos muy presente en las celebraciones del BiCentenario). Estos mitos fungen como nociones integradoras del imaginario plural. Nivón (2006) presenta la revisión de tres etapas del nacionalismo en México:

a) Primer nacionalismo cultural. Búsqueda del mestizaje: tomando lo mejor del español y lo mejor del indio (con poco respeto y consideraciones para éste).

b) Segundo nacionalismo popular. Consideraban al indio "bárbaro". Antes de 1920 se buscaba sacar al indio de su atraso, por medio de la ciencia y la técnica.

c) Nacionalismo popular cultural. Con base en el entusiasmo casi extremo por la población indígena, en la idea del enraizamiento del mexicano a su tierra y su tradición.

El periodo posterior a la Revolución contó con modelos para la población indígena. Nivón (2006) los presenta de la siguiente manera:

a) Integración. Con autores como Manuel Gamio (considerado el fundador de la antropología mexicana), en su célebre libro "Forjando Patria" presenta la incorporación del indígena como la estrategia para formar una nación, donde la exaltación de dicha población era una constante.

“[...] todas las agrupaciones humanas poseen iguales aptitudes intelectuales en iguales condiciones de educación y medio, y que para imponer determinada civilización o cultura a un individuo o a una agrupación, debe suministrársele la educación y el medio inherente a la cultura que se trata de difundir." (Gamio, 1960:24)

Desde esta perspectiva, se buscaba el desarrollo cultural de la población indígena, exaltando sus diferencias (considerándolas como diferentes patrias dentro del país) y la estrategia para unificarlas en una patria era por medio de la educación y la expansión de 
los conocimientos y la cultura nacional. Argumentos que me parecen contradictorios, ya que el exaltamiento del indígena por una parte y la integración al modelo de cultura nacional son premisas que parten de horizontes lejanos.

b) José Vasconcelos. Consideraba que la educación era la forma de lograr que la población indígena se "civilizara".

"Civilizar a la nación era una tarea del proyecto educativo que encontraba en el arte y en la lectura un recurso para dejar atrás la crueldad de la violencia [...] para lograr tal objetivo había que garantizar que la nación, entendida de manera equivalente al poder central, garantizara los aspectos mínimos indispensables para que las diversas regiones se identificaran con una visión de la sociedad y de la historia." (Nivón, 2006: 35)

Considero fundamental la propuesta de Vasconcelos, ya que con la premisa de integración presenta un modelo donde el arte se convertiría en un medio que permitiera el autoconocimiento, la cohesión. El movimiento del muralismo que se da en la época de Vasconcelos es un ejemplo de que el arte y la cultura deberían ser abiertos, para todo público. Aunque la mayoría de los murales se encuentran en espacios privados, a los cuales tenemos acceso. Se buscó expandir el arte a espacios mayores, donde la población pudiera entrar en contacto con esta propuesta artística y no sólo era la noción de espacios sino de contenidos: libertad creativa. Si bien, Vasconcelos no concibió los contenidos de los murales, los artistas plasmaban su crítica al sistema y exponían imágenes revolucionarias, tal es el caso de Diego Rivera o David Alfaro Siqueiros. También contamos con murales como los de Ciudad Universitaria, en particular el denominado "El derecho a la cultura", localizado en la fachada norte de la Rectoría, el cual tiene fechas fundacionales y transformadoras de México. Dicho mural fue reapropiado e intervenido durante la huelga universitaria de 1999 a 2000, con lo cual quiero enfatizar el periodo de Vasconcelos y el apoyo que dio al muralismo como arte público.

c) Moisés Sáenz. Consideraba que la educación era un medio para establecer normas en la sociedad. Lo cual es muy parecido a lo presentado por Gellner y la exoeducación.

d) Aguirre Beltrán (1967: XVII) por su parte, hablaba de "promotores culturales", ya que las políticas culturales no pueden basarse solamente en la 
visión vertical, que viene desde el Estado, en donde éste decide cuáles son las necesidades sociales y culturales. Las políticas culturales deben contar con la participación activa de la población, donde cada sector exprese sus necesidades y propuestas de acción al respecto, para así llegar a un diálogo institucional y social. Dichos promotores culturales serían especialistas, pero también habrá una capacitación a ciertas personas de la población indígena para hacer una transformación desde dentro, desde las necesidades reales y así implementar programas acordes a las verdaderas exigencias de la población.

e) Durante las décadas de los sesenta y setenta. Se elabora una crítica a la utopía unificadora presentada por los autores de este periodo posterior a la Revolución. La premisa de progreso se modificó y tomó como base los derechos humanos, los cuales deberían garantizar cualquier expresión ciudadana.

De esta forma, hemos pasado por diferentes etapas y paradigmas entre Estado y cultura. Cabe destacar que en este proceso se concebía a la población indígena como uno de los mayores obstáculos en la noción de progreso de la nación y por supuesto en la unificación de la misma. Modelo básico era la integración y homogeneización por medio de la educación, dejando de lado la autonomía e identidad cultural de los grupos indígenas (de manera similar a lo propuesto por Gellner, 1998). El Estado era la figura central de las políticas en materia de cultura, el cual prestó gran atención al patrimonio cultural y restó importancia a la cultura del presente, ya que el patrimonio cultural también formaba parte de esas estructuras tangibles de los mitos unificadores.

Es importante considerar la transición a la democracia: sus antecedentes están en los movimientos sociales de los años cincuenta y sesenta[...] pero pasa por la incorporación de la izquierda a la lucha electoral y el sistema de partidos, el desarrollo de la sociedad civil, el reconocimiento de los derechos humanos [...] (Nivón, 2006: 4546)

De este modo, el autor nos presenta un cambio fundamental en la cultura y en su relación con el Estado, ya que la sociedad deja de ser un todo estático, pasivo, para convertirse en hacedor de si mismo, de su cultura, de las acciones en ella. Se deja de 
lado la visión del Estado como figura central, se reconocen los derechos y acciones de la sociedad como vitales para el desarrollo de la cultura, del país y de la toma de decisiones. Para Garretón (en Nivón, 2006), la transición democrática no está fundada solamente en la construcción de instituciones democráticas sino en el diálogo entre los actores sociales: Estado, partidos o agentes políticos y sociedad civil, quienes producen una matriz socio- política (Garretón en Nivón, 2006: 46). De esta forma, el Estado reduce su participación en el campo cultural, pero también disminuye el presupuesto en este sector. Aunque me resulta contradictorio, ya que, durante el periodo neoliberal, la cultura tomó un papel importante en el desarrollo de los países, aunque se redujo el presupuesto al sector cultural, se reconocía la importancia del desarrollo cultural y del desarrollo por medio de la cultura.

Debido a que la política dejó de dar apoyo y ser el único medio constructor de la misma, la economía tomó su lugar, la cual es una de las características fundamentales de la sociedad democrática (Nivón, 2006). De esta forma, la cultura se encuentra con nuevos retos frente a la economía: la globalización, mayor libertad creativa y de desarrollo, pero inmersa en una red compleja donde coexisten actores como: medios de comunicación, nuevas tecnologías, empresas (nacionales y/o transnacionales), organizaciones no gubernamentales, entre otras.

"La cultura se invierte, se distribuye de las maneras más globales, se utiliza como atracción para promover el desarrollo del capital y el turismo, como el primer motor de las industrias culturales y como un incentivo inagotable para las nuevas industrias que dependen de la propiedad intelectual." (Yúdice, 2002: 16)

De esta manera es como llegamos a la cultura como recurso de desarrollo económico y político. Así que la cultura, aunque es difícil de definir, requiere de intentos de acercamiento. Hemos analizado desde las definiciones clásicas como la de Tylor, UNESCO (1982), las cuales no contaban con acciones sino con aproximaciones conceptuales. Pasando a lo cultural como la lucha y el contraste de la definición de cultura, para quién se define y desde dónde, lo cual contemplo para mi tema de investigación. La función cultural del Estado, en particular el mexicano con la creación de instituciones y paradigmas de acción (sobre todo en la época del indigenismo), la creación de instituciones especializadas para la gestión cultural. Terminando con la cultura como un recurso económico y político, aunque quisiera pensar que no todo se ha 
mercantilizado. Para muestra tenemos los artistas callejeros de la calle de Madero, que si bien, consideran el arte como un medio de subsistencia, también tienen algo que comunicarnos, buscando obtener una moneda (la cultura como recurso), pero también se busca la comunicación de mensajes que no se contemplan del todo en las políticas culturales contemporáneas del $\mathrm{CH}$ del DF.

\subsection{Políticas culturales.}

Adentrarme al análisis de este tema (de manera breve), requería el estudio de algunos acercamientos al concepto de cultura y su relación con el Estado. Consideré importante realizar de esta manera la investigación, para partir de la discusión de cultura como todo lo creado por el hombre para llegar a lo cultural (Appadurai retomado por García Canclini, 2008a) como las fronteras de la diferencia y de conflicto simbólico. De esta forma comencé a presentar el papel del Estado con la cultura, pero no he definido, ni analizado claramente las políticas culturales, ya que inmersos en la globalización, son políticas que van más allá del Estado (en muchas ocasiones) y requerían de un acercamiento conceptual previo para poder enfocarnos en su estudio.

Retomando a Nivón (2006) la reflexión sobre política cultural debe contener ejercicio de poder y toma de decisiones (por parte del Estado o de los agentes sociales) en relación al curso que toma la cultura. A este respecto, el autor enfatiza que es necesario definir la política, retomando a Swartz en Nivón (2006:19-20) se refiere a [...] procesos en la determinación e instrumentación de metas públicas [...] De esta manera, la relación de la política con la cultura inscribe una serie de cuestionamientos básicos para poder establecer las diferentes relaciones, un punto de partida es ¿qué se entiende por cultura? Lo cual me remite a lo presentado por García Canclini de lo cultural. En este sentido, es necesario enfatizar que ésta ha tomado un papel fundamental en instancias internacionales, las cuales han dado gran importancia al establecimiento de definiciones y recomendaciones al respecto.

El origen de las políticas culturales (García Canclini, 1987) se remonta a los proyectos de fundación de nuestros países (refiriéndose a Latinoamérica):

"Sería legítimo indagar su origen en los proyectos fundadores de nuestros países, particularmente en políticos intelectuales, como Sarmiento o 
Vasconcelos, que desplegaron una estrategia de desarrollo cultural consciente de sus objetivos finales en cada área social y del modo en que debían articularse la educación, la composición sociocultural de la población y el desenvolvimiento económico." (García Canclini, 1987: 14)

El mismo autor nos remite como antecedente al periodo de la Colonia, para analizar la construcción de los sistemas culturales, de hegemonía política, pero aclara que el denominado modelo de política cultural es reciente. En este sentido, coincido con el autor en los orígenes de la relación cultura-política (como antecedente de política cultural) como de formulación más reciente y podría tener como origen la cooperación internacional e institucional, que en palabras de García Canclini (1987:15) (retomando a Sergio Miceli) es la denominada "construcción institucional del área cultural”. Con lo cual coincide con Nivón (2006) cuando presenta los agentes sociales que intervienen en la cultura, en donde se enfatiza el Estado. Desde 1959 la acción estatal en este sector se ha conformado de manera institucional, lo cual genera una transformación en su análisis y desarrollo.

"La expresión orgánica más antigua ha consistido en la erección de organismos culturales con misiones específicas y aisladas que conformaban un entramado institucional dependiente de ministerios o secretarías distintas. Los museos, bibliotecas, consejos para el fomento de actividades musicales, literarias, plásticas, instituciones de educación y fomento de las artes, son instituciones nacidas en el mundo occidental desde los siglos XVIII y XIX." (Nivón, 2008:16)

De esta forma, la institucionalización de la cultura podría considerarse como el origen de las políticas culturales, que buscan el desarrollo de la cultura y de la sociedad en todos los campos. Es importante destacar que para Nivón (2006) existe una diversidad de sentidos en las políticas culturales: desde la autonomía entre política y cultura (para el autor, no debe tomarse como absoluta y coincido con él), acciones por la apropiación del pasado, su estrecha relación con el desarrollo del Estado moderno (como lo he presentado en el caso de México en el apartado anterior), entre otras. Debido a la complejidad de definición de las políticas culturales es importante retomar la presentada por García Canclini:

"Entenderemos por políticas culturales el conjunto de intervenciones realizadas por el Estado, las instituciones civiles y los grupos comunitarios organizados a fin de orientar el desarrollo simbólico, satisfacer las necesidades culturales de la población y obtener consenso para un tipo de orden o de transformación social." (García Canclini, 1987:26) 
La definición de García Canclini nos muestra que las políticas culturales no son solamente la toma de decisiones del gobierno, implica agentes sociales de todos los sectores y siempre debe tomar en cuenta el aspecto proyectivo, esto es, las posibles transformaciones sociales que éste genere, tanto de rechazo al proyecto como de adhesión al mismo, por eso es necesario que se involucren de manera activa los diversos sectores de la población: gobierno, sociedad civil y grupos organizados. En este sentido, el mismo autor nos aclara que el desarrollo de estas políticas se da en el mismo seno de las transformaciones sociales: por la búsqueda de la sociedad deseada, articulación de intereses individuales y colectivos, serán algunos de los preceptos de estas políticas.

Como mencioné en el primer apartado, sobre el debate de la definición de cultura. Es importante enfocarnos en su ubicación en el ámbito político. En este sentido, quisiera retomar la definición de cultura que presenta García Canclini dentro de las políticas culturales:

"[...] la cultura como un conjunto de procesos donde se elabora la significación de las estructuras sociales, se la reproduce y transforma mediante operaciones simbólicas, es posible verla [...] en la formación de las concepciones políticas y en el estilo que la sociedad adopta en diferentes líneas de desarrollo [...] ha extendido enormemente su "visibilidad social" y ha puesto en evidencia la necesidad de desarrollarla con políticas orgánicas." (García Canclini, 1987: 25)

De esta manera, dicho autor nos presenta a la cultura como eje fundamental del desarrollo de la sociedad, en donde la significación juega un papel primordial, ya que dichas significaciones no están dadas perpetuamente, son construidas y transformadas por la sociedad y/o por las políticas culturales y requieren acciones específicas para su desarrollo. Retomando a Nivón (2006), las políticas culturales han ocupado un lugar fundamental en la sociedad y en la política, ya que se ha reconocido el impacto económico de las culturas tradicionales, las industrias culturales (como lo presentan García Canclini y Ernesto Piedras, 2008b) y los cambios en el tiempo libre de las sociedades actuales, lo cual ha generado la intervención de sectores del arte y de las mismas industrias.

"No hay que buscar en la cultura aquellas prácticas que alejan a los países en desarrollo de los países desarrollados, sino las fuentes de inspiración de esas sociedades y el modo de movilizar las energías en diferentes grupos sociales a fin de lograr que cada sector, comunidad o agregado social encuentre en los 
manantiales de su identidad el poder de transformar su propio entorno.” (Nivón, 2006: 56)

Considero fundamental la cita de Nivón (2006), ya que nos presenta a la cultura como el eje por el que tendrían que pasar las políticas sociales, económicas y estructurales, porque la cultura no debe ser considerada como un obstáculo, sino como un recurso para el desarrollo y la transformación. Como lo he presentado, el Estado ha jugado un papel fundamental en las políticas culturales, pero considerar a la cultura un recurso deberá motivar a dichas entidades y a otros sectores en la toma de decisiones en materia política y económica, ya que la cultura y el desarrollo no son relaciones divergentes. Sin embargo, el Estado está inmerso en un juego mayor al entrar al sistema neoliberal y en la globalización, ya que a pesar del reconocimiento de las políticas culturales y el apoyo a su desarrollo (por ejemplo, en educación e investigación), las crisis económicas vividas durante las últimas décadas del siglo $\mathrm{XX}$, han abierto una grieta en las políticas culturales dictadas completamente desde el Estado. Por lo tanto, Nivón (2006) enfatiza la importancia de las políticas culturales en la globalización:

"Como una concepción que articula acciones aisladas [...] un esfuerzo de articulación de todos los agentes que intervienen en el campo cultural; esto es, del sector público y el privado; del Estado y los diferentes actores de la cultura; del sector artístico y también del de la ciencia y la tecnología; de los grupos mayoritarios y de las comunidades pequeñas y marginadas [...]" (Nivón, 2006:54)

De esta manera, Nivón (2006) coincidiendo con García Canclini (1987) nos presenta las políticas culturales como articulación de diversos sectores, donde confluye el Estado, empresarios, sectores productivos, sociedad civil, culturas populares, artistas, etc., en donde la pluralidad y la participación son ejes conductores de dichas acciones. En este sentido, el GDF propone en el Programa de Desarrollo 2007-2012:

"Es necesario atender la demanda de diversos sectores de mayor participación en el proceso de conformación y realización de las políticas culturales, desde su diseño, agenda, ejecución, evaluación, control y retroalimentación. Es limitada la capacidad de los recursos para atender las iniciativas sociales" (Gobierno del Distrito Federal: 52)

Es así como el Gobierno de la Ciudad de México se adhiere a lo propuesto por los autores mencionados, donde el Estado ya no juega el papel central en las políticas culturales, se busca la participación de diversos sectores de la sociedad. La inclusión de 
actores en las políticas culturales cumple cabalmente con la definición presentada por García Canclini (1987), sin embargo, en el documento de análisis (del GDF) no se proponen acciones concretas al respecto. Se advierte la necesidad de contar con políticas culturales, pero no me parece que las acciones para el arte público sean claras en dicho documento. Se da la importancia a la cultura, por sus valores y la formación que genera, con lo cual coincido, pero me parece que el discurso es más elocuente que las acciones, por lo menos en mi tema de investigación.

Ahora bien, ¿Por qué son importantes las políticas culturales? como lo presenté líneas atrás (basada en la Conferencia de la UNESCO 1982) la cultura tiene un papel transformador, que nos permite reflexionar sobre nosotros mismos y nos permite crear obras que trasciendan. De esta manera, Nivón nos presenta el objetivo público de la cultura:

“[...] entre los que destacan de manera privilegiada, los procesos y productos relacionados con la actividad creativa de los ciudadanos [...] estos procesos tienen que ver con la capacitación para que desarrollen esas actividades (educación artística formal e informal), en otras la posibilidad de acercarse a los productos de la creatividad humana (disposición de servicios culturales), en otras más con la protección de esos productos por el valor histórico, social o artístico que les otorga la sociedad o por el servicio de apoyo a la identidad o el goce que producen (legislación, difusión e intercambio)" (Nivón, 2006: 22)

Considero que lo presentado por Nivón nos da las pautas para el desarrollo y estudio de las políticas culturales, en donde la creatividad será fundamental, la cual requiere de programas de capacitación, oferta cultural, etc. De esta manera, la cultura no es un "todo estático" que solamente requiere visitarse en museos, va más allá, al presentar a la cultura como un proceso (de producción, distribución y consumo), donde la creatividad de la población deberá ser objetivo de acción, contando con apoyo para su formación y para la difusión de sus manifestaciones artísticas y culturales. Es fundamental la argumentación presentada por Nivón (2006, 2008) y García Canclini (1987), ya que la eficacia de las políticas culturales radica en el diálogo entre Estado, asociaciones civiles y población en general (también es importante tomar en cuenta el papel económico y empresarial dentro de dichas políticas). Ahora bien, con el tema de investigación, al parecer no existe un vínculo real en las políticas culturales del $\mathrm{CH}$ y los artistas callejeros de la calle de Madero, sí la creatividad, oferta y capacitación cultural son 
fundamentales, ¿De qué manera se puede lograr un encuentro entre las instituciones y la sociedad que busca expresarse artísticamente en la calle de estudio? Han tenido algunas reuniones con el Fideicomiso del $\mathrm{CH}$ y en la celebrada el 20 de enero de 2011, los artistas expusieron:

"Queremos proponer que se instauren corredores culturales: Filomeno Mata y Gante en sus dos tramos, tratamos de desglosar procesos de funcionamiento de un proyecto bilateral: GDF y comunidad artística. Responsabilidades que asumimos como comunidad artística, habrá que elaborar reglamentos, que el espacio geográfico de Filomeno Mata y Gante se pudiera instaurar como corredores culturales, habría que hacer plan de medios para la banda." (Fuente sin identificar, Reunión con Fideicomiso del CH, 20 de enero de 2011)

La propuesta de corredores culturales como parte de políticas mayores en el espacio del $\mathrm{CH}$ es presentada por los artistas de la calle de Madero. Sin embargo, a varios meses de esa propuesta, no ha habido respuesta al respecto, ni seguimiento de los planteamientos. Así que, desde la perspectiva de esta investigación y con los argumentos presentados en las entrevistas; la participación de los sectores artísticos involucrados ha sido constante, pero no se refleja en una política cultural que apoye las propuestas, ni al arte callejero.

Teóricamente, se debe establecer la intervención del Estado y de la sociedad en la política cultural, donde la cultura sea eje movilizador, en donde se establezca un compromiso de ambas partes, donde deberá existir el diálogo entre sectores para lograr el desarrollo de los individuos y la sociedad. Aunque hay que destacar la complejidad que esto conlleva y los intereses implicados en la toma de decisiones. Como presenta Yúdice (2005), la relación del binomio cultura- desarrollo se ha analizado desde diferentes perspectivas y considerando las diversas dimensiones de la cultura. De este modo, el autor argumenta que la diversidad cultural es la base para el desarrollo cultural, en donde las industrias culturales serán mediadoras en esta relación, en donde (para Yúdice, 2005) y coincido con él en este sentido, debe haber participación activa del Estado, como generador de recursos y apoyo a la creatividad, fomentando la cooperación cultural internacional, etc. El apoyo a las industrias culturales y a la creación como ejes de desarrollo cultural y económico también se han encontrado en el tintero de las políticas culturales de los Estados y por supuesto de organismos como la UNESCO, ya que por medio del apoyo a estos sectores se logrará el desarrollo humano, cultural y económico de los individuos y de la sociedad. 
Ahora bien, es importante retomar lo presentado por Nivón (2006) en relación a la cultura y la transición democrática (democratización política para Nivón 2006 es la extensión de instituciones con régimen democrático). Como presenté en el apartado de Estado y función cultural, ésta ha tenido diferentes expresiones y ha sufrido cambios. Actualmente, el campo cultural se ha transformado, ya que cada día se limitan los presupuestos a este sector y resulta "arriesgado" para el Estado invertir en el campo cultural, así como en la regulación (que implique apoyo o prohibición) de artistas callejeros en las calles del $\mathrm{CH}$.

"Papel de la cultura en esta reconstitución de nuestra vida social en un marco plenamente democrático es muy relevante. Para seguir con el concepto de Garretón, hubo momentos en los que la política dominaba y se imponía sobre el conjunto de la sociedad. Durante el reciente período neoliberal, la política como eje integrador fue sustituida por la economía de mercado.” (Nivón, 2006: 47)

De esta manera, la cultura está en el campo de la economía como eje de desarrollo de las naciones y como motor de múltiples transformaciones de producción, circulación y consumo de diferentes bienes. En el caso de estudio, la cultura y el arte en nuestro $\mathrm{CH}$ tienen diferentes actores involucrados y con diferentes objetivos, como lo presenta la Fundación del CH de la Ciudad de México A.C (la cual depende de la Fundación Carlos Slim):

"La Fundación del Centro Histórico de la Ciudad de México, A.C. se propone ser una organización líder, innovadora, confiable y transparente reconocida por el impulso al desarrollo social, económico, cultural, ecológico y comunitario del Centro Histórico al continuar sus acciones estratégicas, de investigación y de mediación entre distintos niveles de gobierno, instituciones privadas y de la sociedad civil para el desarrollo de la zona promoviendo la identidad de la cultura mexicana y sus valores." (Relaciones Públicas de dicha instancia, 11 de mayo de 2011)

Con la misión de la Fundación no quiero asumir de tajo que la mercantilización de la cultura sea una realidad en el espacio de estudio, pero si se convierte en el eje de un sinfín de intereses. La Fundación apoya el desarrollo cultural, por medio de Casa Vecina, pero deja de lado las manifestaciones artísticas callejeras, las cuales no cuentan con ningún auspicio. Si una de sus funciones es cumplir como mediador entre diferentes instancias y la sociedad, pareciera que no se concibe el desarrollo cultural que promueven los artistas callejeros de Madero, ya que no han tenido ningún acercamiento con ellos, quizá por no considerarlos artistas, por su calidad o por diversos 
intereses que no convergen con mi grupo de estudio.

Las políticas culturales deben encontrar la forma de insertarse a las políticas públicas sin perder de vista su objetivo final: desarrollo cultural. Las instituciones encargadas de las políticas culturales deberán tomar en cuenta los elementos económicos, políticos y culturales de los programas a desarrollar, considerando como elemento fundamental la participación social.

\subsection{Paradigmas políticos de la acción cultural.}

Después de expuesto lo anterior, quisiera destacar la complejidad con que cuentan y en las que se desarrollan las políticas culturales. Partiendo del debate de la definición de cultura, la participación estatal en este campo, los diferentes actores involucrados en la gestión de políticas culturales, por ejemplo: Estado, sector empresarial, sociedad civil, etc. han colocado a dichas políticas en diferentes vertientes. Expondré los paradigmas políticos de acción cultural presentados por García Canclini (1987):

a) Mecenazgo liberal. Considerada la primera forma de promoción moderna de la cultura. Impone menos restricciones sobre el contenido y la forma del arte, dejando cierta autonomía a los creadores. Debido a las crisis económicas y al proyecto neoliberal, el Estado deja de tener control absoluto sobre la producción artística, de esta manera deja espacio para que fundaciones culturales fomenten dicho sector. El desarrollo de la cultura no es visto como una cuestión colectiva [...] sino como el resultado de las relaciones individuales: es una decisión personal la de financiar ciertos gastos culturales y elegir a quién se dará el dinero [...] (García Canclini, 1987:29). De esta forma, existe un mecenas que auspicia la creación, en donde siempre es vital el nombre de la fundación patrocinadora. Un ejemplo de mecenazgo lo encontramos en México (aunque no es la manera institucional general de política cultural en el país) con Fundación Televisa o JUMEX, las cuales apoyan a ciertos artistas o exposiciones en determinado momento para la producción o exposición de obras, dejando siempre claro el nombre de dicha fundación como patrocinador.

b) Tradicionalismo patrimonialista. Se busca la unidad de la sociedad por medio de lazos naturales, deja de lado las diferencias culturales. Su política cultural 
consiste en la preservación del patrimonio folclórico [cultural]: esencias prehispánicas [...] mezclando características indígenas con algunas formadas en la Colonia [...] o en la Independencia. (García Canclini, 1987:32). De esta forma, nos encontramos con la preservación a ultranza del pasado y de las expresiones patrimonialistas, de folclor. Cabe aclarar, que México sigue dando gran peso a ese pasado: como fundador de la nación, de la ideología y que no se remite solamente a la época prehispánica, sino a la Colonia o la Independencia como expresiones perpetuas de la cultura. Es un paradigma que se encuentra muy acorde con el apoyo que se da al patrimonio cultural en el Centro del DF, donde la conservación arquitectónica es una realidad tangible, pero se dejan de lado otros elementos artísticos o culturales que dan vida a este espacio.

c) Estatismo populista. La identidad se encuentra en el Estado, como condensador de valores, generador de cohesión y orden. Al Estado no le interesa el papel transformador de la cultura ni la participación de la sociedad en la toma de decisiones en este ámbito. Muestra una concepción de lo popular como conjunto de gustos, hábitos sensibles e intelectuales "espontáneos" del pueblo, sin discriminar lo que representa sus intereses y lo que le fue impuesto a las masas a través de la educación escolar y comunicacional (García Canclini, 1987: 36). El sector popular se deja de lado, no se toma en cuenta como eje transformador y transformado, por lo tanto, se sufre la invisibilidad de dicho sector.

d) Privatización neoconservadora. Debido al peso que se da a la economía, las políticas se apoyaron en grandes planes económicos. De esta forma, se desarrollaron políticas culturales de gran importancia: construcción de museos, de escuelas, en donde la pluralidad cultural, apoyo a la creatividad y al folclor eran fundamentales. Sin embargo, la crisis económica en América Latina (a mediados del siglo XX) generó la restricción de recursos económicos a esos sectores. El objetivo de la doctrina neoconservadora en la cultura es crear nuevas relaciones ideológicas entre las clases [...] transferir a las empresas privadas la iniciativa cultural, disminuir la del Estado y controlar de los sectores populares. (García Canclini, 1987:40). El Estado dejó de auspiciar la cultura y las artes, cediendo la planeación y desarrollo del sector cultural (incluyendo culturas populares, movimientos socialistas de los años sesenta y 
setenta, etc.) al ámbito privado. De esta forma, para García Canclini (1987), se intenta reemplazar la hegemonía del Estado en las relaciones sociales y culturales, ya que por medio de la privatización, las empresas aparecían como benefactoras de la producción cultural de todas las clases, defendiendo la creación plural, como vínculo entre cultura nacional y transnacional. Como ocurre en el tema de esta investigación, donde, el Estado si interviene en la cultura y las artes, pero no se consideran todas las expresiones urbanas como merecedoras de apoyo (privado ni público)

e) Democratización cultural. Concibe a la política cultural como un [...] programa de distribución y popularización del arte, el conocimiento científico y las demás formas de "alta cultura" [...] una mejor difusión corregirá las desigualdades en el acceso a los bienes simbólicos. (García Canclini, 1987:46). Se consideraba que la difusión podría servir para borrar las desigualdades persistentes. Una expresión importante de la democratización cultural es el derecho a la cultura: Toda persona tiene derecho a tomar parte libremente en la vida cultural de la comunidad, a gozar de las artes y a participar en el progreso científico y en los beneficios que de él resulten (Artículo 27.1 de la XII Declaración de Bogotá, en Juan Luis Mejía, 2009:109). La concepción de la democratización de la cultura, evidentemente amplió el espectro de acción de las políticas culturales, dotando a todos los seres humanos del derecho a la cultura. La ampliación del acceso a bienes culturales es una de sus mayores manifestaciones, la difusión se convirtió en el eje fundamental de acción. Sin embargo, como menciona García Canclini (1987) hubo ciertos problemas de aplicación, ya que se difundía la denominada "alta cultura", generando manifestaciones elitistas del patrimonio simbólico, que producían diferentes apropiaciones de la cultura (debido a las desigualdades económicas). Como consecuencia de la democratización cultural vertical, donde el Estado y algunas empresas eran los únicos que tenían poder de decisión sobre el discurso y las acciones en las políticas culturales, se dejó fuera la educación y reapropiación de diversos sectores. Aunque se tenga derecho a la cultura, si ésta tiene el discurso hegemónico elitista, de alto costo, no se podrá lograr un diálogo ni la reapropiación simbólica necesaria para el desarrollo de la sociedad. Quisiera destacar la crítica presentada por Bonfil Batalla (2002), ya que 
considera que la democratización cultural es una forma de imposición desde la cultura hegemónica y deja de lado el desarrollo de las culturas populares.

f) Democracia participativa. Este modelo con base en la multiculturalidad, genera relaciones de autonomía e igualitarias en la participación cultural. Puesto que no hay una sola cultura legítima, la política cultural no debe dedicarse a difundir sólo la hegemónica sino a promover el desarrollo de todas las que sean representativas de los grupos que componen una sociedad (García Canclini, 1987: 51). Desde esta perspectiva, se da un paso fundamental en las políticas culturales, ya que se consideran las diferentes culturas y expresiones por igual, sin quitar méritos a unas por debajo de la cultura hegemónica o nacional. Se buscan acciones continuas, donde las colectivas tienen gran importancia, los diversos sectores de la sociedad encuentran un sitio de acción y de diálogo. Sus preceptos de acción son: pluralidad y libertad de desarrollo de cada cultura. Un eje de acción que me parece fundamental (aunque no estoy segura si se ha quedado en el discurso) es procurar mejorar las condiciones sociales para desenvolver la creatividad colectiva (García Canclini, 1987:51). Asumo que es una postura plural, donde la diversidad cultural es considerada por igual, su participación se expresa en acciones definidas con base en proyectos de largo alcance. Aunque la propuesta de mejorar las condiciones sociales sigue pareciendo un poco ajena a la realidad. Este modelo de acción política está a la vanguardia en la conciencia y apertura con las diferentes culturas. En el caso de estudio, este paradigma debería imperar en las políticas culturales, donde no existan cánones que den mérito a expresiones artísticas sobre otras. Se debería comprender el derecho a la cultura no sólo como la construcción y asistencia a recintos establecidos, sino con el intercambio y la reflexión que se puede generar desde las calles, donde existe gente que tiene algo que comunicar y se busca el diálogo entre diferentes expresiones. Sin embargo, considero que para que la democracia participativa sea una realidad deberá de existir mayor diálogo, si bien, lo cultural implica el conflicto de quién define, desde dónde y para quién. Me parece que son elementos fundamentales para lograr intercambio de experiencias y de necesidades en las políticas culturales, donde el derecho a disfrutarla (en todas sus variantes) deberá ser una constante. En el caso de la 
Ciudad de México si se considera la participación social, como lo expone el GDF: Tener una política cultural con participación social, que atienda con mayor efectividad las necesidades culturales y artísticas de los diversos grupos sociales. (Programa General de Desarrollo 2007- 2012, Ciudad de México: 53). Sin embargo, como he mencionado, el grupo de artistas callejeros con el que he trabajado no cuenta con ningún apoyo ni participación real, que debería reflejarse en una política cultural inclusiva.

Como lo he presentado en este apartado, el estudio y aplicación de las políticas culturales es difícil: desde la definición de cultura y su relación con el desarrollo, en donde la primera tiene características transformadoras. Otra complejidad es la función cultural del Estado y la presencia de otros actores en las políticas culturales (por ejemplo: organizaciones civiles, no gubernamentales, internacionales, sociedad civil, sector privado, etc.). Las diferentes aristas de las políticas culturales, el desarrollo (por medio de las industrias culturales como lo presentan García Canclini, Piedras y Yúdice) el estudio y aplicación de políticas culturales requieren analizarlas y llevar a cabo acciones, considerando todos estos elementos.

Retomando el papel transformador de la cultura y colocándolo como eje fundamental de dichas políticas, estamos dando pie a que el desarrollo y la cultura converjan. Desde la definición de cultura nos encontramos con la dificultad de acotarla, repensarla y sensibilizarnos al respecto, la complejidad de la definición de cultura y las acciones políticas al respecto, es uno más de los retos de las políticas culturales en nuestros días. Hemos pasado desde definiciones y concepciones decimonónicas sobre la cultura, hasta considerarla como transformadora de la sociedad (por algunos autores y por la UNESCO), cambiando el método de análisis de la cultura a lo cultural como conflictos simbólicos en donde es fundamental la lucha de significados ¿Quién define? ¿Para qué define? He presentado definiciones donde la cultura tiene estrecha relación con el ámbito político, en donde se precisan algunos campos de acción para su desarrollo y que a su vez transforman la sociedad en general.

Partiendo de la complejidad de la cultura, también es importante conocer la función 
cultural del Estado, debido a que la formación del Estado-nación está vinculada estrechamente con las concepciones y acciones en el sector cultural. Estamos en el siglo XXI y vivimos procesos de globalización, los cuales también han modificado la cultura y las acciones en ella. El Estado era el punto central de las políticas culturales y en la actualidad nos encontramos inmersos en redes más amplias, que se expresan en instituciones internacionales, las recomendaciones para el desarrollo cultural y las políticas culturales como en sectores privados que están teniendo injerencia sobre ella. Aunque cabe destacar que el Estado no ha dejado de estar presente en las políticas culturales, ahora dialoga y gestiona con otros sectores de la sociedad (nacional e internacional). El Estado continúa presente en las políticas culturales y es eje fundamental, pero ya no es el actor protagónico en ellas, se ha dado cabida a la sociedad, a grupos organizados y apoyo del sector empresarial, que si bien, habría que enfatizar que en México este sector no tiene tanto peso como en algunos países del mundo, la iniciativa privada ha generado espacios de acción y apoyo a la creatividad y a las políticas culturales.

De este modo, las políticas culturales se encuentran entre la cultura y la economía, pero no por eso caen en una mercantilización extrema, sino como elemento generador de recursos económicos (por ejemplo, mediante las industrias culturales) y de desarrollo. Se requiere mayor diálogo entre sociedad e instituciones, se necesita el apoyo en el proceso de producción, distribución y consumo, en donde la educación, libertad de creación, oferta cultural, entre otros, sean puntos de debate para los diversos sectores, en donde confluyan los intereses sociales, estatales y privados con la premisa común del desarrollo de la cultura, de la sociedad y el arte (en la calle o en foros establecidos). 
Toda ciudad y toda la ciudad son históricas, porque todo lo que ocurre en ella y ella misma son el resultado de la historia. Es la historia la que construye la ciudad. Ello significa que cada rincón, cada porción de la ciudad y la ciudad como un todo son históricas. Mientras la historia construye las cualidades de la centralidad y sus formas, son ciertas centralidades que se forman las que especifican las condiciones que definen a los centros históricos. (Carrión, 2000: 188)

\section{Importancia y acciones en Centros Históricos.}

Los Centros Históricos (en adelante $\mathrm{CH}$ ) a nivel mundial, se han convertido en elementos fundamentales para el desarrollo de las ciudades. "Centro Histórico" es una categoría con amplitud de definición, que cuenta con elementos históricos, identitarios, modernos, mercadológicos, etc. para el desarrollo de los países y las ciudades dentro de los cuales se circunscriben.

La segunda mitad del siglo XX ha mostrado una gran tarea en América Latina por lograr que las Políticas Públicas incluyan el concepto de preservación y rehabilitación de centros históricos. En América Latina y el Caribe existen 31 centros citadinos declarados Patrimonio de la Humanidad por su valor arquitectónico, artístico, social e histórico. Las políticas de preservación y su aplicación no han sido suficientes para el mantenimiento y conservación de los centros, ni para la promoción del desarrollo social. Dentro del desarrollo del $\mathrm{CH}$ se ha caído en la conservación, llegando a convertir a las ciudades en una especie de museos, fríos, desplazando a los habitantes y sus actividades productivas. Hoy, debido a las condiciones económicas de algunos países latinoamericanos se debe avanzar e incorporar los $\mathrm{CH}$ en las políticas de desarrollo, donde se combine la preservación de la riqueza histórica- cultural y la atención a la pobreza.

No existe un consenso sobre el concepto $\mathrm{CH}$ y las modalidades de su intervención. Debido a su complejidad, como eje urbano, variable identitaria, centro de poder político o ideológico de la ciudad, como elemento de políticas públicas, entre otros. Se requiere la relación horizontal, con diferentes instancias: federales, estatales, civiles, privadas y sociedad en general para construir un nuevo proyecto de $\mathrm{CH}$, donde la participación de la ciudadanía sea fundamental. 


\subsection{Declaraciones internacionales sobre los $\mathbf{C H}$}

Como presenta Bouchenaki (2001), desde inicios del siglo XX, en el marco del VI Congreso Internacional celebrado en Madrid (1904) los arquitectos que ahí se reunieron, consideraron que los monumentos se deberían clasificar en dos categorías: en donde se encuentran vestigios de antiguas civilizaciones desaparecidas "monumentos muertos" y la segunda, "monumentos vivos", en los cuales su uso continúa hasta nuestros días. Ambos tipos de monumentos deberán ser conservados. Así que desde hace un siglo se ha considerado el patrimonio cultural como un bien que debe ser preservado. Sin embargo, los $\mathrm{CH}$ todavía no eran considerados como zonas protegidas, ni de resguardo histórico y cultural.

En 1945, con la creación de la UNESCO, se incluye en su Acta Constitutiva: La misión de velar por la conservación del patrimonio universal de libros, obras de arte y otros monumentos de interés histórico y científico, y recomendando a los pueblos interesados sobre las convenciones internacionales al respecto. (Bouchenaki, 2001: 12).

Con la revolución industrial hubo grandes transformaciones en las ciudades históricas, gran respeto a los valores estéticos e históricos de los monumentos. La conciencia sobre el apego a los monumentos históricos se expresa en la Carta de Atenas de 1931 y en la Carta de Venecia de 1964, dando la base a los trabajos de conservación y restauración de monumentos y sitios.

“Artículo 1. La noción de monumento histórico comprende tanto la creación arquitectónica aislada, como el ambiente urbano o paisajístico que constituya el testimonio de una civilización particular, de una evolución significativa o de un acontecimiento histórico. Esta noción se aplica no sólo a las grandes obras, sino también a las obras modestas que con el tiempo hayan adquirido un significado cultural." (Carta de Venecia, 1964)

Desde el inicio de esta Declaración se marca la pauta para la conservación de los monumentos históricos, así como la importancia que tiene el entorno de éstos. Con lo cual, podríamos estar acercándonos a la importancia de los $\mathrm{CH}$, que no son solamente monumentos, sino relaciones sociales en ciertas áreas históricas. A lo que Mutal (2001) agregaría:

"Los años 50 y 60 se caracterizaron por el concepto de realce, procedente de Europa y de las campañas de la UNESCO en Venecia, que consideraban el realce o la puesta en valor de los monumentos como un modo de atraer 
turistas y así justificar la necesidad de financiar su restauración para convertirlos en una fuente de ingresos. Este concepto de financiación mediante el turismo fue recogido en 1967 por la Organización de Estados Americanos, que elaboró las llamadas Normas de Quito sobre Restauración, en las que se volvía a insistir en el turismo como razón válida para emprender obras de realce en los monumentos." (Mutal, 2001: 120 y 121).

Lo presentado por Mutal explica desde otra perspectiva la realidad de las políticas en torno a los monumentos y zonas históricas, que generan protección a los bienes, pero también difusión y ganancias económicas, por lo que en la actualidad el apoyo dado en forma de financiamiento genera resultados importantes de conservación y desarrollo de la zona, por medio del turismo.

Retomando las Convenciones que salvaguardan el patrimonio cultural, en 1964 se crea la Convención para la protección de los bienes culturales en caso de conflicto armado (Convención de la Haya), a lo que Vattel siglos antes agregaría:

"Sea cual sea el motivo por el que se devasta un país, deberíamos salvar aquellos edificios que honran la sociedad humana y no contribuyen a aumentar la fuerza del enemigo, como, por ejemplo, los templos, las tumbas, los edificios públicos y todas las obras de notable belleza [...] es declararse enemigo de la humanidad privarla injustificadamente de tales maravillas del arte." (Emmerich de Vattel, La ley de las naciones, 1758 en Berry, 2003: 9)

Es así como se logró la protección de los monumentos ante conflictos armados, que no iniciaron en el siglo XX sino desde el siglo XVIII como expresa Vattel, en donde se dota de belleza a estos monumentos. Aunque poco se habla de la protección a la sociedad, se comenzó con el apoyo al patrimonio tangible, para así llegar al patrimonio intangible.

Con la creación de UNESCO, se formaron redes de expertos como ICOM (Consejo Internacional de Museos), ICOMOS (Consejo Internacional de Monumentos y Sitios) e ICCROM (Centro Internacional de Estudios para la Conservación y la Restauración de Bienes Culturales). Se consideró que era necesaria una recomendación específica, y en 1976, Se invita a los Estados miembros a asumir una política global relativa a la salvaguardia de los conjuntos históricos y su función en la vida contemporánea (Bouchenaki, 2001: 13).

"Debido a los permanentes y graves prejuicios causados en los centros y barrios antiguos de las ciudades, así como a los pueblos tradicionales, y porque la 
conservación y valorización de los conjuntos son problemas complejos, se juzgó que era necesaria una recomendación relacionada específicamente con este campo." (Bouchenaki, 2001: 13)

Es así como, de la protección de monumentos se da una transformación hacia la salvaguarda del entorno de esos monumentos, donde se incluyen las tradiciones y demás expresiones intangibles del patrimonio. Como lo expresa la autora en relación a la Carta del Consejo de Europa (1975): Desde entonces, la necesidad de 'integrar' la conservación en el urbanismo, de preservar los conjuntos históricos y su ambiente e insertar el patrimonio en la vida económica y social. (La Conservación del Patrimonio Arquitectónico en Europa- Tratados e Informes, 1994: 5 en Bouchenaki, 2001: 14)

Dentro del marco jurídico, se buscaba crear un régimen de protección para los conjuntos históricos. En 1985 en España, el Consejo de Europa adoptó la Convención para salvaguardar el patrimonio arquitectónico del continente, el cual incluye conjuntos arquitectónicos y CH. ICOMOS, adoptó (1987) la Carta de protección de ciudades históricas (Carta ICOMOS de Toledo en Bouchenaki, 2010: 14).

A principios del siglo XXI, la preservación de las ciudades históricas es un sector esencial para organizaciones tanto internacionales como nacionales.

"Ante los peligros reales de uniformidad y de despersonalización del hábitat que conlleva el urbanismo moderno, la supervivencia de los conjuntos históricos reviste una importancia capital de cada pueblo que busque conservar su verdadera dimensión cultural y su individualidad.” (Bouchenaki, 2001: 13)

Destacando la importancia del patrimonio urbano, como factor de identificación cultural (Bouchenaki, 2001), que permite desarrollar el sentido de identidad y pertenencia de las sociedades, que son elementos que dan cohesión social. Desde la visión económica y cuantificable, el patrimonio urbano constituye un atractivo turístico en torno al cual surgen actividades económicas que generan empleo e ingreso. También el patrimonio urbano representa un activo inmobiliario con potencial para las actividades económicas y residenciales que requieren localizaciones centrales. Debidamente restaurado, tiene capacidad de generar ganancias significantes, para que se dé esto se requiere de participación de diferentes actores: gobierno, grupos culturales, propietarios, inversionistas, etc. 


\subsection{Algunas características de los $\mathrm{CH}$ de América Latina y el Caribe.}

a) Albergan la actividad financiera y bancaria. Con lo cual no estoy muy de acuerdo en el caso del DF. En su momento, antes del terremoto de 1985 si era la zona financiera por excelencia. Sin embargo, los grandes corporativos ya no se encuentran en el centro sino en otras zonas como Paseo de la Reforma y Santa Fe. Existe, sin embargo, una tendencia a desplazar algunos de esos servicios hacia otros barrios o hacia otros centros administrativos construidos especialmente para ubicar oficinas de gobierno provinciales. (Mutal, 2001: 129). A lo que agregaría por la experiencia recabada en trabajo de campo: Con los temblores posteriores [refiriéndose a 1985], los centros financieros, el Mexican Wall Street de Venustiano Carranza se fue. Bancomer se fue. Y Santande, se van a otros lados. El mismo movimiento del Senado y de los Diputados que se van a San Lázaro y ahora a otro lado. (Entrevista con Enrique Fuentes, Librería Madero, 24 de marzo de 2011). Es así como, desde la investigación teórica y de campo se encuentran diferentes realidades. Aunque Mutal (2001) admite que ha existido un desplazamiento de las actividades financieras a otras zonas de la ciudad, el comentario de Enrique Fuentes (Dueño de la emblemática Librería Madero, fundada en 1951), quien ha vivido las transformaciones en nuestro $\mathrm{CH}$, nos muestra que el Mexican Wall Street -como él lo llama- se ha ido a otras zonas de la ciudad, posiblemente por la devastación posterior al sismo de 1985, por la inseguridad que se vivía o por encontrar infraestructura en otras zonas de la ciudad. Aunque, cabe aclarar que la calle Venustiano Carranza cuenta de nuevo con actividad financiera, como lo muestra el edificio de Banamex y el Corporativo Telmex.

b) Densamente poblados y edificados. Tampoco creo que nuestro $\mathrm{CH}$ tenga esta característica presentada por Mutal (2001), ya que el CH del DF durante varios años estuvo despoblado, contaba con población fluctuante que iba durante el día, en la actualidad han aumentado los habitantes, pero sigue siendo una prioridad.

"Se empezó un acelerado deterioro social, primero porque la gente que ahí vivía se tuvo que ir, los que vivían ahí dijeron 'para entrar a mi edificio me dejan 50 cms, no puedo entrar ni caminando,' no se diga con bolsas de súper o con sillas de ruedas o sacar un enfermo. Entonces, esta zona se volvió terrible para vivir, la gente empezó a ver un éxodo, se empezaron a ir y los propietarios de los 
inmuebles buscaron un mantenimiento y en el mejor de los casos, a los que les rentaban eran los vendedores ambulantes para usarlos como bodega, se hizo una conversión en sentido negativo del uso de los inmuebles y la mayoría eran bodegas, tugurios, y se vino un deterioro social, además de un abandono, porque mucha de la gente que se dedica al comercio tampoco vive en el centro." (Entrevista con Ricardo Jaral, Autoridad del CH, 5 de abril de 2011)

De esta manera, el deterioro ocurrido en el $\mathrm{CH}$ de la ciudad de México se produjo, entre otras expresiones, por la huida de habitantes. Es así como la densidad histórica que menciona Carrión, también se relaciona con la pobreza económica, por lo menos en esta etapa de la investigación.

c) Se ubican las instituciones religiosas, ayuntamientos, universidades, catedrales.

En la actualidad, el CH del DF busca atraer a las universidades a este espacio, como en su momento lo hizo la UNAM, teniendo sedes académicas por todo el $\mathrm{CH}$, los cuales se conservan como museos y realizan diversas actividades culturales y de investigación. En la actualidad, se cuenta con algunos centros de estudio en el $\mathrm{CH}$, aunque la población escolar no es tan densa como se esperaba.

"Es fundamental para la nueva etapa del Centro el que haya una vida académica intensa y cotidiana, con la presencia nutrida de estudiantes y maestros todos los días. Y ésa es una apuesta con la que estamos comprometidos [...] A nosotros nos toca facilitar los trámites y asociarnos con las instituciones para restaurar edificios históricos, colaborar en el desarrollo de los proyectos, destinar recursos y trabajar en la construcción de ideas." (Inti Muñoz. Director del Fideicomiso del CH en km cero: 2009 , no. $7: 4$ )

A lo que el Vicerrector de Educación del Claustro de Sor Juana (Roberto Arriola) agrega: la impronta que tenemos en lo que es el corredor San Jerónimo-Regina se vaya expandiendo a otras partes del Centro, que todavía tienen problemas de drogadicción, delincuencia y situaciones no deseables. (km cero: 2009, no. 7: 4). De esta manera, se busca que las actividades universitarias regresen al $\mathrm{CH}$ de la Ciudad de México, donde se fundó la primera Universidad de América y para algunos, su nueva ubicación representó la perdida de la centralidad, ya que al no contar con estudiantes y actividades académicas, el $\mathrm{CH}$ se tornó sórdido y propicio para actividades de todo tipo, como lo es el comercio ambulante, delincuencia e inseguridad. 
d) La mayoría de las instituciones culturales se sitúan en el $\mathrm{CH}$ : teatros, ballets, museos. Característica que si cumple nuestro $\mathrm{CH}$, hay un sinfín de museos, casas de cultura, teatros, etc. que buscan el desarrollo y esparcimiento de la población residente y visitante. Respecto a las instituciones culturales, Sergio Ortiz, encargado de Comunicación y Relaciones Públicas del Museo del Estanquillo. Colecciones Carlos Monsiváis expresó:

"Yo creo que la oferta cultural es vasta, interesantísima y para todo público y que va incluso in crescendo. Hace unas semana visité lo que fue la primera Sinagoga, que estuvo atrás de San lldefonso y tienen planeado dar visitas guiadas históricas, para eso, hay público para eso y para más. Siento que en si mismo, se basta el centro para entregar una oferta que es interesantísima, que se va haciendo más rica, tolerante e interesante." (Entrevista con Sergio Ortíz, Museo del EstanquilloColecciones Carlos Monsiváis, 7 de abril de 2011)

De esta manera, especialistas en el tema y que trabajan con él en el $\mathrm{CH}$, consideran que la cantidad de museos es suficiente, que siempre hay propuestas interesantes que darán a la población otra forma de vivir y percibir el arte y la cultura, haciéndolo de manera respetuosa e incluyente.

e) Cuenta con densidad de áreas de interés histórico-artístico. Lo cual desarrollaré en el apartado del CH de la Ciudad de México.

f) Reciben a gran parte del turismo. Elemento fundamental en los $\mathrm{CH}$, no sólo en el DF, se concentra oferta cultural, infraestructura, historia, cultura, tradición para atraer a turistas nacionales o extranjeros.

"El Centro es el sitio más visitado de la Ciudad de México - le siguen Xochimilco, Zona Rosa y Garibaldi. Sin embargo, tiene el cuarto lugar en ocupación hotelera, detrás de las zonas de Torre Mayor-Zona Rosa, ChapultepecPolanco y Perisur- Ajusco, pues sólo capta al 20\% de los turistas que se hospedan en la Ciudad. De los 70 puntos de interés turístico catalogados por la Secretaría de Turismo del Gobierno del Distrito Federal — desde sitios prehispánicos hasta mercados y centros de artesanías-, la mayoría de los turistas sólo visitan seis: Palacio Nacional, Zócalo, Catedral, Templo Mayor y Bellas Artes-Alameda, el llamado circuito tradicional." (Patricia Ruvalcaba, kmcero 2009, número 8: 4)

Si bien, como menciona la nota de kmcero, el $\mathrm{CH}$ de la Ciudad de México ya cuenta con gran importancia y atracción para los turistas, aunque la gran mayoría no se hospeden en esta zona. El convertirse (de nuevo) en el centro de atracción para 
visitantes nacionales y extranjeros genera mayor inversión para infraestructura turística, lo cual contribuye al goce cultural y por supuesto, ganancias económicas. A lo que una de las artistas callejeras de Madero agregaría: No hay un tratado o un acuerdo, un artículo o algo que haga constar que el artista urbano si genera más turismo, o sea, es algo bonito para la visión de la gente que va pasando. (Entrevista con "Sacerdotisa mexica”, artista urbana de la calle de Madero, 19 de enero de 2011). La cita de la Sacerdotisa, en contraste con lo presentado en kmcero, me parece que muestra claramente los estándares para medir el turismo. En kmcero (publicación que depende del Fideicomiso del $\mathrm{CH}$ ) nombran los sitios visitados por los turistas, como lo son Palacio Nacional o el Zócalo, pero no se considera que los artistas que se encuentran en el espacio público de la calle de Madero puedan generar interés y esparcimiento para capitalinos, visitantes nacionales o extranjeros.

\subsection{Análisis de los $\mathrm{CH}$.}

"Las nuevas tendencias de la urbanización en América Latina, la revolución científica y tecnológica en el campo de las comunicaciones y el proceso de globalización, imprimen nuevos derroteros a esta tensión [desarrolloconservación] y llevan a los centros históricos de la región al dilema actual: ser memoria o protagonista de la ciudad." (Carrión, 2000:5)

Carrión (2000) expresa que los $\mathrm{CH}$ han adquirido mayor importancia en la formulación de políticas urbanas (en el caso de América Latina), debido a la relación entre preservación y desarrollo, lo cual se expresa por la pobreza económica de los habitantes, frente a la riqueza histórica y cultural de los $\mathrm{CH}$. Así que, de esta manera, se encuentran los nexos entre el desarrollo, que busca abatir la pobreza por medio de la riqueza simbólica y patrimonial con que cuentan nuestros $\mathrm{CH}$.

La diversidad cultural en la ciudad de México es enorme, es la tercera o cuarta más poblada en el mundo, es un espacio donde convive al mismo tiempo modernidad y pobreza. Con una migración constante, en 1990 el 40\% de los residentes había nacido en ella y casi un cuarto de millón de personas habitaba comunidades y pueblos indígenas dentro de los límites de la metrópoli. En la Ciudad de México se hablan 35 idiomas de distintos países del mundo y unos 60 originarios de México y Centroamérica. Más de la tercera parte de la población del centro tiene nivel de 
indigencia y casi una quinta parte de muy pobre (Alejandro Aura, 1999). De igual manera lo expresa Carman (2006):

"Si tenemos mucha cultura, tendremos menos pobreza, planteó Aníbal Ibarra, ex Jefe de Gobierno de la Ciudad de Buenos Aires, en septiembre de 2004, cuando había sido elegido como tal. Es posible que esta sea la máxima a partir de la cual entender las transformaciones que tuvieron lugar en el barrio estudiado." (Carman, 2006: 20)

La última autora refiriéndose al caso de un barrio emblemático en Buenos Aires, en donde la cultura se convirtió en eje conductor de las acciones. De igual manera ocurre en los $\mathrm{CH}$, los cuales cuentan con historia, cultura, identidad, pero donde se ha dejado de lado a la población, la cual, como menciona Aura, vive con índices de marginalidad. Es así como el $\mathrm{CH}$ se convierte en espacio (geográfico y simbólico) de intervención, donde el desarrollo y conservación se encuentran y desencuentran.

Los $\mathrm{CH}$ requieren de acciones específicas, donde el desarrollo simbólico y material sean una constante. Si partimos de lo presentado por Carrión (2000), sí los pobladores de los $\mathrm{CH}$ se encuentran en condiciones de pobreza, ¿de qué manera generar desarrollo material y simbólico? Muchas políticas urbanas consideran solamente la conservación del patrimonio material, pero si se dejan de lado las condiciones precarias de la población, el $\mathrm{CH}$ se puede convertir solamente en un barrio histórico donde repose la memoria de un pasado que quedó trunco. Este espacio se convierte en el museo de una ciudad, que dejó de existir. (Carrión, 2000: 5)

"Es imprescindible, por un lado, formular políticas sociales y culturales, que logren movilidad social y mejoramiento de la calidad de vida de la población que allí vive y no su expulsión. Y por otro, una cierta flexibilidad de la estructura urbana que se adecue a las nuevas exigencias de la globalización, bajo dos ejes: desarrollo de los servicios y equipamientos de punta e inserción en los nichos de mercado competitivos." (Carrión, 2000: 5-6)

De esta manera, el autor nos presenta las directrices que deberán tomarse en cuenta para la gestión de CH. Sin embargo, no basta con la preservación arquitectónica, se requiere apoyo para el desarrollo inmaterial, para que los habitantes del $\mathrm{CH}$ tengan derechos, metas y se procure establecer espacios públicos que generen la cohesión y desarrollo, donde la participación sea eje fundamental para la gestión. Actualmente, la globalización es un proceso que debemos considerar en la revitalización de los $\mathrm{CH}$, ya 
que se deben concebir políticas que permitan la competitividad a nivel mundial, que los CH se conviertan en espacios y actores vivos, en construcción y resignificación. Sin embargo, también es importante que ésta no convierta a los $\mathrm{CH}$ en city marketing (Tresseras, 2004), lo cual quiere decir que la cultura dota de oportunidades a las ciudades, dentro de un marco mercadológico global. En algunas ciudades se busca cambiar su imagen, dotando de características externas a las metrópolis, siempre buscando tener mayor competitividad a nivel mundial. En este sentido, uno de los casos emblemáticos es el Museo Guggenheim de Bilbao, que se ha convertido en símbolo de la ciudad, intentando cambiar estigmas terroristas por ideales artísticos. Es así como, un Museo de esta envergadura puede transformar la visión mundial que se tenía de la ciudad. ¿Los habitantes locales estarán de acuerdo o es un capricho mercantil? No lo sé, ni es discusión de la investigación, pero la mercadotecnia de ciertas características o recintos de las ciudades las puede convertir en city marketing ante la industria turística.

Continuando con Carrión (2000), enfatiza las corrientes de interpretación y de actuación de los $\mathrm{CH}$ : Espacial, temporal y patrimonial. A lo cual agrega: Al concepto $\mathrm{CH}$ se lo analizará, en primer lugar, separando sus componentes centro (espacio) e historia (tiempo) para, posteriormente, integrarlos a través de la categoría relación social, que es la que permite vincular tiempo (historia) y espacio (territorio): patrimonio (Carrión, 2000:9). De esta forma, el autor marca las diferentes interpretaciones del $\mathrm{CH}$, en donde la relación social- para este estudio: la cultura- es el eje que vincula el espacio y el tiempo: la memoria, las construcciones, experiencias, imaginarios, arquitectura, etc. Por lo tanto, no es de extrañar que las grandes transformaciones de los $\mathrm{CH}$ sean evidentes en el patrimonio cultural tangible, como lo son fachadas, templos, edificaciones en general.

\section{a) Lo espacial.}

Continuando con lo presentado por Carrión (2000). La especialidad en el centro (para el autor) se refiere a atributos que se le confieren, es decir, a una relación. El centro es un concepto relativo en la medida que un conjunto de relaciones lo configuran como eje dentro de la ciudad y su historia (totalidad). (Carrión, 2000:9) Los CH son definidos por: lo urbano (espacio) y lo histórico (tiempo). $\mathrm{CH}$ es escenario, lugar y también es historia, tiempo. La característica histórica es la que dota de centralidad al 
espacio, así que los valores arquitectónicos lo configuran. A lo que agregaría, no es solamente el valor arquitectónico, sino social y que se encuentran en nuestro imaginario, las relaciones sociales y simbólicas que tenemos con el $\mathrm{CH}$. Como categoría relacional, el centro se analiza respecto al resto de la Ciudad. Para Carrión (2001) existen dos visiones para el estudio del espacio:

1. Con base en soportes físicos: edificios urbanos y calles. El 'monumentalismo' es la expresión principal de esta corriente y su intervención se realiza desde la arquitectura y/ o el urbanismo (Carrión, 2001:33). Desde esta visión, el patrimonio tangible juega un papel fundamental para los $\mathrm{CH}$, se busca su restauración a ultranza y se dejan de lado elementos intangibles por dar mayor peso al patrimonio material. En el caso de estudio, en el DF creo que se ha caído en la monumentalidad, si importa el patrimonio intangible, pero el peso que se da para la recuperación arquitectónica es evidente, muchas fachadas están inmaculadas, aunque el entramado social pase a segundo plano en la revitalización de nuestro $\mathrm{CH}$.

2. El espacio depende de lo social, esto es, la organización territorial se fundamenta en las relaciones sociales. En esta corriente, el patrimonio intangible es determinante, las relaciones sociales, identitarias, etc. son las que dan la pauta para el desarrollo de los $\mathrm{CH}$. En el $\mathrm{CH}$ de la Ciudad de México se ha dotado de gran importancia a esta labor, como lo mencionó Anabelí Contreras, Jefa de Unidad de Difusión del Fideicomiso del CH:

"Se ha hecho una cosa que se llama la Escuela de Participación Ciudadana y en diferentes calles donde se hagan intervenciones, donde se arreglen fachadas, se invita a la gente, es una escuela de participación ciudadana y aprender a conocer qué es el patrimonio, dónde viven, cómo ejercer sus derechos, que aprendan a hacer su propia gestión. Sí queremos que se vea, que es muy importante la parte en la que involucramos a toda la gente en este proceso." (Entrevista con Anabelí Contreras, Fideicomiso del CH, 15 de abril de 2011)

De esta manera, en el Centro del DF también se busca la participación, pero no sólo eso, sino la apropiación de los sitios históricos, los cuales dotarán de identidad a los habitantes de la zona. Por lo mencionado en la entrevista, ha tenido gran éxito el enseñar a la gente sobre la historia de sus calles y casas, lo cual los convierte en sujetos patrimoniales de estos sitios. 
Después de expuesto lo anterior, sería importante formular políticas que contemplen no sólo el patrimonio tangible de edificios religiosos, legislativos, museos, etc., los cuales son emblemáticos, sino las relaciones sociales intangibles que se gestan en nuestros $\mathrm{CH}$. Entre el patrimonio tangible e intangible, deberá existir un equilibrio y participación de diferentes sectores para que el desarrollo de políticas sean acordes con las necesidades de la población, y no sólo por la lógica de mercado de ciudades museo.

\section{b) Lo temporal.}

En el caso de los $\mathrm{CH}$, nos remiten a lo moderno y lo antiguo, de ahí su complejidad de acción en este espacio. El pasado, presente y futuro se expresan en él. Como menciona Cantú (2009) refiriéndose al CH crítico espacio urbano actor de la capital, de las demandas sociales más sentidas, tanto en la metrópoli como en las entidades federativas y de la nación. (Cantú, 2009:21). Lo presentado por Cantú expresa el presente y futuro en el $\mathrm{CH}$, las demandas, necesidades y demás expresiones que se muestran en las manifestaciones en el $\mathrm{CH}$ (en particular el de la ciudad de México) del presente, buscando transformaciones con alcances a futuro. En este sentido, el $\mathrm{CH}$ tiene el pasado, presente y futuro en sus expresiones materiales y simbólicas.

Retomando a Carrión (2000), el pasado y el futuro se funden en el CH. Aunque partiendo de estas temporalidades, se establecen criterios de importancia para alguno de los dos momentos.

"La prioridad en lo moderno implica la negación de lo antiguo por lo nuevo, que podría ser caracterizado como el 'fin de la historia' porque rompe con el pasado. Esto supone que la tradición es sustituida y que la continuidad histórica es rota. Por eso, la construcción nueva o la rehabilitación se vacían de los referentes históricos. Sin duda, en este caso, el patrimonio aparece como un obstáculo a la supuesta modernización y al desarrollo urbano. Su antípoda es la posición conservacionista en extremo, que lleva a un retorno, porque pone énfasis en lo antiguo sobre lo moderno. En este caso la propuesta es un intento de congelamiento de la historia en el momento de origen o de fundación de la ciudad, que conduce a una ruptura de la continuidad histórica con el futuro. Esto supone, como política de intervención, la búsqueda del regreso a ese momento sobre la base de un supuesto historicismo. Es una forma de llamar al pasado en el lugar que más cambia de la ciudad: el centro histórico." (Carrión, 2000:10-11)

De esta forma, dicho autor nos presenta la complejidad en la gestión del CH, ¿Apostar por el futuro anulando el pasado o atrincherarse en el segundo dejando de lado 
el presente y futuro? Si el $\mathrm{CH}$ es pasado, presente y futuro, se requiere el diálogo entre distintas temporalidades, no podemos vivir de recuerdos e historias, tenemos que vivir el presente de la ciudad, de la globalización, pero debemos conocer el pasado del cual partimos. Contemplar el pasado, pero no quedarnos con las imágenes de las construcciones ni de los imaginarios que denotan identidad solamente, sino generar reconstrucciones con ese bagaje. Así que la gestión de los $\mathrm{CH}$ se encuentra en la disyuntiva entre ambas temporalidades. Carrión (2000) advierte, que no debemos pensar en CH bajo la secuencia lineal: lo antiguo es generador de lo moderno y lo moderno es una forma de conferir existencia a lo antiguo (Carrión, 2000: 11). De esta manera, no debemos considerar los $\mathrm{CH}$ con temporalidades contradictorias, sino como procesos, sin el pasado no podríamos hablar de lo moderno, por eso la intervención de los $\mathrm{CH}$ no debe de concluir, se debe de construir, reconstruir, reapropiarse socialmente y que las políticas de intervención no cesen.

"La necesaria comprensión histórica del concepto 'centro histórico', lleva a entenderlo como el lugar de encuentro o eslabón que, a través de su actual presencia, integra el pasado con el futuro deseado. Esto es, un proceso social que contiene las distintas fases históricas por las que atraviesa una parte especial de la ciudad, que está articulada con otras al todo." (Carrión, 2001: 37)

Los $\mathrm{CH}$ son parte de la ciudad, de la urbanización, la cual contempla desarrollo, modernidad, historia, pero no están aislados del resto de ella. En su momento, el CH de nuestra ciudad era la urbe completa, se ha ido expandiendo, los grandes corporativos financieros ya no se concentran en él, se han ido a las periferias como Santa $\mathrm{Fe}$ o se ha adecuado circuitos empresariales como Reforma y su continuación hacia el $\mathrm{CH}$, pero no debemos olvidar que en el $\mathrm{CH}$ nace la historia, las avenidas, las experiencias, los imaginarios, etc.

\section{c) Lo patrimonial.}

Nos permite vincular lo histórico con lo territorial. Teóricamente, el $\mathrm{CH}$ es definido por la herencia, legado, con la forma de patrimonio (cultural o natural). Carrión establece que el carácter patrimonial de los $\mathrm{CH}$ debe vincular el carácter social y no sólo la monumentalidad física. Considerando el patrimonio:

1. Ámbito de conflicto social. Tensiones y relaciones entre "herederos" o sujetos patrimoniales. 
2. Lógica de la transferencia socio-generacional del valor patrimonial. Define la continuidad en el cambio. El concepto patrimonio hace referencia a la construcción de la sustentabilidad de los centros históricos, deducida de la transmisión del centro histórico de un período $y$ de una comunidad específicas hacia un momento y a una sociedad distinta. (Carrión, 2000:12)

A lo que Augé agregaría:

"Memoria e historia se conjugan en la ciudad. Cada uno de los habitantes de la ciudad tiene su propia relación con los monumentos que dan testimonio de una historia más profunda y colectiva. En este sentido, el recorrido urbano de cada individuo constituye una manera de apropiarse de la historia a través de la ciudad." (Augé, 1997: 113)

Es así como los denominados sujetos patrimoniales presentados por Carrión (2000), tampoco son un todo homogéneo receptor. Existen conflictos por la percepción del patrimonio cultural, pero también se debe a la individualidad que presenta Augé. Por ejemplo, El Palacio Nacional del DF, no significa lo mismo para un turista, que para un niño mexicano. Para el primero, puede ser parte de la historia de México, una especie de metonimia, donde una parte (esa construcción y su discurso) representan a México. Para un niño de secundaria puede representar un bello edificio, el cual hay que visitar porque se lo han pedido en la escuela. La reapropiación y significación no se pueden generalizar, pero estoy de acuerdo en considerar a los sujetos patrimoniales, así como sus conflictos o tensiones por apropiarse de este patrimonio.

Para lograr el impulso de los $\mathrm{CH}$ se debe considerar el carácter histórico-cultural. La noción de $\mathrm{CH}$ está dotada de la idealización del pasado, "todo tiempo pasado fue mejor" y también en la memoria cultural, como testigo del pasado que debe cuidarse y protegerse. La época del patrimonio artístico y cultural, de la arquitectura considerada como arte y el edificio como escultura, de ahí se conciben los atributos de la monumentalidad. (Carrión: 2000:13). Pensar en el glorioso pasado per se deja de lado realidades actuales que modifican a la sociedad, que requieren reconocimiento y acciones en diferentes sentidos, que el pasado no puede desdibujar el presente y futuro de los $\mathrm{CH}$. Por lo tanto, se requieren acciones que contemplen las diferentes direcciones 
de intervención en estos sitios, no demeritando el pasado, pero dotando de importancia al presente y futuro.

Lo patrimonial existe, en la medida es que es asumido por un sujeto que lo reconoce, lo apropia y proteja (Carrión, 2000:16), lo cual genera una apropiación social y democratización del patrimonio. En definitiva, el patrimonio y su apropiación generan una serie de conflictos entre los sujetos patrimoniales, pero también es la esencia del $\mathrm{CH}$, ya que en él se da la apropiación colectiva de él. De esta forma, el "derecho a la ciudad" es la expresión colectiva del patrimonio, de la ciudadanía.

"La ciudadanía [...] tiene el derecho-deber al disfrute, goce y mejoramiento del centro histórico, porque no es exclusivo y único de sus habitantes o de sus propietarios y mucho menos de los actores externos. Sin embargo, se debe reconocer como derecho prioritario, a los habitantes que moran en el centro histórico, por cuanto sus condiciones de vida son una determinación de existencia del área histórica y el punto de arranque de su puesta en valor. Esto supone la existencia de un patrimonio popular, que reconoce a los sectores populares como (re) constructores de los centros históricos y de su existencia; una reafirmación de que los centros históricos de América Latina habitan estos sectores; y, que el rescate del patrimonio nacional es un medio de defensa de la nacionalidad, que tiende a fortalecer identidades." (Carrión, 2000:17)

Desde esta perspectiva, el $\mathrm{CH}$ es el corazón de la ciudadanía, de las ciudades, de derechos, obligaciones, apropiaciones, reapropiaciones, de identidades, memoria, entre otros. Por lo tanto, su revitalización necesita contemplar todas estas aristas, pero éstas también dificultan su gestión, debido al entramado simbólico y material que los $\mathrm{CH}$ conllevan. Lo patrimonial deberá ser democrático y no generar exclusión. En la preservación de los valores del patrimonio mucho tiene que ver con su democratización, su 'deselitización', la apropiación social, la promoción como interés general, la construcción de un proyecto colectivo, el fortalecimiento del sentido de ciudadanía [...] (Carrión, 2001: 17). Es así como, el patrimonio genera cohesión y libertad debido a su carácter democrático, donde todos somos herederos y sujetos patrimoniales, no solamente de las expresiones tangibles, sino intangibles que nos dotan de identidad cultural. Sin embargo, es importante aclarar, como lo menciona Carrión: El rescate del patrimonio encubre y evade los conflictos sociales subyacentes (Cabrera, 1997: 123 en Carrión 2000: 12). Por lo tanto, el patrimonio juega un rol central en la revitalización de $\mathrm{CH}$, genera relaciones sociales en su apropiación, pero tampoco 
debemos caer en el patrimonialismo a ultranza, se deben considerar factores como los mencionados: pobreza, vivienda, espacio público, demandas ciudadanas, etc. y no intentar ocultar estos elementos con grandes edificios restaurados, porque el sustrato también debe ser considerado en la revitalización de nuestros $\mathrm{CH}$.

Después de haber presentado algunos elementos que considero son pertinentes para el análisis de los $\mathrm{CH}$, es importante mencionar que el patrimonio juega un rol fundamental en las políticas de revitalización de estos sitios, en donde su apropiación genera relaciones sociales y ciudadanas. Aunque, para el tema de mi investigación, pareciera que los espacios públicos, las calles se convierten solamente en testigo de los vestigios conservados. Por lo tanto, es necesario considerar al arte urbano callejero que se expresa en las calles de nuestro $\mathrm{CH}$, ya que el caso de estudio no es aislado, existen diversas manifestaciones artísticas en las calles centrales de diferentes ciudades del mundo. 
En el Centro se dio antes que en ningún otro sitio el canje del nacionalismo por el folclor urbano, y allí la densidad histórica es tan extrema que, cosa rara en la ciudad, cuyo principio regenerativo es el enraizamiento, son demasiados los sitios y las edificaciones que se conservan y remiten a su origen [...] Cada edificio colonial es la suma de la belleza preservada y las calles desbordan fantasmas (a ellos también los asaltan). (Carlos Monsiváis, 2010: 167)

\section{Revitalización del Centro Histórico de la Ciudad de México.}

Como lo he presentado en esta investigación, la gestión de los $\mathrm{CH}$ no es una labor sencilla ni se encuentra aislada de acciones similares en diferentes ciudades del mundo. Tal es el caso del $\mathrm{CH}$ de la Ciudad de México, al igual que otros, se encuentra en constante reconfiguración, lo cual es evidente en el caso concreto de las Políticas Culturales en dicho espacio, las cuales surgen desde el Gobierno del Distrito Federal y otras instituciones especializadas.

Es importante mencionar que la revitalización y reconfiguración del $\mathrm{CH}$ de la Ciudad de México ha tenido gran desarrollo desde 1997, año en el que por primera vez, se ha elegido democráticamente al alcalde de la Ciudad de México, mejor conocido como Jefe de Gobierno (Cuauhtémoc Cárdenas), el cual dijo desde el principio de su gestión:

"Que el centro vuelva a ser parte vital de la vida económica, cultural y social de la capital, que ofrezca vida digna a quienes ahí moren y trabajen, con viviendas mejores y viviendas nuevas, con extensas áreas comerciales, instalaciones culturales, talleres e industrias, que den sustento y consoliden la renovación." (Cuauhtémoc Cárdenas, 1997 en René Couloumb, 2001:140)

Debido a la transformación política y social ocurrida, la cual se expresa tanto en declaraciones, programas de Gobierno, como en acciones en el $\mathrm{CH}$, he decidido comenzar la investigación de este espacio en la ciudad de México desde 1997. Aunque sé que existe información importante sobre la formación de la ciudad desde su fundación en 1325, la cual fue trazada desde el CH.

Aunque para remitir al patrimonio cultural del $\mathrm{CH}$ es importante retomar lo presentado por René Coulomb (2001). En 1934, el INAH catalogó dentro del área del CH: 768 monumentos, para 1964 se habían perdido 422. Sin embargo en 1980, existían 196 monumentos con declaratoria individual, 542 eran protegidos por la Ley Federal de Monumentos y Zonas Arqueológicas, Históricas y Artísticas (1972) y 743 habían 
sido incorporados por el INAH a la lista de inmuebles con valor histórico y arquitectónico.

“A raíz del descubrimiento de la piedra escultórica que representa a la diosa azteca Coyolxauqui, y de las consecuentes exploraciones del Templo Mayor de Tenochtitlan, la antigua Ciudad de México fue declarada, por decreto presidencial del 11 de abril de 1980, Zona de Monumentos Históricos. Al mismo tiempo se creó el Consejo del Centro Histórico con el fin de coordinar las acciones requeridas para su recuperación, protección y conservación.” (Coulomb, 2001: 140)

De esta manera, aunque mi tesis no busca resaltar el patrimonialismo, considero que es pertinente considerarlo, ya que retomando lo expuesto por Carrión (2000), el patrimonio cultural y su apropiación generan relaciones sociales necesarias en los $\mathrm{CH}$. Por lo tanto, es importante mencionar que las gestiones por la conservación del $\mathrm{CH}$ tenían un claro fundamento patrimonialista, como lo muestra Coulomb con la cantidad de sitios históricos contenidos en el área. Quiero destacar que el Consejo del $\mathrm{CH}$ es el primer antecedente en nuestra ciudad sobre una institución dedicada exclusivamente a esta zona, por lo cual, considero que es información importante para analizar el desarrollo de las acciones e instituciones dedicadas a la gestión de este espacio.

\subsection{Aspectos generales del $\mathrm{CH}$ de la Ciudad de México}

El CH comprende 9 kilómetros ${ }^{2}$, con 668 manzanas. El denominado perímetro "A" (3.2 $\mathrm{km}^{2}$ ) está en los límites de lo que fuera la ciudad virreinal (Coulomb, 2001) ${ }^{1}$ y cuenta con mayor número de monumentos. El perímetro "B" (El cual no es analizado en esta tesis) tiene una superficie de $5.9 \mathrm{~km}^{2}$ y en palabras del Fideicomiso del $\mathrm{CH}$, es el área de amortiguamiento.

El CH de la Ciudad de México fue nombrado Patrimonio Cultural de la Humanidad en diciembre de 1987, lo cual genera la creación de instancias y acciones de intervención

\footnotetext{
${ }^{1}$ El número de edificios en el perímetro parece no ser muy claro. Coulomb (2001) dice que comprende 1,348 edificios. El Fideicomiso del $\mathrm{CH}$ en su página de Internet dice que son 1,436 en ambos perímetros. En entrevista con el Arquitecto Martínez (20 de junio de 2011), quien es Director de Proyectos Sustentables en la Secretaría de Obras y Servicios del GDF comentó "El Centro Histórico en su perímetro "A", con $6 \mathrm{kms}^{2}$ son más de 3, 000 edificaciones, de esas, más de 2, 000 son monumentos históricos". El tema de esta investigación no es el catálogo de edificaciones, ni la superficie de ambos perímetros en el $\mathrm{CH}$, pero considero importante hacer la observación sobre las confusiones numéricas existentes en esta área.
} 
en dicho espacio. Sobre la relación que tiene el CH con UNESCO, Anabelí Contreras (Jefa de la Unidad de Difusión del Fideicomiso del CH) me dijo en entrevista:

"El año pasado vino Nuria Saenz, que es la persona que encabeza la parte de UNESCO que supervisa América Latina y el Caribe, fue una reunión para la realización de indicadores de gestión. Es decir, si hay una interlocución directa con UNESCO, se trabaja de manera directa. Por supuesto va en ese sentido, va dirigido por ahí [...] Finalmente, quienes dictan la pauta sobre cómo tiene que ser, son ellos y quienes te ponen como Patrimonio en peligro de extinción o si pierdes pertenecer a la lista: son ellos, hay que trabajar de manera directa todo el tiempo.” (Entrevista con Anabelí Contreras, Fideicomiso del CH, 15 de abril de 2011)

Respecto a lo planteado por Anabelí Contreras, la relación con UNESCO es estrecha, se trata (como ella comentó) del apoyo que brinda la institución, esto es, trayendo expertos en temas relacionados con $\mathrm{CH}$ y patrimonio, donde el intercambio de experiencias es una constante para la gestión de nuestro centro. UNESCO no aporta recursos para la realización de obras, pero si genera proyectos que son discutidos en las instancias locales, donde la conservación, compromiso y desarrollo sean una constante. Anabelí Contreras menciona que formar parte del Patrimonio de la Humanidad es un compromiso grande, importante, trabajo, muchas satisfacciones, a veces hay auto presión, pero bueno, también vale la pena. (Entrevista con Anabelí Contreras, Fideicomiso del CH, 15 de abril de 2011). Si bien, UNESCO no aporta recursos económicos, el pertenecer a la lista de Patrimonio de la Humanidad implica compromiso con la organización internacional que los ha catalogado así y por supuesto se debe mostrar el desarrollo y conservación del área. Un punto que me parece relevante es la importancia que tiene el turismo en el $\mathrm{CH}$, pareciera que formar parte del Patrimonio de la Humanidad para UNESCO es entrar en un catálogo de guías turísticas. Entiendo perfectamente que estar en la lista mencionada es un compromiso y a la vez da visibilidad a una ciudad, a un espacio y que se tienen que preocupar por todos los sectores: habitantes, turistas, residentes, etc. Así que, como mencioné en la parte teórica de los $\mathrm{CH}$ a nivel mundial, el turismo es una industria fundamental para la formulación de políticas en los $\mathrm{CH}$. Tal es el caso de la reunión tenida con UNESCO este año, ya que fue invitado a México: Miguel Troitiño (Junta de Andalucía), que es una autoridad en desarrollar indicadores sobre turismo, trajo a muchos expertos a trabajar con nosotros y con la gente del INAH. (Entrevista con Anabelí Contreras, Fideicomiso del CH, 15 de abril de 2011). Como lo presenté en la primera parte de este capítulo, el 
turismo juega un rol fundamental en los $\mathrm{CH}$ y si el patrimonio cultural tangible es la evidencia de la historia y la identidad, son bienes que causan gran interés a visitantes de todo el mundo. Aunque me sigo cuestionando, ¿Qué ocurre con manifestaciones artísticas o culturales que se realizan fuera de los foros establecidos en el $\mathrm{CH}$ ?

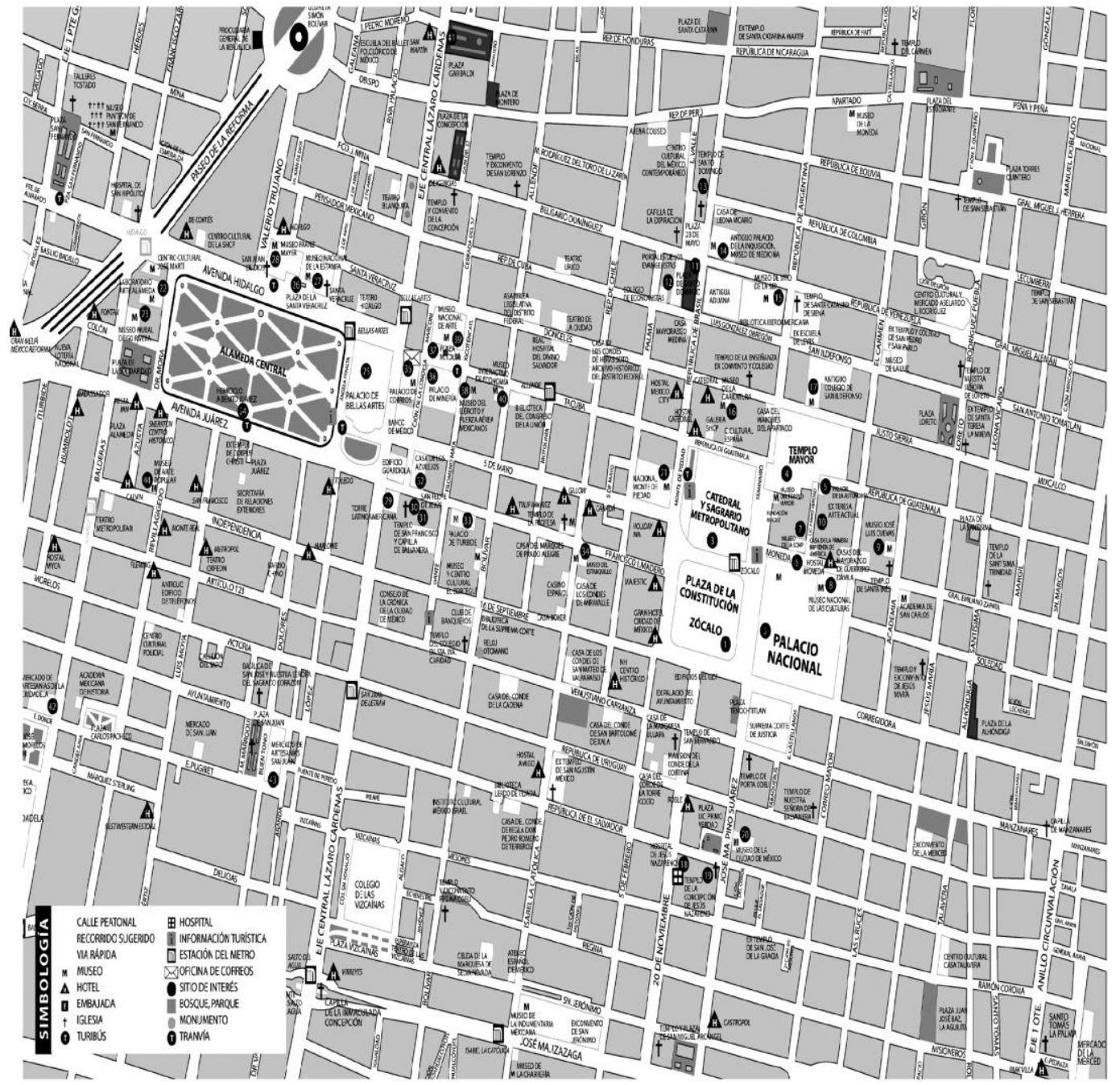

Mapa del Centro Histórico de la Ciudad de México.

Fuente: http://www.accionglobalmexico.org/doc/centroespanol.pdf

Después de presentar esta primera parte sobre el Centro de la Ciudad de México, es importante analizar la gestión de diferentes instancias en este espacio, el cual juega un rol fundamental en la identidad, memoria, recreación, movimientos sociales y libertad de expresión en la Ciudad de México. 


\subsection{Gestión en el CH de la Ciudad de México.}

Como menciona Rene Coulomb (2001)

"El centro histórico 'sufre' la intervención desarticulada de más de 20 instituciones locales o federales de gobierno. La falta de congruencia y unidad de acción gubernamental dificulta la gestión de los más elementales aspectos de orden urbano y convivencia social, como son el mantenimiento de los espacios públicos y la aplicación de las normas básicas de buen gobierno.” (Coulomb, 2001: 144).

De esta manera, la gestión de los $\mathrm{CH}$ no sólo tiene diferentes aristas de intervención, sino diferentes instituciones dedicadas a cada una de ellas, no es de extrañar que se requieran de instancias locales y federales que tengan acciones coordinadas para el desarrollo de proyectos en esta área. Retomando el argumento de comenzar este análisis en 1997 quisiera remitir a lo presentado por Carrión (2001):

"La región vive un proceso de reforma del Estado que tiene, al menos, dos expresiones: por un lado, el incremento significativo del peso de lo municipal en el gobierno de la ciudad, a través del aumento de competencias, recursos y actores; que lleva la administración de los centros históricos. Por otro lado, hay una mayor participación del sector privado en la gestión urbana del patrimonio [...]" (Carrión, 2001: 65)

Retomando lo presentado por Carrión, me parece fundamental que el análisis de la gestión en el CH de la Ciudad de México deberá comenzar para esta tesis en 1997, que como presenté líneas atrás fue un tema que el entonces Jefe de Gobierno del DF contempló desde un principio. Para esta investigación, se marca una transformación política y social con la elección del Primer Jefe de Gobierno y aunque ésta es cultural y no política, es necesaria esta introducción para contemplar las transformaciones ocurridas en los $9.1 \mathrm{~km}^{2}$ que tiene el Centro de la Ciudad de México.

Es así como la gestión del $\mathrm{CH}$ se encuentra con complejidades institucionales que esbozaré a continuación. Si bien, algunas de las instancias podrían ser explicadas de manera cronológica, considero que existe un acontecimiento reciente que transforma por completo la creación y los objetivos de estas instancias, así que comenzaré por este hecho. 


\subsubsection{Consejo Consultivo para el Rescate del Centro Histórico de la Ciudad de}

\section{México.}

El 14 de agosto de 2001 en Palacio Nacional se reunieron, el entonces Presidente, Vicente Fox y el Jefe de Gobierno Andrés Manuel López Obrador y de común acuerdo se estableció este Consejo con apoyo Federal y Local, donde el objetivo primordial era que el $\mathrm{CH}$ se convirtiera en el sitio neurálgico de la Ciudad.

"Nos reúne hoy un propósito digno, la preservación y el rescate a partir de nuevas bases y equilibrios del Centro Histórico de la ciudad de México. Nuestro reto es convertirlo en un espacio renovado y dinámico, representativo de la energía y la decisión de los mexicanos y mexicanas. Porque nuestro porvenir debe partir de la preservación de lo mejor de nosotros mismos, de nuestras profundas y sólidas raíces." (Vicente Fox, 2001)

Se busca preservar y honrar la historia que se encuentra en el $\mathrm{CH}$. Es ámbito de contrastes, aquí conviven bellezas insustituibles de nuestra cultura, con fenómenos lacerantes de pobreza y marginación. (Vicente Fox, 2001). Desde esta perspectiva y siguiendo la línea de esta investigación, se argumenta lo que ya había planteado Carrión (2000): la existencia de contrastes entre riqueza histórica y pobreza económica en el mismo espacio.

"Para desplegar todo su potencial debemos hacer de él un espacio urbano y turístico modelo, por ello se instala este Consejo Consultivo Plural y del más alto nivel, y por ello agradecemos su presencia, su participación y su colaboración [...] Habremos de respetar la arquitectura, diseño original del Centro Histórico de la ciudad de México. Habremos de integrar a todos y cada uno de aquellos quienes viven, quienes trabajan, quienes se benefician dentro del Centro Histórico, estarán incluidos en el proyecto. Habremos de garantizar seguridad y tranquilidad para el disfrute pleno del Centro Histórico de la ciudad de México. Habremos de buscar la autosuficiencia también de este Centro Histórico a través de la promoción de una gran afluencia de visitantes, de pequeños negocios, de actividades de todo tipo que permitan elevar la calidad de vida de quienes hoy habitan dentro de este Centro Histórico.” (Vicente Fox, 2001)

La importancia del $\mathrm{CH}$ se expresó en la toma local y federal de crear dicho Consejo, el cual está conformado, entre otros, por Carlos Slim (Presidente Ejecutivo del Consejo del $\mathrm{CH}$ de la Ciudad de México), José Ezequiel Iturriaga (Presidente Honorario del Consejo del CH). El Gobierno Federal, para el 29 de mayo de 2003 había otorgado 263 millones para turismo, rescate, remodelación y seguridad pública. Para esta fecha (29 de mayo) ya se había inaugurado el Centro de Tecnología TELMEX, la Fuente de Plaza Juárez y se tenía planeado hacer un edificio dedicado a la Secretaría de Relaciones 
Exteriores.

"Este año a estos recursos se sumarán 67 millones de pesos. Con ello estaremos llegando a una inversión de más de 331 millones [...] Para la adquisición de cámaras de circuito cerrado y sistemas de radiocomunicación para la policía aportamos 86 millones de pesos [...] Estamos otorgando estímulos físcales para quienes invierten en el Centro Histórico. El Gobierno Federal ha otorgado incentivos fiscales por un valor de 500 millones de pesos, que han permitido, atraer esas inversiones para construcción, remodelación y rehabilitación en toda la zona por una cantidad cercana a los mil 500 millones de pesos." (Vicente Fox, 2001)

Quisiera destacar que esta declaración es de las pocas en donde se hace mención a la inversión y al capital generado en el $\mathrm{CH}$. Por lo que podemos ver, son erogaciones que repercuten y regeneran de manera directa al centro.

"En el 2001 se da una coyuntura muy interesante, venía esta tendencia mundial de revalorización y rehabilitación de Centro Histórico y arranca. De pronto, se hace una reunión en la que el Gobierno Federal con el Presidente Fox, Andrés Manuel López Obrador como Jefe de Gobierno y un Consejo Consultivo que se forma como con 100 y tantas personalidades, en las que estaban Jacobo Zabludovsky, el Cardenal Norberto Rivera, Guillermo Tovar y de Teresa, Carlos Slim, Don José Iturriaga, un montón de gente y se hace una suerte de pacto de: echamos a andar el Consejo Consultivo y que los gobiernos en su ámbito de competencia hagan una apuesta por el centro, por hacer obras y cosas así." (Entrevista con Anabelí Contreras, Fideicomiso del Centro Histórico, 15 de abril de 2011)

Si bien, la creación del Consejo Consultivo es de 2001 y el Fideicomiso del CH se creó en 1990. Consideré importante comenzar por el Consejo, ya que después de su creación hay un cambio en el Fideicomiso del $\mathrm{CH}$, modificando su figura jurídica y atribuciones para convertirse en el que tenemos actualmente. Otro elemento que me parece relevante del Consejo Consultivo, aparte de amalgamar al Gobierno Federal y Local en la toma de decisiones en la zona, es la intervención del sector privado, el que el Ingeniero Carlos Slim forme parte de este Consejo genera una transformación en nuestro centro. Debido a su interés en este espacio, crea la Fundación del CH de la Ciudad de México A.C, de la cual hablaré más adelante. Así que por eso, he decidido comenzar con la creación del Consejo Consultivo, como un parte aguas en la gestión del CH.

"Se firmó un convenio para que las instancias de la administración pública del gobierno Federal, del gobierno del Distrito Federal y de la empresa privada se coordinasen con el propósito de revertir el deterioro de esta zona y crear condiciones para que volviera a ser un lugar habitable, mejorando la calidad de vida de quienes hoy viven, atraer a nuevos habitantes y atraer inversionistas para crear nuevos empleos.” (Fundación del CH de la Ciudad de México, A.C) 
La Creación del Consejo Consultivo amalgamó diferentes instancias y niveles de Gobierno, pero también contempló la importancia de la iniciativa privada en las inversiones en el $\mathrm{CH}$, que como ya mencioné, Carlos Slim es uno de los mayores promotores de la zona y forma parte de este Consejo. Así que, si para 2001 existían alrededor de 20 dependencias implicadas en la toma de decisiones del $\mathrm{CH}$ (como menciona Coulomb, 2001), en la actualidad existen más instituciones, pero también las líneas de acción han aumentado y los resultados (al parecer) han sido favorables. Cabe aclarar que cada una de las instancias tiene estrecha relación con las demás, se hacen acciones en coordinación, por lo que no es sencillo analizarlas de manera aislada sino por las redes que existen entre ellas.

\subsubsection{Fideicomiso del Centro Histórico}

En 1990 se creó el Patronato del CH, del cual deriva el Fideicomiso del CH (18 de diciembre de 1990), el último tenía como objetivo promover, gestionar y coordinar acciones ante los particulares y las autoridades competentes la ejecución de acciones, obras y servicios que propicien la recuperación, protección y conservación del Centro Histórico, buscando la simplificación de trámites para su consecución (Coulomb, 2001: 142). Es importante mencionar que el Fideicomiso, en su creación y durante varios años era privado, lo cual se modificó en el año 2001 con la creación del Consejo Consultivo para el Rescate del CH.

"Se crea en diciembre de 1990 como un Fideicomiso privado, primero se creó un Patronato en el 90 para el Centro Histórico y luego crean el Fideicomiso, pero era básicamente privado. No empresas, era una figura privada, eran particulares los que lo habían formado, que lo habían organizado y había participación gubernamental, no sé hasta qué grado económicamente. Como había obras, el Comité del Fideicomiso, había gente de Gobierno que asistía a las tomas de decisiones sobre que hacer, sobre todo porque el espacio público era ámbito del Gobierno, en ese momento federal. Hicieron mucho trabajo de gestoría cuando era Fideicomiso privado, para los permisos, conseguían financiamiento para que la gente restaurara sus casas, inmuebles [...] En agosto de 2001, el Fideicomiso se había cerrado, pero no extinguido, pero se buscaba que dejara de ser privado, porque ya no iba a haber participación gubernamental, pero cuando se da todo este rollo [Consejo Consultivo], lo dejan esperando y en febrero de 2002 la apuesta del GDF para reactivar el Centro Histórico es convertir, pasar la figura de privado a público, siendo su Fideicomitente la Secretaría de Finanzas y todos sus recursos vienen del GDF. A partir de ese momento, desde antes, tiene un Comité Técnico con el Gobierno, lo Preside el Jefe de Gobierno, su suplente es el Secretario de Finanzas, hay representantes de todas las secretarías: de cultura, de turismo, de obras, de la delegación Cuauhtémoc, etc." (Entrevista con Anabelí Contreras, 
Fideicomiso del CH, 15 de abril de 2011)

Desde 1991, el gobierno de la ciudad cada año expide un acuerdo, el cual establece estímulos fiscales que apoyen obras de rehabilitación por parte de propietarios, inversionistas privados e instituciones públicas en el $\mathrm{CH}$. Si analizamos el desarrollo del Fideicomiso del $\mathrm{CH}$, es importante destacar el cambio que tuvo a raíz de la creación del Consejo Consultivo, ya que cambiar su figura jurídica de privada a pública lo dota de características que buscan apoyar su labor en la nueva configuración del $\mathrm{CH}$. En febrero de 2002 su Directora era Ana Lilia Cepeda, por lo que Andrés Manuel López Obrador anunció un presupuesto de 500 millones de pesos destinado a rehabilitar un núcleo urbano de 34 manzanas y más de 500 predios delimitados por las calles de Donceles y Venustiano Carranza, Eje Central y 5 de Febrero. (Página del Fideicomiso del CH, 2011). De esta forma, la inversión en el CH desde 1997 a 2002 fue considerable y marca el inicio de una serie de acciones que han llegado hasta nuestros días, donde la continuidad y las zonas de acción prioritaria son evidentes para habitantes, paseantes, comerciantes, etc.

Los recursos para las actividades que realizan dependen del Gobierno Local y Federal: FONCA tiene un apartado específico para proyectos en ciudades patrimonio, la Secretaría de Turismo Federal tiene recursos que da a través de convenios con el DF, tiene diferentes ramos, y entre otros, está para centros históricos y no sé muy bien a qué se refiere el ramo 23, pero cuando recibimos dinero de esa parte del Gobierno Federal se utiliza para hacer obra pública. (Entrevista con Anabelí Contreras, Fideicomiso del $\mathrm{CH}, 15$ de abril de 2011). Los recursos, al parecer solamente son públicos, ya que al preguntarle sobre la iniciativa privada en el $\mathrm{CH}$ aclaró: No hay dinero privado, si podemos recibir donativos privados. Sin embargo, no recibimos, hasta la fecha no hemos recibido. Si bien, no es tema de esta investigación el origen de los recursos utilizados para la revitalización del $\mathrm{CH}$, se ha convertido en una constante escuchar que este espacio es de Slim, por lo tanto, quise indagar en ello, no obtuve mayores resultados, salvo saber que las inversiones del Gobierno Local y Federal son las que permiten las obras en estos $9 \mathrm{~km}^{2}$ de nuestra ciudad. 
Respecto a la importancia que dan al patrimonio cultural tangible, que como menciona Carrión (2001), es la máxima expresión de relación social y de conservación de los CH. Es importante precisar que como parte de mi hipótesis y de la experiencia al ir constantemente al centro, las fachadas y las construcciones remodeladas o conservadas se encuentran casi inmaculadas ante la mirada de visitantes, comerciantes, habitantes, etc. por lo que me interesaba saber por qué enfatizaban el valor de las fachadas:

"Desde que Inti Muñoz entró como Director General (abril de 2008), se le ha dado un impulso muy fuerte al trabajo que se venía haciendo, por ejemplo, este programa de fachadas, tiene mucho que ver con los vecinos, porque se creó todo un mecanismo para hablar vecino por vecino, reunirlos, entrar en contacto con los propietarios de los inmuebles, un rollo ciudadano para ayudar a las fachadas, se ha dado más impulso a la participación ciudadana." (Entrevista con Anabelí Contreras, Fideicomiso del CH, 15 de abril de 2011)

Con lo cual, de la misma manera que lo expone Carrión (2001), el patrimonio genera relaciones sociales de reapropiación, lo cual se expresa en el disfrute y los derechos que ejerce la ciudadanía en ciertos espacios. Así que, al parecer en nuestro $\mathrm{CH}$, el patrimonio funge como conexión entre identidad, presente, sociedad, con lo cual asumo que lo propuesto por Carrión (2001) y las acciones llevadas a cabo por el Fideicomiso cuentan con semejanzas en la manera de realizar cambios profundos en la intervención y el tejido social presente en este espacio. Es importante mencionar que el Fideicomiso del CH realizó el Plan Estratégico de Desarrollo Integral del CH (1998), el cual expondré más adelante. En la actualidad se encuentra realizando el Plan de Manejo del $\mathrm{CH}$, que es un compromiso por formar parte del Patrimonio de la Humanidad. Cuando te quieres inscribir a la lista de patrimonio, tienes que presentar un Plan de Manejo, Plan Maestro de las políticas, cómo hacerlo sustentable, es un requisito. (Entrevista con Anabelí Contreras, Fideicomiso del CH, 15 de abril de 2011)

\section{a) Apoyo al arte.}

"Conciertos en plazas, los últimos conciertos de Rita Guerrero los dio aquí, en plazas, en calles, exposiciones, obras de teatro, obra plástica. En Regina tenemos un muro que se llama el muro de las intervenciones, con intervenciones periódicas vas poniendo instalaciones o murales. Te decía, música, teatro, danza, se ha apoyado, se ha buscado apoyar a las asociaciones que existen aquí. En Regina está Arte Circulatorio o está la Central del Pueblo, que es un proyecto bien interesante. Se busca apoyar de esa manera, con acciones de este tipo." (Entrevista con Anabelí Contreras, Fideicomiso del CH, 15 de abril de 2011) 
Como se observa, al parecer el apoyo al arte está delimitado a calles específicas del centro y a colectivos de artistas con renombre o que se encuentren asociados de manera legal. Así que, si no se cuenta con esos requisitos no se podrá acceder a tener apoyo por parte del Fideicomiso. En el Fideicomiso, al no tener una página donde se especifiquen de manera clara los programas y acciones, la información la hice con base a la entrevista que realicé a Anabelí y a la que circula en Internet. Más adelante expondré su visión sobre los artistas de la calle de Madero y las acciones que han tenido al respecto.

\subsubsection{Fundación del Centro Histórico de la Ciudad de México A.C ${ }^{2}$}

"No queremos un Centro Histórico recuperado, restaurado y sin vida, solo y abandonado. Menos aun una majestuosa y gran pieza de museo llena de fantasmas. Queremos recuperar el deterioro de tantos años y la destrucción de varios de sus inmuebles paro también vivirlo y sentirnos partes de él al conocernos mejor" (Carlos Slim, 2001. Información proporcionada por Rosalba Garza, Fundación del CH de la Ciudad de México, A.C)

Debido a la Creación del Consejo Consultivo, del cual forma parte Carlos Slim, se tomó la iniciativa de formar una Asociación Civil que tuviera acciones específicas en el CH. Dicha Fundación depende de la Fundación Carlos Slim. Se creó en 2002, trabaja en colaboración con el Gobierno Federal, GDF, sector privado para mejorar la seguridad y servicios públicos, desarrollo económico y social. Tiene programas de salud, educación, oferta de vivienda, empleo, cultura y esparcimiento, su objetivo es hacer un Centro Histórico vivo y revitalizado. (Información proporcionada por Rosalba Garza, Fundación del CH de la Ciudad de México, A.C)

Cuenta con los siguientes programas:

a) Programa de Desarrollo Social. Impulsa la participación para fortalecer relaciones y lazos sociales de los habitantes del $\mathrm{CH}$.

b) Programa de Desarrollo Local Comunitario. Realizan actividades de prevención de riesgos psicosociales y de educación social para habitantes y visitantes del $\mathrm{CH}$.

\footnotetext{
${ }^{2}$ Quiero mencionar que para obtener los datos de la Fundación del CH de la Ciudad de México A.C no hice entrevistas de campo. Realicé la solicitud para que me concedieran una entrevista, pero el resultado fue el envío de un documento sobre la Fundación: Programas, ejes de intervención y sobre todo su apoyo al arte y la cultura. Así que la presentación de la Fundación es más esquemática, debido a que esa fue la forma en que me enviaron la información.
} 
c) Programa de Desarrollo Económico. La formación de jóvenes por medio de talleres para el empleo y autoempleo. Es el único programa con el cual tuve contacto, por medio de Mali Haddad, quien es la encargada de esta área, pero durante mi investigación de campo no conocí a nadie que hubiera acudido a ninguna de las actividades mencionadas en los programas.

d) Programa cultural. Por medio de Casa Vecina (Mesones casi esquina con la recién peatonalizada Regina). Es un laboratorio especializado en la producción, montaje e intervención de arte contemporáneo [...] Busca proporcionar la infraestructura y financiamiento necesarios para colaborar con la investigación de artistas invitados. (Información proporcionada por Rosalba Garza, Fundación del $\mathrm{CH}$ de la Ciudad de México A.C) Realizan concursos como "Conoce el CH" en escuelas públicas (primarias) para el aprendizaje del patrimonio histórico y arquitectónico. Tampoco he conocido a alguien que haya participado en esta actividad, pero supongo que debe de funcionar como una forma de desarrollar el sentido de identidad y cohesión. "Concurso de ofrendas y conmemoración de tradiciones mexicanas", "Exhibiciones en el Atrio de San Francisco" Crea un espacio público para el acercamiento a la obra de grandes artistas. (Información proporcionada por Rosalba Garza, Fundación del CH de la Ciudad de México A.C) Durante mi investigación de campo observé algunas exposiciones en este espacio (ya que se encuentra en mi calle de estudio: Francisco I. Madero), es una gran área en la cual las intervenciones en el espacio público son aplaudidas y cuentan con diferentes discursos, como la exposición sobre Niños Dios el día de la Candelaria. Sin embargo, este espacio, el cual fue rehabilitado (en coordinación con el Fideicomiso del $\mathrm{CH}$ ) para el arte público, no apoya de ninguna manera a los artistas callejeros que se encuentran a escasos 10 metros de ahí y tienen que padecer las vicisitudes de encontrarse en un espacio público no permitido para expresiones artísticas, cuando a unos metros se encuentra este atrio, recuperado ex profeso para la presentación de artistas en un espacio plural.

Es así, como la Fundación del CH de la Ciudad de México ocupa un lugar importante en la revitalización de este espacio. Promoviendo la inversión desde la iniciativa privada en 
diferentes sectores del centro. No quiero demeritar el trabajo que realizan, pero es importante mencionar que la gran mayoría de las acciones que llevan a cabo son en colaboración con otras instituciones, como el Fideicomiso del CH. Si bien, existe el rumor de que el $\mathrm{CH}$ se está privatizando, en las entrevistas realizadas nunca se asume esta posición. Al contrario, como lo mencionó Anabelí Contreras refiriéndose a la Fundación:

"Nosotros los apoyamos a ellos. Ellos son una Fundación privada, que lleva a cabo acciones específicas en el centro, que de pronto colaboramos. En 2004 ó 2005 cuando se hace el Museo del Estanquillo, ese edificio es del GDF, el permiso administrativo irrevocable del inmueble lo tiene la Fundación del $\mathrm{CH}$, pero la restauración del inmueble la hizo el Fideicomiso, pero nosotros no recibimos de ellos, más bien, nosotros les damos a ellos y a mucha otra gente, bajo figuras normadas, porque nos auditan." (Entrevista con Anabelí Contreras, Fideicomiso del $\mathrm{CH}, 15$ de abril de 2011)

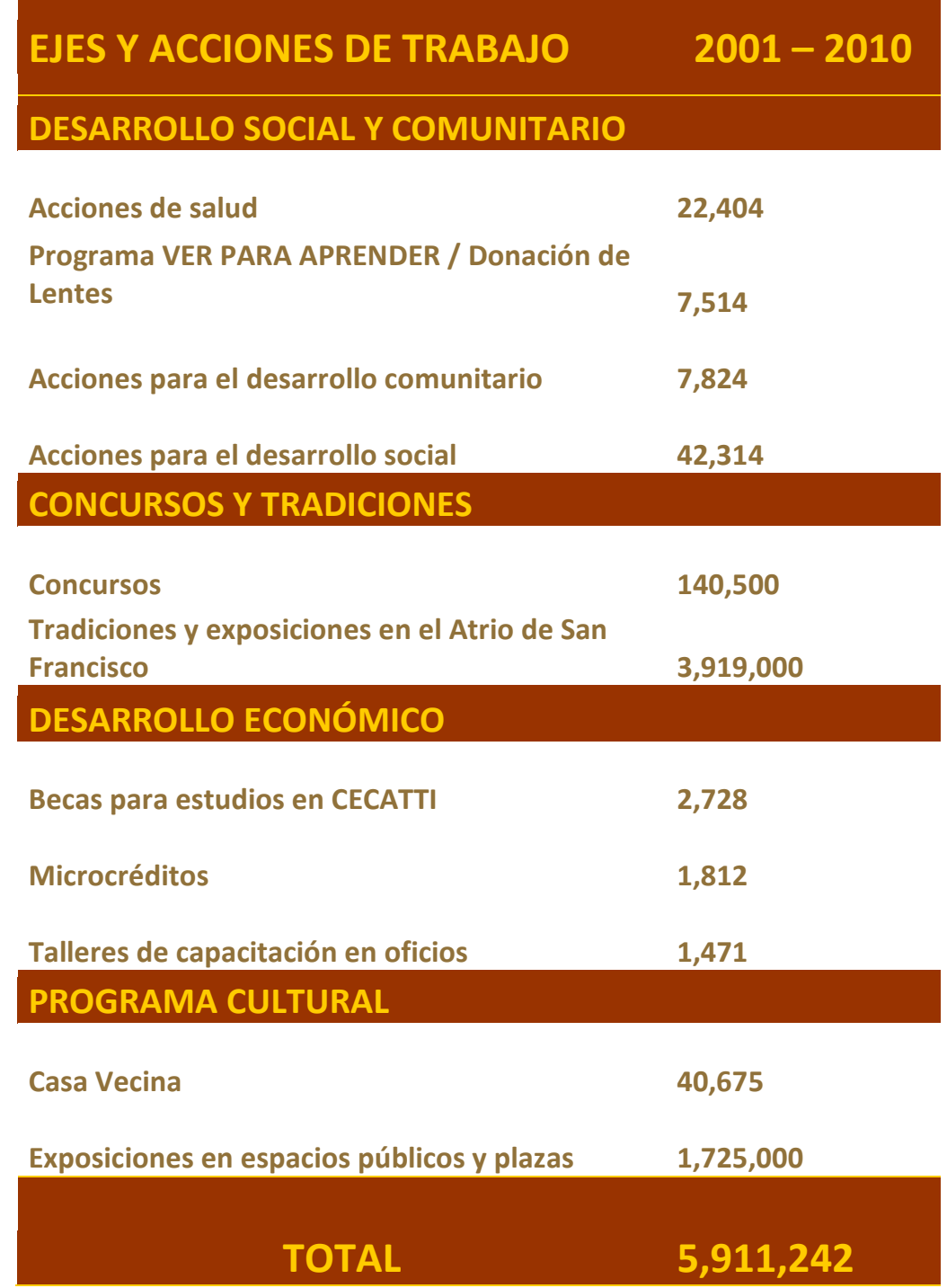

Información proporcionada por Rosalba Garza. Encargada de Relaciones Públicas de la Fundación del Centro Histórico de la Ciudad de México A.C 
Es importante mencionar que desde las personas entrevistadas en diferentes instancias no se asume una postura que privatice el $\mathrm{CH}$ con la inversión de Carlos Slim. Aunque no es motivo de mi investigación, quise informarme al respecto y no obtuve mayor respuesta. Lo que si es importante destacar de la labor de la Fundación es lo que he mencionado: ha generado colaboración entre Gobierno Federal y Local (con la creación del Consejo Consultivo, del cual forma parte Carlos Slim), las inversiones privadas en los inmuebles del $\mathrm{CH}$ ha sido notoria, como lo es el caso de Puerta Alameda, proyecto que depende directamente de la Fundación. Sin embargo, hay que destacar que la Fundación colabora en coordinación con otras instancias dedicadas al $\mathrm{CH}$.

\subsubsection{Autoridad del Centro Histórico}

El 22 de enero de 2007 fue publicado en la Gaceta Oficial del Distrito Federal la creación de la Autoridad del CH:

"Que es necesario crear un Órgano de Apoyo a las Actividades del Jefe de Gobierno, denominado Autoridad del Centro Histórico, donde se concentren por delegación, las atribuciones de las Dependencias de la Administración Pública Centralizada del Distrito Federal, que tengan su ámbito de competencia material en dicho territorio: Que este Órgano administrativo de apoyo deberá actuar con criterios de unidad, autonomía, funcionalidad, eficacia, coordinación e imparcialidad para la planeación y ordenamiento del desarrollo territorial, económico y social del Centro Histórico" (Gaceta Oficial del Distrito Federal, 22 de enero de 2007: 2)

Es así como surge la Autoridad del $\mathrm{CH}$, la cual está encargada de dar seguimiento y coordinar acciones en el perímetro de esta zona. Es necesario mencionar que las acciones que lleva a cabo no son unilaterales, ni aisladas, sino en comunicación y coordinación con las dependencias antes mencionadas y con otras que tengan impacto en la zona del CH. Este órgano depende directamente del Gobierno del Distrito Federal y llega a acuerdos con su titular, así que, podría decir que es la instancia con más atribuciones, ya que depende directamente de la Jefatura de Gobierno del Distrito Federal. Los aspectos que quisiera destacar de esta Dependencia son las siguientes:

a) Recuperar el espacio público, haciéndolo seguro, accesible y plural.

b) Modernizar la infraestructura y los servicios públicos.

c) Mayor seguridad pública

d) Conservar inmuebles emblemáticos, los cuales forman parte de la identidad y 
son elementos simbólicos para la sociedad.

e) Impulso para que los inmuebles respondan a las demandas de los habitantes de la zona.

f) Promoción de vivienda.

A continuación analizo algunas líneas de acción, pertinentes para mi investigación, desarrolladas por esta instancia.

\section{a) Fachadas y Patrimonio cultural tangible}

Quisiera destacar que el inciso sobre inmuebles emblemáticos me parece que retoma el paradigma patrimonialista mencionado en el capítulo de políticas culturales. Este enfoque de conservación de inmuebles y fachadas no es nuevo, comenzó en 1991 como menciona Coulomb:

“A partir de 1991, el gobierno de la ciudad promovió la inversión de los particulares en la restauración y/o rehabilitación de fachadas e inmuebles, a través del programa Échame una manita. Este programa, apoyado técnicamente por el Fideicomiso, contó con incentivos fiscales y facilidades administrativas [...] De 1990 a agosto de 1999 los incentivos fiscales otorgados por los gobiernos, tanto Federal como de la Ciudad de México, sumaron US\$D 8,500,000, para beneficio de las intervenciones que realizaron particulares e instituciones gubernamentales en 525 inmuebles, con una inversión toral de cerca de US\$D 250,000,000.” (Coulomb, 2001: 142)

De esta manera, el patrimonio cultural y su conservación han tenido gran apoyo por parte de las instituciones dedicadas a la administración del $\mathrm{CH}$. Aclaro que el monto no es motivo de análisis, pero si en diez años se invirtió un cuarto de millón de dólares, podría haberse dado apoyo a manifestaciones artísticas y/o culturales con una pequeña parte de ese monto. No cuestiono el apoyo a las fachadas, ni a la conservación del patrimonio tangible, pero me parece que las cifras y la balanza no son equilibradas con otros rubros que podrían ser de interés en el $\mathrm{CH}$, como lo es la creación de un corredor cultural donde pudiera existir libertad de expresión para los artistas callejeros que han laborado en él desde hace décadas y que tienen algo que comunicar.

Continuando con las atribuciones de la Autoridad del CH, evidentemente el Programa "Échame una manita" no dependía de esta institución, puesto que fue en los noventa (cuando ésta no existía), pero ha continuado con apoyo a fachadas de la 
mano del Fideicomiso del CH: Lavado de fachadas y cantera, remoción tierra, flora parásita y de graffiti. Restauración de aplanados y pintura del inmueble. Reparación de ventanas. Pintura de herrería. Retiro de cables. Clausura de puertas y ventanas que no existían originalmente. (Autoridad del $\mathrm{CH}, 2011$ ).

Quisiera destacar que, al parecer, el apoyo para la conservación y restauración de fachadas comenzó como un proyecto meramente arquitectónico, en donde por medio de incentivos fiscales se daban facilidades a propietarios e inversionistas para poder intervenir en la zona. En la actualidad, según lo expresado por Anabelí Contreras (2011), la conservación de fachadas y del patrimonio cultural tangible es una forma de tener comunicación con los residentes del $\mathrm{CH}$, lo cual aplaudo, ya que no podemos pensar en el patrimonio tangible separado de la población, que en palabras de Carrión (2000) son sujetos patrimoniales. Así que, aunque sigue habiendo mayor apoyo para el rescate del patrimonio cultural tangible, considero importante mencionar que se tiene comunicación con los residentes de la zona, que como mencioné líneas atrás, se realiza la Escuela de Participación Ciudadana, lo cual es importante destacar, ya que la participación y el derecho a disfrutar de un barrio conservado, deberá ser una prioridad en las acciones del $\mathrm{CH}$.

Por último, otro programa que realiza la Autoridad del $\mathrm{CH}$ en coordinación con el Fideicomiso del $\mathrm{CH}$ es la intervención de edificios históricos, no existe argumentación (en las páginas de las dependencias) para elegir los predios a intervenir, pero quisiera mencionar que algunos de ellos se realizan en coordinación con la Fundación del CH A.C, como lo es el Edificio Rule (a un costado de la Torre Latinoamericana, sobre Eje Central):

"El rescate del edificio Rule, situado a un costado de la Torre Latinoamericana, que es- en colaboración con World Monuments Fund- uno de los proyectos a futuro de mayor importancia, dado que será la puerta de entrada al Centro Histórico, en calidad de Centro de Documentación e Información para Visitantes y sede de la Casa de Cultura de Colombia." (Página de la Fundación del CH de la Ciudad de México A.C, septiembre de 2009)

Como he mencionado, no intento encontrar la correlación entre instituciones, pero me parece que hay un entramado de ellas, en donde, en ocasiones no queda claro qué hace cada una. Si la Autoridad del CH menciona en su página que la intervención en edificios 
con valor histórico es por medio del Fideicomiso del CH, ¿Por qué la Fundación del CH se atribuye la obra? No es motivo de esta investigación, pero es un ejemplo más del complejo institucional que existe en el $\mathrm{CH}$ de la Ciudad de México, lo cual dificulta la comprensión del conocimiento de esta zona de la ciudad.

Sobre la difusión de las acciones realizadas y la riqueza del $\mathrm{CH}$, existe la publicación kmcero (Depende de la Autoridad del $\mathrm{CH}$ y el Fideicomiso del $\mathrm{CH}$ ). Su directora explicó sobre el patrimonio:

"Hay una necesidad muy fuerte de poner el valor, que la gente que visita y vive en el Centro Histórico, sepa cada vez más sobre el valor de lo que hay aquí. Es importante decir, que nosotros hemos entendido que ese valor no es sólo los edificios con sus larguísimas historias, como piezas o los museos, sino que parte de esa riqueza del Centro Histórico tiene que ver con la gente, con los comercios que hay aquí, con historias que son larguísimas y que tiene que ver con esa riqueza, no es sólo los edificios y las obras y tal, sino la gente que vive aquí y lo que hace la gente que vive aquí." (Entrevista con Sandra Ortega, Directora de kmcero, 11 de abril de 2011)

Me parece pertinente mencionar que, si bien, existen diferentes programas para conservar, proteger y restaurar el patrimonio cultural tangible desde las instituciones. También se ha buscado dar peso a las acciones de difusión sobre patrimonio cultural inmaterial de la población de $\mathrm{CH}$, para muestra tenemos la publicación kmcero, con un tiraje de 15 mil ejemplares de distribución gratuita, donde se tratan diferentes temas de interés. Así que, por lo menos desde esta publicación y al revisar sus contenidos, no todo es el patrimonialismo a ultranza.

Ahora bien, la recuperación del espacio público es una de las acciones que me interesa desarrollar, ya que el estudio de la calle Francisco I. Madero es un espacio público de convivencia, expresión, paseo y que muestra una de las facetas que tiene por ofrecernos el $\mathrm{CH}$, como lo es la peatonalización de esta calle y de otros sectores de ambos perímetros del centro.

\section{b) Peatonalización.}

"La estrategia de corredores peatonales es congruente con la política del GDF para la recuperación del espacio público. Al generar nuevos ejes articuladores y de continuidad del espacio público con recorridos peatonales, integrarán zonas y edificaciones con valor histórico y patrimonial reactivando la actividad 
económica." (Página de la Autoridad del CH)

La estrategia de peatonalizar calles en el $\mathrm{CH}$ es realizada por la Secretaría de Obras y Servicios del Gobierno del DF. Como mencionó el Arquitecto Martínez en entrevista (20 de junio de 2011):

"Desde mi punto de vista la peatonalización de una calle no es por moda, ni por parámetros con otras ciudades, debe tener una solución, un sentido muy cuidadoso y pragmático en la zona que estás evaluando. La oportunidad de Regina, detecté que teníamos la oportunidad de rehabilitar, desde el punto de vista de su estructura social y sus condiciones en la zona sur poniente, eran zonas inseguras, sucias, donde se llevaban a cabo acciones delictivas, narcotráfico en pequeña escala, asaltos, todo este tipo de fenómenos, que son reflejo de la desestructuración." (Entrevista con el arquitecto Alejandro Martínez, Secretaría de Obras y Servicios del GDF, 20 de junio de 2011)

Como menciona el arquitecto y coincido con él, la intervención se da en zonas o calles donde existe una desestructuración social, en el caso de Regina por la delincuencia y basura de la calle, era necesario intervenir en el espacio urbano (como el arquitecto menciona) para generar una transformación en el tejido social de los habitantes. Otro elemento que tuvo gran peso para peatonalizar la calle de Regina fue el tipo de habitantes que existían en la zona:

"Regina nace con la intención de proyecto urbano para favorecer la estructura social de la zona. Otro factor que detecté fue: era una zona donde había indicios de jóvenes habitantes en una visión cultural, artistas contemporáneos, artistas con carácter de innovación, de experimentación y eran pequeños focos que comenzaban a habitar la zona. Reconocí que estos nuevos pobladores fueron fundamento para la peatonalización." (Entrevista con el arquitecto Alejandro Martínez, Secretaría de Obras y Servicios del GDF, 20 de junio de 2011)

Ahora bien, si la población artística que residía en Regina tuvo influencia para mejorar las condiciones urbanas y hasta ciudadanas surgidas de su peatonalización, podríamos estar acercándonos a la importancia que tienen los artistas en la zona del $\mathrm{CH}$. Sé que Regina no fue peatonalizada solamente por tener habitantes con características artísticas, pero como menciona el arquitecto Martínez, se buscó dar las condiciones para que los nuevos y viejos habitantes de Regina se desarrollaran de mejor manera: con libertad en un espacio público, con seguridad, limpieza e iluminación. Así que el arte, al parecer, influyó en la decisión de peatonalizar Regina, lo cual aplaudo, ya que el reconocimiento para el arte y la cultura como detonantes de una transformación tan 
importante es digno de admirar. Sin embargo, sigo preguntándome ¿Qué ocurre con manifestaciones artísticas presentes en el $\mathrm{CH}$, las cuales no cuentan con apoyo ni reconocimiento? ¿Vivir en Regina da más validez a los artistas, que el salir a trabajar a las calles del $\mathrm{CH}$ ?

Continuando con la peatonalización de Regina, ¿Qué elementos tenía Regina para decidir su peatonalización?

"Había muchos fundamentos: Un eje vertebrador en la zona sur poniente que vincula desde Eje Central a 20 de noviembre, la intención fue desarrollar esta especie de corredores, que permean las zonas donde están ubicados. Regina cubre un cuadrante del Centro Histórico, su ubicación estratégica determina generar sinergias tanto al norte como al sur, tiene la capacidad de generar estas sinergias, tiene una visión de reestructuración del espacio [...] Entonces, Alhóndiga como peatonal, da continuidad a esta estructura de corredores culturales y que la idea es que puedan permear la totalidad del perímetro "A", con una visión social y acompañada con el tema cultural." (Entrevista con el arquitecto Alejandro Martínez, Secretaría de Obras y Servicios del GDF, 20 de junio de 2011)

La idea de generar corredores culturales es una propuesta que quiero destacar, donde se busca la vinculación y conexión entre distintas zonas del $\mathrm{CH}$, para lograr mayor cohesión en el tejido social de los habitantes y visitantes. Aunque, remitiendo al primer capitulo de esta investigación, una propuesta por parte de los artistas callejeros del $\mathrm{CH}$ era la creación de corredores culturales, donde pudieran trabajar, comunicar y entretener a la gente. Sin embargo, la definición de corredor cultural desde la Secretaría de Obras y Servicios y la presentada desde el artista no tienen muchos elementos en común. El primero se refiere al corredor cultural porque vive gente en estos sitios donde se hizo la intervención, lo cual genera transformaciones sobre el uso y disfrute del espacio. Para el artista, el corredor cultural se refería a la oferta artística que se podría presentar en un espacio público. Así que de nuevo remito a la complejidad de lo cultural: quién define, para quién y desde dónde lo hace. No ataco ninguna de las posturas, pero la frase corredor cultural y su intervención, tiene diferentes significados y resultados para los sectores analizados. Es así como surge un primer conflicto por la intervención y uso del espacio público generado con la peatonalización de las calles del $\mathrm{CH}$. Más adelante abordaré la peatonalización de la calle de estudio: Francisco I. Madero. Por el momento, solamente presento algunos elementos generales sobre la peatonalización en calles anteriores a la intervención de la calle Francisco I. Madero. En términos 
generales, la idea es una, Centro Histórico más peatonal, que podamos restringir el uso del automóvil. Pero ofreciendo una oferta para cambiar del automóvil a caminar, a llegar en metro, en metrobús, que ya viene ese proyecto. (Entrevista con el arquitecto Alejandro Martínez, Secretaría de Obras y Servicios del GDF, 20 de junio de 2011)

Con lo presentado sobre algunas instituciones dedicadas a gestionar el $\mathrm{CH}$, intenté mostrar de manera breve la complejidad burocrática y de acciones en esta zona. No entrevisté a las personas encargadas de todas las instituciones mencionadas, en algunos casos (como lo especifiqué) la información fue obtenida de su página de Internet y por referencia de otras instituciones. Para terminar este apartado sobre la gestión en los $\mathrm{CH}$ quiero destacar que es una labor complicada, en donde existen diferentes agentes e intereses, por momentos no queda claro qué hace cada institución, pero si se sabe que trabajan en constante coordinación.

Ahora presentaré brevemente el análisis del Plan Estratégico para la Regeneración y Desarrollo Integral del Centro Histórico de la Ciudad de México, el cual fue realizado en 1998 por el Fideicomiso del CH. Actualmente están elaborando un Plan de Manejo, que como mencioné líneas atrás, es un requisito de UNESCO por formar parte de la lista de sitios considerados Patrimonio de la Humanidad (1987).

A continuación presento un esquema con las instituciones analizadas:

\begin{tabular}{|c|c|c|c|c|}
\hline Institución. & Apoyo. & $\begin{array}{l}\text { Año de } \\
\text { creación. }\end{array}$ & $\begin{array}{l}\text { Objetivos y/o programas } \\
\text { principales. }\end{array}$ & $\begin{array}{l}\text { Director (a) } \\
\text { actual. }\end{array}$ \\
\hline $\begin{array}{l}\text { Consejo } \\
\text { Consultivo } \\
\text { para el Rescate } \\
\text { del Centro } \\
\text { Histórico de la } \\
\text { Ciudad de } \\
\text { México. }\end{array}$ & $\begin{array}{l}\text { Gobierno } \\
\text { Federal y } \\
\text { Gobierno } \\
\text { del Distrito } \\
\text { Federal. }\end{array}$ & $\begin{array}{l}14 \text { de agosto } \\
\text { de } 2001 \text {. }\end{array}$ & $\begin{array}{l}\text { "[...] Preservación y el } \\
\text { rescate a partir de nuevas } \\
\text { bases y equilibrios del } \\
\text { Centro Histórico de la } \\
\text { ciudad de México [...] } \\
\text { Nuestro porvenir debe } \\
\text { partir de la preservación } \\
\text { de lo mejor de nosotros } \\
\text { mismos, de nuestras } \\
\text { profundas y sólidas } \\
\text { raíces." (Vicente Fox, } \\
\text { 2001) }\end{array}$ & $\begin{array}{l}\text { Presidente } \\
\text { Ejecutivo: } \\
\text { Carlos } \\
\text { Slim. } \\
\text { Presidente } \\
\text { Honorario: } \\
\text { José } \\
\text { Ezequiel } \\
\text { Iturriaga. }\end{array}$ \\
\hline
\end{tabular}




\begin{tabular}{|c|c|c|c|c|}
\hline $\begin{array}{l}\text { Fideicomiso } \\
\text { del Centro } \\
\text { Histórico. }\end{array}$ & $\begin{array}{l}\text { Gobierno } \\
\text { del Distrito } \\
\text { Federal. } \\
\text { Secretaría } \\
\text { de } \\
\text { Finanzas. }\end{array}$ & $\begin{array}{l}1990 . \\
\text { Fideicomiso } \\
\text { Privado. } \\
2002 . \\
\text { Fideicomiso } \\
\text { Público }\end{array}$ & $\begin{array}{l}\text { Programa de apoyo para } \\
\text { restauración de fachadas. } \\
\text { Escuela de Participación } \\
\text { Ciudadana. } \\
\text { Apoyo al arte. } \\
\text { Publicación kmcero. }\end{array}$ & Inti Muñoz. \\
\hline $\begin{array}{l}\text { Fundación del } \\
\text { Centro } \\
\text { Histórico de la } \\
\text { Ciudad de } \\
\text { México A.C. }\end{array}$ & $\begin{array}{l}\text { Privado. } \\
\text { Depende de } \\
\text { la } \\
\text { Fundación } \\
\text { Carlos } \\
\text { Slim. }\end{array}$ & 2002. & $\begin{array}{l}\text { Desarrollo Social. } \\
\text { Desarrollo Local } \\
\text { Comunitario. } \\
\text { Desarrollo Económico. } \\
\text { Cultural. }\end{array}$ & $\begin{array}{l}\text { Carlos } \\
\text { Slim. }\end{array}$ \\
\hline $\begin{array}{l}\text { Autoridad del } \\
\text { Centro } \\
\text { Histórico . }\end{array}$ & $\begin{array}{l}\text { Gobierno } \\
\text { del Distrito } \\
\text { Federal }\end{array}$ & $\begin{array}{l}22 \text { de enero } \\
\text { de } 2007 \text {. }\end{array}$ & $\begin{array}{l}\text { Recuperación del espacio } \\
\text { público. } \\
\text { Modernizar la } \\
\text { infraestructura y los } \\
\text { servicios públicos. } \\
\text { Seguridad Pública. } \\
\text { Conservar inmuebles } \\
\text { emblemáticos: Fachadas } \\
\text { y patrimonio cultural } \\
\text { tangible. } \\
\text { Peatonalización de calles. } \\
\text { Publicación kmcero. }\end{array}$ & $\begin{array}{l}\text { Alejandra } \\
\text { Moreno } \\
\text { Toscano. }\end{array}$ \\
\hline
\end{tabular}

Elaboración propia con la información recabada en campo y de las páginas de Internet de las instituciones.

\subsection{Plan Estratégico para la Regeneración y Desarrollo Integral del Centro}

\section{Histórico de la Ciudad de México.}

En 1998, el Fideicomiso del CH elaboró una propuesta de regeneración de este espacio. En julio de ese año, dicha institución propuso un documento denominado Plan Estratégico para la Regeneración y Desarrollo Integral del CH de la Ciudad de México. Con base en tres principios (Coulomb, 2001: 144-146):

a) Participación Social. Debido a la amplitud del trabajo y los recursos 
escasos, los proyectos son de mediano y largo plazo. Por lo tanto, se requiere de planeación estratégica y continuidad en las acciones a futuro, para lo cual es necesario un proceso de participación que incluya a los diferentes actores e intereses que confluyen en el $\mathrm{CH}$. En este punto, quiero aclarar que en el caso de la peatonalización de la calle Francisco I. Madero si se llevó a cabo una consulta, al respecto el dueño de varios locales de la calle me comentó: Si, hacen un tipo de encuestas, pero en lo personal pienso que las decisiones ya están tomadas. No creo que las encuestas sirvan para tomar una decisión, las preguntas pueden ser encaminadas a ciertas respuestas, son tan tendenciosas que no te dan una idea clara. (Entrevista con Salomón Masliah, locatario, 16 de marzo de 2011). Pero también tenemos el caso que me fue presentado en el Fideicomiso del $\mathrm{CH}$, en donde existe la Escuela de Participación Ciudadana, lo cual es una forma clara de comunicación. De esta manera, con ejemplos, con resultados positivos y otros que al parecer no fueron claros, se intenta que exista participación en la toma de decisiones.

b) Heterogeneidad. La base del proceso de regeneración se funda en la equidad. Por lo tanto, el proceso no debe generar exclusión social. La construcción de un espacio urbano heterogéneo será la base de la sustentabilidad de un proceso de regeneración y desarrollo económico, social y cultural del $\mathrm{CH}$, democráticamente equitativo. Me parece una premisa fundamental para cualquier tipo de intervención social, la inclusión y el desarrollo de los sectores involucrados debe convertirse en una realidad. Retomando el tema de análisis, si se busca la inclusión social, ¿Por qué no apoyar las actividades que realizan en las calles del $\mathrm{CH}$ ? Evidentemente, debe de existir un reglamento que regule este tipo de actividades, pero ¿No es posible generar otras estrategias para apoyar sus actividades en el $\mathrm{CH}$ o por lo menos que no sean remitidos ante un Juez Cívico? Me parece que se está cayendo en la exclusión con estas acciones.

c) La integralidad de las acciones. La integración es un desafío para el diseño de las Políticas Públicas. En el CH existen problemáticas territoriales, económicas, sociales, políticas y culturales. una herramienta de la integralidad se encuentra en definir "zonas de actuación prioritaria", donde haya acciones públicas, privadas y mixtas en esas zonas. 
Para René Coulomb (2001), el Plan Estratégico se considera una propuesta de Programa para el Desarrollo Integral del $\mathrm{CH}$ de la Ciudad de México. Busca ser la base para la acción conjunta de los sectores público, social y privado, y la coordinación entre Gobierno Local y Federal (Cabe aclarar que este Plan se realizó tres años antes de que se integraran ambos niveles de Gobierno con la creación del Consejo Consultivo para el Rescate del $\mathrm{CH}$ ). Uno de los principales objetivos del Plan es la rehabilitación de las viviendas del $\mathrm{CH}$, ya que aunque es una de las zonas con servicios, oficinas, comercio, cultura, etc., también se contaba con un problema de despoblamiento, debido a la inseguridad, miedo al $\mathrm{CH}$, falta de conocimiento de la riqueza del sitio o por considerarlo para población vulnerable, por ejemplo, niños de la calle. Así comenzó el repoblamiento como un eje conductor en el desarrollo de las Políticas Públicas en dicho sitio, para así recobrar esa identidad con el $\mathrm{CH}$ que hemos dejado de lado y que se refleja en muchos otros ámbitos de nuestra vida y que es necesario revivir. Lo cual es expresado por el arquitecto Jorge Jesús Carrillo, miembro del Fideicomiso del $\mathrm{CH}$ :

"El deterioro físico y social es el reflejo de la pérdida de identidad social y cultural de sus habitantes; pero también lo es por la progresiva desapropiación del centro por parte de los habitantes del conjunto de la ciudad. Una importante consecuencia de la pérdida de la apropiación colectiva de la centralidad es la degradación del patrimonio urbano del Centro Histórico, que se expresa en la pérdida de identidad, del simbolismo y fortaleza de sus plazas y jardines, así como en la privatización de parte de sus calles.” (Jesús Carrillo, 2000)

El Plan Estratégico para la Regeneración y Desarrollo Integral del CH de la Ciudad de México, para Jesús Carrillo (2000) tiene cuatro estrategias de actuación: a) Rescate de la centralidad, b) Regeneración habitacional, c) Desarrollo económico y d) Desarrollo social. De este Plan destaco para mi investigación, la estrategia espacio -social, que busca el rescate de la heterogeneidad social y cultural, que caracterizaba la antigua Ciudad de México, entre otras acciones, mediante el mejoramiento de la imagen urbana, sistema de transporte, corredores urbanos, plazas públicas y jardines.

a) Rescate de la centralidad. El deterioro físico se expresa en la degradación del patrimonio urbano, privatización de las calles. El espacio público se había convertido en sitio de conflicto y no de encuentros. Algunas acciones: Recuperación colectiva del espacio público con la rehabilitación de 63 plazas y jardines, apoyo a la difusión de festividades patronales y de barrio, etc. Rescate de monumentos y conjuntos patrimoniales: Atrio y Claustro de 
San Francisco (calle Francisco I. Madero, que la Fundación del CH A.C tiene como programa de trabajo). Ampliación y mayor difusión de la oferta cultural del $\mathrm{CH}$ : Promoción del corredor turístico y cultural del $\mathrm{CH}$, desarrollo de oferta cultural diversificada (Por ejemplo, tranvía por cantinas, museos con visitas nocturnas, caminatas por calles recuperadas, etc.). Seguridad Pública con participación ciudadana. Considero que el rescate de la centralidad se ha cubierto cabalmente, el centro ha vuelto ha ser el sitio de encuentro, de gozo, de conocimiento, pluralidad. Sin embargo, aunque la oferta cultural es amplia, el conflicto por el uso de los espacios públicos para manifestaciones artísticas (como es el caso de estudio), no ha logrado encontrar una solución entre libertad de expresión por medio del arte, que también es una forma de vida y las regulaciones en las calles del centro.

b) Regeneración habitacional. Para Jesús Carrillo (2000) y el Fideicomiso del CH (2011), afirman que, durante los últimos 20 años, el $\mathrm{CH}$ ha perdido la tercera parte de su población, posiblemente por el deterioro de los inmuebles, falta de mantenimiento, cambios en uso de suelo, etc. Las acciones en este sentido son: Ampliación y diversificación de la oferta de vivienda (estímulos fiscales). Rescate del uso habitacional en edificios patrimoniales, por medio de subsidios a las familias que los habitan y estímulos fiscales para la restauración. Generación de oferta de vivienda a nivel medio para estimular la renta. Los resultados son los siguientes, como lo menciona Anabelí Contreras del Fideicomiso del CH:

"En los resultados de los últimos censos de población, por primera vez, la población del $\mathrm{CH}$ aumentó en 20 años. Del 90 hasta el 2005 había ido hacia abajo, cuando rompes la tendencia a la baja y empieza a subir, por supuesto es un logro extraordinario, se está buscando mucho que la gente vuelva a vivir en el centro" (Entrevista con Anabelí Contreras, Fideicomiso del CH, 15 de abril de 2011)

Lo comentado por Anabelí, a 13 años que se desarrolló este Plan Estratégico muestra que las acciones se han llevado a cabo y que los resultados son visibles, el repoblamiento del $\mathrm{CH}$ es una realidad y se busca que la población siga aumentando, porque un $\mathrm{CH}$ sin habitantes está sin vida, no es suficiente con hacer intervenciones a inmuebles, se necesita gente que los disfrute y apropie (como menciona Carrión, 2001).

c) Desarrollo económico. Para Jesús Carrillo (2000), la economía del CH 
ha sufrido la pérdida de actividades industriales y el incremento en participación de actividades comerciales y servicios. Una preocupación principal del Plan Estratégico es incrementar la participación de los sectores económicos ya presentes en el Centro, y fomentar el desarrollo de nuevas actividades, particularmente en las unidades micro del sector servicios y el turismo. (Jesús Carrillo, 2000). Acciones: Desarrollo de actividades económicas vinculadas al turismo (lo cual ya he mencionado). Aprovechamiento del Patrimonio Histórico. Desarrollo de micro y pequeñas empresas: Apoyo a la capacitación y fomento a micro empresas de manufactura y artesanías. Regulación y reordenamiento del comercio en vía pública ${ }^{3}$.

d) Desarrollo social.

"Presencia de grupos sociales con mayor vulnerabilidad: indígenas, niños de la calle, jóvenes, ancianos, indigentes, personas con discapacidad, trabajadoras sexuales, personas con adicciones y madres solteras adolescentes. Estos grupos son reflejo de la pérdida de la identidad social y cultural en detrimento de los lazos de solidaridad y del deterioro en la cohesión de los barrios." (Jesús Carrillo, 2000)

$\mathrm{El}$ autor comenta que, para repoblar el $\mathrm{CH}$ no debe contemplarse solamente una oferta de vivienda de interés social y popular o para la clase media, sino mejorar las condiciones existentes. Acciones: Elaboración de programas de atención a grupos vulnerables como población indígena, adultos mayores, personas con discapacidad ${ }^{4}$, indigentes, víctimas de violencia, etc. Consolidación de proyectos promovidos por Organismos Civiles y de Asistencia Privada, un ejemplo claro es la vinculación con la Fundación del $\mathrm{CH}$ de la Ciudad de México A.C. Rehabilitación de equipamiento educativo, de salud, abasto, cultural y de asistencia social, por medio de Programas culturales, deportivos y recreativos en calles, barrios y plazas. De manera general, estos son los ámbitos de acción del Plan Estratégico para la Regeneración y el Desarrollo del CH de la Ciudad de México. En esta investigación me interesan los 4 ejes presentados,

\footnotetext{
${ }^{3}$ Debido al Programa de Apoyo para la Reubicación del Comercio Popular del CH de la Ciudad de México del GDF, fueron retirados 19500 comerciantes (2007) http://www.milenio.com/node/628272 . Sin embargo, siguen existiendo los denominados "toreros" que ponen una pequeña manta en el suelo, en donde colocan sus productos y recogen su mercancía al ver a los policías. También es importante mencionar que aunque no existan comerciantes ambulantes, sigue existiendo control en el $\mathrm{CH}$ por parte de los dirigentes de dichos comerciantes (En el último apartado comentaré este punto).

${ }^{4}$ En relación a las personas con discapacidad, en los corredores peatonales - en particular Francisco I. Madero- que es la zona de estudio, se cuenta con rampas y préstamo de sillas de ruedas para la movilización de personas con alguna discapacidad motriz.
} 
ya que todos se relacionan y permiten analizar de manera clara la Política social y cultural, donde el patrimonio y la identidad barrial son una constante, se menciona (aunque no se desarrolla) la formación artística, se considera la oferta cultural como elemento fundamental para visitantes y habitantes. 
“[...] El plantear el arte público supone, automáticamente [...] plantearse el problema de la cultura urbana en la actualidad, al mismo tiempo que el tema de las politicas culturales" (Remesar, 1997:53)

\section{Expresiones artísticas en espacios públicos:}

Arte público y estatuas humanas.

Como lo he presentado en esta tesis, el tema que investigué en el $\mathrm{CH}$ de la Ciudad de México, en particular en la calle Francisco I. Madero, es sobre las denominadas estatuas humanas. Después de presentar en los primeros capítulos las discusiones teóricas sobre políticas culturales, en donde el conflicto que existe desde lo cultural es de gran importancia para esta investigación, debido a que es difícil encontrar puntos de acuerdo entre dichas políticas y las expresiones artísticas en la calle Madero. Por lo tanto, debemos analizar desde dónde son definidas esas políticas, cómo son aceptadas, apropiadas, resignificadas. En el caso de estudio, son acciones complejas que desarrollan la creación y participación de diversos sectores artísticos y ciudadanos, pero dejan de lado expresiones artísticas como las que he estudiado estos meses. Quisiera aclarar que la dificultad en la gestión del $\mathrm{CH}$ es una variante que evidentemente modifica las políticas públicas y sobre todo culturales, en donde, pareciera que el arte se restringe a las expresiones en foros cerrados, de artistas con cierta trayectoria y estudios especializados, perfil que no es cumplido por los artistas de la calle de Madero. Hay que destacar que ellos se autonombran artistas callejeros, consideran que no son urbanos porque también se expresan en pequeños pueblos, en donde encuentren una plaza... surgen sus personajes. Para fines de esta investigación he decidido analizar estas expresiones dentro del arte público, como una forma de comunicación en espacios abiertos, para todo público, en donde no hay un sistema de codificación y comunicación tan estricto - aunque en este caso- las restricciones para el uso del espacio público si tienen limitaciones, pero la comunicación del artista y el público en un espacio abierto abre canales entre ellos, que un foro cerrado no se contempla del todo. Si bien, centraré esta investigación en las estatuas humanas de la calle de Madero, existen otras manifestaciones artísticas (las cuales desarrollaré en el último capítulo de esta tesis). 


\subsection{Aproximaciones al arte en espacios públicos}

Como lo mencioné en el primer apartado, retomando a García Canclini (2010), debido a la complejidad del arte en la actualidad, no podemos considerar definiciones totalizadoras, ni precisas, se debe tomar en cuenta, "lo que dicen los que dicen que hacen arte". Pareciera una expresión difícil de comprender, pero estoy de acuerdo con el autor, ya que existen manifestaciones artísticas (como el caso de estudio) que no cumplen cabalmente con las normas artísticas convencionales: en su gran mayoría no estudiaron carreras relacionadas con el arte y solamente buscan una manera de comunicar mensajes a la población por medio de éste, sin importar sus limitaciones académicas, se quedan inmóviles ante las miradas y con las restricciones propias de un espacio no especializado para estas manifestaciones. Así que, debemos partir de la autodefinición de "los que dicen que hacen arte" tienen de si mismos y de sus expresiones, es una primera premisa para esta investigación y creo que es un punto de partida importante para el tema de análisis.

Aunque no debemos de partir de definiciones como tal, considero importante un acercamiento al concepto de arte para analizar algunas aristas de éste. Al respecto García Canclini (2010) menciona que es compleja y requiere del análisis de la autodefinición de los artistas. Sin embargo, en este documento, para fines metodológicos, utilizaré la concepción de arte presentada por García Canclini:

"Ser escritor o ser artista, por tanto, no sería aprender un oficio codificado, cumplir con requisitos fijados por un canon y así pertenecer a un campo donde se logran efectos que se justifican por sí mismos. Tampoco pactar desde ese campo con otras prácticas-políticas, publicitarias, institucionales- que darían discusión a los juegos estéticos. La literatura y el arte dan resonancia a voces que proceden de lugares diversos de la sociedad y los escuchan de modos diferentes a otros, hacen con ellos algo distinto que los discursos políticos, sociológicos o religiosos." (García Canclini, 2010: 60).

De esta manera, García Canclini da una aproximación al arte desde la creatividad, donde la academia y la institucionalización no lo son todo, ya que el artista resignifica y expresa su percepción de la realidad. Siguiendo con la discusión en torno a la definición de arte, quisiera agregar la presentada por Sánchez Vázquez (1967):

"Si el hombre [...] es sobre todo un ser creador, el arte es una esfera donde esta potencia de creación se despliega renovada e ilimitadamente [...] es creación, no sólo el reflejo de lo real, sino instauración de una nueva realidad [...] Cuando el 
artista se enfrenta ante la realidad, no la toma para copiarla, sino para apropiársela, convirtiéndola en soporte de una de una significación humana." (Sánchez Vázquez, 1967: 106).

Ambos autores nos presentan el arte como expresión y resignificación de la realidad, que busca la comunicación con el espectador. Sí la creatividad es inherente al ser humano, las actividades artísticas no solamente se aprenden en aulas sino en la sensibilización del artista. Es así, como los cánones establecidos para el arte desde la academia no son los únicos elementos que determinan la creación artística. Asumo que las herramientas y metodología aprendida en las aulas dota de mayores capacidades a los artistas, pero la creatividad es algo inherente, así que partiendo de ésta y la comunicación como características fundamentales del arte, intentaré dejar de lado si el arte es aprendido en la academia o si se convierte en una forma de expresión y de sobrevivir (como ocurre en el caso de estudio).

Ahora bien, ¿Qué es el arte público? Como menciona Remesar (1997), existen dos discusiones en relación al arte público:

"La primera cuestión hace referencia al hecho de defender que todo arte es arte público, debilitando así el posible desarrollo del concepto y englobándolo en la espantosa dimensión de la definición de arte. La segunda, ligada en buena medida a la primera, hace referencia al rechazo del término arte público y a la reivindicación del arte para espacios públicos.” (Remesar, 1997:5)

De esta manera, nos adentramos a dos posturas sobre el arte público, en donde la primera me remite a lo presentado por García Canclini (2010) sobre la complejidad de las definiciones universales de arte y la segunda postura se asemeja más al campo de estudio de esta investigación. Para continuar con este análisis es necesario definir qué es un espacio público:

"El espacio público moderno resulta de la separación formal (legal) entre la propiedad privada urbana [...] y la propiedad pública, [...] que normalmente supone reservar este suelo libre de construcción (excepto equipamientos colectivos, infraestructuras de movilidad, actividades culturales y a veces comerciales, referentes simbólicos monumentales, etcétera). El espacio público también tiene una dimensión sociocultural. Es un lugar de relación y de identificación, de contacto entre las personas, de animación urbana, y a veces de expresión comunitaria." (Borja y Muxi, 2000:28)

Borja y Muxi realizan una exhaustiva revisión sobre el espacio público y una de las 
propuestas que más me interesa es la presentada en estas líneas, ya que el espacio público cuenta con diferentes dimensiones, que es necesario reconocer y considerar. En el plano jurídico, evidentemente existen normas, es libre y abierto, pero no se permite cualquier actividad. En el caso de estudio, se rige por el Código Civil del DF, que establece las restricciones y actividades en esta área. Me interesa marcar la importancia sociocultural que tiene el espacio público como lugar de encuentro, de gozo, de conocimiento, reconocimiento con el otro y la esfera pública, que se puede definir como “Ámbito en el cual la sociedad civil, constituida precisamente en público, se informa, debate, se constituye en opinión pública y arriba eventualmente a consensos en torno a asuntos de interés general" (Dauhau y Giglia, 2008: 46). En el CH es evidente que en el espacio público y la esfera pública se expresan y discuten temas de interés, lo tenemos muy claro con las constantes manifestaciones en esta zona, así como con los plantones casi permanentes en el Zócalo, por lo que el espacio público y la esfera pública en este son evidentes. Remesar (1997) agrega:

"El espacio público, a pesar de las distintas aproximaciones, es considerado como la reserva territorial dedicada a la movilidad, al contacto social y al disfrute del entorno. De ello se deriva la necesaria política de dotación, acondicionamiento y decoro de los espacios públicos en los que el arte debe cumplir un papel sustancial." (Remesar, 1997:15)

Retomando el arte público y lo presentado por Remesar (1997), una de las primeras expresiones del arte público son los monumentos, que como presenté en el apartado de $\mathrm{CH}$, su conservación es una constante en las políticas de estos sitios, por la importancia identitaria que representan, por historia, arquitectura, etc. Remesar lo expone de la siguiente manera: En este sentido hay que leer esta lógica tanto desde el punto de vista de la preservación del pasado [...] a través de los monumentos históricos, cuanto a la proyección espúrea del presente en el futuro a través de la determinación de la monumentalidad artística. (Remesar, 1997: 9). Como lo expresé en apartados anteriores, no estoy en contra de las políticas monumentalistas, ni patrimonialistas, pero es necesario considerar el desarrollo artístico y cultural actual, no caer en determinismos hacia el pasado. Sin embargo, tanto en políticas culturales en el $\mathrm{CH}$ como en las manifestaciones de arte público, el monumentalismo, que se sitúa en espacios públicos, es una constante que preciso mencionar. Como afirma Remesar (1997) refiriéndose a Bohigas (1982): el monumento es la expresión de una identidad y no un vacío grande y 
teórico construido para ocultar hechos problemáticos. (Remesar, 1997: 49). En el apartado anterior presenté la postura de Carrión (2001) sobre el patrimonialismo en los $\mathrm{CH}$, en donde, el autor argumenta lo opuesto a Bohigas, ya que en los $\mathrm{CH}$, en muchas ocasiones, las políticas de conservación patrimonialista buscan ocultar los problemas sustanciales de los $\mathrm{CH}$, como la pobreza, prostitución, etc. se busca que el $\mathrm{CH}$ y sus monumentos nos remitan a historia, identidad, riqueza arquitectónica y se intenten borrar los problemas sociales existentes. A lo que Remesar agrega (refiriéndose a los casos de Barcelona y Glaslow):

"Pudiera ser que algunos de los logros más importante en la financiación del arte público hayan sido [...] el trabajo efectuado en rehabilitar y limpiar edificios en el centro urbano, ha mejorado apreciablemente la estética del ambiente, sin requerir una gran aportación de carácter artístico. Se han plantado árboles y se han creado pequeños espacios abiertos para hacer posible la vieja idea de Palladio: cuanto más amplia es la calle mejor podemos ver las fachadas. Por otra parte este tipo de actuaciones permite una re-utilización y re-monumentalización de la ciudad gracias a la regeneración urbana." (Remesar, 1997: 51-52)

La regeneración urbana de los $\mathrm{CH}$ a partir de la monumentalidad, como presenté en el capítulo respectivo, es una constante, ahora, desde el arte público también se emplea como una estrategia estética, artística para modificar las estructuras sociales y remitirnos al pasado, a la identidad, a la historia, etc. El crear espacios públicos para admirar mejor las fachadas barrocas de nuestro $\mathrm{CH}$ es una realidad en la actualidad, las calles peatonales proveen de espacios de admiración y tránsito a través de la historia, con los edificios como testigos de ella. Así que, la monumentalidad en las políticas de revitalización de $\mathrm{CH}$ y como expresión de arte público es una constante, que no le quito méritos, pero debemos considerar otro tipo de expresiones artísticas contemporáneas, en donde el espacio público es escenario de manifestaciones que van más allá de la monumentalidad. ${ }^{5}$

Continuando con Remesar, es importante mencionar la lucha que existe por el arte público para /en espacios públicos, como lo menciona el autor:

\footnotetext{
${ }^{5}$ Retomando la monumentalidad del arte público, E. H. Norman y J.M. Norman (2000: 510): "Public art is art made public. As sculpture, public art occupies public space and often it is permanently fixed, either to outdoor pedestals or to buildings. Traditionally, its purpose has been either commemoration (statues of the famous) or ornamentation."
} 
"La calle, la plaza, el parque, en definitiva el espacio público, se han convertido en la arena en la que diversas ciudades compiten por poseer la marca inefable de los demiurgos, de los mejores arquitectos, escultores, ingenieros, diseñadores, etc. No es posible competir en las diversas ligas de las ciudades sin el aval reedificado de determinadas obras de autor. Parece como si el espacio urbano fuera inmaculado, inmenso e inacabable libro de autógrafos en el que las ciudades coleccionistas conservan y producen su valor.” (Remesar, 1997:22)

Coincido con el autor, ya que los espacios públicos y el arte expresado en él por medio de monumentos, estatuas, etc. se han convertido en una forma de colección de historias, de arte de autores renombrados, que no discuto su valor artístico, ni histórico, pero si cuestiono la falta de apoyo para las manifestaciones artísticas de estudio. Retomando lo presentado por Remesar (1997), un ejemplo artístico en espacio público en el CH del DF es el "Caballito" de Manuel Tolsá afuera del Museo Nacional de Arte, a dos calles del corredor peatonal donde realicé la investigación. Dicho Museo cuenta con la explanada Tolsá, en donde se encuentra la estatua del "Caballito", donde podrían realizarse festivales o dar tolerancia a artistas callejeros para poder expresarse en esta área. Como menciona Remesar (refiriéndose a Raven, 1989): el arte público no puede ser ya más un héroe montado en un caballo. (A. Raven, 1989 en Remesar, 1997: 24). No estoy en contra de la estatua de Carlos IV montado en un caballo, pero efectivamente, el arte público no debe ceñirse sólo a esas expresiones artísticas, ya que en la actualidad existen otras manifestaciones artísticas que buscan comunicarse con el público en estos espacios públicos. En el caso de la Plaza Tolsá, es un área casi inmaculada, en donde no se debe intervenir, ni estorbar con la arquitectura del Museo, así que el espacio público y el arte tienen restricciones (no sólo legales) sino estéticas en ciertos lugares emblemáticos.

El arte público tiene importancia, no sólo por la libertad de expresión por medio de intervenciones en este espacio, sino por permitir el desarrollo de otros programas en zonas urbanas en el mundo (Remesar, 1997):

"El arte público, por sus características compartiría espacio en el terreno de las obras y economía públicas (financiación total o parcial por parte del Estado); en el dominio público (operación en el conjunto de instancias públicas); en el espacio público (como soporte de su desarrollo o como forma generada por su actuación); en la acción social y cooperativa (debido a la necesaria participación activa de los ciudadanos en su diseño y gestión. En este sentido sería arte de interés público y, finalmente en la esfera pública (debido fundamentalmente a las estrategias de 
promoción de la ciudad que en buena parte utilizarían las imágenes del arte público para generar operaciones de atracción de capital, turismo, toma de decisiones, etc.)" (Remesar, 1997:23-24)

Desde la perspectiva de Remesar, y coincido con él, las expresiones artísticas en espacios abiertos no sólo cumplen con necesidades estéticas sino de cooperación con otras áreas de las políticas públicas. Por ejemplo, el caso de estudio, la calle Francisco I. Madero (en el siguiente apartado lo desarrollaré de manera completa), fue peatonalizada recientemente, los motivos pueden ser arquitectónicos, urbanistas, de comunicación, etc. Sin embargo, en esta misma calle existen monumentos de gran importancia, la historia de esta calle también la dota de características distintivas, pero no solamente cuenta con edificios de arquitectura renombrada sino con personajes que día tras día se colocan como ornamento para atraer a los visitantes, usuarios y habitantes, se busca tener comunicación con ellos y decir algo: sobre la cultura mexica, sobre la libertad de expresión, etc., estos personajes -según comentarios de los visitantes- dan un paisaje diferente a la calle, atraen a más gente y generan un paseo enriquecedor para las familias que asisten a él. Así que, siguiendo la postura de Remesar, el arte público, en la calle de estudio si genera un flujo y comunicación con el público, en donde las políticas públicas de regeneración del espacio público y la esfera pública son evidentes y comprensibles para la ciudadanía que se acerca a esta calle, unos motivados por los artistas de la calle, otros por la arquitectura y algunos por el gozo de caminar por una calle remodelada, pero el arte público juega un rol importante en el éxito de este espacio.

Remesar (1997) retoma a Miles (1989) sobre la importancia del arte en espacio público: 1. Produce una sensación de lugar. 2. Ayuda a implicar al público en el uso de este lugar. 3. Proporciona un modelo de trabajo imaginativo. 4. Ayuda a la regeneración urbana. (Remesar, 1997: 26). De esta manera, el espacio público (que en un primer intento es monumentalista) genera relaciones sociales entre el público, hacia la obra, con la creatividad y a su vez con la ciudad, por lo que, me cuestiono ¿Por qué no apoyar el arte público callejero en la calle de Madero? En el caso de estudio, existen diferentes posturas al respecto y coincido con que la acumulación de personas en esta calle puede tornarse peligrosa, tanto para el visitante como para el artista. Sin embargo, eso no los 
convierte en delincuentes, como ha ocurrido en los últimos años, al remitirlos al Juez Cívico por colocarse en determinadas calles del $\mathrm{CH}$, ya que permiten el desarrollo social, artístico y urbano, características que quizá ninguna de las instancias dedicadas al CH ha contemplado. Lo presentado por Remesar (1997) me remite a lo expuesto por Olea (1980):

"Se trata desde luego de un arte útil para la comunidad en un sentido más riguroso: regeneración del espacio público, revitalización semiótica de los objetos urbanos, la conformación de espacios lúdicos y de información, todo ello con la participación real o virtual de la comunidad." (Olea, 1980: 41)

Olea (1980) presenta algunos efectos del arte público, que como mencioné con lo expuesto por Remesar (1997), si se consideraran estas características en las legislaciones y sanciones para los artistas públicos de la calle de Madero, se tendría mayor oportunidad de diálogo y no existirían tantas restricciones por el uso de espacios públicos para expresiones artísticas contemporáneas. Asumo que en el caso de estudio, la calle no fue planificada para este tipo de actividades, lo cual modifica el diálogo entre autoridades y artistas, pero si tomamos en cuenta los efectos que tiene el arte público en los espacios: público, artistas, ciudad, podríamos llegar a convenios claros, donde se apoyen estas manifestaciones, donde la seguridad sea elemento fundamental, pero también se logren acuerdos para las expresiones artísticas en la actualidad. Si las políticas culturales se encuentran en el paradigma de la democracia participativa, ¿Por qué no hacer partícipes a los artistas de la calle sobre la toma de decisiones sobre su modo de vida y de expresión? Si la participación es una de las características de la democracia, será necesario que se generen canales de comunicación, no sólo entre el entramado de instituciones del $\mathrm{CH}$, sino entre sectores involucrados en este espacio, como lo son los artistas de la calle de Madero. El arte público debe ser, tanto para la gente como planteado por la gente. (Remesar, 1997: 49). Es una tarea difícil de lograr, como en el caso de estudio, pero deberá permitir la participación de la sociedad en la toma de decisiones sobre el uso y disfrute de los espacios públicos y sobre el arte en ellos. Donde las expresiones artísticas no sufran de restricciones, sino de regulaciones que permitan mayor calidad interpretativa y discursiva, pero no cayendo en estigmas delictivos como ocurre en esta calle. 
El arte público que podríamos denominar itinerante en las ciudades, no es contemplado teóricamente como tal, quizá porque es efímero, un día están colocadas las estatuas y al día siguiente tal vez no, pero en el caso de Barcelona, las actividades de las estatuas vivientes son constantes en Las Ramblas, sin embargo, no son consideradas en el arte público como tal (por lo menos para Remesar, 1997) sino en la categoría de performance (la cual desarrollaré más adelante). El mismo autor retoma a Krauss y hace una definición amplia de posibles campos de acción para el artista: Ampliar la acción y expandir realmente el campo de la escultura hacia otros dominios del arte (performance, fotografía, video, etc.) o de otras disciplinas cercanas (diseño industrial) (Remesar, 1997: 157). De esta manera, las acciones que contempla el arte no se limitan a esculturas estáticas o la construcción de monumentos, no demerito ninguna de estas actividades, pero el que el arte público contemple expresiones tan variadas como la performance y video, abre el reconocimiento a nuevas expresiones artísticas, como las estatuas humanas que he mencionado a lo largo de esta investigación, las cuales (en ocasiones) son poco valoradas, por lo menos en el contexto institucional del $\mathrm{CH}$ de la Ciudad de México.

En el caso del CH del DF, el arte público ha sido constante y con resultados interesantes para la estética y construcción social del espacio y la identidad, como lo presenta (Gallo, 2010 y Monsivais, 2006) con el análisis de las intervenciones realizadas por Francis detto Alÿs en la década de los noventa:

“Alÿs realizó una serie de performances con el título colectivo de Paseos. Para realizar estas obras efímeras - y generalmente documentadas en fotografías o videos- el artista pasó varias horas deambulando por las calles de la ciudad, realizando acciones sencillas que resaltan algunos de los aspectos más enigmáticos de la vida cotidiana en la capital. Estas obras pueden leerse como un esfuerzo por ponerse en el lugar de los habitantes del centro, al menos durante el corto tiempo que dura el performance" (Gallo, 2010: 170-171)

Lo presentado por Gallo (2010) nos acerca a actividades artísticas en el espacio público del $\mathrm{CH}$, las cuales no tienen que ver con la monumentalidad sino con la experiencia a pie de calle, en donde el caminar y sentir la ciudad puede generar expresiones artísticas importantes, como las realizadas por él. Es una lástima que este tipo de intervenciones ya no tengan el apoyo, respeto, ni tolerancia que debieran, ya que como lo he mencionado, en el caso de estudio: los artistas callejeros de la calle de Madero, no 
tienen reconocimiento, diálogo, ni intenciones de tenerlo con autoridades. Por lo tanto, el espacio público y las actividades artísticas están cayendo en un círculo vicioso, donde la cerrazón de ambas partes no permite el reconocimiento, ni disfrute del público por el arte en espacios públicos. Sin embargo, en el $\mathrm{CH}$ si se apoyan otro tipo de actividades (como los mencionó Anabelí Contreras en el capítulo anterior) y como lo expresó Sandra Ortega (Directora de la publicación kmcero):

"Por un lado, se hace mucho arte público, es muy frecuente que haya instalaciones, recorridos, conciertos, cuestiones en donde los artistas salen a ocupar la calle y trabajan con la calle o simplemente la usan como espacio de presentación. Es muy común, la gente trabaja mucho en la calle. La Central del Pueblo trabaja en la calle, hay centros culturales que están constantemente ocupando, ya sea como foro o como espacio para interactuar o intervenir, el Festival de México también lo ha hecho mucho. Creo que es como muy natural, la calle como escenario, como espacio para interactuar con la gente, para que este arte, esta creatividad entre en diálogo con la gente. Creo que es de los más natural, ocurre mucho, yo creo que es como muy enriquecedor para la gente que circula y recorre el centro." (Sandra Ortega, Directora de kmcero, 11 de abril de 2011)

Ahora bien, si la calle y el apoyo al arte público implican la libertad y riqueza interpretativa y receptiva (como lo presenta Sandra Ortega), ¿Qué ocurre en el caso de estudio? De igual manera, el conflicto es por el uso del espacio público, que en muchas ocasiones es apoyado y aplaudido desde las instituciones. Sin embargo, en la calle de Madero la situación no es tan pacífica como en otros espacios, quizá porque no cuentan con estudios formales de arte, porque no están organizados o no dependen de alguna casa de cultura, etc., pueden ser muchas razones. Lo importante, es intentar analizar este conflicto por el arte en espacios públicos, cuando nos encontramos ejemplos exitosos donde si existe esta vinculación.

\subsection{Del arte público al performance: estatuas vivientes.}

"La articulación narrativa del territorio es la que va a permitir el desarrollo de los mecanismos de apropiación del lugar por parte del usuario. Lo dicho anteriormente reza para lo que denominamos arte público estable, pero también para el temporal (sobre todo si es una instalación) y para las acciones que denominamos performance." (Remesar, 1997: 47)

Como lo presenté en el primer apartado de este capítulo, la discusión sobre arte público es amplia y abarca la monumentalidad de edificios, esculturas, fuentes, intervenciones que transforman el entorno del espacio y la apropiación del mismo. Sin embargo, como 
lo he desarrollado en esta investigación, el arte público que analizo no es monumental ni estático, está vivo y su lenguaje es el cuerpo. Aparentemente no tiene relación con el arte público estático a escala: monumentos, esculturas, etc. Según Noviel y Ocaña (en Celdrán, 2010: 11) las estatuas humanas: Pueden ser promotoras de cultura y revalorizar la memoria (que es el objetivo que cumplen los monumentos o las esculturas). Por lo que, existen diferentes posturas para el análisis de arte público, para Novel y Ocaña (Presidenta y Secretaria de la Asociación Española y Comunitaria de Estatuas Vivientes y Artes Escénicas) las estatuas humanas o vivientes si cumplen funciones de arte público, forman parte del paisaje urbano actual y remiten a memoria, pasado, futuro o hasta otras culturas. Este último punto podría ser discutido, ya que en teoría, las estatuas humanas deberán reflejar la cultura en la cual se presentan, por ejemplo, en el $\mathrm{CH}$ del DF deberían remitir a la cultura mexica, como lo menciona Enrique Fuentes (Dueño de la Librería Madero): Simplemente que nos trae imágenes que no obedecen a la búsqueda de un patrón de identidad con nosotros los mexicanos, son ejemplos que vienen sustraídos de otras partes de la literatura. (24 de mayo de 2011, Librería Madero).

En el caso de estudio, para un locatario de la calle Francisco I. Madero, los personajes creados por las estatuas humanas no representan la cultura mexicana, por lo que son criticados por Enrique Fuentes. Sin embargo, el arte no debe de representar y comunicar siempre a la cultura de origen, se pueden considerar hibridaciones culturales y artísticas. A lo que James O. Young (2006) agregaría: In other words, the experience of living as a member of a given culture is a necessary condition of being able to create successful works of the types developed by the culture. (457), refiriéndose a la condición cultural del arte, esto es, la cultura es determinante para el tipo de expresión artística que se realiza. Sin embargo, considero que la cultura de origen no es una limitante para las manifestaciones artísticas, si bien, artistas mexicanos expresan su creatividad y sus mensajes a través de símbolos culturales mexicanos, el comunicar a través de otros símbolos e imágenes no debe demeritar la expresión artística. Como lo presenta Gallo (2010) haciendo referencia a las influencias de los artistas visuales en la Ciudad de México:

“Al parecer los artistas de todo el mundo han adoptado una actitud alejada de nacionalismos. Más que referirse a un contexto cultural en particular, estas obras 
tienden a reflejar la condición globalizada de nuestra existencia, un mundo donde tanto los estilos artísticos como los estilos de vida, se han vuelto cada vez más homogéneos. Pero el caso de México es más complejo. El joven de los noventa tiene escaso interés en lo mexicano, pero abunda en referencias a otras culturas y naciones." (Gallo, 2010: 38)

Lo presentado por Gallo (2010) y Young (2006) muestran la complejidad del arte y de su análisis. En donde, no sólo importa la preparación académica para realizarlo, sino el conocimiento y la experiencia de leer, pensar y admirar otras culturas y la propia. En otra arista, nos encontramos con el señor Enrique Fuentes, quien critica a las estatuas humanas de la calle de Madero por no contener suficientes referentes culturales mexicanos, con lo cual, para él no se cumple con los objetivos identitarios del arte. Sin embargo, para Gallo (2010), el arte es más amplio que los referentes simbólicos nacionalistas, por lo que, la hibridación cultural y artística es una constante en estas expresiones en la última mitad del siglo XX y en la actualidad.

Retomando el arte público de la calle Francisco I. Madero, el cual está representado por estatuas vivientes, músicos y personajes. Esta expresión se basa en el espacio, en mensajes que buscan ser comunicados por medio de una sonrisa, de un movimiento, de una frase, en donde el ocio y el arte en un espacio público se expresan día a día. Algunos artistas cumplen con funciones políticas, como lo expresa Remesar (1997), en donde el cuerpo se convierte en su instrumento y mensaje a comunicar a un público (especializado o no) que busca distracción, aprendizaje y espacio de expresión. Por lo que considero que el arte público de la calle Madero cumple con algunas características presentadas por Remesar (1997) y otros autores, pero no es estático, podría parecer que no cumple con funciones sociales (lo cual discuto, ya que el arte en cualquier espacio busca comunicar por medio de la creatividad), así que no podemos cerrarnos a la idea de que no es arte porque no cumple con los antecedentes académicos, si el artista realiza obras por medio de su creatividad y las comunica al público, las estatuas vivientes son arte, que busca generar canales de comunicación y reflexión, en espacios que, quizá no son los especializados para su expresión, pero generan comunicación y disfrute social.

"El arte del cuerpo, del cuerpo como presencia plástica, o del cuerpo como actor de un sistema de representaciones, se abre como uno de los campos más interesantes en el desarrollo del arte público. En este sentido otra de las tradiciones artísticas de las que debe beber el arte público se situaría en el terreno de la performance." (Remesar, 1997: 39) 
Para Remesar, la performance, como lo comenté líneas atrás, forma parte del arte público, ya que el cuerpo como medio de comunicación debe considerarse arte y si es en espacios públicos, por supuesto que cumple con lo requerido para el arte público. Es necesario definir qué es performance para continuar con esta investigación sobre arte público y estatuas humanas. La performance ha sido considerada una manera de dar vida a muchas ideas formales y conceptuales en las cuales se basa la creación del arte. Los gestos vivos se han utilizado constantemente como un arma contra las convenciones del arte establecido. (Goldberg, 1988:7). Goldberg realiza un análisis exhaustivo sobre performance y la complejidad que conlleva, es una forma de cambiar los cánones establecidos del arte académico, en donde el cuerpo se convierte en instrumento para comunicarse con el público.

"Por su propia naturaleza, la performance escapa a una definición exacta o sencilla más allá de la simple declaración de que es arte vivo hecho por artistas. Cualquier definición más estricta negaría de manera inmediata la posibilidad de la propia performance. Puesto que recurre libremente a cualquier número de disciplinas y medios de comunicación- literatura, poesía, teatro, música, danza, arquitectura y pintura, además de video, filme, dispositivas y narración- en busca de material, los despliega en cualquier combinación. De hecho, ninguna otra forma de expresión artística tiene una manifestación tan ilimitada, puesto que cada intérprete hace su definición particular en el proceso y la manera propios de la ejecución." (Goldberg, 1988: 9)

Como Remesar (1997) mencionó en el apartado anterior, performance es una de las manifestaciones del arte y del arte público si se realiza en espacios públicos, por lo tanto, la noción de arte público monumental se expande a expresiones artísticas contemporáneas, sin un guión definido, ni en un foro especializado, pero si contiene mensajes que comunicar al público por medio del cuerpo. Sin embargo, su definición es amplia, como menciona Goldberg (1988) es arte vivo hecho por artistas. Lo cual me remite a la complejidad de definición del arte planteado por García Canclini (2010), en donde se tiene que referir a lo que dicen los que dicen que hacen arte. De igual manera, performance art, no tiene definición concreta, es una forma de expresión corporal, que no está limitada por cánones estéticos, sino fluye desde la creatividad para comunicar algo al público.

"Al mismo tiempo que esos artistas estaban trabajando en sus cuerpos como objetos, manipulándolos como si fueran una pieza de escultura o una página de poesía, otros desarrollaron performances más estructuradas que exploraban el cuerpo como un elemento en el espacio [...] que tenía una relación directa con la 
escultura." (Goldberg, 1988:159)

Lo presentado por Goldberg (1988) sin duda abre aún más la complejidad y creatividad de la performance, donde el cuerpo es lienzo para expresar un mensaje, que va más allá de la identidad local o de las influencias de culturas ajenas, es la síntesis de la experiencia, de la creatividad y de observación para comunicar diferentes mensajes. Su versatilidad y riqueza artística radica en la mezcla con otras expresiones como la escultura, teatro, poesía, pintura, pantomima, entre otras. Por lo tanto, performance contiene amplitud de definición o de no definición, si fuera restringida se cortarían las alas de la creatividad y de la expresión desde diferentes medios, ya que performance refiere al cuerpo como materia prima de comunicación. La relación con otras manifestaciones artísticas, como escultura y teatro se hace evidente en las estatuas vivientes del mundo, las cuales podrían denominarse:

"Arte utilitario: pueden servir como mobiliario urbano en las ciudades y atraer a los turistas, como decoración estética de eventos [...] es un arte efímero, que dura el tiempo de ejecución en que el actor realiza su ejecución [...] La educación juega un papel fundamental en la sociedad y las estatuas vivientes pueden ser de gran utilidad para formar parte de la cultura o de nuevas maneras de expresión." (Noviel y Ocaña en Celdrán, 2010: 11)

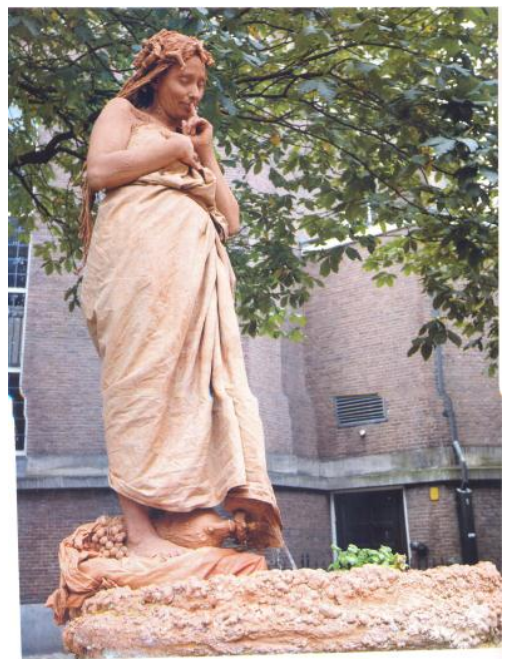

Sin título

Fotografía de Raúl García-Juez en Celdrán, 2010.

Como lo expresan Noviel y Ocaña, las estatuas humanas cumplen con funciones en el espacio público, como lo son la estética, la reflexión por medio del mensaje transmitido (educación) y aunque ellas no lo mencionan, forman parte de estrategias culturales para el ocio y la recreación. Sin embargo, política y legalmente no son consideradas (en México), ni apoyadas. En este apartado intento explicar la importancia artística de las estatuas humanas, desde la performance y la riqueza con que cuenta, mezclando teatro y escultura, donde el cuerpo es materia y mensaje, para así llegar a comprender la riqueza artística de las estatuas humanas en la ciudad de México, que forman parte del arte público por estar colocadas efímeramente en estos espacios de la Ciudad, en el caso de estudio, en una calle del $\mathrm{CH}$ de esta capital. 


\subsection{Estatuas humanas en México y el mundo.}

Como lo he presentado en esta investigación, el arte público -a grandes rasgosconsidera los edificios, esculturas y fuentes como parte de expresiones artísticas en espacios públicos. Lo cual, como mencioné puede llegar a limitar la creatividad de diversos sectores artísticos. Sin embargo, hay un cambio conceptual en el arte público (presentado por Remesar, 1997), ya que se amplía el arte público considerando la performance, que para Goldberg (1988) no se puede definir como tal, simplemente se expresa que el arte está vivo y hecho por artistas. El cuerpo se convierte en objeto y mensaje de los artistas, se busca expresarse sin seguir los cánones establecidos y por medio del cuerpo y el juego espacial se comunican mensajes diversos. En el caso de estudio, las estatuas humanas o vivientes forman parte de la performance, en donde se sintetizan teatro, escultura, pantomima, etc. sin reglas definidas, siguiendo la creatividad y la libertad de expresión, que en ocasiones no se realiza en lugares especializados como galerías, sino en la calle, como ocurre con la mayoría de las estatuas vivientes en el mundo, México no es la excepción.

\section{a) Performance en la década de los setenta: escultura viva.}

Antes de continuar, es necesario aclarar que la investigación teórica sobre estatuas humanas no es realizada en México, sino recabada de libros editados en España. Por lo tanto, el análisis teórico de este apartado lo hice con base en información de dicho país, en donde se revisa a fondo la performance y estatuas humanas contemporáneas. Así que, tomando en cuenta esta aclaración, este apartado no se centrará en México sino en otros países, que como expliqué líneas atrás, la hibridación cultural que se expresa en el arte nos muestra la riqueza artística y creativa de los artistas contemporáneos. Es el “sujeto humano" como obra de arte en sí misma, tiene un significado y un significante, expresa, habla por sí sola, transmite un mensaje. (Noviel y Ocaña en Celdrán, 2010:11)

Debido a que la performance buscaba expresarse con medios poco convencionales y rompiendo las estructuras estrictas del arte academicista, en 1969 en Inglaterra, Gilbert

y George (estudiantes de la Escuela de Arte de St. Martin's de Londres) buscan transformar la manera de hacer arte y los instrumentos para expresarse fueron sus cuerpos:

"Personificarían la idea de arte: ellos mismos se convirtieron en arte al declararse 
$<<$ escultura viva〉> . La primera <<escultura cantante>> consistía en dos artistascon las caras pintadas de dorado, vestidos con trajes corrientes, uno llevando un bastón y el otro un guante- moviéndose de una manera mecánica, como de títere, encima de una pequeña mesa durante más o menos seis minutos con el acompañamiento de la canción [...] de Flanagan y Allen [...] La ironía inherente a centrar la obra de arte en sus propias personas y convertirse ellos mismos en el objeto de arte era al mismo tiempo un medio serio de manipular o hacer observaciones sobre ideas tradicionales acerca del arte." (Goldberg, 1988:167)

Como lo presenta Goldberg (1988) al referirse a la actuación de Gilbert y George, se buscaba hacer una crítica al arte académico (a pesar de que ellos eran estudiantes formales), no bastaba con los cánones establecidos, encontraron en sus cuerpos y en los personajes creados la forma de expresar su creatividad y criticar a los escultores academicistas, ya que llevaban un pergamino en el que, entre otras frases expresaban: 2. Haga que el mundo crea en usted y pague mucho por este privilegio. (Goldberg, 1988:167). Muestran la critica al mercado del arte, a la mercantilización extrema, en donde todo pareciera ser producto y ganancia económica, por lo que Gilbert y George intentaron hacer una critica al sistema y a los artistas formales de la época, quienes, al parecer hacían obras solamente pensando en la ganancia económica que eso les generaría o en la venta de la creatividad para producir arte como lo demandara el público, lo cual molestaba a Gilbert y George, quienes por medio del cuerpo encontraron una forma de expresión y de crítica a un sistema, con el cual no estaban de acuerdo. ${ }^{6}$ Gilbert y George, al estar en contra del circuito artístico establecido en Londrés en la década de los setenta buscaron transformarlo llevando siempre un letrero con la leyenda jArte para todos! (Goldberg, 1988:168). Cabe aclarar que estas manifestaciones artísticas eran realizadas en espacio cerrados, pero la consigna de ¡Arte para todos! me remite a las expresiones artísticas de las estatuas humanas en la actualidad, las cuales encuentran en la calle el gran escenario para comunicarse con la gente que pasa, algunos se detienen a observarlos, a tomar fotografías y colocan una

\footnotetext{
${ }^{6}$ La importancia del campo artístico en Londres (con lo cual estaban en desacuerdo Gilbert y George en la década de los 60 y 70), se expresa también en la década de los años noventa, como lo menciona Aidan While (2003): Emphasis is placed on the role placed by London's extended art World in terms of providing the networks, associations and facilities - ranging from studio spaces to well-established (and internationally oriented) Networks of critics, dialers and galleries- that are necessary in bringing together and promotion an international avant- garde art movement. (Aidan While, 2003: 251-252). Desde mi perspectiva en México, considero que aunque no tengamos las redes ni la infraestructura para el arte y la cultura como en Londres, las políticas culturales en nuestro país han dado resultados favorables (como lo mencioné con anterioridad). Sin embargo, es necesario aclarar que para los artistas que no están dentro de un circuito artístico sigue siendo difícil entrar en él. Por lo que, cuarenta años después, creo que la propuesta de Gilbert y George y su crítica al sistema del arte en Londres continúa vigente.
} 
moneda, otros no lo hacen, sin embargo, se cumple con dar arte para todos, en el espacio de todos: la calle.

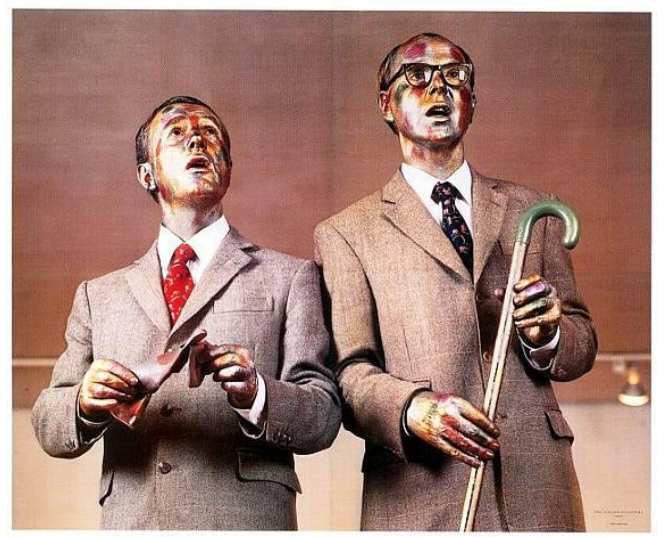

Gilbert y George. "Escultura viva".

Fuente: andrewgrahamdixon.com

David Hockney (reconocido artista inglés y precursor del Pop Art con Andy Warhol) dijo de Gilbert y George: Pienso que lo que están haciendo es una extensión de la idea de que cualquiera puede ser un artista, que lo que ellos dicen o hacen puede ser arte. El arte conceptual se anticipa a su tiempo, ampliando horizontes. (Goldberg, 1988: 169). Es así como, artistas contemporáneos alabaron la creación de Gilbert y George y abrían la puerta a la creatividad, en donde los estudios formales del arte no deberían limitar la creatividad ni las oportunidades de comunicarse con el público. Como expresé líneas atrás, ellos eran estudiantes de arte, sin embargo, se dieron cuenta que el arte rebasa la academia y que la creatividad (inherente al hombre) busca comunicar, por lo tanto, no deberá ser requisito estudiar arte para ser artista, con lo cual coincide Hockney y que en el caso de estudio, las estatuas vivientes de la calle de Madero, es fundamental considerar que el arte desde la academia no es la única expresión de creatividad, ya que las manifestaciones artísticas de la calle de estudio, en su gran mayoría no cuentan con formación profesional en arte. Sin embargo, tienen creatividad y mensajes que comunicar al público que se detiene a verlos y también para los que no los ven, ya que transforman el espacio público y el tiempo libre de los visitantes y habitantes de la calle. Así que, para ser artista no es requisito indispensable tener estudios formales de arte, considero que sí dotan de herramientas y lenguajes profundos que facilitan y mejoran la calidad artística, pero si las estatuas vivas de Gilbert y George eran la crítica al sistema (desde dentro del mismo), es necesario tener una visión amplia del arte y no ceñirnos solamente a los estatutos establecidos del arte.

En el caso de la calle Madero del $\mathrm{CH}$ de la Ciudad de México, una estatua viviente me comentó sobre su actuación y la definición de su expresión escénica: Puede ser un señalamiento, performativo, como un "happening" y como se dice: romper la 
estructura cotidiana, lo extra cotidiano que siempre está entrando ahí, ésto de acuerdo a la teoría normal y común. (Entrevista con Mario Peña, "Watt", performance- estatua viviente, 25 de enero de 2011). Así que, para Watt la performance es la manifestación mediante la cual lo cotidiano se vuelve diferente: los mensajes, los sentidos se abren a otras expresiones y salimos de nuestra realidad normal, para así entrar a la atmósfera que la estatua viviente nos ofrece.

Como lo he presentado en este capítulo, la performance de la escultura viva, es una síntesis entre teatro y escultura, que como menciona Goldberg (1988), por momentos se cree que no es realizada por el hombre, sino que son esculturas de verdad. Lo mismo ocurre con las estatuas humanas en las calles del mundo, con la diferencia de que el escenario y la perspectiva para el público es el espacio público, la calle, en donde no hay iluminación, telón, maquillistas, ni tramoya, simplemente está la creatividad del personaje y la percepción del público en un espacio que no ha sido creado para este tipo de actividades, ya que como presenta Remesar (1997), el arte público se refiere a los monumentos y esculturas localizadas en estos espacios, sin embargo, debemos ampliar el arte público, como lo presenta el mismo autor y considerar la performance. Así que, después de expuesto lo anterior, analizaré brevemente a las estatuas humanas en las calles del mundo, en donde se sintetiza performance (como lo presenté en este apartado), teatro, pantomima y la calle como el gran escenario del arte público.

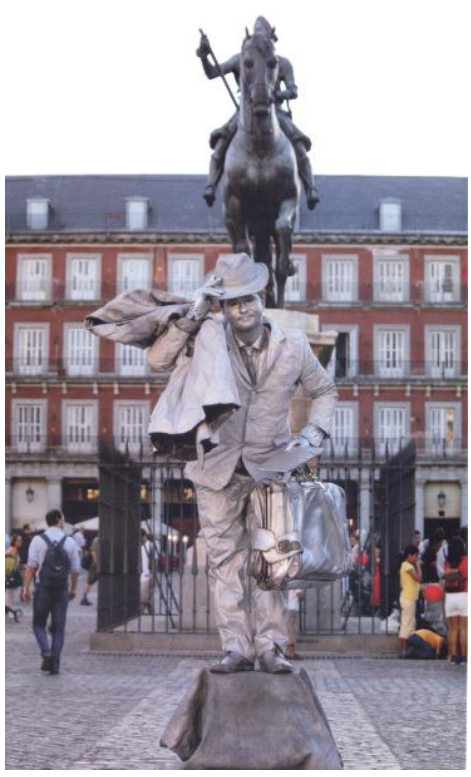

Sin título

Fotografía de Raúl García-Juez en Celdrán, 2010.

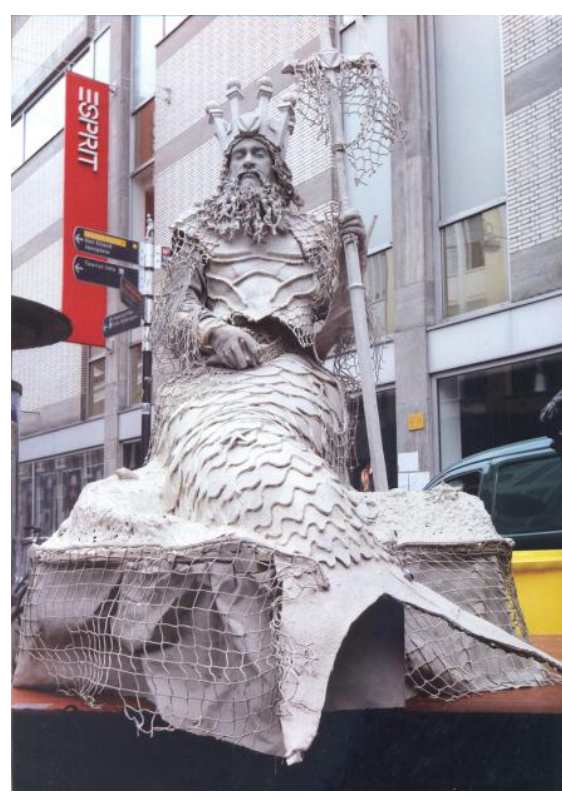

Sin título

Fotografía de Raúl García-Juez en Celdrán, 2010 


\section{b) Estatuas humanas: teatro, pantomima y calle.}

Como he desarrollado, la performance es la forma de expresión artística donde los cánones académicos establecidos no se cumplen cabalmente, el cuerpo se convierte en el objeto por medio del cual se transmite el mensaje. La performance realizada en foros cerrados por Gilbert y George manifiesta la transformación del arte, en donde el teatro, estatuas y la crítica se hacen presentes. Lo cual se asemeja a lo realizado por las estatuas humanas en el mundo. Sin embargo, enfocaré el análisis de este tema al teatro, pantomima y el escenario de presentación: la calle. Como mencioné líneas atrás, la bibliografía del tema no es mexicana, ni considera el desarrollo de esta actividad en México, así que lo analizaré desde Europa para así presentar el caso de estudio en el $\mathrm{CH}$ del DF.

"La estatua humana o viviente es una expresión artística, proveniente del arte de la pantomima corporal y gestual; es producto de la fusión entre la escultura y la pintura dentro del teatro, y de las artes escénicas. Es el estudio de las formas y del movimiento en estática, una acción congelada, como si fuera un fotograma. Ha tenido su evolución a través de la historia desde su surgimiento hasta que los grandes maestros franceses Étienne Decroux y Marcel Marceau, investigaron y diseñaron una técnica, que engloba la respiración, la concentración, la pantomima gestual, el equilibrio, la armonía y la circulación de la energía." (Noviel y Ocaña en Celdrán, 2010: 7)

Lo presentado por Noviel y Ocaña demuestra que la creación y representación de estatuas humanas es una expresión artística en donde se mezclan elementos de teatro, escultura y artes escénicas. El desarrollo formal de estas expresiones artísticas comenzó con el estudio del cuerpo y de la técnica de Decroux y Marceau. Es importante mencionar, retomando a David Hockney en Goldberg (1988:169) que la creación de estatuas vivas rompe con los paradigmas establecidos del arte desde la academia, ya que plantea ¡Arte para todos! Como público y como artistas, por lo que, los cánones formales del arte abren sus puertas a la creatividad de la población. Aclaro este punto porque las estatuas humanas del $\mathrm{CH}$ del DF (en su mayoría) no cuentan con estudios formales de teatro, ni artes escénicas, sin embargo, la creatividad y disciplina son notables, así que derivando de la transformación estética y creativa de la performance, no podemos caer en reduccionismos académicos con las expresiones artísticas contemporáneas. 
"Los maestros de la pantomima Étienne Decroix y Marcel Marceau no pensaron esta modalidad de hacer arte como teatro de bajo formato, o como teatro a pie de calle, sino a modo de pequeñas dramaturgias (porción mínima de una obra de teatro) o escenas de pantomima corporal y gestual, que unidas conformaban una pieza de Teatro para Sala" (Noviel y Ocaña en

Celdrán, 2010: 7)

Sin título

Fotografía de Raúl García-Juez en Celdrán, 2010.

Desde esta perspectiva, las estatuas humanas que derivan del teatro y la pantomima no son menos que las expresiones realizadas en foros cerrados especializados, sino que se convierten en una forma de comunicar diferentes mensajes a más público, con la calidad que tendría en un foro establecido, pero con la libertad interpretativa que proporciona
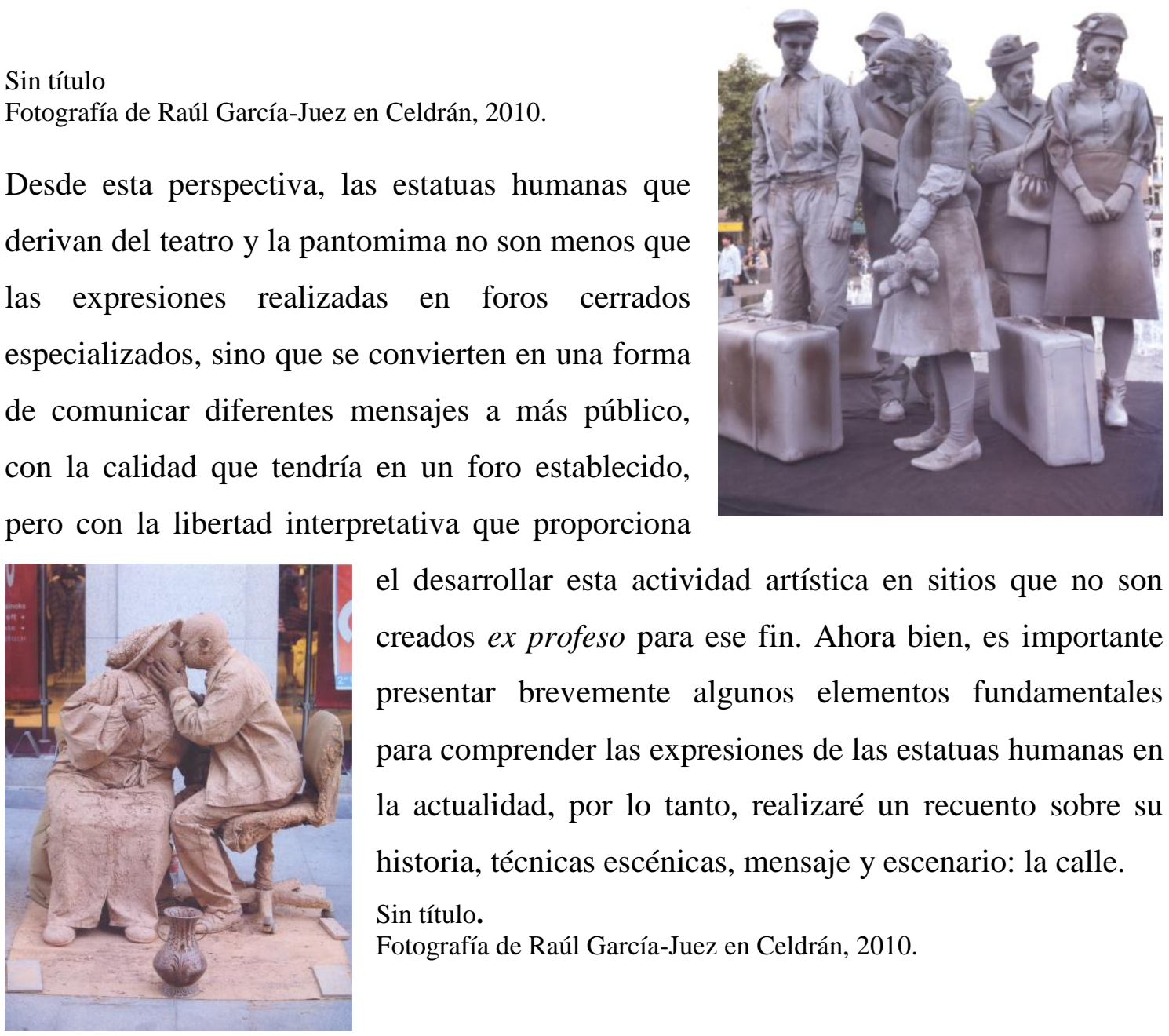

el desarrollar esta actividad artística en sitios que no son creados ex profeso para ese fin. Ahora bien, es importante presentar brevemente algunos elementos fundamentales para comprender las expresiones de las estatuas humanas en la actualidad, por lo tanto, realizaré un recuento sobre su historia, técnicas escénicas, mensaje y escenario: la calle.

Sin título.

Fotografía de Raúl García-Juez en Celdrán, 2010.

Dichos temas permitirán dar información sobre la importancia que estas manifestaciones han tenido a lo largo del tiempo, para así poder comprender su complejidad y en el caso de México (último capítulo) la falta de comprensión y tolerancia (término empleado en el $\mathrm{CH}$ para referirse a que si se da permiso o no a dichas manifestaciones) que se tiene en el espacio público del $\mathrm{CH}$ del DF.

"En definitiva, la estatua viviente trasciende los límites de la obra de arte, deja de ser materia para ser sujeto humano e interactuar con el público. Decroux [...] afirmaba rotundo que el cuerpo presenta lo invisible: emociones, tendencias, dudas, pensamientos". (Noviel y Ocaña en Celdrán, 2010: 11) 
- Esbozo histórico de las estatuas humanas y su escenario: la calle.

Como presenté en la introducción de este apartado, la información recabada para éste no cuenta con autores mexicanos ni latinoamericanos, por lo tanto, considero que es de vital importancia contextualizar este tema, no sólo geográficamente, sino cultural y artísticamente en distintas sociedades a lo largo de la historia. Comenzaré con la etimología de estatua, la cual deriva del latín stare, que significa permanecer de pie, estar inmóvil y firme, no se permite la emisión verbal sino la corporalidad como instrumento para comunicar mensajes. Las estatuas humanas contemporáneas derivan del mimo y la pantomima:

"Mimo y pantomima dominaron la escena en Roma con el apoyo de emperadores aficionados al género. Tal es el caso de Nerón y Trajano, entre otros. Este género, ajeno a toda expresión verbal, centra su mensaje en la expresión corporal: gestos, imitación, danza, llegando sus representaciones a abordar argumentos trágicos como ha quedado de testimonio en pinturas al fresco, mosaicos, bajorrelieves labrados en piedra" (Celdrán, 2010: 16)

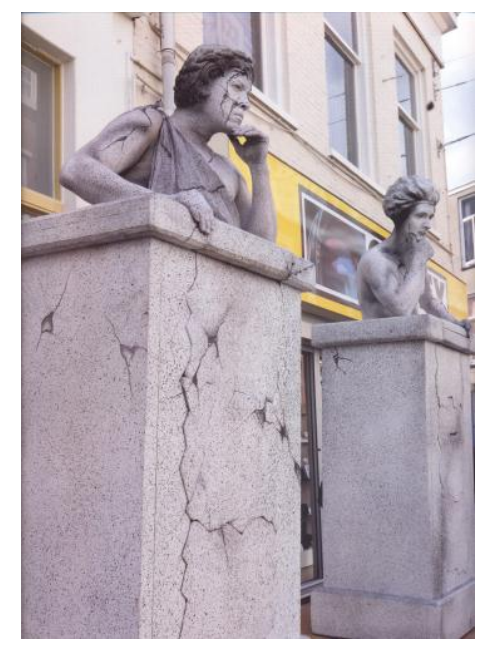

Sin título

Fotografía de Raúl García-Juez en Celdrán, 2010.

La mímica y pantomima son la relación directa con la performance realizada por las estatuas humanas en el siglo XXI. El término mimesis es griego: de mimestikai: imitar. Originariamente se imitaba a una persona, aunque ésta podía a su vez estar en representación simbólica de una idea, de una divinidad, de un héroe. (Celdrán, 2010: 16). Esta actividad no es reciente, tiene antecedentes en Roma y en el caso de Egipto había estatuas humanas que hacían sátira de Alejandro Magno: Cuando Alejandro Magno asumió la personalidad divina del dios Amón, algunos se mofaron de él adoptando la figura del rey conquistador de Egipto, y fueron castigados por su osadía. (Celdrán, 2010: 17-18). Desde esta perspectiva, la imitación y la sátira eran elementos fundamentales de las estatuas vivientes en la antigüedad, en donde, eran castigados por burlarse del mandatario, pero la expresividad corporal ha sido una constante.

"En aquella tradición grecolatina era género muy popular. Aquella modalidad artística se conservó a lo largo de los tiempos medievales gracias sobre todo al teatro ambulante, desembocando todo ello, sin solución de discontinuidad, en la 
commedia dell'arte ya en el siglo XV" (Celdrán, 2010: 21)

Las manifestaciones artísticas en espacios abiertos han sido una constante a lo largo de la historia del arte. Estas actividades en las plazas de templos, en las calles, en los lugares donde más gente los viera, donde pudieran comunicar su mensaje y generar reflexión en el público, por lo tanto, el escenario ideal para ellos fue la calle, ya que el espacio público, abierto y gratuito, permite emitir mensajes a mayor número de personas, así como el disfrute del tiempo libre.

"Los actores itinerantes del mundo antiguo, que floreció en la Edad Media y en la figura del juglar, han mutado en una serie de realizaciones artísticas cómicas o dramáticas: nuestros artistas que llevan a cabo representaciones efímeras llevando su arte a pie de calle con un único guión: su mirada, su gestualidad, su cuerpo." (Celdrán, 2010: 21)

Si en la Edad Media existían los juglares como artistas callejeros, las estatuas humanas $\mathrm{y}$ artistas callejeros actuales son herederos de los juglares, se manifiestan en la calle, tienen mensajes que compartir con el transeúnte, como lo explica Ana de Alba (Cantante de ópera que se coloca en la calle Madero del $\mathrm{CH}$ ): El juglar llegaba al pueblo y le decía al pueblo lo que estaba pasando, narraba la historia, bailaba y cantaba, hacían piruetas, el pueblo feliz de verlos. Esa tradición la podemos rescatar nosotros, de llevar la música, el arte, la danza, todo lo que se hace aquí de arte urbano llevarlo al pueblo. (Entrevista de Ana de Alba, cantante de ópera, 20 de enero de 2011). Así que, histórica e ideológicamente, el juglar es la representación artística fundadora de los artistas callejeros en las ciudades del mundo, no sólo de las estatuas (los cuales son herederos de la mima y la pantomima) sino de las expresiones artísticas llevadas a cabo en plazas y calles del mundo.

Durante la Ilustración, Diderot abordó el tema en su Enciclopedia (sobre la relación entre mimo y pantomima): Al actor cabe exigirle habilidad para combinar pantomima y discurso, capacidad para mezclar escenas habladas con escenas mudas y estáticas en aras de un realismo escénico. (Celdrán, 2010:28). Es así como, la inmovilidad y la importancia de la expresión corporal (más allá del lenguaje) ser convierte en elementos fundamentales para el arte. En este período surge la manifestación artística denominada “Cuadros vivientes" (Celdrán, 2010: 28):

“Al actuante en solitario, a la estatua humana propiamente dicha, no tardó en 
unirse el grupo estático o cuadro viviente. Esta modalidad fue practicada por el pueblo etrusco, que recreaba sobre estrados y plataformas, e incluso sobre carromatos que se desplazaban, cuadros, escenas, momentos a modo de retablillo relacionado a asuntos, personajes, historias que estaban en la experiencia del pueblo y que eran queridas y recordadas por éste, tanto en el ámbito de la religión como en el de la vida patriótica [...]”' (Celdrán, 2010: 28)

Los etruscos buscaron la manera de manifestarse artísticamente recordando pasajes de su historia en la calle. Encima de una especie de carros alegóricos hacían representaciones significativas para su cultura, las cuales eran realizadas por un grupo de tres o cuatro personas que estaban sentadas o de pie haciendo pequeñas escenas de su historia, quedando estáticos y sin hablar remitían a su pasado y sus valores religiosos en el espacio público.

"A lo largo de los siglos XIX y XX surgieron personalidades relevantes en materia escénica, teóricos y artistas que renovaron ese mundo y se implicaron en la investigación e impulso del mismo [...] A Decroux le sirvió para [...] fijarse en el cuerpo humano con mirada de escultor, recopilando para el archivo de su memoria poses, actitudes, desplantes, desgarros, movimientos que el alma imprime al cuerpo y que él sabía captar en trazos y bosquejos." (Celdrán, 2010: 28)

Decroux (en Celdrán, 2010) fue el impulsor de las estatuas vivientes en el siglo XX, analizó la mima y pantomima, donde los movimientos comunican algo al espectador, desde los objetos imaginarios, los movimientos bruscos, pero suaves que hipnotizan al público. No solamente perfeccionó la técnica sino el escenario de interpretación: la calle, ya que consideraba que era el espacio donde se tenía mayor relación con el espectador y por supuesto, el mensaje sería comunicado de manera más clara. Como lo presenta Celdrán (2010), refiriéndose a la transformación artística de principios del siglo XX: El enaltecimiento de la figura del actor en cuanto a cuerpo y presencia física; se valoró [...] La cultura del cuerpo y su redescubrimiento supuso la valoración de la mímica e incluso del teatro estático. (Celdrán, 2010: 80). Es así como el cuerpo se convirtió en sujeto y mensaje del arte, por medio de la mímica, la pantomima y el teatro se logró conformar una expresión artística que cumple con lo presentado desde la performance, en donde la libertad creativa y la síntesis realizada desde diferentes variantes del arte confluyen en el cuerpo, el cual nos comunica un sinfín de mensajes. Como presenté, las estatuas humanas (teóricamente e ideológicamente) derivan del juglar, el cual estaba en las calles comunicando y entreteniendo al pueblo. 
Aunque artísticamente su antecedente es la mímica y la pantomima, las cuales forman parte del teatro (Celdrán, 2010). Ahora bien, ¿Por qué se representan en la calle? Históricamente, era el escenario por excelencia, pero también contaba con limitaciones políticas y religiosas (Celdrán, 2010:84). Sin embargo, en el siglo XX, gracias a Decroux la calle, el espacio público se convirtió en el escenario de la creatividad estática mímica:

"Ducroux ponía de relieve la importancia de la interacción, de la puesta en escena en la vía pública de un pensamiento a transmitir, de una idea creativa en la que en definitiva confluyen los elementos principales de la escenificación teatral: un actor que se expresa mediante lenguaje físico, no verbal, y cuyo vehículo aglutinante con el espectador son sus gestos y sus ademanes que se destapan como si de una caja de sorpresas se tratase; creando, descubriendo con vaivenes un cuerpo estático desde la inmovilidad inicial al flujo del movimiento." (Celdrán, 2010: 32)

Sin título

Fotografía de Raúl García-Juez en Celdrán, 2010.

Considerando lo propuesto por Decroux, no hay mejor escenario que la calle, ya que permite la interacción constante con el público, el asombro por encontrar lo desconocido en la calle conocida, el compartir el espacio con el arte sin limitaciones, donde la fluidez de los mensajes es

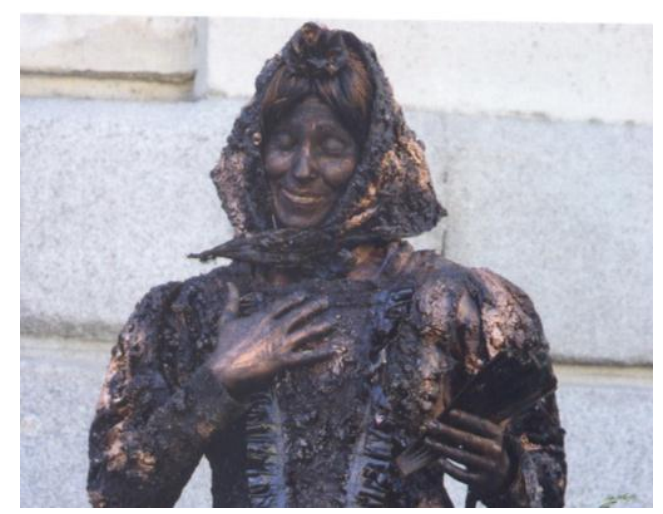
más efectiva, la interacción genera el autoconocimiento a través del arte, sin grandes distancias de por medio, ni escenarios ostentosos que alejen al público del artista. La calle permite el contacto directo con el arte, como si se tratase de todos, como si fuera ¡Arte para todos! (como planteaban Gilbert y George). A lo que Celdrán agrega:

"Ese espacio donde la distancia entre el actor y público que preocupó antaño a tantos expertos escénicos se resuelve en este fenómeno adaptado a nuestra perspectiva crónica. El escenario es la calle. El público rodea al actor como si se tratara de una estatua de bulto redondo y el graderío semicircular o semi-frontal habitual que nos obligaba a una visión angular, desparece.” (Celdrán, 2010: 32)

De esta manera, el público tiene cercanía con la estatua humana, como en su momento lo tenía con el juglar o con el histrión latino. La calle se convierte en el escenario sin tramoyas, sin grandes escenografías, se pueden ver a detalle los gestos de la cara, los movimientos, el parpadear, el cuerpo con todo su potencial es sujeto, mensaje y 
lienzo para el público, el cual puede acercarse a verlo a detenidamente o en algún momento a conversar con la estatua humana (cuando termina su presentación). Sin embargo, la calle también es un riesgo, así como es el escenario donde las distancias no existen y los detalles son evidentes, también es el marco donde se puede perder el artista, no cuenta con telones, tramoyas, luces, simplemente es el paisaje, la calle, los edificios como testigos de la escenificación: El cuerpo se vuelve escenario por si mismo, en respuesta al tamaño de la calle que siempre te va a avasallar. (Entrevista con Eduardo Álvarez, Malabarista, 28 de enero de 2011). Es así como la calle también puede convertirse en un espacio difícil de llenar, donde la atención del público se puede perder, pero si el escenario es la calle en si misma y el espacio, las estatuas humanas tienen un gran reto para superar.

"El público se agolpaba en torno a la estatua y la abarcaba con toda serie de detalles, contemplando la corporalidad que nos muestra, la secuencia gestual, suave deslizamiento de expresividad y creatividad mientras el actor, la estatua, en un barrido de mirada acapara al espectador a quien no distrae elemento otro que la figura única que impone su presencia. Y todo sucede en un corto espacio de tiempo como característica obligada en el mimo.” (Celdrán, 2010: 33)

Como presenta Celdrán, el estatuismo viviente callejero tiene gran relación con el público, al estar en contacto directo con el artista, ambos sincronizan sus expresiones, ya que las estatuas vivientes, aunque tienen una idea concreta de lo que quieren presentar con sus movimientos, el guión se escribe en la calle, ante el público y con el público. No hace falta guión ni argumento sino brevedad en la acción, limpia metamorfosis de estatua a cuerpo [...] como si la estatua dibujase consigo misma y con lo que interpretare: un dibujo perfecto. (Celdrán, 2010: 33).

Casiodoro (en Celdrán, 2010: 22) se refiere a la pantomima representada en Roma de la siguiente manera:

"Con la sola capacidad de expresión en sus rostros dicen más que otros con muchas palabras, yaciendo estáticos, a todo remitiéndose con la mirada, burlona ahora y luego llorosa ponen en el ánimo de quien sigue sus movimientos interiores un cúmulo grande de sensaciones [...] Se trata de hombres que hablan con la boca cerrada, tienen un silencio dotado de voz merced a que sus manos elocuentes tienen una lengua en cada dedo, y caminan sin moverse. Son estatuas. [Subrayado mío]" (Celdrán, 2010: 22) 
Es así como las estatuas humanas se relacionan con el escenario, con el público y con el cuerpo (sin voz) para transmitir un mensaje, ¿Para quién? A quien quiera detenerse a verlos por unos minutos, ya que el tiempo es corto, se deberán hacer movimientos sutiles, precisos, en un lapso breve, lo cual complejiza su expresividad, pero en ello radica el encanto. Sobre la improvisación, el no tener guiones se explica (como me comentaron mis entrevistados) porque los movimientos y la historia a contar se arma cuando se colocan el vestuario, se pintan y se suben a una cubeta, cajón o al pedestal que tengan, es en ese momento cuando se hace la historia con el espectador. A lo que Remesar (1997), desde la visión academicista del arte comenta: Una performance sin guión, es decir, sin coherencia entre los actos, la escenografía marcada por el lugar y la coreografía que permitirá la interacción, se convierte en algo tedioso y aburrido. $O$ en una desorganización total que puede llegar a tener consecuencias nefastas para el propio lugar. (Remesar, 1997: 47). Por lo tanto, existen diferentes posturas sobre el arte público, desde la performance, este autor considera que la existencia de un guión y secuencia de escenas es vital para la expresividad corporal. Sin embargo, cuando el cuerpo es el escenario, el medio y el mensaje a comunicar (desde la pantomima), el guión se escribe a cada momento, ante la mirada del público. Es importante mencionar que aunque los movimientos son una especie de improvisación, si existe la marca corporal de cada personaje. Por ejemplo, no podríamos pensar en la representación de "La Muerte" que asusta constantemente al público, sin olvidar la concepción que de ella se tenga en cada cultura. En el caso de México, "La Muerte" representada por Raúl en este contexto tiene tintes graciosos, lo cual atrae a la gente, ya que resulta paradójico que el fin de la vida pueda hacer ese tipo de movimientos, sin embargo, en nuestro país "La Muerte" si cuenta con connotaciones que van más allá del temor, se juega con ellas y con la idiosincrasia de nuestro país.

El cuerpo se convierte en el medio para transmitir un mensaje, pero no es el cuerpo en movimiento, sino inmóvil ante las miradas del público, provocando sensaciones en éste, presentándose en el gran escenario de la ciudad: la calle, en donde se pueden crear y recrear emociones que nos saquen de la cotidianeidad. La calle, al no ser un escenario especializado de estas manifestaciones artísticas dota de escenografías variables a los personajes y a sus expresiones corporales. 
- Mensaje y público de las estatuas vivientes.

"El milagro de la comunicación de emociones estéticas se ha llevado a cabo merced a los elementos fundamentales de la acción escénica: cuerpo, espacio y tiempo. Todo se justifica, todo se sacrifica al fin estético buscado. En este juego sutil estriba el arte: en la capacidad de levantar en el corazón del espectador sueños, imaginaciones, sentimientos profundos, anhelo de belleza, nostalgia por el pasado." (Celdrán, 2010: 33)

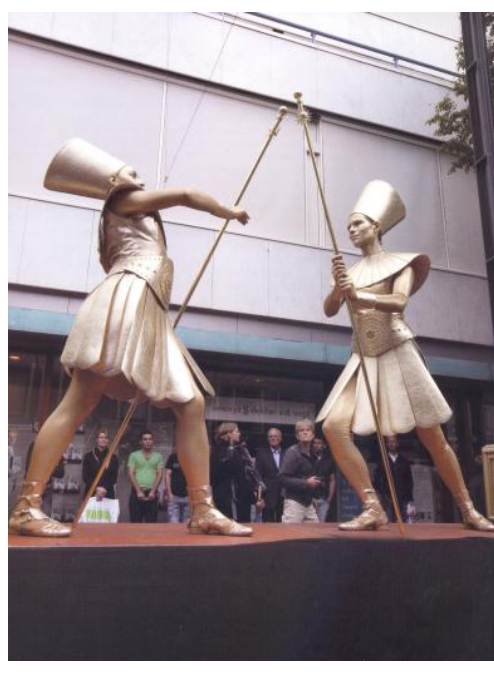

Sin título

Fotografía de Raúl García-Juez en Celdrán, 2010.

El arte busca generar emociones en el espectador, lo mismo buscan las estatuas humanas. Algunos intentan sacar al público de su cotidianeidad (como lo menciona Watt). A grandes rasgos, se busca provocar y evocar. Esto es, la provocación de sentimientos de felicidad, angustia, disfrute, por medio de los movimientos de las estatuas vivientes se intenta elevar el alma, sacar al público de la vida cotidiana y cambiar su sintonía hacia el arte y las emociones. Cuando evocan es por medio de representaciones de hechos o personajes históricos, con los cuales nos identificamos o sentimos un rechazo, nos evocan alguna emoción: Todo es materia de representación. Lo sagrado y lo profano: a todo se le ve dimensión ridícula que a menudo tiene, el detalle chocarrero del que tirar para determinar desnudando el personaje o el asunto. (Celdrán, 2010: 83). La evocación de hechos conocidos y la crítica o burla hacia estos es una constante, no es el único mensaje comunicado, pero es importante mencionarlo (es muy parecido a lo realizado por el juglar en la Edad Media).

Los mensajes a comunicar varían, se comunica desde el mismo hecho de permanecer estático ante las miradas del público. Este recorrido emocional que consiguen las estatuas es una contrapartida emocional [...] es la naturaleza de las exhibiciones estatuarias en la calle donde la distancia [...] juega un papel importante, favoreciéndole a internarse en su ánimo [...] (Celdrán, 2010: 83). La distancia, como mencioné en el apartado anterior genera la sinergia necesaria para la identificación del público con el artista y de éste con sus observadores, dentro de un gran escenario, se crea un corto espacio que permite la interacción profunda y emotiva entre ambos.

"Las reacciones del público son diversas: muchos necesitan tocar al actor 
para saber si es verdadera materia o es humano; otros intentan buscan el contacto con los ojos, se detienen fijamente a mirar la estatua y le hacen gestos y guiños para ver si consiguen que el actor se mueva; otros, sencillamente, no lo entienden como arte y pasan de largo, indiferentes. Los menos. Pero la magia se da cuando el actor se vuelve sujeto en la mirada del público, y como una especie de espejo éste le devuelve la mirada de lo que él está interpretando. El actor, al transmitir sentimientos, es un sujeto en la mirada del público; de este modo deja la cosificación para tornarse obra viva. En definitiva, la estatua viviente trasciende los límites de la obra de arte, deja de ser materia para ser sujeto humano e interactuar con el público. Decroux, creador del mimo corporal dramático, afirmaba rotundo que el cuerpo representa lo invisible: emociones, tendencias, dudas, pensamientos". (Noviel y Ocaña en Celdrán, 2010:11)

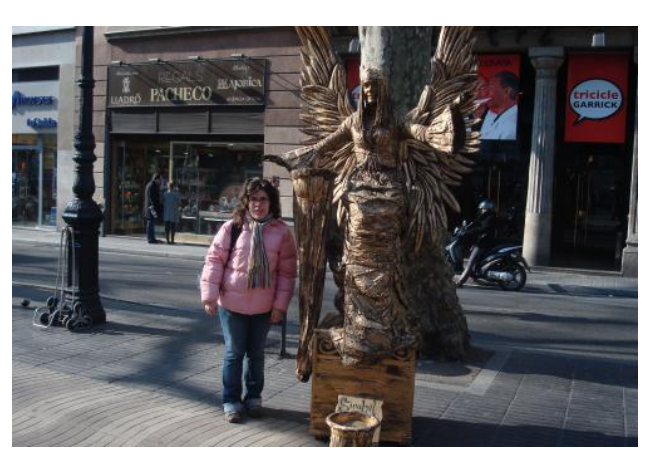

Sin título.

Fuente propia, Barcelona febrero 2009.

El público al que van dirigidos es todo aquel que pase por la calle donde se colocan, algunos prestan gran interés en ellos, otros los atacan por considerar que no es un trabajo digno (en el caso de México). Sin embargo, si el arte debe generar emociones, positivas o negativa, se logra el cometido de estos artistas. Una gran discusión alrededor de esta actividad, la cual apoya Celdrán (2010) y con la cual no estoy de acuerdo es considerar que: Ser estatua es una profesión. Coyuntural casi siempre y no deseada la mayoría de las veces. Estamos siempre ante una persona, componiéndolas con mínimos recursos de utilaje [para] generar en el espectador, de prisa, [...] una sonrisa [...] una moneda. (Celdrán, 2010:93). Considero que lo presentado por Celdrán podría demeritar la labor artística de las estatuas humanas, evidentemente las realizan para ganar una moneda, es un hecho indiscutible, pero no creo que el convertirse en estatua humana sea solamente la consecuencia del desempleo en el mundo, ya que aunque las crisis económicas son una realidad, existen algunos empleos, quizá no los idóneos. Sin embargo, en la actividad como estatuas humanas encuentran otras satisfacciones, como la reacción del público, la libertad creativa y sin reglas rigurosas para su desarrollo: El arte público, bueno, el arte es algo que debe de compartirse con las demás personas, no debe de quedarse encerrado en la mente de cada quién, por eso debe de compartirse aquí en la calle, no nada más en los foros cerrados donde nada más van tres especialistas y ya. Es un derecho de la gente, es un 
derecho de uno mismo para expresarse. (Entrevista con Watt, estatua humana, 25 de enero de 2011).

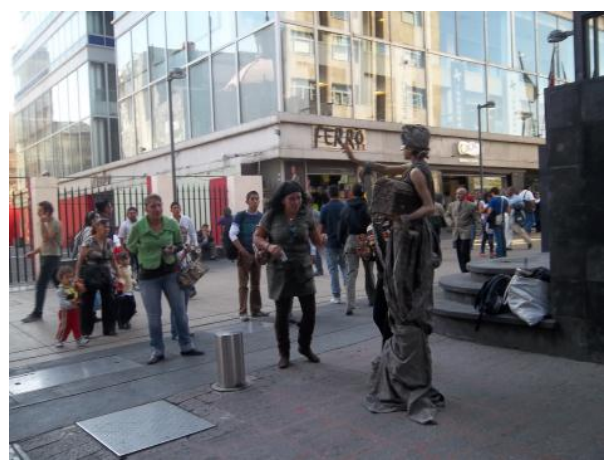

"Sacerdotisa mexica"

México, enero de 2011

Es así como la libertad de expresión se presenta en un amplio espacio para toda la población que transita por estas calles, no sólo de México, sino del mundo, como Las Ramblas en Barcelona, Grafton Street en Dublín, etc., son calles peatonales (en el caso de Las Ramblas cuenta con un extenso camellón, lo cual permite caminar en ella), en donde el arte por medio de estatuas humanas o artistas callejeros convierten la calle y el paseo en una exposición monumental, sin guiones, sin predisposiciones, en donde la libertad del artista y el público se conjugan en un espacio abierto.

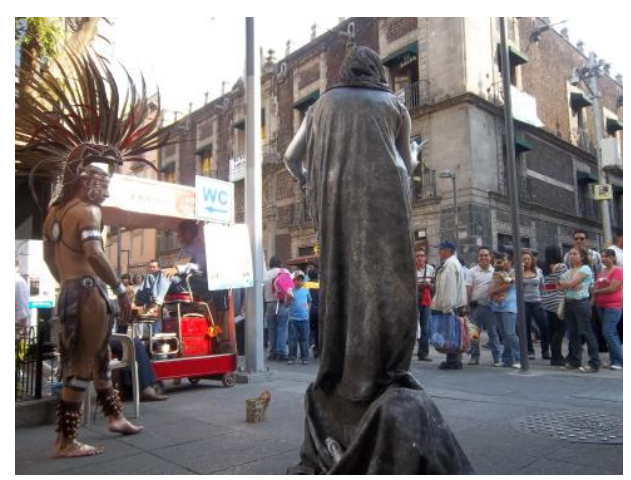

"Azteca dorado" y "La muerte" México, febrero de 2011

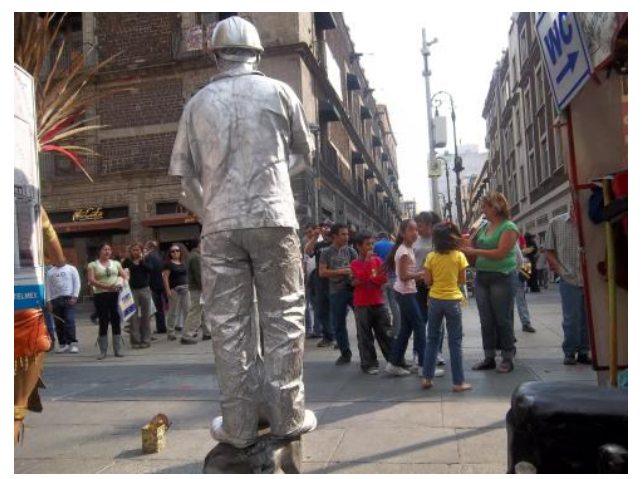

"El Obrero"

México, marzo de 2011

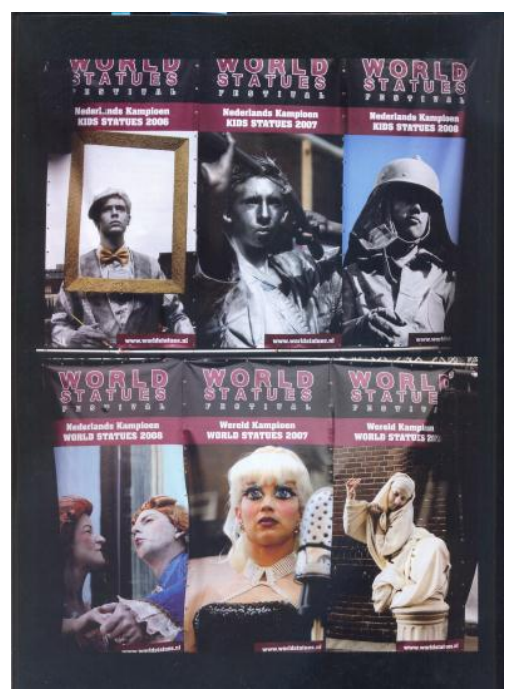

Continuando con la importancia de las estatuas vivientes a nivel mundial, aunque su actividad es remunerada con las monedas del público y con el aplauso del mismo, también existe reconocimiento a nivel internacional de esta actividad (por lo menos en Europa), en donde anualmente se realiza World Statues Festival.

Poster de World Statues Festival. Fotografía de Raúl García-Juez en Celdrán, 2010. 
En dicho evento se reúnen estatuas humanas de todo el mundo, se premia a las mejores en diferentes categorías: exótica, performance (Celdrán, 2010: 92). De esta manera, estas estatuas vivientes logran el reconocimiento (más allá de la moneda contenida en el bote). Por lo tanto, es una actividad artística digna y atractiva para el público, sin importar el sitio donde se logre el encuentro artístico:

"El arte es siempre la creación y la recreación de la presencia. Todo es teatro, y el hombre va convirtiendo en escenario cualquier lugar donde se encuentre. También la estatua viviente, que deja de ser una presencia fría para ser una obra de arte, dependiendo de la habilidad innata de quien es capaz de insuflar hálito vida a la materia." (Celdrán, 2010: 21)

La calle se convierte en escenario, el cuerpo en vehículo, como el lienzo en donde se trazan las dramaturgias del arte. Que si bien, es aceptado y aplaudido por unos, no es valorado por otros. Como ocurre en el $\mathrm{CH}$ de la Ciudad de México, en donde no existen festivales para reconocer su labor, exigir calidad o acercarse a esta manifestación artística. Por lo tanto, consideré necesario realizar este capitulo sobre la importancia estética e identitaria derivada del arte público (así como urbanista y arquitectónica), para adentrarnos a la performance como manifestación artística en espacios públicos, en donde se mezclan literatura, pintura, teatro, danza, literatura, etc., su libertad genera que el arte público no sean solamente los monumentos o las estatuas de bronce, sino la diversidad artística y de mensajes a comunicar. La performance puede ser el antecedente formal de las estatuas vivientes (como lo realizaron Gilbert y George), pero los antecedentes artísticos van más allá de la performance, el uso de la calle para sus manifestaciones se remonta a la historia Grecolatina, a la Edad Media por medio de los juglares, los cuadros vivientes y las estatuas vivientes, en donde la pantomima y mímica se conjugan con artes escénicas para tener comunicación con el extenso público que transita las calles, que se detiene a admirarlos, a tomarles fotografías, los comenta día a día, se sorprenden y recomiendan. Esta es la historia del arte público y las estatuas vivientes, con reconocimiento mundial, pero con problemas legales para poder comunicarse con el público en una calle del $\mathrm{CH}$ del DF, ya que ellos solamente quieren trabajar, entretener al público, generar reflexión, diversión, cercanía entre arte y público, pero no se ha logrado tener un diálogo con las autoridades competentes del área de estudio, lo cual limita sus actividades y el goce del público de tener arte a pie de calle: sin restricciones, ni guiones formales, sino libertad creativa: ¡Arte para todos! 
Galería: Estatuas vivientes en Europa.
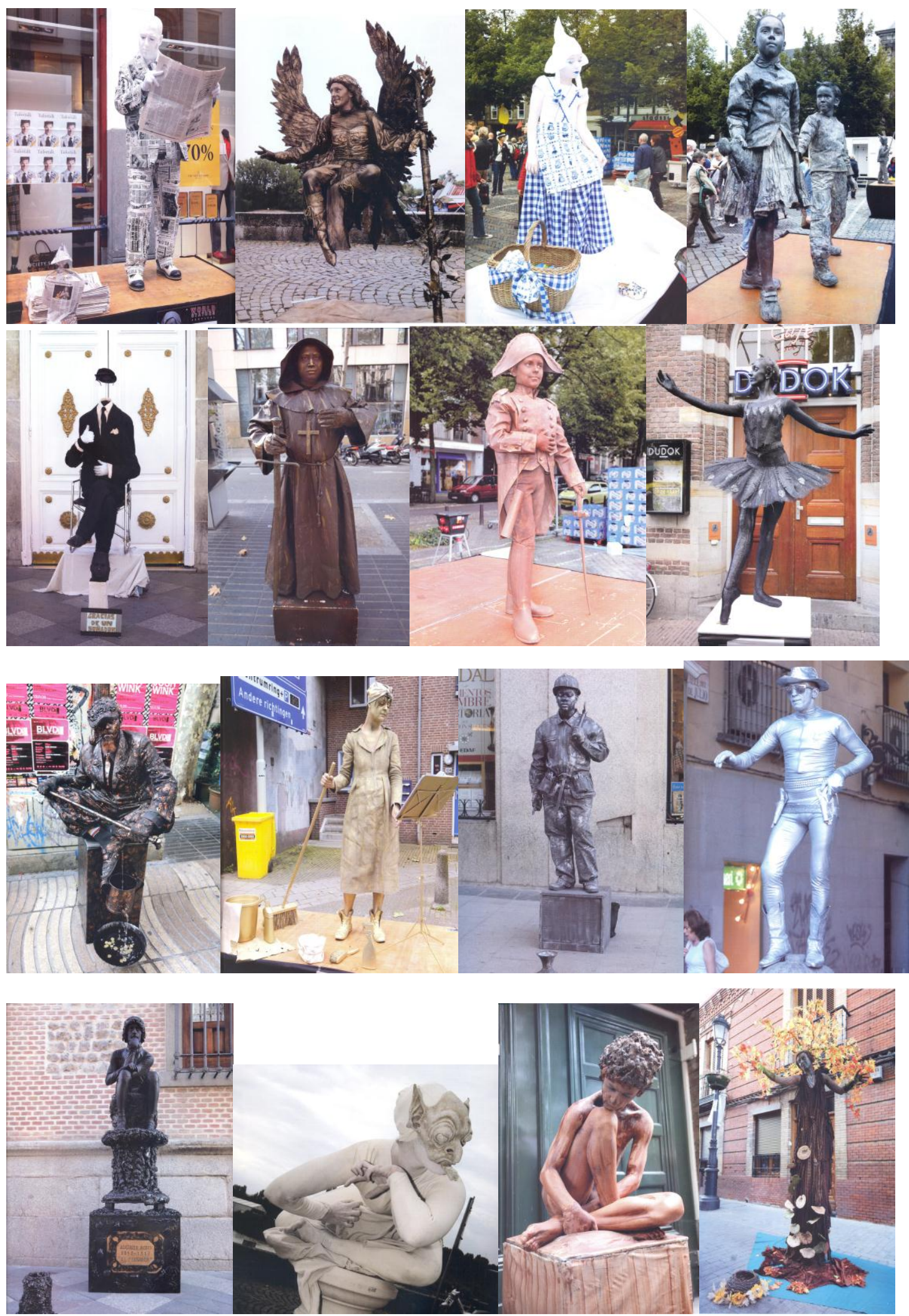

Fuente: Fotografía de Raúl García-Juez en Celdrán, 2010. 
"La modalidad de arte llevado a la calle centra en el cuerpo su lenguaje como vehículo de provocación, excitación, lirismo, ensueño. En la estatua callejera, estatua viviente, se cuenta una historia con el mismo hecho de estar presente."

(Celdrán, 2010:22)

\section{Rehabilitación de la calle Francisco I. Madero:}

\section{El conflicto por el espacio público desde el arte.}

Como he presentado a lo largo de esta investigación, en los $\mathrm{CH}$ se da la conjunción de espacio y tiempo, donde el patrimonio juega un rol fundamental. También es la expresión de políticas culturales, que en muchos casos caen en el monumentalismo, que no cuestiono, pero creo que debería de existir un equilibrio entre el apoyo otorgado a los edificios históricos y las expresiones artísticas contemporáneas, quizá todo esto ocurra por el conflicto que existe desde lo cultural, ¿quién define qué es arte y cultura? ¿Para quién está dirigido? Son preguntas complejas, necesarias en el planteamiento de acciones desde las políticas culturales. Si bien, en el CH de la Ciudad de México existe apoyo para manifestaciones artísticas de diversas índoles (como lo he presentado en esta investigación), el respeto y diálogo entre instituciones gubernamentales y los artistas callejeros no ha tenido resultados favorables.

El arte público es diverso y contempla los monumentos: edificios, estatuas, fuentes; como presenta Remesar (1997) se abren las categorías del arte público hacia la performance, que podría ser el antecedente creativo de las expresiones artísticas de la calle Madero. Las estatuas humanas, las cuales abundan en ésta, responden a necesidades económicas, pero también a intereses estéticos y de libertad para fomentar el arte y entretenimiento en esta calle, lo cual -desde las instituciones públicas que gestiona el $\mathrm{CH}$ - no es contemplado, simplemente remiten a que debido a la afluencia de personas es peligroso que estén ahí o que las actividades que realizan no son arte, debido a que no cumplen con cánones académicos establecidos, por otros, son considerados como ambulantaje en el $\mathrm{CH}$, así que las visiones son diversas, la competencia, la falta de diálogo y de apoyo son constantes en esta calle.

Quiero aclarar que los capítulos presentados con anterioridad, son necesarios para comprender la complejidad de expresiones, aristas, visiones, técnicas, acciones y 
percepciones sobre las políticas culturales, el $\mathrm{CH}$, arte público, lo cual confluye en los mil metros lineales de la calle Madero, como una especie de laboratorio de todos estos temas, en donde el disfrute y belleza es indudable, pero donde también se respira tensión entre expresiones artísticas a pie de calle y los conflictos existentes: mafias de ambulantes, poco apoyo de autoridades, conflictos internos y algunos puntos que podrían mostrar una esperanza para la armonía en esta calle.

\subsection{Breve historia de la calle Francisco I. Madero}

Si bien, la historia de la calle no es tema de esta investigación, es importante considerarla para poder analizar las transformaciones que ha sufrido. No existe una extensa bibliografía sobre el tema, así que me remitiré a lo poco que se encuentra sobre ella, así como a la información otorgada por mis entrevistados en la investigación de campo.

En la época virreinal, esta calle era llamada San Francisco, debido al convento que se encontraba en ella, el cual era considerado el más grande de América Latina (San Francisco el Grande). En la actualidad, se conserva una parte de la Iglesia de dicho convento y como mencioné en el apartado del $\mathrm{CH}$ del $\mathrm{DF}$, hace un par de años se rehabilitó el Atrio como espacio público para realizar exposiciones artísticas.

Siguiendo lo presentado por Montero (2010), desde el año 1580, por orden real, en esta calle se concentraban los más importantes maestros de la platería. El objetivo era doble: vigilar que no realizaran "obras imperfectas contra el arte” y que pagaran los debidos impuestos a la corona española (el famoso quinto real, o veinte por ciento del valor total de la pieza). (Montero, 2010:49). Sin embargo, existe otra referencia sobre esta ordenanza real:

"El origen de esas calles, que primitivamente se llamaron de San Francisco, consta en una de las Ordenanzas tocantes al arte de la platería, dadas por don Lope Diez de Armendáriz, Marqués de Cadereyta, el año de 1638 el virrey que fue de la Nueva España. Dice así la tocante al asunto: 26a ${ }^{\mathrm{a}}$ - Ordenanza que todos los plateros se congreguen en la Calle de San Francisco y fuera de ella no puedan tener sus tiendas-con penas-(subrayado mío)" (González, 1947: 223)

Es así como, desde el siglo XVI y XVII, la calle actual Madero mostraba su vocación comercial. La importancia de los plateros ubicados en ella era tal que, algunos de los 
artículos realizados en esa época se encuentran en museos de todo el mundo, de ahí la importancia de la manufactura de piezas de arte hechas con plata y, por lo tanto, el localizar al gremio especializado en esta calle. En esta avenida se encontraban los talleres y casas de los maestros, las cuales eran compartidas con sus aprendices, durante 3 ó 4 años, el tiempo necesario para que conocieran el oficio platero y la perfección del arte con dicho metal.

El considerar a los plateros como una actividad tan importante, así como exigirles calidad, precisión, arte, nos muestra que el dotar a la calle actual Madero como la zona de los Plateros, la convertía en un sitio especial, donde se encontraba el comercio especializado de la época, de metales como la plata. Por lo que, la vocación comercial de la calle es una constante, así como su importancia espacial en el $\mathrm{CH}$, lo cual persiste hasta nuestros días. Sobre los plateros, Montero (2010) presenta su distinción frente al resto de la población: [...] No es ser aspirante al camorreo, no juntarse con gente de baja estofa, ser de genio apacible y sosegado, temeroso de Dios y de conocida calidad, procederes y costumbres. (Montero, 2010: 50). Los plateros eran parte de una elite comercial en el México Novohispano, tenían una calle exclusiva para sus actividades comerciales y de vivienda, por lo que ésta, aunque ha tenido un sinfín de transformaciones, ha sido fundamental para el desarrollo comercial del $\mathrm{CH}$.

Durante el siglo XVIII, la riqueza de los plateros era tal que, hacían grandes fiestas para sus santos patronos: San Eligio (1 de diciembre), Inmaculada Concepción y San José. En honor de dichos santos, los plateros realizaron un sinfín de procesiones en la actual Madero: procesiones y mascaradas, lidias de toros, decoración de fachadas, certámenes poéticos, convites, desfile de gigantes, música, teatro, bailes y fuegos artificiales. (Montero, 2010: 52). Desde esta perspectiva, la calle Madero (antes Plateros) ha tenido diferentes manifestaciones artísticas en el espacio público, antes se realizaban por conmemoraciones religiosas, ahora...por necesidad y ganas de expresarse ante un público que quiere distraerse por medio del arte. Sobre las suntuosas fiestas realizadas en honor de sus santos patronos, existe el relato de un cronista (Montero, 2010) sobre la majestuosidad de éstas: [...] Limpiaron la imagen de plata, y le echaron rayos en el cuerpo, de plata sobre dorada, y una corona imperial de piedras 
y perlas, luego al sábado siguiente se lidiaron toros sueltos en la calle de los Plateros, cerrando las bocas de la plaza y casa Profesa. (Montero, 2010: 54). El gremio, la fiesta, la diversión, religiosidad se encontraban en esta calle emblemática, de las más importantes de la Nueva España, en ella la plata era trabajada, aprendida, vendida y celebrada. En la actualidad sigue habiendo centros joyeros en la calle, sin embargo, su vocación ha cambiado ante las exigencias del mercado y la versatilidad comercial.

Tomás Gage (en Montero, 2010) describe las calles de México en 1625 de la siguiente manera:

"No hay calle en ciudad alguna de la cristiandad que se acerque a las de México en limpieza y aseo, y mucho menos en la opulencia de las tiendas que las adornan; sobre todo las platerías son dignas de admiración por las grandes riquezas y exquisitas obras que en ellas se ven." (Montero, 2010:54)

La majestuosidad de la calle de Plateros (actual Madero) era reconocida en todo el mundo, las fachadas, las vitrinas de los plateros, los talleres, sus celebraciones, son representación de la importancia del gremio y por supuesto de su personalidad: comercial, de bienvenida al Zócalo, de paso para unos y de deleite para otros. Si bien, la calle de Plateros era donde existía el gremio dedicado a ese metal, por muchos años siguió esa vocación joyera.

En la actualidad ya no existen tantos locales joyeros, sino pequeñas plazas comerciales, donde hay diferentes locales con vitrinas llenas de joyas, la importancia de los plateros ha pasado a segundo término ante las exigencias del mercado:

“Antes eran las joyerías elegantes, buenas. Ahora son pequeños locales que satisfacen la necesidad de la gente, pero los mismos locatarios de las joyerías se están quejando, porque antes pasaban las camionetas, vendían. Ahora nadie está vendiendo, se están vendiendo helados, charritos y botes de agua." (Entrevista con Enrique Fuentes, Librería Madero, 24 de marzo de 2011)

De la joyería a la venta de helados, de la majestuosidad de los plateros a las ópticas, tiendas de perfumes, McDonald's, Restaurante Palacio de Hierro, son algunas de las grandes transformaciones de esta calle. Que si bien, sigue siendo comercial, ya no es la calle elegante de antes, ni la dedicada al gremio platero. Quiero comentar que, quise hacer entrevistas a joyeros, para conocer su opinión sobre los cambios ocurridos en ella. Sin embargo, no tuve éxito, intenté acercarme a algunos de ellos por medio de 
otro informante, pero no aceptó, así que nos quedaremos con la teoría de la calle de Plateros, porque en campo no fue posible el acercamiento desde esta perspectiva.

Como mencioné, la calle va desde el actual Zócalo al Eje Central y era llamada de San Francisco, solamente la $1^{\mathrm{a}}$ y $2^{\mathrm{a}}$ calles se llamaron Plateros, después continuaba con el nombre de Profesa (Iglesia situada actualmente en Madero esquina con Isabel La Católica) y los tres tramos restantes (hasta actual Eje Central) se llamaban San Francisco. El cambio de nombre a Francisco I. Madero se dio, porque es la calle por la que entró dicho personaje en 1911, sin embargo, el nombre seguía siendo San Francisco. Su actual nomenclatura ocurrió cuando el 8 de diciembre de 1914, Villa colocó una placa en la esquina de la calle de San Francisco, cambiando el nombre por Francisco I. Madero. (Página de bicentenario.com.mx). He aquí una breve semblanza sobre la calle de estudio, que cuenta con gran importancia histórica, económica y social. En la actualidad ha sufrido otra transformación al hacerla peatonal y al convertirse en espacio de disputa entre artistas callejeros, ambulantes y autoridades del $\mathrm{CH}$. Ahora bien, presentaré algunos elementos de patrimonio cultural tangible de ella, para así considerar el apoyo arquitectónico y su importancia histórica.

\subsection{Patrimonio cultural tangible: Museos y sus edificios emblemáticos.}

Como he comentado, esta tesis no busca hacer una semblanza del patrimonio cultural de los $\mathrm{CH}$, sin embargo, la hipótesis de esta investigación es que se da más apoyo a estas representaciones artísticas y culturales que a las contemporáneas (intangibles), las cuales se representan en esta calle. Por lo tanto, mencionaré brevemente algunos edificios y museos de Madero, como parte del patrimonio tangible, casi inmaculado. También he decidido remitir a algunos de estos edificios, porque la recién escrita Nueva Guía del Centro Histórico de México (2010) da un peso relevante a las construcciones de este espacio, por lo tanto, considero que es una forma de expresar las políticas culturales de las instituciones de gobierno de esta zona. Aunque dicha Guía no es editada por ninguna instancia de Gobierno, fue presentada ante el Jefe de Gobierno por la Directora de la Autoridad del CH: Alejandra Moreno Toscano. Así que, aunque en el texto de ella no se establece como dependiente de ninguna institución, en la presentación realizada en febrero de 2011 se menciona que fue escrita por cronistas o 
dramaturgos de renombre. Será de vital importancia para visitantes y turistas del $\mathrm{CH}$, debido a la calidad y seriedad de la información. (Página de http://www.noticiasdetuciudad.df.gob.mx/). Por cuestiones de espacio y relevancia, solamente presentaré algunos edificios de la calle, ya que no puedo dedicar el suficiente espacio a todos las construcciones históricas de ella.

El arte y la cultura en este corredor se encuentra en cada paso que damos por los casi 1000mts lineales (Desde Eje Central a la Plancha del Zócalo). Encontramos construcciones emblemáticas como la Torre Latinoamericana, la cual fue diseñada por el arquitecto Augusto H. Álvarez (desde 1956 a 1972 fue el edificio más alto de la ciudad). Frente a ella nos encontramos con el Edificio Moderno del Banco de México (Edificio Guardiola), que en sus escaleras permite las actuaciones de sinfín de artistas callejeros y botargas. A los costados de los edificios mencionados, se encuentra el emblemático Sanborns de Los Azulejos (adquirida en 1662 por Don Antonio Urrutia de Vergara para darla en dote a su hija, la Tercera Condesa del Valle de Orizaba. Su fachada fue restaurada en 1735 por el Conde de Orizaba) ${ }^{7}$. Frente al Sanborns se encuentra la Iglesia de San Francisco (restaurada, como se expresa en el Plan Estratégico), es el único recuerdo arquitectónico que queda de lo que fue el convento más grande de América y debido a eso, daba nombre a esta calle. Junto a él está la Iglesia de San Felipe de Jesús con su fachada neoclásica. En esa acera también se ubica el Palacio de Cultura Banamex - Palacio de Iturbide (en 1780 fue casa del Conde de San Mateo Valparaiso. Posteriormente, en 1822 fue residencia de Agustín de Iturbide cuando fue proclamado Emperador) ${ }^{8}$. Otra construcción de gran importancia es la Iglesia de La Profesa (Madero e Isabel La Católica). Estos son algunos edificios catalogados como patrimonio cultural, sus fachadas e interiores han sido remodelados y se conservan de manera casi museística, lo cual genera gran entusiasmo a todos los visitantes, quienes se toman fotografías en estos edificios.

\footnotetext{
${ }^{7}$ Cédula colocada en la fachada del Sanborns de los Azulejos

${ }^{8}$ Cédula colocada en la fachada del "Palacio de Iturbide"
} 
a) Casa del Conde del Valle de Orizaba/ Casa de los Azulejos

Se cuenta que la remodelación de este edificio fue por una frase que el Conde de Orizaba Don Rodrigo de Vivero y Aberrucia dijo a su hijo: Hijo, tú nunca harás casa de azulejos. (Nueva Guía del CH, 2010: 54). Así que su hijo, años después mandó hacer esta casa, donde el ornamento en cada rincón de la fachada son los

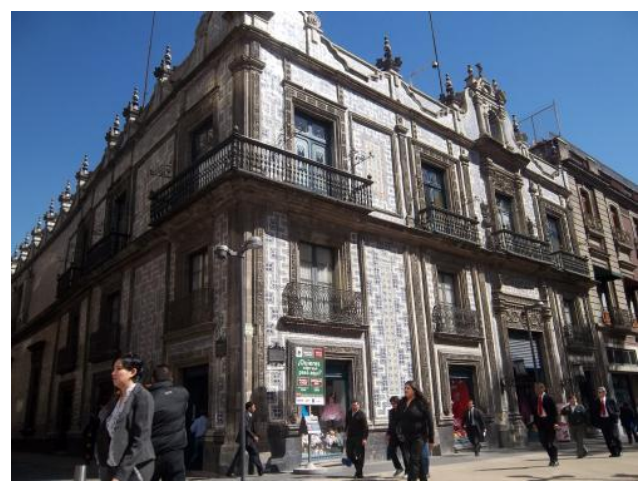
azulejos.

Los descendientes del Conde vivieron en esta casa hasta 1871. La belleza y ubicación en esta calle la muestra como testigo de acontecimientos históricos, se encuentra en la acuarela donde se retrató la entrada del Ejército Trigarante (1821). En el Porfiriato, esta casa fue sede del Jockey Club. Durante la Revolución Mexicana, en ella se ubicó la Casa del Obrero Mundial y fue en esa época en la cual se realizaron en ella los murales de José Clemente Orozco y de Pacolague. En 1917, fue convertida en restaurante Sanborns (de los hermanos Walter y Frank).

En la actualidad forma parte de la cadena de tiendas y restaurantes Sanborns. Su ubicación, belleza e historia son dignas de resaltar. Su fachada e interiores se encuentran casi inmaculados del paso del tiempo, su conservación es notable y forma parte del Programa Federal: ¿Quieres saber qué pasó aquí?, es una campaña en la cual se colocan anuncios afuera de los edificios emblemáticos de la ciudad, en donde, por medio de un mensaje de texto a cierto número celular, nos contarán la historia de estas construcciones. El número de monumento para pedir esa información es el 2206. Así que, el patrimonio cultural tangible de esta casa es invaluable, forma parte del Programa Federal antes mencionado, ha sido testigo de la historia, de la entrada triunfante de líderes a los largo del tiempo. Su conservación arquitectónica es notable y reconocida por habitantes, visitantes y turistas de todo el mundo. Para algunos habitantes de la Ciudad de México ha sido testigo de su vida, como me comentó la Señora Margarita en una plática informal. Ella tiene alrededor de 80 años y todos los días (desde que utilizaba tobilleras, como ella expresó) va tomar su café a este Restaurante. Como ella, 
muchas personas de la tercera edad se reúnen diariamente en la denominada barra de Sanborns. Entrar alrededor de las 11 de la mañana a dicha zona del Restaurante es encontrarse con la historia de un par de docenas de personas de la tercera edad, los cuales asisten diariamente a tomar café o te, acompañado de una pieza de pan dulce. Ellas, por mi experiencia en campo, asisten a este lugar a platicar con quien se encuentre al lado, al frente o con las meseras, las cuales los conocen de nombre y saben sus historias. Esos son algunos relatos que se encierran en esta Casa de los Azulejos, donde su arquitectura es bella, conservada ante el paso de los años y que en la actualidad es atractivo turístico, símbolo de la calle y testigo de relatos a lo largo de más de un siglo.

Esta casa se encuentra en la esquina de las ahora peatonalizadas: Madero y Callejón de la Condesa. En dicha esquina se colocan algunos artistas callejeros con los cuales tuve contacto, al parecer, no tienen problema con los administradores de este Restaurante, pero esa esquina, con esa arquitectura es un bello escenario para los artistas: Ese callejón de Condesa se estuvo calentando por 3 artistas diferentes, que fue: El minero, El charro y el Hombre alebrije [...] Aleatoriamente nos poníamos [...] (Entrevista con Jorge Baena, "Charro Cantor", estatua humana, 23 de enero de 2011). Al comenzar mi investigación de campo, durante la semana, se colocaba la "Sacerdotisa Mexica", con la cual tuve contacto y le parecía que era un buen lugar para trabajar entre semana, ya que sábados y domingos estaba lleno de botargas y no podía trabajar bien.

Así que, junto a construcciones majestuosas como la presentada, con patrimonio tangible y artístico (en los murales de sus paredes), nos encontramos con artistas que intentan entretener, generar reflexión, una sonrisa, ganar una moneda con la gente que camina diariamente por esta calle. Sin embargo, aunque ellos también han sido testigos de la historia de la calle, de las manifestaciones que entran por ella, buscan ganarse una moneda honradamente; la realidad de sus expresiones y el uso artístico de esta calle es tenso, existen diferentes conflictos que no permiten que desarrollen de la manera deseada estas actividades. 


\section{b) Antiguo Palacio de Iturbide / Palacio de Cultura Banamex.}

Esta casa fue construida por el Conde de de San Mateo para regalarla a su hija en 1779 (Nueva Guía del CH, 2010: 57). Ha quedado en la memoria de los capitalinos como el Palacio de Iturbide (como es expresado en una de las cédulas del edificio), ya que fue habitada por Agustín de Iturbide cuando fue proclamado Emperador, dejó de vivir en ella en 1822. Después sirvió como sede alterna del Colegio de Minería (debido a la remodelación de éste). Más adelante se ubicó en este edificio la Academia de San Carlos. En 1847 fue

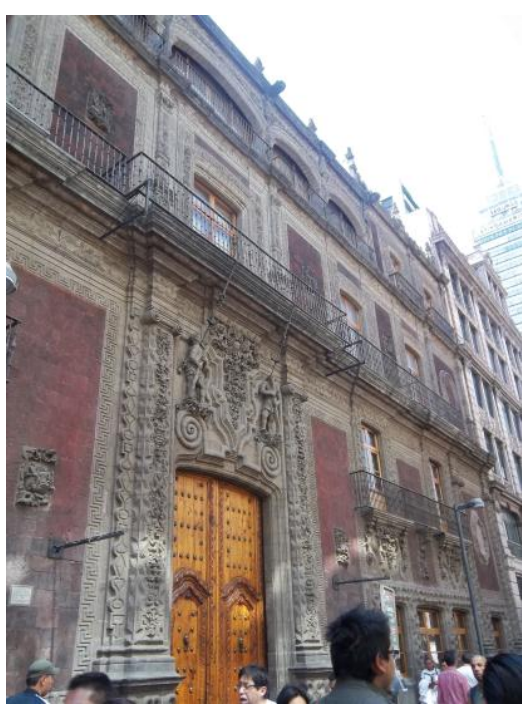
cuartel de las tropas estadounidenses y entre 1851 y 1928 se convirtió en el lujoso Hotel Diligencias y después en Hotel Iturbide. Su estilo arquitectónico es barroco y con tezontle.

Desde 1966, el edificio pertenece a Banamex. El Museo propiamente como tal, Fomento Cultural Banamex tiene 40 años. El Palacio de Cultura Banamex: es el museo, tiene operando más de 20 años como Palacio de Cultura Banamex o Centro Cultural desde 2004, son 7 años ya. (Entrevista con Gilberto Ramírez, Comunicación Interna de Fomento Cultural Banamex, 25 de abril de 2011). Así que, aunque pertenece a Banamex desde hace más de 40 años, ha sufrido transformaciones para convertirse en el Museo que conocemos en la actualidad. Estos cambios se debieron a que antes solamente se utilizaba el patio para las exposiciones, en la actualidad todo el edificio forma parte del Palacio de Cultura Banamex. En donde, no sólo se presentan exposiciones sino investigaciones sobre arte en México.

"Investigación, más que la realicemos directamente en Fomento, sino que trabajamos con instituciones especializadas, básicamente el Instituto de Investigaciones Estéticas de la UNAM, la Universidad Iberoamericana en Historia e Historia del Arte y mucho con la Universidad Nacional Autónoma de México, así es que promovemos las investigaciones, damos seguimientos. Todos nuestros proyectos son investigaciones por iniciativa de Fomento Cultural Banamex." (Entrevista con Gilberto Ramírez, Comunicación Interna de Fomento Cultural Banamex, 25 de abril de 2011) 
Aunque el edificio es de Banamex, ha tenido una diversificación desde hace algunos años. No sé qué tipo de investigaciones realicen, ni el alcance de las mismas. Supongo que el apoyo otorgado por las instituciones se refleja en las exposiciones presentadas en este sitio. A lo cual, es necesario aclarar que su visión del arte y cultura (en las exposiciones) enfatiza la obra de artistas consagrados:

“[...] No trabajamos con artistas, procuramos no trabajar mucho con artistas vivos, por política, para evitar que haya suspicacia de que se está promoviendo a determinado artista o tal artista, normalmente se buscan exposiciones de orden plástico. Cuando se habla de plástica, de artistas ya consagrados o de artistas que ya hayan fallecido, normalmente les damos su espacio, que también sirve para divulgar, difundir la información del Banco Nacional de México que no necesariamente, siempre está expuesta la colección, se aprovecha mucho para lo mismo." (Entrevista con Gilberto Ramírez, Comunicación Interna de Fomento Cultural Banamex, 25 de abril de 2011)

Lo planteado por Gilberto Ramírez nos muestra que el arte presentado en este Museo es consagrado, de artistas de renombre, que hayan tenido alguna relación con México. Las exposiciones presentadas denotan la visión del arte que se tiene en esta institución, en donde, se procura no presentar obras de artistas vivos para no caer en suspicacias, así que para estar en una exposición de este Museo es necesario ser artista reconocido y estar muerto. No critico la postura, pero nos muestra una de las tantas visiones que existen para el arte. Por lo tanto, no es de extrañar que a Gilberto Ramírez le molesten los artistas callejeros de la calle Madero, en el primer capitulo retomé una cita de la entrevista, en la cual define el arte con los cánones que da la academia, por lo que, las manifestaciones artísticas fuera de este foro (en la calle) no le agradan:

"Esta actividad de estatua viviente o de botargas, que también ha transformado y trastornado mucho la vialidad, no sólo es sucia, está concentrada hacia el Eje Central y hay variedad, hay de todo tipo, de todos los gustos, pero insisto, hay que valorar si es una actividad artística, más que nada lo veo enfocado como una actividad de esparcimiento, no tanto como artística. [...] Hay gracia en los implementos o en los vestuarios, hay algunas capacidades de estos chicos que se dedican a hacerla de estatua viviente, pero creo que carecerían de una serie de elementos extras como para poder definir su actividad, como una actividad artística como tal, por eso simplemente [...] Para mi se ha vuelto un mugrero y un cochinero, porque además traen basura." (Entrevista con Gilberto Ramírez, Comunicación Interna de Fomento Cultural Banamex, 25 de abril de 2011)

Coincido con lo que expone sobre las botargas, rompen con el esquema artístico que pudieran tener las estatuas vivientes. Sin embargo, para Gilberto Ramírez, pareciera que estatuas, músicos y botargas se encontraran en la misma categoría: 
ensucian la calle, no cumplen con los denominados cánones para el arte, por lo tanto, se deben de quitar de la calle. Para el encargado de Comunicación Interna del inmaculado Palacio de Cultura Banamex, este tipo de actividades solamente se recuerdan por la cantidad de basura dejada en la calle, no se contempla su inclusión al arte formal, ni sus manifestaciones como artísticas, ya que no tienen estudios formales, ni le atrae la propuesta. Si tomamos en cuenta el discurso artístico que tiene este Museo, no es de extrañar que se tenga esta visión de los artistas callejeros: no son consagrados, ni cuentan con estudios formales, ni mucho menos se dedican a hacer obras como las presentadas en el Palacio de Cultura. Banamex. Sin embargo, ¿Esto es suficiente para demeritar el trabajo de los artistas callejeros? No sé si puede valorarse la creatividad con los parámetros marcados por Gilberto Ramírez. Otro comentario respecto a la oferta cultural de la calle y que quiero mencionar es que, para él solamente existe este Museo en la calle Madero, ya que el Estanquillo y la Pinacoteca de la Profesa no tienen entrada sobre Madero sino sobre Isabel La católica. No conoce, ni sabe de la existencia del Museo Mexicano de Diseño-MUMEDI- (el cual se encuentra en la calle de estudio). Así que, considero que su visión del arte no es tan amplia, ni conoce la propuesta artística de estudio, ni siquiera los museos de esta calle. Aclaro que, intenté hacer una entrevista con el encargado de MUMEDI, pero no obtuve respuesta. Por medio de la Fundación del CH de la Ciudad de México A.C tuve acercamiento con el encargado del Museo, es el dueño y gerente, pero tampoco ha respondido el correo enviado. Así que, lamentablemente lo dejé fuera de esta investigación.

\section{c) Antigua Joyería La Esmeralda / Museo del Estanquillo.}

Este edificio, igual que el de la Compañía de Seguros La Mexicana (mejor conocido como edificio La Mexicana) cuenta con arquitectura con influencia francesa de la época del Porfiriato. Fue construido en 1890 (Nueva Guía del CH, 2010: 59), cuenta con elementos arquitectónicos que se han conservado a lo largo de más de un siglo, como lo es la yesería en la parte superior, en la fachada se

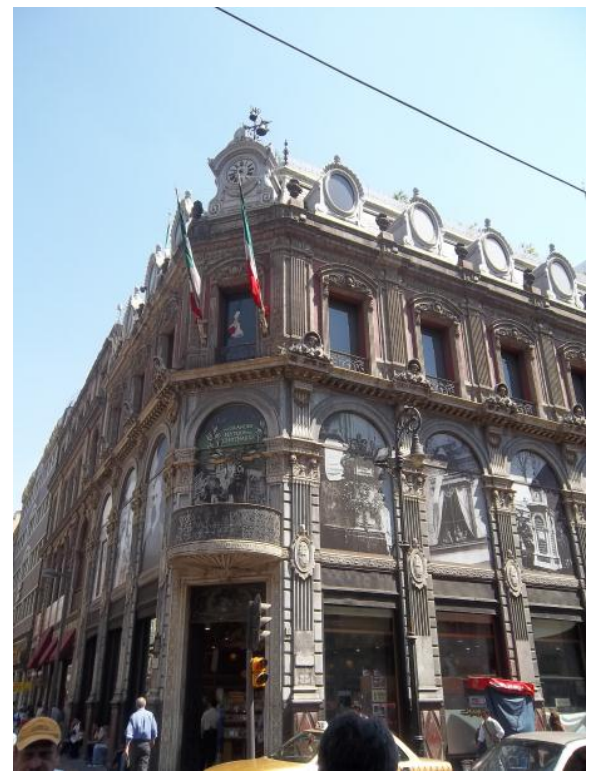


encuentran las iniciales de los dueños de la joyería: Hauser-Zivy y Via. El edificio se encuentra perfectamente conservado. Como mencioné en un apartado anterior, el edificio es de la Fundación del CH de la Ciudad de México A.C (Dependiente de la Fundación Carlos Slim). Sin embargo, la remodelación del edificio y las adecuaciones las realizó el Fideicomiso del CH. Es uno de los edificios emblemáticos de la calle, cuenta con una bella terraza, desde la cual, la vista a la calle Madero es extraordinaria, se aprecian los detalles del edificio La Mexicana y La Profesa.

Actualmente alberga una tienda de música: Mixup y el Museo del Estanquillo. Colecciones Carlos Monsiváis. Por obvias razones, el interés de este edificio lo centraré en el Museo del Estanquillo. Se abrió en noviembre de 2006, el elegir tener un recinto de este tipo en esta calle fue porque el $\mathrm{CH}$ ya contaba con suficiente oferta cultural, lo cual podía favorecer el interés del público hacia las exposiciones presentadas en este Museo.

"Al tener ya una oferta cultural, fue factible conseguir para las Colecciones de Carlos Monsiváis el antiguo edificio de la Esmeralda y se unieron esfuerzos entre Gobierno Federal, Instituciones Públicas y Privadas, GDF y todos se unieron para lograr mostrar las colecciones de Carlos Monsiváis en este lugar emblemático y ahora, prácticamente sobre el corredor de Madero, muy beneficiados por la revitalización de esta área." (Entrevista con Sergio Ortiz, Comunicación y Relaciones Públicas del Museo del Estanquillo. Colecciones Carlos Monsiváis, 7 de abril de 2011)

Este Museo es un claro ejemplo del entramado institucional en el $\mathrm{CH}$, donde Gobierno Federal, local, iniciativa privada, etc., de manera coordinada realizaron un proyecto museístico con la colección privada de Carlos Monsiváis. La propuesta artística en este sitio es mucho más abierta que la presentada en el Palacio de Cultura Banamex, por lo menos no se rigen por cánones fijos sobre el arte desde la academia, sino sobre el impacto de diversas expresiones artísticas. Monsiváis, al ser un cronista, historiador y fanático de la cultura mexicana tenía piezas de todo tipo: maquetas, historietas, libros, comics, etc., sobre nuestra cultura.

“Él tenía una importante colección en el 2006, pero él se dedicó más de 40 años a coleccionar artículos, al principio se pensó, todo el mundo, las personas que iban a su casa y veían su enorme colección un tanto arrumbada, en una casa no puedes mantener más de 20 mil objetos, piezas de una manera muy estética. Gráfica, lo que más tiene, además de los libros, que es cosa aparte, porque no pertenece al acervo del museo. Además de los libros, tenía colecciones de comics o de revistas ya encuadernadas, gráficas, fotografía, grabados, piezas, podrás ver las 
maquetas, a las cuales era aficionado, maquetas de Teresa Nava, de Teodoro y Susana Torres." (Entrevista con Sergio Ortiz, Comunicación y Relaciones Públicas del Museo del Estanquillo. Colecciones Carlos Monsiváis, 7 de abril de 2011)

Al contar con una colección tan amplia, en donde la cultura mexicana es el eje de las exposiciones, las obras no tienen que ser de artistas consagrados, ni muertos; pueden ser de maquetas, de las celebraciones del Centenario de la Independencia (exposición muy interesante y acorde con el Bicentenario celebrado hace unos meses), sobre José Guadalupe Posada, autor de la famosa Catrina, pero que también hizo varias historietas de la época. Es así como, el discurso museográfico es diverso, al tener una colección variada, donde la cultura mexicana es protagonista, no se podría pensar en la visión del arte academicista a ultranza, sino en manifestaciones artísticas identitarias y enraizadas en nuestra cultura. Es la vocación de este museo, en respeto a esta visión, es de historia, más que de arte popular, formada si, por gráfica, por grabados, por caricaturas, por maquetas, por artículos de arte popular, de arte objeto, quizás también, es una visión histórica. (Entrevista con Sergio Ortiz, Comunicación y Relaciones Públicas del Museo del Estanquillo. Colecciones Carlos Monsiváis, 7 de abril de 2011). Por supuesto que es histórica, nos refleja el arte y la cultura mexicana en distintas etapas, en rincones de nuestro país y sobre todo, la visión de los artistas y artesanos locales de su propia realidad. Si, él coleccionó cosas, que al final de cuentas, dan cuenta de la historia de México en distintas épocas, principalmente siglo XIX y XX. (Entrevista con Sergio Ortiz, Comunicación y Relaciones Públicas del Museo del Estanquillo. Colecciones Carlos Monsiváis, 7 de abril de 2011). La propuesta museográfica es variada, libre y da reconocimiento a propuestas, que desde al arte formal, podrían no ser consideradas obras de arte, como las maquetas. Al preguntar a Sergio Ortiz sobre las estatuas vivientes de Madero, expresó:

"Yo creo que aportan un espectáculo, un sentido también de embellecimiento, por qué no? yo los admiro hasta porque estén tan vestidos y tan pintados en el sol. Ellos, aportan un sentido estético, tampoco estoy a favor de que cada día vaya habiendo más en cada esquina, pero si siento que le dan un sentido estético y entre más estético y el publico pueda admirar ese tipo de cosas, adelante." (Entrevista con Sergio Ortiz, Comunicación y Relaciones Públicas del Museo del Estanquillo. Colecciones Carlos Monsiváis, 7 de abril de 2011).

Para Sergio Ortiz, los artistas callejeros de la calle, aportan algo a la ciudadanía: estética y diversión, considero que son argumentos suficientes para valorarlos y no demeritar su 
labor. No sé si su visión sobre los artistas urbanos de esta calle sea por su formación en Comunicación, por la diversidad y creatividad presentada en las Colecciones Carlos Monsiváis o porque simplemente, no podemos demeritar expresiones artísticas por no cumplir con cánones establecidos del arte. A lo que agrega, Una necesidad estética, para mi eso puede ser un performance, para mi eso es, un performance. (Entrevista con Sergio Ortiz, Comunicación y Relaciones Públicas del Museo del Estanquillo. Colecciones Carlos Monsiváis, 7 de abril de 2011).

Así, de los ejemplos presentados, no todos consideran a los artistas callejeros como una propuesta fuera de contexto o como sucios, sino con un aporte a la población, el contar con entretenimiento estético en la calle es razón suficiente para considerarlos como parte del arte público. Sin embargo, no olvidemos que existen regulaciones en este sitio, por lo tanto, la gestión de sus actividades se torna complicada.

De esta manera termino con los edificios emblemáticos de la calle de estudio, en donde existen construcciones con alto valor arquitectónico y patrimonial, como La Casa de los Azulejos - la cual cumple, entre otras, con una función social de convivencia entre personas de la tercera edad, como lo mencioné en ese apartado-. El Palacio de Cultura Banamex, que se encuentra en un edificio patrimonial muy conservado, pero que también tiene una propuesta museística y artística, donde los estudios formales y la consagración del autor son fundamentales. En cambio, el Museo del Estanquillo cuenta con mayor apertura para las propuestas artísticas presentadas en dicho recinto y para las contempladas en la calle Madero. Reitero que, los edificios presentados son sólo una pequeña muestra del conglomerado de patrimonio cultural tangible de la calle, los cuales se encuentran inmaculados ante el paso del tiempo, lo cual nos muestra que las políticas de conservación de monumentos en esta calle es una constante, el caminar por los 1000 metros es un museo completo: los edificios nos reciben como si estuvieran en una especie de vitrinas, para admirarlos, gozarlos y remontarnos a distintas épocas de nuestra historia.

Ahora bien, para analizar el caso concreto de los artistas callejeros en la calle Madero es necesario considerar la peatonalización de ella. No solamente como una obra 
urbanística, sino como parte de la transformación de intereses que se encuentran plasmados en esta calle.

\subsection{Peatonalización de la calle.}

Remitiendo a lo presentado en el capitulo 3, la gestión del CH de la Ciudad de México tiene diferentes instancias encargadas de ella. En este caso, la peatonalización surge como una propuesta de la Secretaría de Obras del GDF (con anterioridad habían realizado la peatonalización de Regina y Alhóndiga), la cual fue presentada a la Autoridad del $\mathrm{CH}$ y el resultado es esta gran calle peatonal, que para algunos es maravillosa por la fluidez y seguridad, para otros, no han mejorados las condiciones, ya que la gente que va a esa calle no compra como antes. Así que, veamos el proceso de transformación para así comprender algunos aspectos generales del escenario de los artistas callejeros, así como las diversas posturas que giran en torno a esta calle.

La propuesta de peatonalización de calles en el $\mathrm{CH}$ la desarrollé en el capitulo 3, partiendo del emblemático caso Regina. El caso de Madero era una propuesta que se venía manejando por los urbanistas de la Ciudad de México:

"Madero era desde mi punto de vista, como el vox populli de la materia. Mi intervención fue: ya está Regina, está funcionando; está Alhóndiga, está funcionando y aprovechar una sinergia que te puede dar la oportunidad de ser más contundente. A la Dra. Moreno Toscano hace año y medio le comenté ahora es cuando, que se tenía que hacer Madero peatonal y era una cuestión de aprovechar una sinergia que había dado paso un caso como Regina, Alhóndiga. Un tema de rehabilitación de calles y que todo ese empuje, esa dinámica de transformación urbana, debíamos aprovechar con un Madero peatonal." (Entrevista con el arquitecto Alejandro Martínez, Secretaría de Obras y Servicios del GDF, 20 de junio de 2011)

La sinergia a la que se refiere el arquitecto es porque ya se tenía un ritmo con las obras, la gente estaba acostumbrada a tenerlas y era necesario continuar con la peatonalización, ante el éxito obtenido con las primeras dos calles peatonales que realizaron. El crear espacios para los peatones también responde a una necesidad de generar menos tráfico en el $\mathrm{CH}$ :

"El $65 \%$ de los vehículos que ingresan al $\mathrm{CH}$ no tienen como destino el $\mathrm{CH}$, solamente es porque pasan del sur al norte o del norte al sur. Eso lo que genera es que el Zócalo se había convertido, aunque sigue siendo en una de las glorietas más grandes del mundo, cuando todos decimos El Zócalo es el ombligo de la luna, el punto de energía, no es otra cosa más que la glorieta más grande del mundo. 
(Subrayado mío)" (Entrevista con el arquitecto Ricardo Jaral, Coordinador Ejecutivo de Conservación del EP de la Autoridad del CH, 5 de abril de 2011)

El Zócalo dejó de ser el centro de energía del país, para convertirse en la glorieta de la ciudad, frase que es usada comúnmente por las instituciones encargadas del $\mathrm{CH}$, ya que Anabelí Contreras emplea la misma frase para referirse al conflicto vehicular en este espacio. En realidad, la peatonalización de Madero se hizo como una forma de cerrar el tránsito a vehículos, para así dotar de espacios públicos seguros a la población que visita y habita el CH. Si bien, la propuesta de peatonalizar la calle surge de los creadores y ejecutores de las calles de Regina y Alhóndiga, la idea de cerrar esta calle no es nueva, como comenta el arquitecto Alejandro Martínez, era una idea que rondaba en la cabeza de urbanistas y planificadores, pero no habían logrado concretarla. ¿Por qué peatonalizarla?

"Cualquier día de la semana, tenía banquetas de 1.50, toda la gente se iba empujando y se desbordaba. Cada vez más se enfatizaba como puerta del corredor frontal de la zona oriente: Reforma, Alameda, metro Hidalgo, Bellas Artes, una puerta al $\mathrm{CH}$, a la Plaza de la Constitución y donde los flujos eran impresionantes. Madero tenía que ser esta vía de acceso, desde mi punto de vista es más un corredor peatonal, de flujos. Es evidente por su connotación de uso comercial, de servicios, con focos culturales, la historia y los monumentos, es un carácter muy particular y que también su diagnóstico propio tenía toda la cabida para su solución peatonal." (Entrevista con el arquitecto Alejandro Martínez, Secretaría de Obras y Servicios del GDF, 20 de junio de 2011)

Vista panorámica de Madero (previo a su inauguración) Fuente propia. Octubre de 2010.

La peatonalización de Madero, al parecer, era necesaria. Se considera, por la gran mayoría de los entrevistados como la entrada natural al $\mathrm{CH}$, por lo que la afluencia es grande y va creciendo, conecta con otros espacios públicos como lo son la Alameda, explanada de Bellas Artes y el Zócalo, por lo tanto, su peatonalización era inminente para seguridad y disfrute de la gente. Si bien, es una propuesta que surge desde los creadores de Regina y Alhóndiga, en el

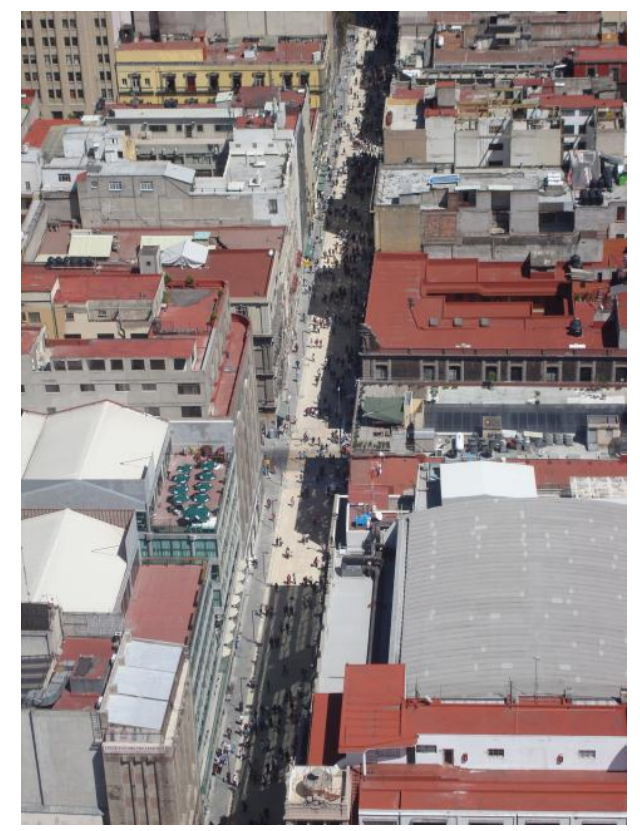
diagnóstico que llevan a cabo para analizar la "personalidad" de la calle (Entrevista con 
arquitecto Ricardo Jaral, 2011) fue: una calle comercial, de uso mixto, donde no hay población habitando en la calle. Por lo tanto, las obras y servicios prestados no son iguales a las otras calles peatonales, en donde si vive gente.

Cabe aclarar que, aunque la propuesta surge de la Secretaría de Obras y Servicios del GDF, la realización de la obra no corrió a cargo de ellos, sino de la Secretaría de Desarrollo Urbano y Vivienda (SEDUVI): El proyecto físico se da a SEDUVI, porque Madero tiene esta lógica de conectividad evidente, con el tema de la Plaza de la República, de Garibaldi, como un polígono. (Entrevista con el arquitecto Alejandro Martínez, Secretaría de Obras y Servicios del GDF, 20 de junio de 2011). SEDUVI estaba haciendo las obras de la Plaza de la República y Garibaldi, por lo que la peatonalización de Madero formaba parte de esa zona, así que SEDUVI se sumó a hacer las obras en esta calle. De esta manera, tenemos otra instancia implicada en el $\mathrm{CH}$, no pude tener contacto con las personas de SEDUVI para realizar la entrevista pertinente, por lo que no analizo el proyecto urbanístico planteado, sino la transformación ocurrida en esta calle, en donde el arte callejero se encuentra entre las disputas de intereses por el espacio público.

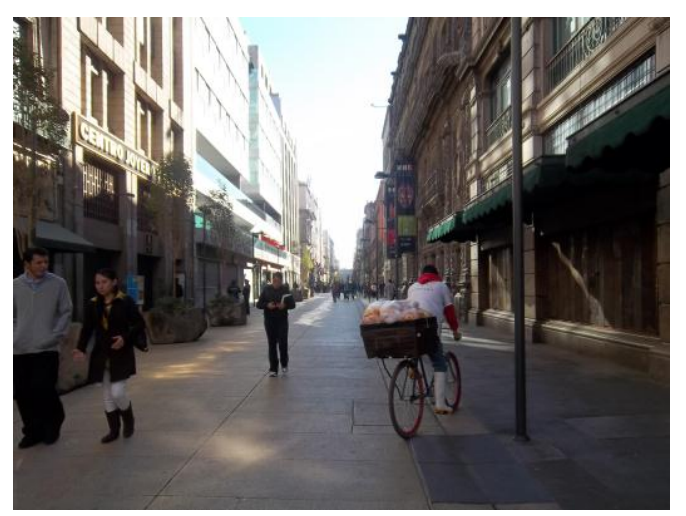

Madero por la mañana entre semana. Fuente propia. Enero de 2011

Es importante mencionar que, si bien, la inauguración de la calle peatonal fue en octubre de 2010, desde diciembre de 2009 comenzó a cerrar el paso a coches, para convertirla en el acceso peatonal que une Zócalo y Alameda.

"En este mes de enero se iniciarán las obras para renivelar la calle, se instalarán bancas, se crearán zonas de sombra y se colocarán árboles y macetas; para ellos se invertirán entre 15 y 20 millones de pesos [...] Luego del cierre de esta vía los fines de semana, el $80 \%$ de las personas que hemos monitoreado están de acuerdo con esta medida." (Titular de SEDUVI en kmcero, enero, 2010:7)

Desde esta perspectiva, el cambio en la calle Francisco I. Madero fue gradual y contó con el apoyo de la ciudadanía, aunque no presentan la metodología para dar estos resultados. La obra de esta calle comenzó en junio de 2010, por ella transitan (Fuente Fideicomiso del $\mathrm{CH}$ en kmcero, febrero, 2011: 4) unas 200 mil personas al día. Por 
lo tanto, es uno de los corredores peatonales ${ }^{9}$ con más visitas.

"La intervención del corredor peatonal Francisco I. Madero, responde a su condición de espacio público emblemático para los habitantes de la Ciudad de México: por su valor histórico y arquitectónico, comercial, de entretenimiento, de encuentro y de movilidad. Madero destaca como eje articulador de tres espacios urbanos simbólicos para la convivencia social: Plaza de la Constitución, la explanada del Palacio de Bellas Artes y la Alameda Central, y en el circuito de calles peatonales ya existentes en el Centro Histórico como el corredor cultural Regina, Motolinía, Gante, Filomeno Mata, Talavera, Alhóndiga y Santísima." (Secretaría de Desarrollo Urbano y Vivienda. Subdirección de Imagen Institucional y Difusión, 18 de octubre de 2010).

El costo total de este corredor es de 30 millones de pesos (kmcero, febrero, 2011: 6), cuenta con 35 monumentos históricos catalogados por el INAH y tiene intersecciones con otras calles peatonales, lo cual genera flujo de personas de manera constante.

"Se inaugura el corredor peatonal Francisco I. Madero. Las obras de acondicionamiento forman parte de la política de recuperación y regeneración de espacios públicos del gobierno de la ciudad. El acondicionamiento del corredor incluyó un proyecto urbano, paisajístico y de movilidad para todo tipo de peatón." (Secretaría de Desarrollo Urbano y Vivienda. Subdirección de Imagen Institucional y Difusión, 18 de octubre de 2010).

Así que, desde esta perspectiva, el corredor Madero forma parte fundamental de la recuperación del $\mathrm{CH}$, ya que uno de los ejes del Plan Estratégico es la recuperación y creación de espacios públicos, que como explica el mismo documento:

"Las medidas de acondicionamiento de este corredor forman parte de la política de recuperación y creación de espacios públicos que el Gobierno del Distrito Federal, a través de la SEDUVI y la Autoridad del Espacio Público, impulsa para ofrecer mayor calidad de vida a los capitalinos. Estas acciones fueron asumidas, el año pasado, por el gobierno de la ciudad en el marco de la celebración del Día del Peatón: espacios peatonales como espacios públicos y el caminar como medio de

\footnotetext{
${ }^{9}$ En la revista Kmcero, editada por el Fideicomiso del $\mathrm{CH}$ denominan la calle de Madero como corredor peatonal, pese a tener 35 monumentos catalogados históricos por el INAH. En cambio, el Corredor Cultural Regina tiene 18 monumentos, pero lo catalogan como cultural. La distinción entre ambos corredores es: Si, en Regina hay eventos todo el tiempo, hicimos obras de teatro, conciertos adentro y afuera de Regina Coelli, tenemos intervenciones, performances, si hay una diferencia. En Madero, tú dime, tú lo ves, en Madero no hay manera. ¿Qué pasa? No sé cómo se determina, si las valoraciones las hizo espacio público (SEDUVI). Sin embargo, el centro era, Madero es la entrada natural y es la calle que todo el mundo conoce, hubo un momento en que era un peligro la convivencia de los vehículos con los peatones que se bajaban de la banqueta, calculan que por lo menos se han triplicado los peatones en esta calle. (Entrevista con Anabelí Contreras, Jefa de Unidad de Difusión del Fideicomiso del CH, 15 de abril de 2011). La distinción entre ambos corredores es porque Regina tiene condiciones para que se realizan eventos culturales. En cambio, en Madero, por la cantidad de gente que va diariamente no se pueden llevar a cabo estos eventos. Retomando lo presentado en el capítulo sobre $\mathrm{CH}$ del DF, también podría deberse a que Regina tiene uso habitacional, por lo tanto, es "cultural" y Madero es considerado comercial, debido a su vocación inicial y actual.
} 
transporte." (Secretaría de Desarrollo Urbano y Vivienda. Subdirección de Imagen Institucional y Difusión, 18 de octubre de 2010).

\section{a) Acciones y posturas en torno a la peatonalización.}

Esta calle responde a necesidades de dar mejores servicios a la ciudadanía, generando espacios públicos donde el peatón se sienta seguro, disfrute de su tiempo libre y de la caminata diaria por esta calle. Sin embargo, los resultados de la peatonalización de Madero no han sido tan favorables para las personas que trabajan en dicha calle, como lo mencionaron algunos de los entrevistados. Una de las grandes críticas a esta calle, lo cual parece que no fue planeado en el proyecto inicial, es la inmensa cantidad de gente que transita por ella:

"Si fue un éxito y era necesario, nos muestra que la gente si disfruta que sea peatonal, que si se utiliza, que si es viable, que si quita unos problemas, genera otros, pero hay que aprender a lidiar, hay que echarle imaginación, experiencia para encontrar las maneras de solucionarlos, pero creo que es un éxito, creo que si nos muestra que hacen falta más espacios así. No se ha desbordado, lo que muestra es que por ahí va, lo que necesitamos hacer es otras peatonales para dar otras centralidades al mismo centro." (Entrevista con Anabelí Contreras, Jefa de Unidad de Difusión del Fideicomiso del CH, 15 de abril de 2011)

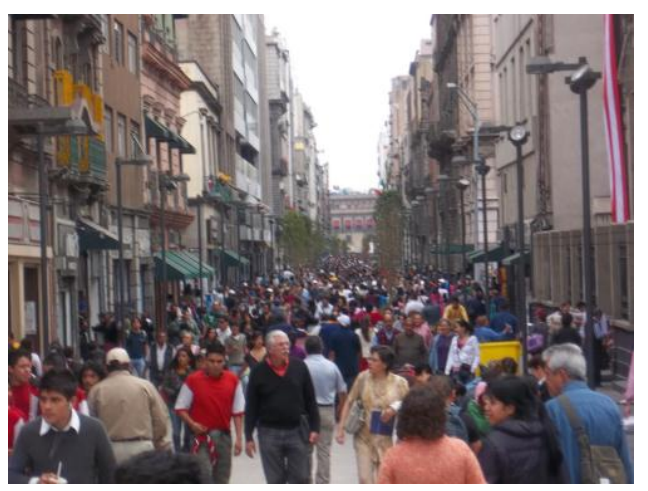

Paseo dominical en Madero.

Fuente propia. Febrero 2011

La afluencia a la calle Madero es evidente, a la hora y día de la semana que vayamos. podemos encontrar ríos de gente caminando, sentada, comprando, gozando del espacio público. Sin embargo, para algunos locatarios, la peatonalización de la calle no ha ayudado a que mejoren sus ventas o visitas a sus locales. Sobre las ventas a raíz de la peatonalización expresó un locatario: En parte no, por los clientes que teníamos. Digamos, venían, se bajaban y el carro daba vueltas. Ahorita como ven que está cerrada Madero pues creen que es muy complicado el acceso. Más aparte porque no hay suficientes estacionamientos [...] digamos nuestros clientes que teníamos, casi ya no vienen. (Entrevista con Víctor Romero, encargado de local, 20 de enero de 2011). Como lo presenta Víctor, la afluencia a la calle no significa que las ventas hayan aumentado, ya que, para el tipo de productos que ofrece la tienda (religioso), las piezas, estatuillas, etc., son complicadas de comprar si no se llega en 
coche a la puerta de la tienda.

Los locatarios entrevistados expresan que las ventas no han aumentado, pero lo que si ha crecido es la cantidad de gente que transita diariamente por la calle, aunque para ellos no representa que tengan mayor número de compradores: El que hayan hecho la calle peatonal no nos ha traído cambios económicos, pero es un cambio. (Entrevista con Salomón Masliah, dueño de varios locales, 16 de marzo de 2011). Salomón tiene una heladería Santa Clara, una frutería llamada Di Frutetto y en marzo de este año abrió otra heladería en la misma calle, sin embargo, él dice que las ventas no han aumentado. A lo que Ricardo Jaral agregó en entrevista: Ya abrió otra sucursal a otra cuadra, y son del mismo, porque desde la primera semana que se abrió Madero, la primera tienda se convirtió en la tienda con más ventas de la República Mexicana y desde ese día hasta hoy, no ha bajado del ler lugar. (Entrevista con arquitecto Ricardo Jaral, Coordinador Ejecutivo de Conservación del espacio público, Autoridad del CH, 5 de abril de 2011). No es motivo de esta investigación el saber si aumentaron las ventas en los locales de la calle Madero. Sin embargo, existen contradicciones entre lo presentado por los locatarios y los funcionarios, así que podríamos pensar que su percepción sobre las ventas no es tan veraz. En el Palacio de Iturbide me dijeron lo mismo, la afluencia no ha aumentado desde que se hizo peatonal la calle: La banqueta hacía que la gente circulara por la banqueta y hacía que pudieras entrar, tener una accesibilidad más directa con la banqueta, al no tener banqueta el público pasa de largo. Es un efecto contrario al que se piensa y al que la gente ve. (Entrevista con Gilberto Ramírez, Comunicación Interna en Fomento Cultural Banamex, 25 de abril de 2011). Lo presentado por Gilberto Ramírez muestra lo mismo que lo expresado por algunos locatarios, donde la gran cantidad de gente que transita por la calle no tiene como consecuencia la afluencia a sus locales o museo. Cabe aclarar que, no todos consideran que la calle peatonal haya repercutido negativamente en sus lugares de trabajo, ya que Sergio Ortiz (Museo del Estanquillo) si aplaude la iniciativa, considera que va más gente al museo, se volvieron más visibles ante el público, aunque la masa que camina día a día por la calle si llega a molestarlo. 
Otros elementos derivados de la peatonalización son la limpieza y seguridad. Sobre la limpieza, la dependencia encargada es la Autoridad del $\mathrm{CH}$, por medio de la Coordinación Ejecutiva de Conservación del Espacio Público:

"En Madero hay 12 personas por turno. En 5 de mayo, 16 de septiembre, en otras calles tenemos instaladas papeleras a cada determinado espacio. En Madero decidimos quitar las papeleras, generamos un refuerzo con personal, con sus contenedores, todo el tiempo tenemos atención, de tal suerte que si caminas por la calle de Madero siempre vas a encontrar donde depositar basura y una persona haciendo el barrido." (Entrevista con el arquitecto Ricardo Jaral, Coordinador Ejecutivo de Conservación del espacio público, Autoridad del $\mathrm{CH}, 5$ de abril de 2011).

Así que, la peatonalización de Madero también implica generar nuevas estrategias para atender las demandas ciudadanas, una de ellas es la basura. El colocar contenedores en lugar de papeleras para la basura, genera, para el arquitecto y Noemí Ortega (mujer que barre uno de los tramos de Madero) que la gente adquiriera mayor conciencia o vergüenza para tirar la basura. El tener contenedores y el ojo vigilante de las personas de intendencia ha generado una calle limpia, con mayor respeto. Sin embargo, también se han enfrentado con conflictos como los provocados por los chicles en la calle, ya que el pavimento colocado en ésta no sirve para disimular las huellas dejadas por los innumerables chicles tirados y pisados. Sin embargo, para algunos locatarios o trabajadores, el tener contenedores y limpieza extrema no es lo mejor, lo es mientras se siga haciendo, pero surge el temor de ¿Qué ocurrirá con la limpieza cuando Madero se convierta en una calle más del $\mathrm{CH}$ ? Ahora goza con un sinfín de acciones especializadas, para generar mayor seguridad y atractivo, pero en algún momento llegará a convertirse en una calle más del $\mathrm{CH}$ (comentan en entrevista).

Otro elemento que cambia la visión y estética de Madero es la seguridad en cada rincón de la calle. La presencia policíaca genera una sensación de tranquilidad (poco común en nuestra metrópoli). A este respecto, existen diferentes sectores policíacos que se encargan de vigilar esta calle, el oficial en jefe de uno de los sectores me dijo en entrevista:

"Con el paso peatonal de Madero: cero ambulantaje, nada de ambulantaje. Por eso es que esta calle está muy bien vigilada para evitar todo tipo de labores de ese tipo de personas. El problema que enfrentamos aquí es que llegan personas que no quieren cumplir las normas, la normatividad del Programa de Seguridad, en el caso del ambulantaje. Pero graves problemas hasta ahorita no ha habido." 
(Entrevista con Segundo Oficial Rubén Mazariegos, Policía Auxiliar del DF, 28 de enero de 2011).

Es necesario destacar, por lo presentado en la entrevista, que uno de los mayores riesgos y que necesita control extremo es que regrese el ambulantaje a esta calle, eso es lo que se vigila en ella. El oficial me comentó en la entrevista que no había ningún asalto en la calle, por lo menos desde octubre a enero, pero lo que era necesario vigilar era que no llegara el ambulantaje a ocupar este espacio. Si bien, no existe ambulantaje colocado en esta calle, si hay indicios de éste, como lo es la Asociación PRO- DIANA A.C, dirigida por Diana Barrios (Hija de Alejandra Barrios- líder de ambulantes en el CH-). Dicha asociación tiene sus oficinas en el Pasaje Pimentel (en la calle Francisco I. Madero) y cuenta con el control sobre el uso del espacio público en esta calle. Esta A.C es uno de los actores implicados en el conflicto por el uso de la calle.

Después de expuesto lo anterior, es importante mencionar que los cambios sufridos en la calle Madero a raíz de su peatonalización han generado diferentes percepciones: de agrado, molestia y crítica hacia las decisiones tomadas. Para unos, genera un paseo agradable y seguro con la familia y amigos (como lo comentaron los visitantes en entrevista), para otros, es tal la cantidad de gente y los pocos beneficios para sus ventas, que preferían que fuera vehicular. Otros critican el tipo de comercios en la calle, porque no representan del todo a una calle mexicana, no hay tiendas de artesanías, ni de productos mexicanos: Es lo más triste y con lo que no estoy de acuerdo, que según sea, quieran hacer algo de cultura y yo no veo la cultura mexicana. (Entrevista con Gladys, "Sacerdotisa mexica", estatua humana, 19 de enero de 2011). Lo presentado por Gladys y algunos visitantes también es una realidad, aunque para la mayoría, la calle cumple cabalmente con lo que necesitan: comercio, entretenimiento, seguridad, limpieza y disfrute. Algunos quieren más bancas, otro tipo de piso o de luminarias. Pero el tema de esta investigación no ahondará más en estas aristas sino en el conflicto suscitado entre artistas callejeros, autoridades, asociación PRO- DIANA A.C por el uso del espacio público, que podría convertirse en el gran escenario de expresiones artísticas, pero que ha tenido un sinfín de inconvenientes a lo largo de estos años, sobre todo desde que se hizo peatonal la calle. 


\subsection{La lucha por el espacio público desde el arte en la calle Francisco I. Madero.}

La calle Madero, cuenta con arquitectura barroca, neoclásica, virreinal, moderna, etc., edificios de gran importancia e historia ligada al desarrollo de nuestro país. Sin embargo, esta calle no solamente tiene edificios, también nos encontramos con artistas callejeros (como ellos se definen), los cuales buscan despertar alguna emoción en los transeúntes y recabar una moneda como forma de vida. Por lo tanto, deberían de estar incluidos en las políticas culturales de este espacio emblemático e identitario de la ciudad de México.

Como lo presenté en el capítulo anterior, el arte público genera sinergias en la sociedad, disfrute del tiempo libre, reapropiación de la ciudad, etc. Sin embargo, el arte público callejero cuenta con problemas para expresarse en Madero, quizá porque como menciona García Canclini (2004) Lo público es el lugar imaginario donde quisiéramos conjurar o controlar el riesgo de que todo esté permitido (García Canclini, 2004: 15), aunque como mencionan Borja y Muxi (2000) y el mismo García Canclini, si existe una dimensión jurídica en el espacio público. Si lo público es donde no se encuentra Dios ${ }^{10}$, no hay tantas restricciones, por lo tanto, nos encontramos ante espacios que denotan libertad, pero también ciudadanía, donde el miedo, violencia, inseguridad se desdibujan o se critican, pero se puede hacer en el ámbito público y no solamente desde nuestras trincheras en casa o trabajo.

Desde esta perspectiva, el espacio público, tiene reglas, pero es el espacio de la libertad de expresión, por ejemplo, las manifestaciones, el espacio público es reapropiado, regenerado, revivido y resignificado por los habitantes de la ciudad. De esta forma, el espacio es transformado (simbólicamente) y éste a su vez modifica a los habitantes.

Como lo presenté en el capitulo anterior, el arte expresado en las calles no es un fenómeno aislado, sino forma parte de la tradición de los juglares, etruscos, etc. Sin embargo, en la actualidad, en la calle Francisco I. Madero la lucha por el espacio se ha convertido en conflictos políticos, internos y económicos, pero donde el arte busca resistir ante los embates.

\footnotetext{
${ }^{10}$ Como expresa García Canclini (2004: 15)
} 
En la calle de estudio, existen alrededor de 30 artistas callejeros: entre músicos, estatuas, personajes y botargas ${ }^{11}$, nos sorprenden a cada paso por esta calle, se encuentran como testigos de la historia a pie de calle, forman parte del paisaje en Madero, de los paseos dominicales de las familias, pero también se encuentran fuera de toda norma en el $\mathrm{CH}$, lo cual complica la realización honrada de sus actividades. Por lo

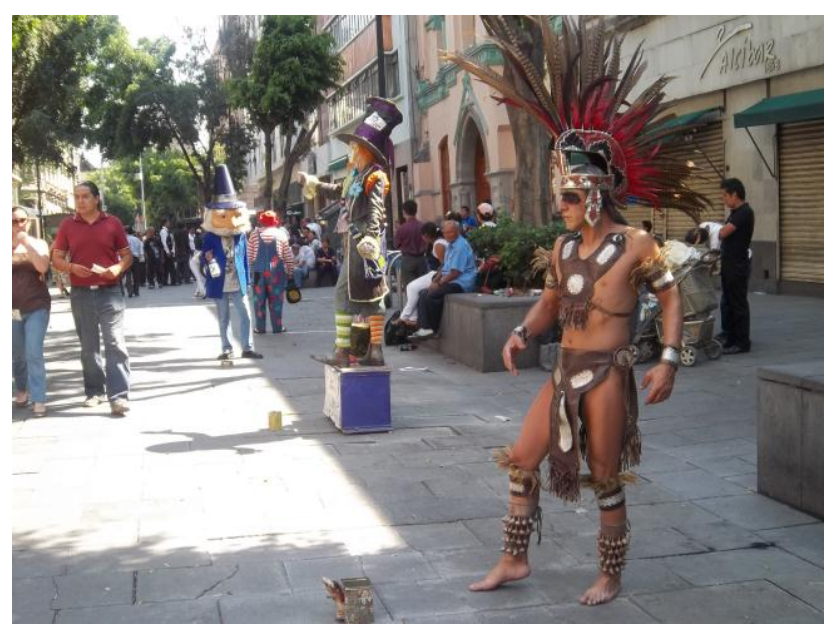
tanto, decidí darles voz a estas personas que sin decir palabra nos entretienen cada día. Su voz es la realidad de diferentes conflictos vividos en el espacio público del $\mathrm{CH}$ y dentro del gremio artístico. Sus palabras son diversas y tienen varias aristas de análisis, pero el conflicto por el espacio público es la temática que me interesa, donde las políticas urbanas, parece que dejan de lado el derecho a la cultura. Si bien, existen museos en esta calle, ¿Por qué no apoyar las manifestaciones artísticas callejeras? Es un tema que intentaré presentar, para así escuchar la voz de los artistas, de esas manos que sin hablar dicen más que mil palabras, de esas máscaras que cubren el rostro y donde la mirada nos muestra la riqueza artística. Estas son sus voces ante las dificultades vividas en la calle de estudio y en otras calles del $\mathrm{CH}$. Quiero aclarar que no solamente tengo la versión de los artistas, sino de las instituciones responsables de la regulación en este espacio.

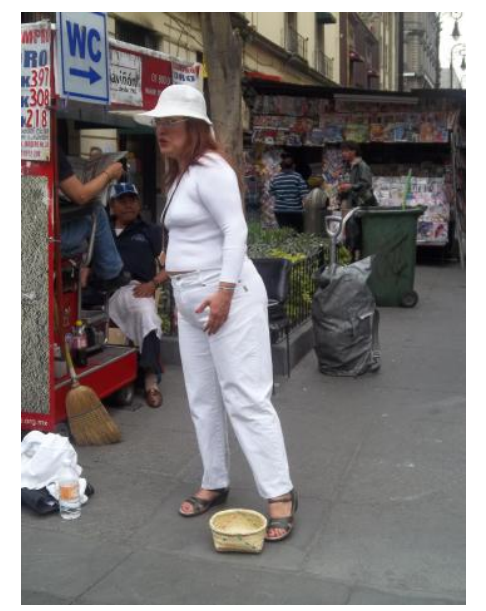

¿Qué ofrece el arte en esta calle?

“[Su objetivo es] El sorprender al público que no está en esa frecuencia de venir, a ver un espectáculo. La calle es un sueño, cuando de repente tú estás soñando unas cosas y entras a otra ¿Cómo ya estoy en otra cosa? Pues porque el artista urbano ya te metió a su frecuencia, de su rollo." (Entrevista con Ana de Alba, cantante de ópera, 20 de enero de 2011)

Ana de Alba "Cantante de ópera"

Fuente propia. México, Marzo de 2011

\footnotetext{
${ }^{11}$ Decidí no trabajar con botargas, porque desde la perspectiva del arte público, éstas no cumplen con los mínimos lineamientos, como la expresividad o creatividad.
} 
Lo referido por Ana, que estudió la Licenciatura en Canto con especialidad en Jazz y que dos o tres veces a la semana se coloca sobre Motolinia y canta música popular es un ejemplo de la riqueza encontrada en un escenario como esta calle, donde no solamente importa ganarse unas monedas, sino el goce de encontrarse ante diversos públicos, en un espacio que no ha sido creado para representaciones artísticas. Ana, al igual que la Sacerdotisa y otros entrevistados tienen poco tiempo de colocarse en la calle Francisco I. Madero. Sin embargo, para los veteranos, la cantidad de gente que se ha comenzado a colocar en la calle también genera conflictos internos, los cuales no pueden ser regulados dentro, ni fuera del gremio. Así que, nos encontramos con dos problemas: luchas internas y por el uso del espacio público.

\section{a) La necesidad y el arte confluyen en Madero.}

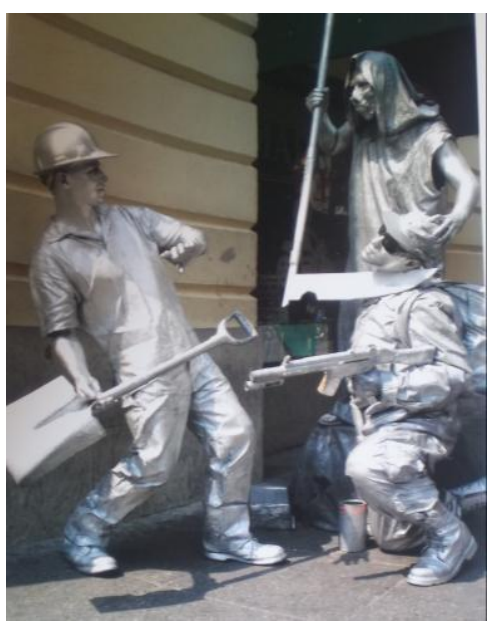

"La Muerte", "El obrero" y "El Soldado"

Foto entregada por ellos. México. Marzo de 2011

El arte callejero en el $\mathrm{CH}$ data de alrededor de 10 a 15 años, no se sabe con claridad quién fue el primero en encontrar en estas calles el escenario para sus propuestas artísticas. No es motivo de esta investigación conocer a detalle los inicios de estas actividades en este espacio, sin embargo, para futuras investigaciones podría ser contemplado este aspecto. Para realizar esta tesis me interesaba el origen, pero no sólo histórico sino personal de cada uno de los entrevistados, ¿Cómo decidieron presentarse en las calles del $\mathrm{CH}$ ? Es una pregunta amplia y tiene un sinfín de respuestas: como la necesidad económica, la cual es una realidad ante la falta de empleo, pero también es la libertad que esta actividad genera. No contar con patrón, rutina de trabajo clara, ya que cada día, a cada momento el público cambia y las reacciones también cambian.

Como he presentado a lo largo de esta investigación, en su mayoría, los artistas callejeros de Madero no cuentan con preparación formal en arte, así que es interesante preguntarse ¿Cómo se sintetizan la necesidad económica y el arte callejero? Ya que si no cuentan con preparación previa (la mayoría) podrían dedicarse a otro tipo de 
actividades. Sin embargo, encontraron en el arte callejero una forma de expresión auténtica, donde los límites creativos son propios, los horarios son moldeables y la retroalimentación es constante, esta es su historia.

En el siguiente apartado comenzaré a plantear la lucha constante por el espacio en las calles del $\mathrm{CH}$, pero también tienen un reto constante por presentar espectáculos con calidad, sencillos, ya que los recursos no sobran, pero la creatividad los desborda. Las calles del $\mathrm{CH}$ han sido testigos de manifestaciones, entradas triunfales, etc., pero también lo han sido del trabajo de estos artistas, que por medio de sus expresiones nos recuerdan que existen, que el arte está en todos lados y que la moneda que les entreguemos genera una retroalimentación vital para ellos. Así que la necesidad y el arte se encuentran en estas calles, de paseos para unos, de trabajo para otros, con museos, edificios inmaculados y los artistas públicos como cronistas de nuestras calles, observan y se mueven pausadamente esperando acaparar nuestra atención.

El convertirse en artista callejero no ha sido una decisión sencilla para ellos. Algunos, los menos. vienen de presentarse en foros establecidos, como Ana de Alba "Cantante de ópera" y "Watt". Así que la calle se convirtió en un recurso económico y de expresión que los recintos especializados no contemplan. Los requisitos para ser artista callejero son muchos, pero se pueden abreviar como lo comentó Eduardo Álvarez "Teatrero, malabarista":

"Primero, huevos, una honestidad a toda prueba, le vas a hablar al niño, a la niña, al anciano, al oficinista, al burócrata, a todos con el mismo discurso y va a ser tan flexible que todos te van a entender, todos se pueden constituir en un público. Necesitas honestidad y una tremenda exigencia física de soportar el esfuerzo, sin comer, sin ir al baño, a veces sin poderte sentar. Se necesita mucha honestidad, primero muchos huevos, segundo mucha honestidad para no discriminar como Bellas Artes, que el que puede pagar entra. Como artista callejero no haces eso, como artista estás obligado a conocer sus fundamentos, asimilarlos, usarlos para crecer y amor por el oficio." (Entrevista con Eduardo Álvarez, "Teatrero, malabarista", 28 de enero de 2011)

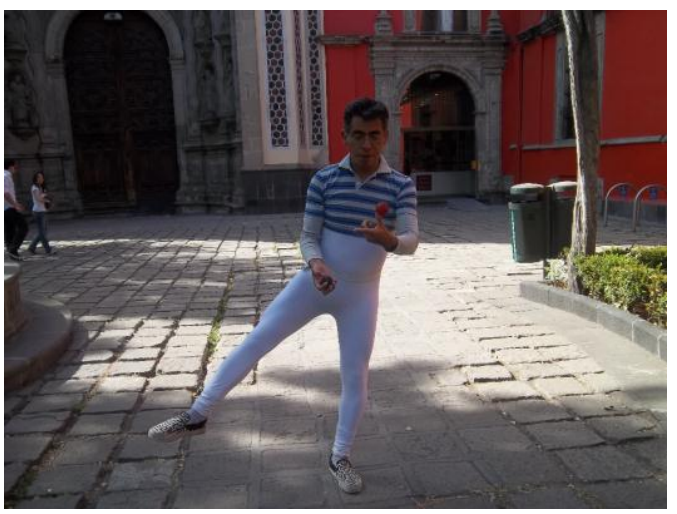

Como lo menciona Eduardo y todos coinciden, se necesita gran valor para presentarse en la calle, que como mencioné en el capítulo anterior, se convierte en el escenario de sus 
representaciones, pero estar parado en ella y ante el público es un reto personal y profesional. El contar con preparación para realizar sus actividades debería ser un requisito, aunque no todos lo cumplen, se dice en la calle, que aunque no todos lo sepan, se han hecho frente al público, éste los pule.

La variedad artística en esta calle es extensa, así que presentaré elementos importantes de algunos personajes. Son hombres y mujeres que están de pie alrededor de 7 horas al día, utilizan pintura, barro o cualquier otro material que nos transporte al estatuismo, que nos haga olvidar por un momento que son seres humanos. De esta manera nos encontramos con personajes que representan no sólo la cultura mexicana o los valores de nuestro país, sino héroes de cine o caricaturas.

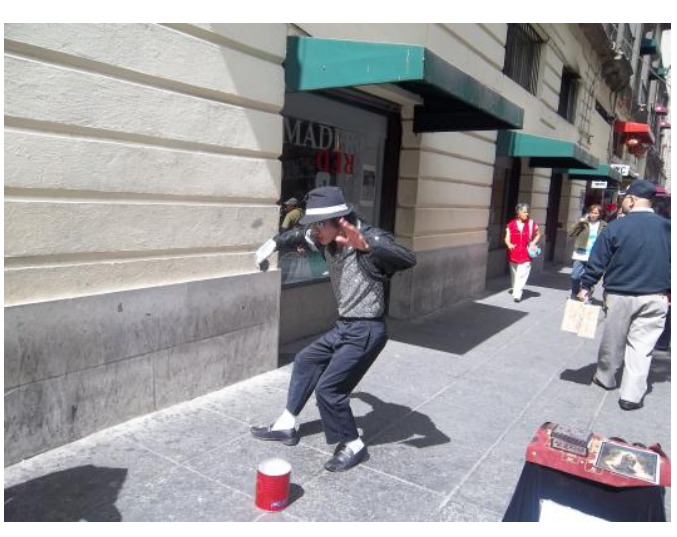

Quiero aclarar que no tuve contacto con las personas que utilizan personajes televisivos, a excepción de Abraham, quien se disfraza de "Batman", pero es pieza clave en las relaciones de esta calle, ya que es considerado como uno de los más antiguos en el $\mathrm{CH}$. Otro personaje con base en la televisión y las majors es Sergio, quien se viste cada fin de semana de "Michael Jackson", estatua que baila al colocarle una moneda en su bote, para él es entretenimiento popular (Entrevista con Sergio Sierra, "Michael Jackson", personaje, 23 de enero de 2011) y le gusta hacerlo porque no se aburre, siempre ve gente diferente. La calle da esa libertad creativa, genera intercambios constantes con el público, el cual no está en la sintonía de ver un espectáculo en la calle y mucho menos con estas características, sin grandes distancias entre espectador y artista, sin telones y sin tramoya, ni maquillistas, solamente la creatividad del artista que busca comunicarse con el espectador.

Los personajes de esta calle son diversos, comenzando por "Watt", quien nos recibe desde las escaleras del Edificio del Banco de México, que desde su trinchera hace arte para todo público, jugando con las cadenas, con su personaje y con su realidad en este 
espacio. Atemoriza a algunos por su imagen agresiva y la voz en su megáfono, pero cuando la gente pasa lo escuchan. El uso de la calle como escenario, le da a "Watt" la posibilidad de tener mayor alcance, que más gente lo escuche en un contexto que no es el ideal, pero que es la real. Su personaje busca algo en la vida, un muñeco que trae en la mano, pero mientras recorre el camino del autoconocimiento para encontrarlo y encontrarse recita a Zaratustra, Diógenes, etc.:

"Saqué elementos del personaje de una novela de Samuel Beckett que también se llama Watt. Samuel Beckett de teatro del absurdo y de teatro del absurdo toda su escritura. El personaje busca algo, algo en la vida, no sabe qué busca, sin embargo, lo tiene en la mano: los muñecos. Ha ido evolucionando mi personaje y en lo que busca algo, es un juglar. Más que nada es un juglar, si está difícil de definirlo, por la vestimenta que tiene algo de surrealista, expresionista, como se le pueda etiquetar. La vestimenta que saqué de una exposición de Leonora Carrington." (Entrevista con Mario Peña, "Watt", performance- estatua viviente, 25 de enero de 2011)

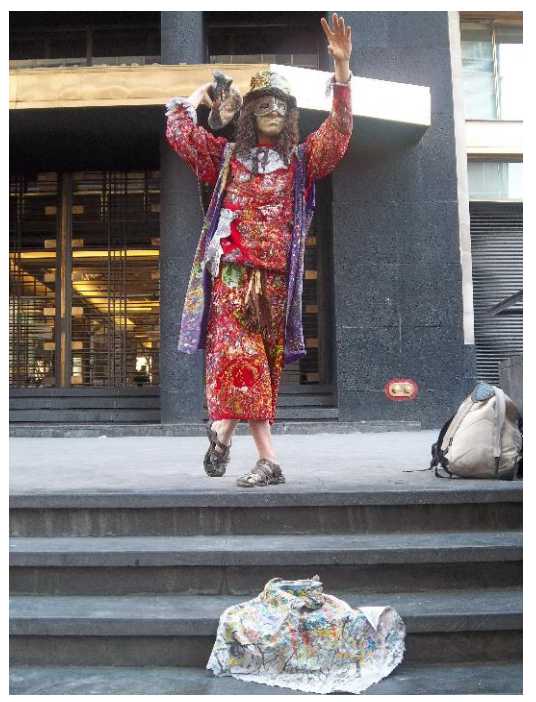

"Watt" nos recibe con música, declamando o como estatua, ya que él considera que no es solamente estatua, sino performancero. Su ruta artística comenzó en Guadalajara, donde estudió teatro por un año y se presentó en algunos foros de esa ciudad. Sin embargo, se dio cuenta que necesitaba mayor libertad creativa, el autoconocimiento lo llevó a reconocer en la calle el gran escenario de sus personajes, donde no hay reglas sobre su interpretación, ni se reservan el derecho de admisión:

"No creo que sea para una torre de cristal [refiriéndose al arte], creo que es para la calle y con el tiempo lo he ido construyendo, como que es para la calle, para la casa, para los espacios que se pueden comunicar, interpretar y alimentar mutuamente. Lo cual ha requerido para mi un gran tiempo, más qué entender cómo transmitir a la gente, llegar a la conclusión, para mi, y después poder transmitírselo a los demás." (Entrevista con Mario Peña, "Watt", performanceestatua viviente, 25 de enero de 2011)

Como "Watt", Eduardo y otros, encontraron en la calle el escenario para expresarse, como dice Eduardo, busco comunicar la verdad del cuerpo. (Eduardo Álvarez, “Teatrero, malabarista", 28 de enero de 2011). La verdad del arte es compleja e 
individual, la estética y los mensajes son variados, pero es una constante el tener comunicación. Por lo tanto, la calle se convierte en el medio de comunicación de estos y muchos artistas, que no han encontrado apertura en los foros especializados, que necesitan mayor libertad creativa o que con unas monedas en su bote pueden administrar su tiempo y actividades de manera autónoma. Si, la necesidad también importa, no lo discuto. Sin embargo, me sigo preguntando, ¿Cómo personas de tan diversos sectores sociales y académicos encuentran en el arte en las calles el medio de vida? Entiendo que las necesidades económicas son elementos fundamentales, pero ¿Cómo el arte provee de una vida honrada a estos artistas? Es una incógnita que no puedo responder, quizá por la creatividad inherente en ellos, por la libertad individual que genera esta actividad, por el gusto de ser vistos, aplaudidos y reconocidos, son sólo algunas respuestas iniciales. Aclaro el término vida honrada, ya que como Ana de Alba me comentó: Aquí hay como 2 ó 3 niños que vienen de estatuas y vienen de la calle, que me parece mиy bueno que algunos chavos los han estado asesorando para que trabajen. (Entrevista con Ana de Alba, Cantante de ópera, 20 de enero de 2011). No me consta que fueran niños de la calle, pero en este gran gremio saben el origen y calidad de cada uno, así que no lo dudo. La calle no es sólo el escenario de los pobres, como muchos artistas de renombre argumentan, sino también un espacio de rehabilitación para personas que no han encontrado cabida en otros sectores, pero que encuentran en el arte una forma honrada de ganar una moneda, lo cual aplaudo sin dudarlo. A lo que "Watt" agrega:

"El uso que se le da a los espacios por parte de la autoridad para que sean para el arte, ¿Qué quieren a cirqueros o a sicarios? Es mejor que tengan la ciudad llena de cirqueros que de sicarios, [subrayado mío] por ese punto digo, que se pongan todos estos chavos, no tienen preparación, pero que hagan esto en lugar de ir a asaltar o hacer algo así, porque varios si que andaban en esos pasos, yo los conozco y que bueno que ya anden acá." (Entrevista con Mario Peña, "Watt", performance- estatua viviente, 25 de enero de 2011)

El argumento de "Watt" y la "Cantante de ópera" nos muestran que el arte también es un medio para cambiar la vida de mucha gente, no solamente es el mensaje hacia el público, sino el encontrar en el arte una forma de vida honrada en medio de las crisis políticas, económicas e ideológicas en nuestro país. Aunque nunca supe quiénes eran los chavos de la calle o los asaltantes, yo conocí a un sin número de artistas callejeros con propuestas estéticas y laborales, que se mataban trabajando hasta 8 horas al día para 
ganarse una moneda honradamente, por lo tanto, la calle y el arte en ella, no cuenta con tantas restricciones académicas y esto provoca una regeneración en muchos chicos, dotando al tejido social de personas productivas y creativas que buscan esforzarse para ganarse el dinero de la manera más honesta que han encontrado. Sin embargo, la calle tampoco es el escenario que demerita la labor, como lo expresó Ana de Alba:

"El hecho de que estés en la calle no quiere decir que estés como pordiosero, mal presentado. Estás presentando arte, eres un artista, tienes la dignidad de un artista y la seriedad, aunque digan lo que digan. Aunque estemos en la calle, es mucho más difícil que cualquier foro. Yo que he trabajado en tantos foros, incluso mundialmente. La calle no se compara, o sea, es una experiencia fuera de serie [...] Es que es sorprendente, es un foro muy especial, tú sorprendes a la gente, la gente no tiene pensado entrar a verte y escucharte como en un concierto. Entonces, te paras y vas al Zócalo, vas pensando en todas tus broncas y de repente ves a una persona cantando o a alguien vestido de algo y dices "no puede ser, ¿qué significa?" (Entrevista con Ana de Alba, "Cantante de ópera," 20 de enero de 2011)

El considerar que el arte callejero es menor o que este gran escenario sea menos que un foro es un error terrible, en el cual se cae bastante, por lo menos eso me comentaron los entrevistados, y que los llegan a considerar limosneros, cuando lo que hacen es mayor esfuerzo que muchas otras actividades. Noviel y Ocaña (en Celdrán, 2010) mencionan que una estatua humana que dura dos horas inmóvil tiene un desgaste físico equivalente a correr seis kilómetros. Así que el estatuismo y las actividades artísticas callejeras requieren de gran formación para controlar el cuerpo, las vicisitudes de la calle, ataques del público o autoridades, por lo que, tienen todo, menos ser limosneros, ya que realizan un gran esfuerzo físico para poder llamar la atención y la reflexión de la gente, la cual no está preparada para ver un espectáculo como este en la calle, por lo tanto, su reto es todavía mayor, el desgaste físico es innegable, el clima, ruido, polvo, son algunos elementos que dificultan su ejecución y con los cuales luchan día a día, además de agentes externos como falta de reconocimiento, cerrazón por parte de algunas autoridades, falta de legislación, etc.

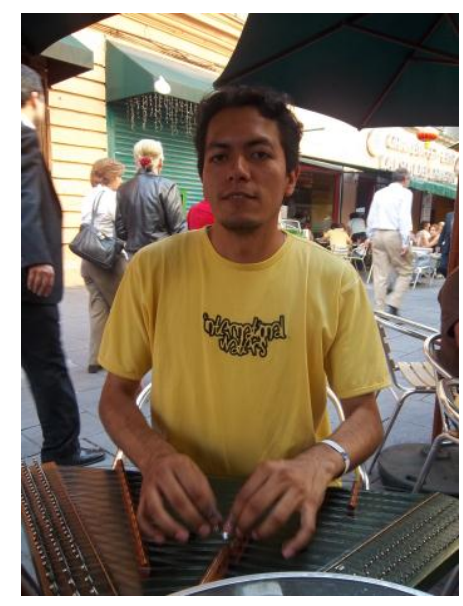

Celdrán, 2010 agrega: se incorporan actualmente como recurso transitorio una serie de artistas desorientados que salen de escuelas de arte dramático y buscan enriquecerse artísticamente en la variedad, vistosidad y calidad de estas 
manifestaciones. (Celdrán, 2010: 27). Así que, la calle no es solamente el escenario de las personas sin preparación profesional en el arte, sino es la forma de que artistas profesionales experimenten ante diversos públicos:

"Iba a estar en el Vive Latino con Liber Terán. Cuando anunciaron el Vive fuimos a Reactor a tocar a dúo y ahí me dí cuenta que me puse a temblar cañón. Entonces dije, pensé que ya no me iba a pasar mucho, me pasó en la estación y dije, me voy a ir a tocar a la calle. Si me sirvió, más bien lo que quería era vencer el miedo." (Entrevista con Esteban Balkan, Salterista, 28 de mayo de 2011)

Por lo tanto, la calle no es solamente el escenario para la gente más necesitada, sino el escenario ideal para músicos profesionales, los cuales quieren tener contacto directo con el público, en donde las reacciones son inmediatas, como el caso de Esteban, quien a pesar de ser músico profesional y teniendo en puerta el tocar ante 70 mil personas, decidió regresar a la esencia del arte, el público cercano. La retroalimentación generada en las calles es rica, como mencionó Esteban: Lo más impresionante es que de repente llega gente, se quedan y se van las demás personas, se quedan y después se acerca y me empieza a hablar, porque su tío tocaba el salterio o cosas así. (Entrevista con Esteban Balkan, Salterista, 28 de mayo de 2011). Por lo tanto, la calle no es sólo el escenario de los pobres, de los no profesionales, ni para un público poco exigente, también es la experimentación de artistas que encuentran en la calle el sitio de expresión. Esteban es un músico preparado que encontró en la calle la forma de enfrentar sus miedos y abarcar público inimaginable.

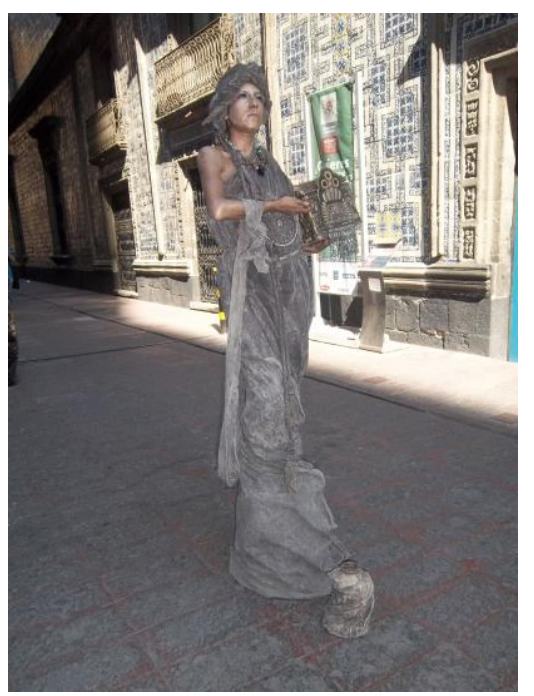

En esta calle también nos encontramos con la "Sacerdotisa Mexica" (conocida como Wicca, su nombre es Gladys) pasa alrededor de una hora pintando su piel con barro, se coloca su vestuario - una especie de túnica- y después de un par de horas (cuando no hay mucho sol) se coloca sobre una cubeta de pintura y haciendo equilibro se queda inmóvil por horas, hasta que cae una moneda y saca de su pequeño cofre una frase de autores mexicanos, su objetivo es: 
"Lo que quiero de la gente es fomentar un poco la lectura, cuando ellos se paren a verme yo les dé el papel, se pongan a leer después de que hayan recibido el papel o ahí mismo, pero que lean y que reconozcan algo de su cultura, que es la cultura azteca, la cultura mexica, porque creo que se les ha olvidado bastante. Lo que estamos haciendo, lo que yo estoy haciendo es regalar información para que la cultura no se pierda." (Entrevista con Gladys, "Sacerdotisa mexica", estatua viviente, 19 de enero de 2011)

La misión de la "Sacerdotisa mexica" se cumple al entregar los papeles, hay quienes los leen en voz alta o los casos raros de gente que regresa al cabo de un par de horas y le comenta algo sobre la frase que ella entregó, con lo cual se puede sentir satisfecho un artista, ya que está generando algo en su público. Las monedas que caen en su bote (después de 5 ó 6 horas) son su sustento, con eso se va a su casa a descansar para regresar el siguiente día a la esquina de Calle Condesa y Madero" ${ }^{12}$ La "Sacerdotisa mexica" también ha hecho malabares y artesanías, pero decidió trabajar en esta calle creando este personaje para recordar a la gente lo bella que es su cultura, intenta dar un mensaje a la gente para que no pierda sus raíces.

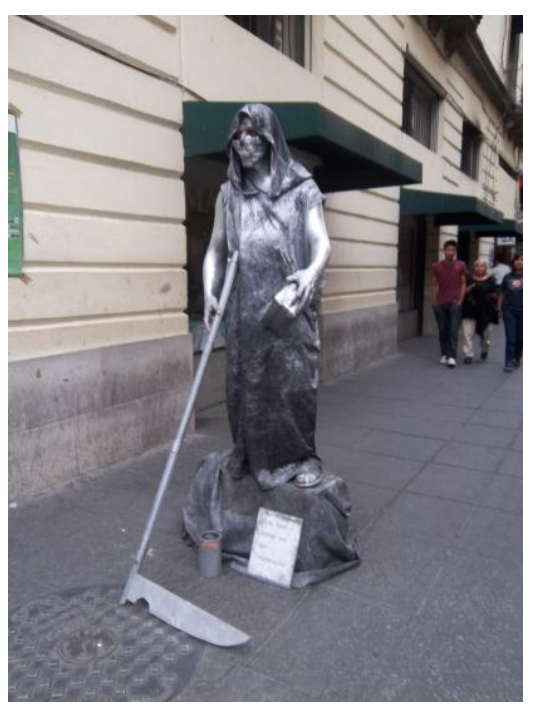

Otra estatua constante en sus presentaciones, ya que va todos los días a entretener al público y a ganarse una moneda con el sudor de su frente, dolor de espalda y el anonimato es Raúl Vázquez "La Muerte”. Él comenzó a colocarse en la Alameda hace cuatro años y su personaje lo hizo por el interés que genera en él y por la información que tenía de ella en otras culturas, como lo expresó:

"Si te das cuenta, desde tiempos ancestrales y no nada más en nuestra cultura, sino en todas las demás, hay como un ser de obscuridad para cualquiera. No podemos decir, como muchos dicen ahora: la muerte acaba de existir. Como por ejemplo, cuando lo catalogan de la Santa Muerte, yo siento que eso viene desde tiempos ancestrales, no es de ahorita. Me llamó la atención, porque es lo que te comentaba, jugar un poco con la psicología de la muerte. Más que nada me gusta ver la reacción en la cara de la gente y cómo reacciona al verme." (Entrevista con Raúl Vázquez, "La Muerte", estatua viviente, 23 de enero de 2011)

\footnotetext{
${ }^{12}$ Los lugares donde se colocan cambian, según lo marquen las autoridades y/o "coordinadores" de la calle.
} 
Para Raúl, este personaje que es estatua humana busca recrear en la gente una sensación: de placer, temor, miedo, dolor, alegría, etc., porque "La Muerte" representada por él no es triste, sino sorprendente. Cuando entra en personaje no parpadea, no mueve ni un dedo, pero cuando la gente se acerca, "La Muerte" cobra vida, así de paradójica es la vida y la muerte, es una representación divertida, donde las sonrisas están por todos lados, la gente no deja de reír y sorprenderse ante sus movimientos, que sin voz expresa más que mil palabras, ese es el reto de la estatua viviente, decir palabras sin hablar. "La Muerte" representada por Raúl es una de las estatuas más reconocidas en el gremio, lo aplaude el público y los colegas, que admiran la perseverancia que ha tenido, la mejoría estética de sus movimientos y el éxito que tiene con el público. Otro elemento que tiene "La Muerte" es dar pequeños papeles al público, en lo cuales están escritas frases sobre la vida, que según Raúl, sirven para que la gente se lleve una buena impresión de su actuación, la cual necesita mucho valor, el pararse durante 6 a 8 horas sobre una caja de refrescos y sorprender al público no es tarea fácil, mucho menos lo es el acoso de las autoridades, ni la falta de comprensión de una parte del público, ya que también considera que en ocasiones le faltan al respeto, colocándole piedras o rondanas en su bote, como una agresión hacia su actividad. Pero también recuerda que los mismos policías le han dicho: Yo prefiero que hagas esto a que andes robando. (Entrevista con Raúl Vázquez, "La Muerte”, 23 de enero de 2011). Así que el arte callejero, desde distintos sectores y con información de diferentes artistas es un medio de rehabilitación para muchos.

Respecto al público, Raúl me comentó: Es como dice una de las frases "La vida es como un espejo, si la miras sonriendo, te sonríe igual”. Hay gente que viene a divertirse con nosotros, para eso estamos, igual nos divertimos con ellos. (Entrevista con Raúl Vázquez, "La Muerte”, estatua viviente, 23 de enero de 2011), pero también el público los hace, para "La Muerte", el estar frente al público todos los días es lo que ha pulidos sus movimientos y los mensajes que quiere comunicar, que como he dicho, son escritos en papel, pero la expresión corporal ha ido madurando con los años y con las reacciones del espectador. Como me comentaron en entrevista algunos visitantes de la calle: Muy bien, entretenido. También está padre que te den un papelito, porque casi todos hacen una pose cuando te tomas la foto con ellos y él te da algo a cambio. Añadió 
interacción, la interacción es agradable. (Entrevista con visitantes, San Luis Potosí, 19 de abril de 2011). Es así como la vida de los artistas callejeros transita entre el reconocimiento, el aplauso, una moneda y las restricciones y falta de reconocimiento de las instituciones de Gobierno, que si bien, han tenido intentos de regularizar su situación, la realidad es otra y sufren de maltrato por parte de algunos sectores, todo por expresarse y ganarse una moneda de manera honrada.

Como ellos, existen alrededor de 30 estatuas y/o personajes ${ }^{13}$ en la calle de estudio. Ellos se quedan inmóviles ante las miradas, ante la lluvia, empujones y agresiones de todo tipo, lo hacen por arte, por dinero y por encontrar una forma de vida honrada. El arte en esta calle intenta crear una atmósfera de entretenimiento y reflexión para el público. Sin embargo, su labor no es sencilla, ni cuenta con el reconocimiento de una actividad artística, para algunos (como lo presenté con la cita de la entrevista de Ana de Alba), se considera que estas actividades son como pedir limosna, pero el esfuerzo, aplomo y disciplina que se requiere para ser artista callejero no es solamente colocar un bote para que la gente coopere, eso es lo más sencillo. El reto es constante, llamar la atención de la gente por medio de la expresión corporal, vestuario, sin emitir palabra, simplemente con el cuerpo como lienzo y generar sinergia con el público, transmitir mensajes sin hablar no es tarea fácil, mucho menos cuando se cuenta con el mayor escenario: la calle, que puede terminar por opacar al artista, por lo tanto, se requiere de preparación mental y física, así como gran valor para enfrentarse a la gente. El clima, viento, polvo, sol, lluvia son otros elementos que tienen en contra para sus manifestaciones artísticas. Otro problema, ante el cual se enfrentan día a día es la falta de reconocimiento y apoyo de las autoridades competentes en el $\mathrm{CH}$, que como presenté son variadas y actúan en coordinación constante, pero en ellas no se reconoce, ni legisla la actividad de estos artistas, quienes traen historias personales diversas y han encontrado en el arte la manera de que su creatividad aflore, la libertad laboral y de expresión que ansiaban. Esta es la historia de aquellos que sin palabras nos dicen mucho

\footnotetext{
${ }^{13}$ El número de artistas en esta calle no se sabe con claridad, no se puede constatar más que con la información que dan los entrevistados. En la categoría personajes entran: Michael Jackson, Batman y un sinfín de botargas que se colocan los fines de semana. En este documento no exploro el tema, pero causan gran conmoción a los artistas, ya que ponerse un disfraz del "Chavo del Ocho", no es considerado arte para ellos. No he tenido contacto para hacer entrevistas con las botargas, pero sé que las dirige la señora Alicia, y es motivo de uno de los tantos conflictos existentes en la calle.
} 
a todos los que transitamos por las calles del $\mathrm{CH}$, en particular la recién peatonalizada calle Madero.

\section{b) La calle como escenario y el cambio de coordenadas en el $\mathrm{CH}$.}

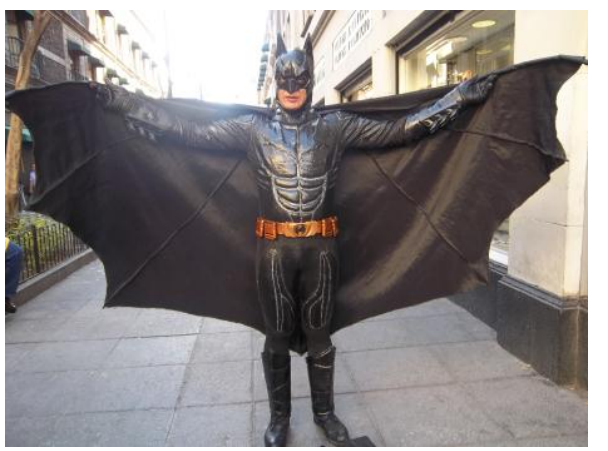

Si bien, el espacio público denota libertad, con reglas, es el disfrute de la ciudad. No es un lugar especializado para manifestaciones artísticas, como las estatuas vivientes, músicos o personajes que se colocan día a día en la calle Francisco I. Madero. Su andar por el $\mathrm{CH}$ no ha sido sencillo, ni comenzó

(en muchos casos con la peatonalización) sino desde hace más de 10 años, como me comentó Abraham Álvarez "Batman":

"Trabajaba en la calle de Empedradillo, ahí junto a Catedral. La decisión de cambiar de calle, fue del Gobierno, que nos fueron empujando a esta calle. Entonces, yo iba allá y estábamos solos, tranquilos, pero de que entró Marcelo Ebrard cambió todo nuestro panorama de trabajo. Hubo operativos de limpia, nos tomaron como comerciantes y nos corretearon, nos encarcelaron en el Juzgado 33. Nos trataron como criminales, hasta el momento nos mandaron hasta acá, a Madero, cada vez más adentro, nos expulsaron del Zócalo, estamos acá exiliados.” (Entrevista con Abraham Álvarez "Batman", personaje artístico ${ }^{14}, 28$ de enero de 2011)

La historia de los artistas callejeros del CH data de alrededor de 10 ó 15 años, como me comentó Abraham, no se tiene la fecha exacta de estas expresiones en las calles del $\mathrm{CH}$, pero "Batman" me dijo:

“Comencé antes del 2000, prácticamente estábamos solos en la plancha. Hubo una generación anterior en donde estaba Cantinflas, estaban varios, el Mensajero Galáctico y aparecimos la segunda generación: Mario [Watt], Paco Sarza, sensacionales muchachos y yo. Tuvimos el valor para trabajar ahí, para enfrentarnos nosotros a la calle, sin ayuda de nadie." (Entrevista con Abraham Álvarez "Batman", personaje artístico, 28 de enero de 2011)

\footnotetext{
14 Es importante mencionar que Batman podría no ser considerado artista, ya que él no crea su personaje, sino lo toma de una película. Sin embargo argumenta que Aquí se actúa, yo cuando me pongo una máscara, no me la quito en todo el tiempo enfrente de la gente, nunca me verán sin máscara en la calle, no me verán comer, tomar agua, ni sentarme, ni nada...se está actuando. (Entrevista con Abraham Álvarez "Batman", personaje artístico, 28 de enero de 2011). Si bien, podría no cumplir con las características artísticas, debido a que el personaje no es creado por él, la actuación que realiza podría ser parte del arte, así como la manufactura artesanal de su vestuario. Otro elemento por el que consideré vital entrevistarlo es que es de los artistas veteranos en las calles del $\mathrm{CH}$ y es respetado por el resto de los artistas.
} 
Debido a que la calle es como un pequeño hogar para los artistas, el gremio se conoce, con nombres, apodos y personajes. Sin embargo, no se sabe con exactitud cuándo comenzaron las representaciones artísticas en estas calles, de las personas con las que estuve trabajando en campo, Abraham y Mario (Watt) son los veteranos, lo cual da información fundamental para esta investigación, no sólo en el $\mathrm{CH}$ sino en el resto de la ciudad, ya que los artistas del $\mathrm{CH}$ han estado en Coyoacán, Condesa o cafés de Polanco, así que no están establecidos todo el tiempo en el $\mathrm{CH}$, es un gremio amplio, con el cual pude tener contacto y para investigaciones a futuro el tema se puede ampliar a otras zonas de la ciudad o del mundo.

Retomando la cronología de los artistas en el CH, "Watt" me comentó: Empecé desde el 2003 para acá. Comencé a trabajar en la calle haciendo performance y estatua en 99 en Guanajuato y de ahí dando el rol por todo el país. Haciendo estatua, pero en las capitales de los estados, porque en los pueblos la gente es muy cerrada. (Entrevista con Mario Peña, "Watt", performance- estatua viviente, 25 de enero de 2011). Sin embargo, al igual que lo expresó Abraham, la decisión de colocarse en la calle Madero no fue propia, sino por presión de las autoridades, a lo que "Watt" agrega:

"En un principio estaba en Motolinia, yo era el primero que se ponía en Motolinia. Ya después llegó el que se pone de "Hebreo", que se ponía con un perchero entonces. Ya después que lo vi, me moví a 5 de mayo. Luego, no me gustó ahí, me moví para los arcos. Después estuve en la catedral [con Batman] como 3 años. Me fui unos meses y cuando regresé valió madres, estaba todo lleno de estatuas, eran como 30. Eso fue en 2007, yo me moví entonces a la calle de Moneda, ahí estaba bien feliz. Luego, ya para marzo, a volar todos, nos movió la autoridad de aquí y nos llevaban a los separos." (Entrevista con Mario Peña, "Watt", performance - estatua viviente, 25 de enero de 2011).

Ahora bien, la decisión de colocarse en Madero no fue propia, sino consecuencia de no permitirlo en otras calles. Sin embargo, las tolerancias (permisos provisionales que dependen del Jefe Policíaco o del encargado de Programas Delegacionales, y de las cuales no se saben los criterios para otorgar o quitar). Así como las tolerancias no están reglamentadas, tampoco existe una norma dentro del gremio para aceptar o rechazar gente en las calles de trabajo, la nula regulación también se percibe entre los artistas callejeros, que buscan un sitio de trabajo, sin hacer daño a nadie, sin embargo, ellos tampoco pueden restringir el acceso de nuevos artistas, lo cual genera conflictos internos e institucionales. 
Como mencionó "El charro cantor” y "Batman” fue a raíz de la limpieza del CH (2007), cuando se quitaron a los ambulantes, se intentó quitar a toda persona de la calle, incluidos los artistas callejeros, que han estado en diferentes sitios del $\mathrm{CH}$ y los resultados han sido los mismos (desde 2007), no hay tolerancia para realizar sus actividades: A las estatuas también se nos prohibió trabajar ahí alrededor de la plancha y entonces, a partir de eso, tuve que ir a trabajar, sólo se abrieron 2 espacios, que fue: la calle de Motolinia y la calle de Gante. (Entrevista con Jorge Baena, "Charro cantor", estatua viviente, 23 de enero de 2011).

En un principio se colocaban en la plancha del Zócalo, el gran espacio público por excelencia, sin embargo, a pesar de no estorbar, para las autoridades entrantes no era una actividad aceptada en ese espacio, ni cerca de Catedral, por lo tanto, fueron "invitados" a colocarse en las calles de Gante y Motolinia, aunque los resultados tampoco fueron mejores, ni han sido respetados, tanto por artistas como por autoridades. El deambular por estas calles generó que el número de estatuas humanas y personajes aumentara exponencialmente, como lo presenté en la entrevista de "Watt", el tener 30 estatuas humanas generaba molestia entre quienes llevaban años haciendo esta actividad, así que la competencia y la lucha por encontrar un lugar de expresión y trabajo se tornó difícil, violenta en algunos casos y es una lucha que no cesa.

La llegada de los artistas callejeros a Madero no fue por elección, sino por la persecución en otras calles del $\mathrm{CH}$; debido a la limpieza de ambulantes en este espacio, se prohibió toda manifestación en espacios públicos, ya que obstruye la vía pública. Sin embargo, la llegada y el aglomeramiento ocurrido en Madero no es por decisión de los artistas, sino porque dos calles que hacen esquina con ésta, fueron otorgadas para estas manifestaciones, pero años después, ni esas calles que fueron permitidas, lo son en la actualidad. Ahora todo depende de las tolerancias otorgadas por Programas Delegaciones o por pagar una plaza a la asociación de comerciantes ambulantes PRO DIANA A.C, que es la única organización que apoya a estos artistas, aunque todo se hace por el cobro de espacios en la calle. Así que la calle Madero ya no cuenta con vendedores ambulantes, pero si con el poder que éstos tienen sobre las calles. Sin embargo, ha sido la única manera de sobrevivir al ambiente y violencia vividos en esta 
calle. La travesía institucional que han tenido estos artistas es compleja, existen diferentes versiones, pero todos coinciden en lo que presentaré en el tema 5.5 sobre los intentos de regulación para el arte callejero en la calle Francisco I. Madero.

\section{c) Del comercio ambulante al artista callejero ¿Sólo hay un paso?}

La limpieza del CH significó no sólo el quitar ambulantes y todo aquel que obstruyera o generara reflexión en la vía pública, como lo son los artistas callejeros. También se provocó una crisis existencial del grupo de artistas en estas calles, ya que fueron tomadas por pseudo artistas, provenientes del gremio del ambulantaje, lo cual trajo un sinfín de consecuencias: el número de personajes y estatuas aumentó, en detrimento de la calidad interpretativa. Si bien, como mencioné en el apartado a), en las expresiones artísticas callejeras se ha dado cabida a niños de la calle y a posibles ex asaltantes, estos han sido casos aislados, no llegó una oleada de este tipo de personas. Sin embargo, en el caso del ambulantaje, según comentan los entrevistados, llegaron muchas personas derivadas de las restricciones de la venta en vía pública. Uno de tantos problemas que enfrentan surge a raíz del ambulantaje en el $\mathrm{CH}$, esta actividad comercial ha sido una constante desde hace 4 años dentro del gremio de artistas callejeros. Quiero aclarar que yo no pregunté si los artistas actuales se dedicaron al ambulantaje en algún momento. Sin embargo, algunos artistas entrevistados de manera individual me comentaron este aspecto, por lo tanto, consideré importante explicarlo en este apartado, ya que eso ha llegado a degradar la actividad del artista callejero, la calidad ha disminuido y la competencia ha aumentado exponencialmente.

"Disfrazados, la representación está difícil con los ambulanteros y con toda esta gente que su visión no es representar nada, es sacarse un buen cambio y vámonos a volar. La gran mayoría es eso, la gran mayoría de las estatuas son ex ambulantes y aparte su actitud los denota ¿Cómo te fue AYER?, me saqué una quiña (\$500), cámara. Esos güeyes no saben de arte, te dicen: Somos cultura, somos arte." (Entrevista con Mario Peña, "Watt", performance - estatua viviente, 25 de enero de 2011).

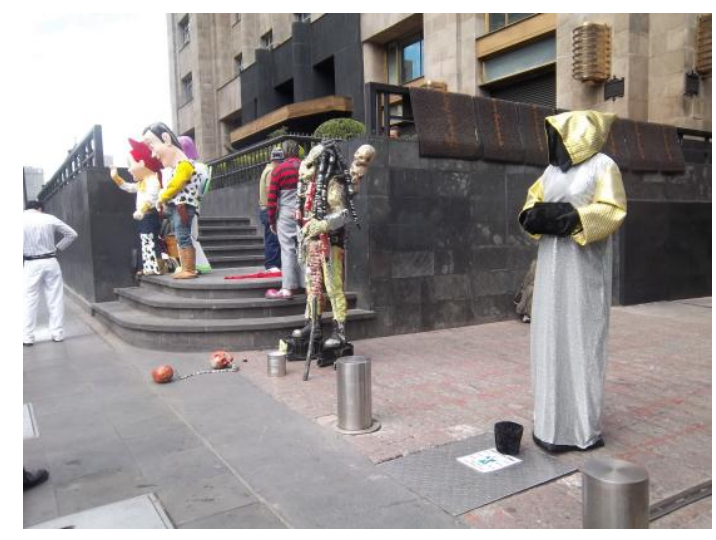

La presencia de ambulantes disfrazados de artistas callejeros se hizo notoria con la aparición de botargas y Místicos (en el argot de la calle se nombra así a las personas que están cubiertas de pies a cabeza con una 
capa, agitan una caja de zapatos y te dicen tu futuro en pequeños papeles). Las críticas hacia los Místicos surgen porque eso no requiere de ninguna preparación mental, ni física. Además de que una misma capa de Mago Merlín (Místicos) puede ser utilizada por 4 ó 5 personas en un día, solamente es cuestión de quitarse la capa y colocarla en alguien más. En campo llegué a ver el cambio de capa de los Místicos y es verdad, cuando uno se cansa, se baja y le da la capa a otro para que mueva la caja de zapatos que nos dice frases del futuro. Sin embargo, al público no le disgustan estas manifestaciones. Otra expresión del ambulantaje es la presencia exponencial de botargas, que para los artistas, no es arte, ya que solamente se colocan un disfraz, no gesticulan, ni controlan el cuerpo en ninguna de sus expresiones:

"La botarga ocasiona muchos conflictos de espacio, aparte que no es algo artístico, es publicitario, no fue hecha para crear una atmósfera artística, está hecha para entretener a los niños, para un medio publicitario. Es cuando existe la controversia sobre ellas, también les dieron mal manejo, anunciar las fotos como si fueran vendimia." (Abraham Álvarez, "Batman", personaje artístico, 28 de enero de 2011)

Las botargas no representan ninguna expresión artística, para mis entrevistados y para mí, ya que su postura y expresión corporal es invisible ante el disfraz comprado y colocado sobre el cuerpo. Éste deja de ser su instrumento de comunicación ante el disfraz. Han ocasionado graves problemas de espacio y ruido, ya que existen merolicos junto a las botargas que gritan ¡De a 10 la foto, llévese la foto! Obviamente, los personajes de las botargas son atractivos para los niños y es un medio de vida honrado, pero los conflictos por los disfrazados: entre místicos y botargas (dirigidos por la señora Alicia) genera gran inconformidad entre los que se consideran artistas callejeros. Por lo tanto, el artista callejero en el $\mathrm{CH}$, que ha tenido que sufrir por la limpieza de ambulantes, por las constantes comparaciones con dicho sector comercial, lucha día a día por legitimar sus actividades, que si bien, no cuentan con preparación profesional, la calle los ha hecho aprender sobre su cuerpo, el arte y la cultura en estas calles. Para los entrevistados, los ambulantes disfrazados han demeritado la labor del artista callejero. Así que la dicotomía artista urbano y ambulantaje es casi indisociable en el conflicto interno e institucional del sector creativo de nuestra calle del $\mathrm{CH}$. Si existiera una organización y reconocimiento a las actividades artísticas, no se pensaría que cualquiera podría dedicarse a ellas. Sin embargo, como lo presenté, también ha sido una forma de 
rehabilitar a chicos de la calle y asaltantes, así que la gestión es mucho más compleja de lo que parece.

\subsection{Intentando regularizar el arte callejero en Madero.}

Cabe aclarar que la gran disputa por este espacio público esta regulado por la obstrucción en la vía pública y todo se abrevia en lo peligroso que se torna que se hagan "bolas" de gente alrededor de los artistas callejeros, así que desde este argumento distintas instancia de Gobierno, como Fideicomiso del $\mathrm{CH}$, Autoridad del $\mathrm{CH}$, Programas Delegacionales (Cuauhtémoc) y otras instancias responsables de este espacio se han dado a la tarea de no dejar que se coloquen a hacer sus representaciones o intentar regularizar el uso de este espacio. Como comenta Anabelí Contreras:

"Si tú tienes esta cantidad de gente circulando y de pronto tienes una estatua viviente, si pasa algo, porque si se hace un círculo donde le abren metro y medio y detienes el flujo, eso genera un caos, rompe la circulación, es peligroso. Es decir, en Gante hay terrazas, en el callejón de 5 mayo hay terrazas, en Madero no hay terrazas. No son viables, es decir, no es viable tenerlos, es peligroso." (Entrevista con Anabelí Contreras, Jefa de Unidad de Difusión del Fideicomiso del CH, 15 de abril de 2011)

Lo presentado por Anabelí Contreras es el principal conflicto de las manifestaciones artísticas en esta calle, rompen con el flujo peatonal, ya que se genera aglomeración de personas, lo cual es insostenible para la calle. Situación con la que estoy de acuerdo, sin embargo, ¿Por qué ciertos días tienen tolerancia para colocarse y otros no? Esa es la gran incógnita, ya que como presentaré más adelante, han tenido acercamiento con distintas instituciones de Gobierno Local y por temporadas tienen permitido colocarse, así que el argumento del caos peatonal que generan es válido, pero pareciera que no es un argumento firme. En la entrevista con el arquitecto Martínez me aclaró que en un primer ejercicio comparativo, la calle Madero es equivalente a las Ramblas de Barcelona, por la densidad de visitantes, como calle principal, por las actividades comerciales y artísticas de ambas calles. Sin embargo, especifica:

"En Madero se provocaban bloqueos, de plano la gente estaba detenida, porque es más un embudo, incluso en la Rambla tienes la oportunidad de ir a la banqueta, acá no. Desde mi punto de vista, desde la visión funcional estrictamente, no recomendaría la acumulación de personas a partir de la instalación de las estatuas, de los chicos que bailan break. Yo diría que en primer término está la sección de Madero, veo muy lógico, una correcta decisión el procurar que no se instalen este tipo de manifestaciones, todos tenemos derecho sobre el espacio urbano, pero aplicaría el esquema: es el bien de la mayoría." (Entrevista con el arquitecto 
Alejandro Martínez, Director de Proyectos Sustentables de la Secretaría de Obras y Servicios del GDF, 20 de junio de 2011)

Lo presentado por ambos funcionarios es una realidad y por supuesto que preocupa a las autoridades, ya que pensando en los riesgos, si puede ocurrir un accidente o alguna emergencia que no se pueda controlar. Sin embargo, lo mismo podría ocurrir con una marcha o un plantón en Reforma, y las acciones no son como en este caso, criminalizando a los implicados, sino entendiendo la situación y buscando alternativas al problema. Algunas acciones para los artistas de esta calle, han sido exigirles que no se coloquen sobre Madero, sino en las calles de Motolinia, Gante y Condesa, mínimo un metro dentro de éstas, para que así no se invada esta calle. Sin embargo, a pesar de cumplir con las normas establecidas, los problemas con las autoridades continúan y el atrincheramiento de cada sector no ha permitido llegar a acciones claras al respecto. A continuación presento algunos intentos por regularizar las actividades artísticas en Madero.

\section{a) Remitidos al Juez Cívico 33: Obstrucción de vía pública.}

Quiero destacar que la presencia de estas actividades en el espacio público no cuenta con regulaciones claras al respecto. En ningún artículo de la Ley de Cultura Cívica del DF se prohíbe la presencia de estas manifestaciones artísticas. El remitirlos a los separos se hace tomando el artículo 25 fracción II:

"Impedir o estorbar de cualquier forma el uso de la vía pública, la libertad de tránsito o de acción de las personas, siempre que no exista permiso ni causa justificada para ellos. Para estos efectos, se entenderá que existe causa justificada siempre que la obstrucción del uso de la vía pública, de la libertad de tránsito o de acción de las personas sea inevitable y necesaria y no constituya en sí misma un fin, sino un medio razonable de manifestación de las ideas, de asociación o de reunión pacífica." (Ley de Cultura Cívica del Distritito Federal, 31 de mayo de 2004)

Si bien, son remitidos por este artículo. En ningún momento la Ley de Cultura Cívica contempla que el arte en las calles sea delito. Sin embargo, la realidad es otra, son remitidos constantemente por obstruir la vía pública, teniendo que pagar mínimo $\$ 300$ por la multa para que el Juez Cívico de la agencia 33 (la famosa 33 en Pino Suárez) los deje salir libres o quedarse remitidos por 48 horas, si es que no tienen dinero para pagar la multa, aunque en el papel entregado al pagar solamente dice $\$ 50$. Así que la 
legislación es ambigua, pero exige de ellos el pago de una multa que es difícil solventar,

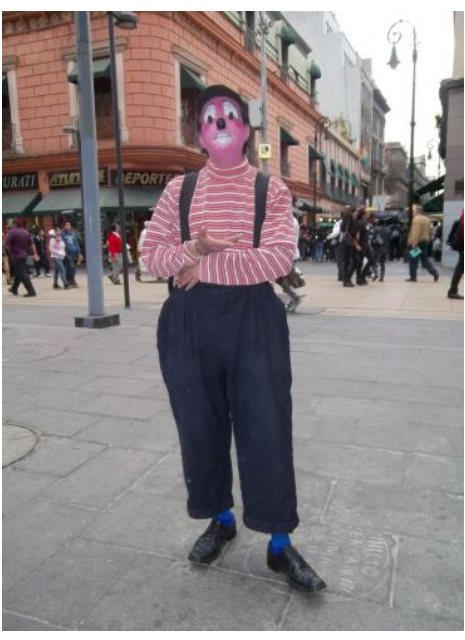
humillante para unos, injusta para otros, pero el conflicto persiste, son remitidos sin mayor argumento, hasta por estar vestidos con sus personajes, como le ocurrió al "Payaso Picolín" el domingo 6 de febrero de 2011, saliendo del metro fue subido a la patrulla y llevado a los separos, su delito fue estar vestido de payaso en la vía pública, esas son las leyes en el $\mathrm{CH}$. No todos son remitidos por estar vestidos como payasos sino cuando están realizando sus labores artísticas, como le ocurrió a

"Batman" en once ocasiones:

"A mi nunca me golpearon, te llevaban todo disfrazado al Juez Cívico, oye déme chance de quitarme el traje: así te quiero llevar. Te llevaban ahí, te trataban como comerciante, delincuente, te sentaban en una galera oliendo a orines, te sacaban dinero, variaba, de $\$ 250, \$ 330$ a $\$ 800$ ó tus 48 horas guardadito. A mi me llevaron once veces, para que te des una idea de lo que es estar aquí." (Entrevista con Abraham Álvarez, "Batman”, personaje artístico, 28 de enero de 2011)

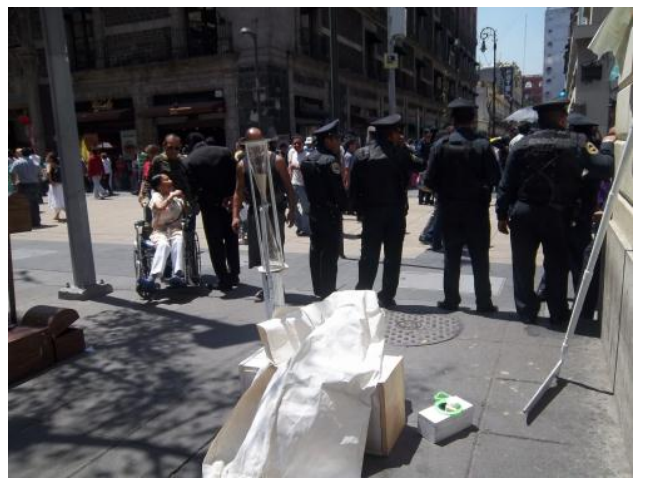

Policías vigilando que no se coloquen los artistas callejeros.

Fuente propia. México, Abril de 2011

Como a Abraham, todos los entrevistados (excepto Ana de Alba y Ana Álvarez) fueron remitidos al Juez Cívico 33, por obstruir la vía pública. Argumento válido si se toma en cuenta que la gente se aglomera alrededor de lo artistas y personajes, pero que no debería ser un delito, ni mucho menos llevarlos ante un Juez Cívico, no le hacen daño a nadie, pero las leyes son estas y se acatan, aunque eso implique que sean considerados ambulantes, ya que éstos últimos son los sectores que obstruyen la vía pública y así tratan legalmente a los artistas callejeros, con las mismas leyes que al ambulantaje.

\section{b) Credenciales de la Secretaría del Trabajo: No asalariados.}

La regulación de los artistas callejeros es compleja, ya que no se cuenta ni siquiera con un padrón de personas dedicadas a esta actividad, así que regular sin conocer el problema de raíz es un primer motivo de conflicto por parte de los artistas. Si bien, en 
2007 comenzó la limpieza del CH, quitando ambulantes y toda actividad en vía pública, como lo son los artistas callejeros. En 2008 se dio un gran giro para la regulación de estas actividades, ya que la Secretaría del Trabajo y Previsión Social hizo la convocatoria para darles credenciales de No Asalariados, este Reglamento específica:

"Para los efectos de este Reglamento, trabajador no asalariado es la persona física que presta a otra física o moral, un servicio personal en forma accidental $u$ ocasional mediante una remuneración sin que exista entre este trabajador y quien requiera de sus servicios, la relación obrero patronal que regula la Ley Federal del Trabajo.” (Reglamento de Trabajadores no asalariados, artículo 2º 1975:1)

En este Reglamento están incluidos los aseadores de calzado, estibadores, maniobristas y clasificadores de frutas y legumbres, mariachis, músicos, trovadores y cantantes, organilleros, artistas de la vía pública, plomeros, hojalateros, afiladores, peluqueros, albañiles, etc. Es así como los artistas en espacios públicos están en la misma categoría que un boleador, cargador y demás oficios llevados a cabo en la calle. Debido a estos artículos, en 2008 se ofreció otorgar 12 permisos para trabajar en la vía pública:

"Se ofrecieron 12 permisos para más de 100 estatuas, artistas callejeros pues, entre estatuas y personajes, se ofrecen 12 permisos para 100. Entonces, se hacen legales a 12, que están en Motolinia y Gante y a todos los demás se les hace ilegales y comienza una persecución del artista callejero." (Jorge Baena, "Charro cantor", estatua viviente, 23 de enero de 2011)

Sin embargo, los requisitos para solicitar dichas credenciales fueron un enigma, ya que muchos de los artistas no se enteraron de la entrega de credenciales, ni de lo requisitos para las mismas. De los entrevistados en campo, solamente Juan "El Mago" cuenta con dicha credencial y en efecto, el resto fue criminalizado por no contar con dicha acreditación. Si bien, el Reglamento especifica en su artículo $10^{\circ}$ que es requisito presentar Cartilla Militar (si es mayor de edad), tener domicilio, acta de nacimiento, certificado de primaria (mínimo) y si se es menor de 16 años entregar dos cartas de buena conducta. A los artistas callejeros del $\mathrm{CH}$ les exigieron otra serie de requisitos, como lo expresó Raúl:

"Cartilla militar o la precartilla, comprobante de estudios, comprobante de domicilio, IFE, CURP, 6 fotos, 8 cartas de recomendación. O sea, imagínate, todavía dos videos para ver cómo trabajas y si ameritas un permiso, porque si no lo ameritas o te falta algún permiso no te dejan trabajar." (Entrevista con Raúl Vázquez, "La Muerte," estatua viviente, 23 de enero de 2011)

Los requisitos eran exagerados, en relación al Reglamento, en realidad se 
pedían más documentos a los artistas en la vía pública. Raúl entregó todos sus documentos hace 3 años y no le han dado respuesta, así que este intento por regularizar la situación de los artistas callejeros parece que no fue del todo equitativo, ya que los requisitos eran exagerados, considerando que no todos cuentan con instrucción formal en arte, además de haber otorgado solamente 12 permisos a un total de más de 100 artistas, las probabilidades de tener una credencial eran escasas, muchos artistas se enteraron de esta convocatoria por escuchar que alguien más la estaba tramitando o ya la tenia. Por lo tanto, las probabilidades eran todavía menos, considerando los requisitos, tiempo de solicitud y falta de comunicación en el gremio.

"A mi no me tocó, finalmente me he enterado a través de muchos medios legales que no es la gran cosa, es como una credencial de no asalariado, no es un permiso. En el CH ni en ningún lado de la Ciudad de México existen permisos para trabajar en la vía pública, no se puede, no hay permisos, aquí hay tolerancias. Son mentiras, solamente son tolerancias, te tolera por acuerdos de que no estorbes, de que permitas esto, que cuando te digan que no, pues ni modo." (Entrevista con Abraham Álvarez, "Batman", personaje artístico, 28 de enero de 2011)

De tal manera que los que no cuentan con credencial tampoco tienen gran diferencia, ya que dichas acreditaciones, como se comenta en la calle, no te da permiso de tener un lugar fijo, te permite trabajar sin tantos inconvenientes, pero si se termina la tolerancia o hay veda, a todos (con credencial o no) los quitan.

"La Secretaría del Trabajo, después de haber hablado con 2 ó 3 fulanos: Pedro Bello- trabajo no asalariado, no...Pedro Bello es gestión social. El otro fulano de programas delegacionales: Jesús Romero. El otro fulano: Profesor Cortés de trabajo no asalariado y unos de Vía Pública de la Delegación Cuauhtémoc y todos quedaron de acuerdo: Si va a ver lugar, nada más para ustedes [con credencial]" (Entrevista con Mario Peña, "Watt", performance- estatua viviente, 25 de enero de 2011)

Las credenciales de trabajadores no asalariados fue el primer intento por regularizar la situación de los artistas callejeros del $\mathrm{CH}$, pero el resultado fue el mismo: inconformidad de parte de unos y comenzó un nuevo conflicto interno: los legales y los ilegales. Conflicto que se ha extendido durante varios años, ya que aunque la credencial no da un permiso permanente para colocarse, ni genera gran cambio ante las autoridades, mucho menos ante el público, si generó una fisura entre los que tenían credencial y los que no habían cumplido los requisitos para obtenerla. Se llegó a comentar que quienes tenían la acreditación si eran artistas y los que no la obtuvieron no cumplían con las especificaciones del arte. 
Aunque en aparente calma, se dividió el gremio, estaban los "artistas profesionales" de Gante y el resto podría considerarse como "los disfrazados": Algunos se consideran super artistas, los de Gante se sienten privilegiados, que son de escuela y los que no tenemos escuela no nos metemos con ellos, pero si atacan mucho a los muchachos, a las botargas sobre todo. (Entrevista con Abraham Álvarez, "Batman", personaje artístico, 28 de enero de 2011). Así comenzó otro de los muchos conflictos internos, entre los que tenían credencial y se sentían más artistas que el resto. Considero que se hizo una grieta en el gremio a partir de eso. A los de la credencial y a varias personas se les dio ponerse como energúmenos con sus credenciales, que son los artistas y aventarles a la policía a los demás. (Entrevista con Mario Peña, "Watt", performanceestatua viviente, 25 de enero de 2011). Lo presentado por "Watt" marca el nuevo conflicto generado por la entrega de 12 credenciales a un total de 100 artistas, así que es uno más, de los existentes dentro de este gremio. Por lo tanto, la gestión se dificulta cada vez más, si las autoridades se hubieran tomado el tiempo de hacer un análisis previo de la situación y cantidad de estos artistas, se podrían haber tomado otro tipo de decisiones, las cuales no generaran aún más conflicto en esta actividad.

\section{c) Del Punto de Acuerdo del Diputado Arturo López Candido a la creación de ES CULTURA VIVIENTE FUERA DE TIEMPO A.C}

Después de la experiencia de la entrega de credenciales, con ellas o sin ellas, seguían siendo remitidos al Juez Cívico 33 por obstrucción de vía pública, aumentaba el número de "disfrazados" en las calles y las tolerancias se quitaban a diestra y siniestra. Así que cansado de esta situación, uno de los artistas (con credencial) "Azteca Plateado" (ya no se coloca en la calle porque tuvo un sinfín de conflictos con la asociación PRO DIANA, por lo tanto, no lo entrevisté). El “Azteca Plateado" decidió a tomar cartas en el asunto para regularizar la situación de los artistas callejeros. Dicen los demás artistas que el "Azteca Plateado" fue corrido de las calles del $\mathrm{CH}$, ya que los ambulantes no querían que se colocara, ya que para la asociación PRO DIANA A.C, este personaje se estaba convirtiendo en el coordinador de la calle y hacía mal uso de ella, como me comentó uno de los "Coordinadores de la calle de Madero" (PRO DIANA A.C): Esa persona acomodaba a la gente a su manera, como a él le convenía. Él era artista o es artista. De hecho, nosotros le invitamos a que se adhiriera con nosotros, pero él, sus intereses 
son otros. Él quiere los espacios para él solo. (Entrevista con David Reyes, Coordinador de la calle Madero, PRO DIANA A.C, 26 de enero de 2011). Lo comentado por David, muestra que el "Azteca Plateado" era bien conocido y casi líder de los artistas callejeros, lo cual comenzó a molestar a la A.C, por lo que, para "Watt", dicha asociación corrió al "Azteca" de la calle, debido a que no quiso pagar la cuota de $\$ 50$ por colocarse "libremente" a trabajar.

La inconformidad de este personaje lo llevó a pedir ayuda a la Asamblea Legislativa del DF, fue atendido y apoyado por el Diputado López Candido (Vicepresidente de la Comisión de Cultura), quien en entrevista me comentó lo que padecían los artistas del $\mathrm{CH}$ :

"Porque los espacios en el $\mathrm{CH}$ tienen que ver con control político, tienen que ver con control económico y tienen que ver con control de los diferentes grupos a nivel de instancias de gobierno. Entonces, eso hace que se frene y se pelee la gente, a mí se me hace que eso no debe existir, aquí todo el mundo tiene posibilidad de manifestarse, cualquiera de sus expresiones: políticas, sociales, artísticas. Entonces, no son vendedores ambulantes y no los deben tratar como vendedores ambulantes, son una expresión artística de la ciudad que tiene derecho a expresarse." (Entrevista con Diputado Arturo López Candido, Asamblea Legislativa del DF, 6 de abril de 2011)

Cuando el "Azteca Plateado" buscó al Diputado López Candido, éste decidió apoyarlos, pero no desde la Comisión de Cultura del DF, sino a título personal. Aunque, cabe aclarar que actualmente (según palabras de la Secretaria Particular del Diputado), a esta lucha se han unido la Diputada Carmen Quiroga, la Diputada Estela, el Diputado Leobardo y la Diputada Mendicuti, pero todos lo hacen a título particular, no dentro de dicha Comisión. Coincido plenamente con lo presentado por el Diputado López Candido sobre el control de los espacios, que nada tiene que ver con el arte sino con política y economía, sin embargo, las leyes y la realidad no protegen en ningún sentido a los artistas callejeros que se colocan en Madero.

Documento proporcionado por Jonathan Ríos “Azteca Dorado" Febrero de 2011

Las negociaciones con el Diputado López Candido tuvieron resultados el 25 de junio de 2010, fecha en que éste hizo la primera carta otorgando tolerancia a

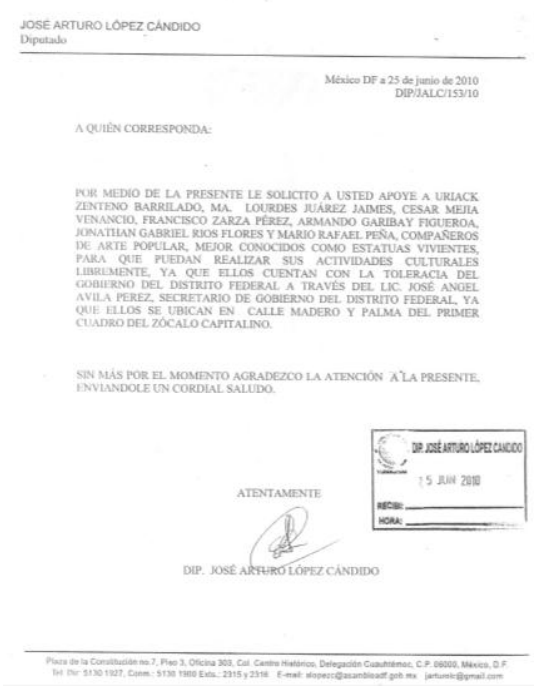


seis artistas callejeros, lo cual muestra gran avance en las negociaciones por el espacio público en Madero y Palma.

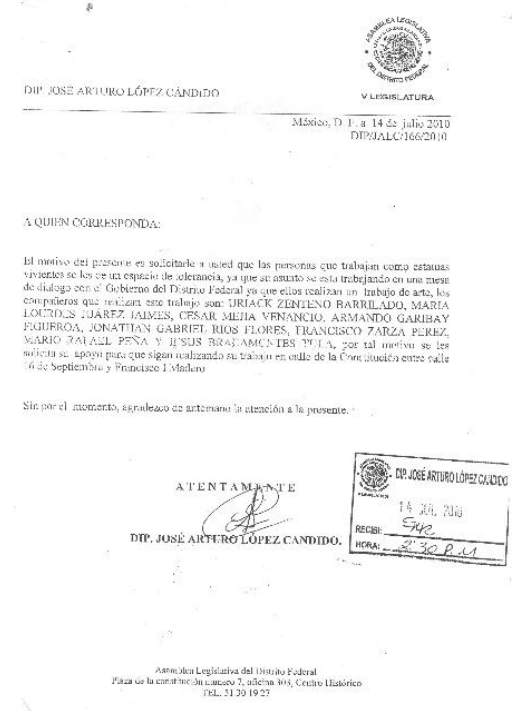

Documento proporcionado por Jonathan Ríos “Azteca Dorado". Febrero de 2011.

Después de la primera misiva, realizó otra el 14 de julio de 2010, en la cual se otorgaba espacio para siete artistas en la calle de Constitución, entre 16 de Septiembre y Madero (supongo que se refiere a la Plaza de la Constitución). Estas cartas son un gran paso para el reconocimiento y apoyo a las actividades artísticas en las calles aledañas a Francisco I. Madero. El gran avance surgió cuando se dejaron de hacer cartas apoyando a personas particulares y se realizó un Punto de Acuerdo en la Asamblea Legislativa del DF, en donde se intenta dar apoyo formal a estas actividades en el $\mathrm{CH}$.

En dicho Punto de acuerdo se exhorta a la Secretaría de Cultura y a Dependencias dedicadas al orden público en el $\mathrm{CH}$, para que permitan la presencia legal de músicos, esculturas vivientes y magos en las calles que confluyen en Madero, Gante y calles del $\mathrm{CH}$. Enfatizando que, este punto de acuerdo tendrá efectos mientras se realice una legislación y reglamentación adecuada para estas actividades. Hasta este momento, pareciera que sus actividades artísticas contaban con protección en las calles del $\mathrm{CH}$, ya que al tener reconocimiento podría realizarse una legislación acorde. Sin embargo, un Punto de acuerdo, se puede quedar en el tintero, como me comentó en entrevista el Diputado López Candido: Un planteamiento [...] que luego es subido al pleno para que lo apruebe y de seguimiento, porque sino son como los llamados a misa, no pasa nada. Por eso la Asamblea es muy noble, pero si no das seguimiento a las cosas, no sirven de nada. (Entrevista con Diputado Arturo López Candido, Asamblea Legislativa del DF, 6 de abril de 2011). 
Punto de Acuerdo: 4 de agosto de 2010
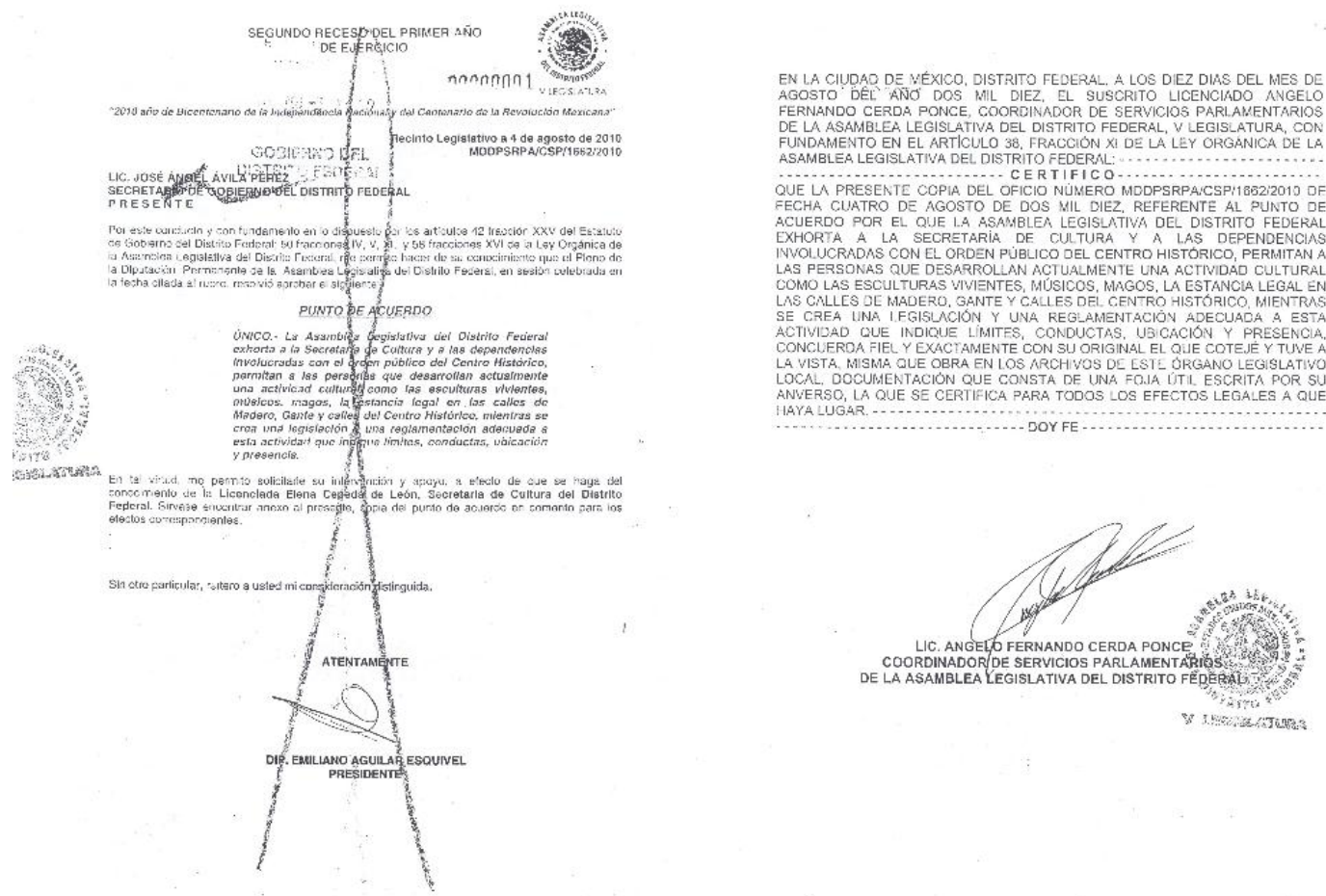

Documento proporcionado por Jonathan Ríos “Azteca Dorado”. Febrero de 2011

Como resultado de ese Punto de acuerdo se les otorgaron acreditaciones para poder colocarse en las calles del $\mathrm{CH}$, las cuales fueron firmadas por miembros de la Asamblea Legislativa. De esta manera se estaba avalando la labor de los artistas callejeros del $\mathrm{CH}$ y se apoyaba con estas medidas mientras se hacía una reglamentación al respecto.
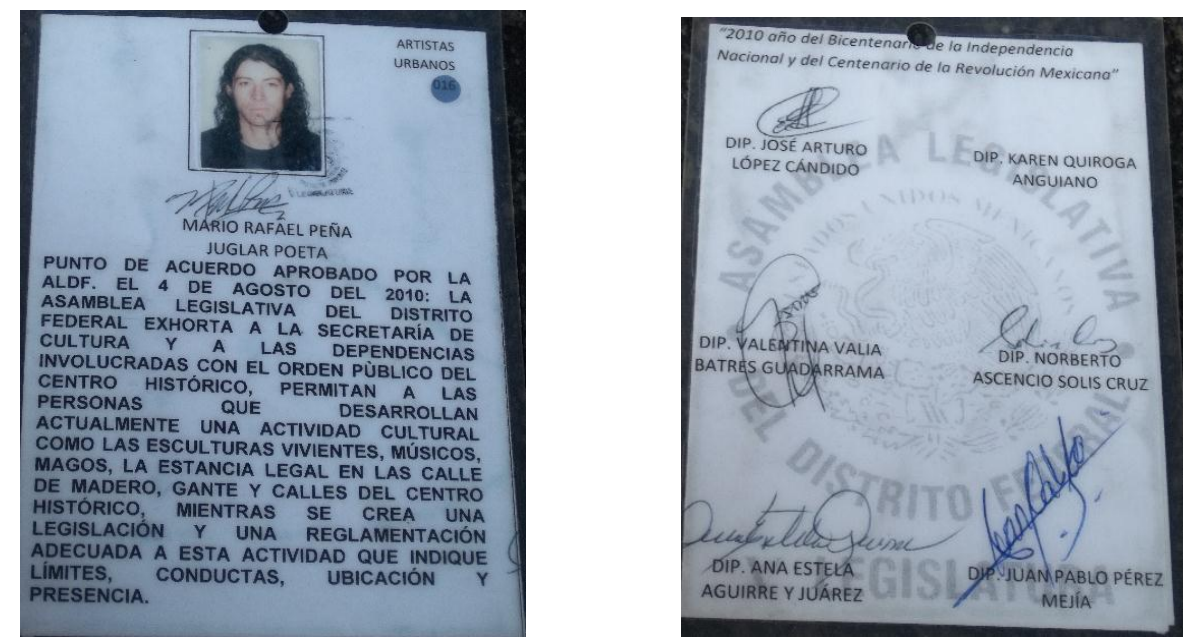

Documento proporcionado por Mario Peña "Watt”. Enero de 2011

Aparentemente, este es el inicio legal del reconocimiento y apoyo a las actividades 
artísticas en el $\mathrm{CH}$, en particular en la calle Madero. Sin embargo, requería de mayor presencia e intervención con otras instancias dedicadas a la gestión del $\mathrm{CH}$, por lo que el Diputado López Candido decidió tomar cartas en el asunto y acudió al Fideicomiso del $\mathrm{CH}$ para que hicieran un plan para apoyar las manifestaciones artísticas callejeras y se lograra reconocimiento, respeto y derechos. El apartado de la gestión con el Fideicomiso lo presentaré más adelante.

Cabe destacar que el Diputado López Candido sabe perfectamente de la existencia y del cobro de plaza realizado por la asociación de Diana Barrios, sin embargo, en estas calles hay demasiados intereses económicos y políticos, pero el saber de la situación y no frenarla, nos puede dar una idea del poderío de dicha Asociación. Ponen muchos pretextos [refiriéndose a las autoridades], como en el $\mathrm{CH}$ donde tienen miedo a esta Barrios, porque a los músicos que no los puedes tratar como vendedores ambulantes, judicial o de represión, de golpes, todo ese tipo de cosas, ha sido difícil. (Entrevista con Diputado Arturo López Candido, Asamblea Legislativa del DF, 6 de abril de 2011). Así que es una realidad que todos conocen y nadie frena, pero la gestión del $\mathrm{CH}$ no depende sólo de las instancias de Gobierno, sino del control ejercido por dicha Asociación.

\section{- ES CULTURA VIVIENTE FUERA DE TIEMPO A.C}

Los esfuerzos y avances mostrados por el Diputado López Candido y otros, no eran suficientes para el reconocimiento del arte callejero, se requería de mayor cooperación de este grupo de artistas. Para "Watt" y otros artistas de la calle, dicho funcionario solicitó al "Azteca Plateado":

"Después, con el tiempo, de ese mismo año [2010], intentó hacer una asociación, hizo su asociación, el Diputado López Candido le dijo: Pero junta mucha gente. Así que fue por todos los borrachos, mendigos y tipos que estaban tirados en la calle y los pintó y: mira, ya hay un chingo de estatuas e invitó a todos los que antes estaban y llenó esto, pero lo llenó a madres. Entonces, otro grupo, los payasos que también son muy mafiosos: No, nosotros no. Esos son los payasos y ciertas personas: señora Alicia de botargas." (Entrevista con Mario Peña, "Watt", performance- estatua viviente, 25 de enero de 2011)

De esta manera, la propuesta del Diputado no parecía estar mal, crear una asociación de artistas callejeros del $\mathrm{CH}$ podría ser el primer gran paso para regularizar su situación. Teniendo el conocimiento y un pequeño censo de las distintas disciplinas artísticas 
realizadas en la calle Madero. Sin embargo, como expresaron mis informantes en entrevistas, en dicha asociación no se buscó la calidad, ni verdadero apoyo a los artistas callejeros que han luchado durante años por sus espacios, ya que apuntan que el autonombrado Presidente de la Asociación: “Azteca Plateado” se dedicó a agremiar a todos los "vagos" de la calle en esta unión. Como he comentado, no creo que el encontrar en el arte una forma digna de vivir y ganarse el dinero de manera honrada sea cuestionable, pero desde el gremio artístico fue una decisión injusta, ya que vulneraba el trabajo de todos y la calidad podía mermar al resto de los artistas callejeros. Así que a pesar de tener un gran avance con la Asamblea Legislativa del DF, la A.C creada por los artistas callejeros fue motivo de conflicto interno, nuevamente. Ninguno de mis informantes tenía más papeles sobre dicha Asociación, solamente tenían las obligaciones y estatutos legales, pero nadie votó para elegir Presidente al "Azteca Plateado", así que los conflictos internos no se hicieron esperar, ya que los agremiados que contaban con años trabajando en el $\mathrm{CH}$ consideraron injusto que se integraran a dicha organización a artistas no conocidos, a "vagos", boleadores. Fue como chivo expiatorio [refiriéndose al "Azteca Plateado"]. Asoció a la gente: 59 eran, luego hasta 70 y para todos ponerse ahí. (Entrevista con Mario Peña, "Watt", performance- estatua viviente, 25 de enero de 2011). El Presidente de la Asociación se tomó muy en serio su papel y se dedicaba a organizar y otorgar espacios a los artistas, dando los mejores lugares a los que consideraba eran artistas y restringiendo se colocaran todos los agremiados. Desde una visión estética es una buena manera de que se aprecie el arte, con espacio, libertad y esparcimiento, pero dentro del gremio se llegó a comentar que si se colocaba un artista que no fuera su amigo, le mandaba a los policías para que lo quitaran, son historias que se cuentan en Madero y varios informantes coinciden con esta versión. 

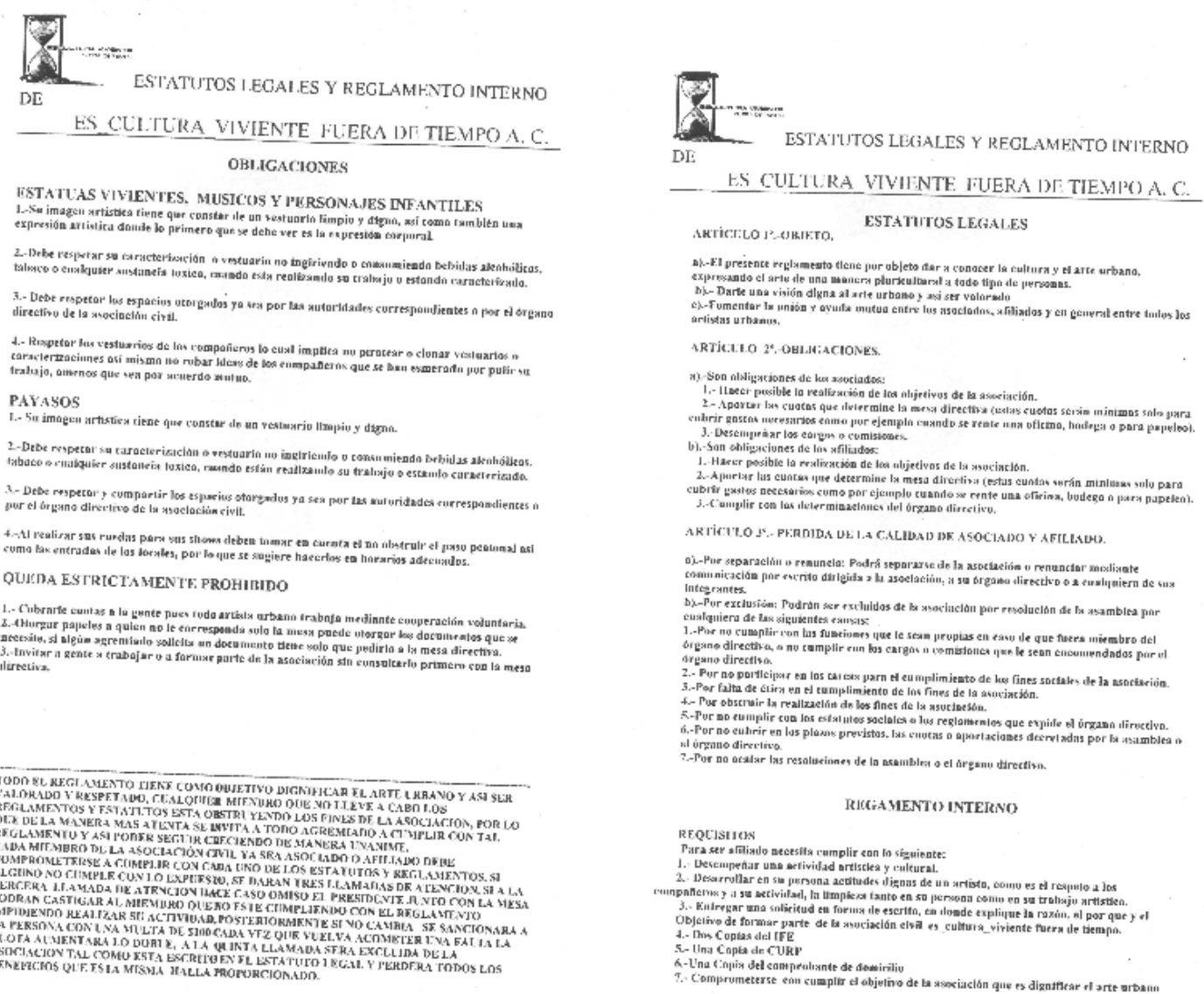

Documento proporcionado por Jonathan Ríos “Azteca Dorado". Febrero de 2011

La creación de ES CULTURA VIVIENTE FUERA DE TIEMPO A.C trajo como resultado la entrega de credenciales a los agremiados, sin embargo, dichas acreditaciones eran vendidas en $\$ 70$, lo cual molestó a los artistas callejeros, pero cedieron con tal de obtener un derecho en las calles del $\mathrm{CH}$. No me quería dar la credencial, yo fui por unos cuates que también hacen malabares y cosas acá, y fueron por golpeadores, rodearon al "Azteca Plateado" y nos dieron las credenciales, sino no hubiera sacado esas credenciales para nosotros. (Entrevista con Mario Peña, "Watt", performance- estatua viviente, 25 de enero de 2011). Aunque cabe mencionar que la credencial no era sólo como reconocimiento a sus agremiados, sino que fue avalada por la Diputada Mendicuti (Presidenta de la Comisión de cultura de la Asamblea Legislativa del DF), lo cual debería de haber dotado de reconocimiento legal a los artistas callejeros, pero la realidad fue que, siguieron siendo remitidos al Juez Cívico 33. 

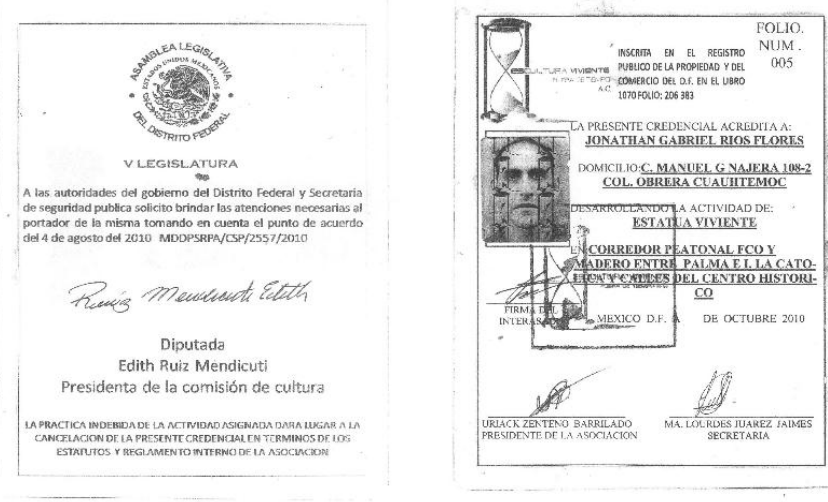

Documento proporcionado por Jonathan Ríos “Azteca Dorado". Febrero de 2011

De esta manera, la Asociación no parecía ser una solución viable, ya que el poder corrompe a cualquiera y al parecer, el autonombrado Presidente de la Asociación estaba cayendo en conflictos por el uso del espacio y el derecho de sus agremiados. Este fue otro de los muchos conflictos internos en los artistas callejeros de Madero. Si bien, el intento de crear una asociación para tener un censo, reglas y derechos es una instancia necesaria, el resultado no fue favorable para la gran mayoría. Sin embargo, con la credencial entregada podían colocarse sin mayores problemas, comenta "Watt" que los policías les decían que si López Candido los apoyaba no tenían problemas. Mientras tanto, el "Azteca Plateado" (dice "Watt") comenzó a hablar con Jesús Romero (Programas Delegacionales) y con la Diputada Mendicuti (quien había firmado su credencial en apoyo a sus actividades e intentando facilitar la gestión).

En entrevista con "Watt", quien tiene más claro el proceso de gestión, me comentó: "Es que se van a tener que afiliar a Alejandra Barrios". En noviembre "Se van a tener que afiliar a Alejandra Barrios porque sólo así vamos a volver a estar en Madero”. Eso lo estaba diciendo Mendicuti. (Entrevista con Mario Peña, "Watt”, performance- estatua viviente, 25 de enero de 2011). Por lo tanto, aunque ya se contaba con el reconocimiento y diálogo con autoridades, la realidad en la calle era otra, ya que a pesar de tener credenciales que apoyaban y permitían su labor por parte de la Asamblea Legislativa del DF, para poder trabajar era necesario afiliarse a PRO DIANA A.C. Es importante aclarar que durante todo este proceso de negociaciones con autoridades y la creación de la A.C de artistas callejeros en el CH, la presencia de la Asociación PRO DIANA era una constante, con la cual tenían que lidiar: entre policías, cobradores, Presidentes de asociaciones y demás elementos tenían que encontrar el momento y la paz para poder trabajar por medio de sus gestos y sus suaves movimientos. 


\section{d) Del Punto de Acuerdo a la intervención del Fideicomiso del CH y PRO DIANA}

A.C

Considero que el parteaguas en la gestión del espacio público para las manifestaciones de artistas callejeros es la relación y los resultados obtenidos con el Diputado López Candido, que si bien, no todos conocen el alcance, saben que existe un Diputado que intentó ayudarlos. Sin embargo, aunque el Punto de Acuerdo aprobado el 4 de agosto de 2010 no ha tenido avances legislativos, ni parece que los tendrá. Dicho funcionario decidió apoyarse para la gestión de los artistas en la instancia de Gobierno del $\mathrm{CH}$ que tiene más cercanía y éxito (según palabras de Anabelí Contreras) con la gente de este sitio, así que recurrieron al apoyo para tener negociaciones con el Fideicomiso del $\mathrm{CH}$ : Quien hace esa negociación es la Secretaría de Programas Delegaciones y Ordenamiento de la Vía Pública. A nosotros nos han invitado a participar por el éxito que se ha tenido en construir acuerdos. (Entrevista con Anabelí Contreras, Jefa de Unidad de Difusión, Fideicomiso del CH, 15 de abril). Si bien, como comenta Anabelí Contreras, la gestión no depende solamente del Fideicomiso, se convirtió en interlocutor entre las partes involucradas, de esta manera se dificulta más la gestión y aumenta el número de instancias responsables del $\mathrm{CH}$, por lo tanto, los acuerdos no han sido sencillos, ni del todo satisfactorios.

"Los primeros que nos empezaron a apoyar en este trabajo fue el Fideicomiso del $\mathrm{CH}$, llevamos una coordinación, les habían dado cursos a las estatuas vivientes, botargas, payasos y músicos. Unos cursos, porque hay personas que se ponen a trabajar y no saben ni dónde están trabajando, ellos apoyaron con esos cursos, si hubo un trabajo bastante coordinado con ellos, con asuntos delegacionales, pero como te comento, cuando se viene a insertar esta persona es cuando lo revienta todo, este avance que traíamos, se nos revierte, pero por eso buscamos la coordinación con el Secretario de Gobierno." (Entrevista con Fabiola, Secretaria particular del Diputado Arturo López Candido, 6 de abril de 2011)

Respecto a las negociaciones con el Secretario de Gobierno del DF no tengo mayor información que la otorgada por Fabiola, ya que ninguno de los artistas callejeros lo comentó o quizá ni lo saben. Respecto al Secretario de Gobierno, la Secretaria del Diputado López Candido comentó:

"El Secretario dice que si, que necesitamos darle las ubicaciones de estas personas, dónde estaban laborando para poder bajo estas circunstancias regular los espacios, cuántas personas van a empezar a trabajar, porque por el desempleo que ha habido en el país, muchos se han metido a hacer esto y no tienen conocimiento, sino que ven una oportunidad de trabajo y se insertan. Sin embargo, cuando los conoces, vas viendo que hay personas que se preparan hasta para hacer 
un soldado, estudian cómo se visten, para intentar insertarse en la mentalidad de un soldado." (Entrevista con Fabiola, Secretaria particular del Diputado Arturo López Candido, 6 de abril de 2011)

Lo comentado por Fabiola, quien tiene conocimiento del tema y de las gestiones realizadas, muestra que si puede haber una solución para ubicar a los artistas callejeros del $\mathrm{CH}$. Asume que la mayoría de éstos se preparan, por lo menos observando y actuando como lo harían las personas en las cuales se basan sus personajes. Quiero retomar que si Fabiola dice que el Secretario de Gobierno está dispuesto a ubicar a los artistas callejeros es porque no están prohibidas sus actividades, ni sus presentaciones en espacios públicos. Aunque eso genera una contradicción más, ya que según la Ley Cívica del DF, todo aglomeramiento de personas está prohibido, así como lo comentado por "Batman": está prohibido trabajar en las calles del CH. Sin embargo, el que la discusión sobre este tema esté en diversos niveles de Gobierno, muestra que es un problema que tendrá que resolverse, quizá realizando una propuesta de política cultural en este espacio, en donde sean consideradas estas expresiones artísticas en las calles. Asumo que puede convertirse en un riesgo que se coloquen en calles con mucha afluencia, pero el considerar estas actividades como parte del desarrollo social (dentro del gremio y para el público), así como el derecho que tenemos a disfrutar la ciudad, es fundamental.

Ahora bien, como lo mencioné líneas atrás, el Diputado López Candido acudió al Fideicomiso del $\mathrm{CH}$ para solicitar apoyo para las gestiones de los artistas callejeros del $\mathrm{CH}$. No hay claridad en las fechas en que comenzaron a gestionar con el Fideicomiso, me comentaron que fue en diciembre de 2010, ya que a pesar de contar con sus credenciales, respetar los lugares y no colocarse sobre Madero, surgió un problema más el 1 y 2 de noviembre, ya que llegaron muchos "disfrazados", por lo que fue prohibida la actuación de cualquier artista callejero. Por lo comentado por mis entrevistados, el Fideicomiso del $\mathrm{CH}$ les propuso (en reuniones previas) darles otros puntos para trabajar:

"En noviembre el Fideicomiso del $\mathrm{CH}$ estuvo trabajando, estuvimos en juntas interminables para buscar lugares que no fueran en Madero, para darnos una alternativa que no fuera en Madero, nos dieron plazas en Lic. Verdad, Plaza Loreto, de la Conchita, del Teatro Blanquita, de las Vizcainas. No querían que estuviéramos en Madero, que por medidas de seguridad." (Entrevista con Eduardo Álvarez, "Teatrero, malabarista", 28 de enero de 2011) 
Las calles que les dieron para trabajar no los convencían, ya que dicen que no pasa suficiente gente y por lo tanto, las monedas en su bote disminuyen, así que la disputa por Madero y calles principales continuaron, a pesar del ofrecimiento de darles concesiones para trabajar en otros sitios del $\mathrm{CH}$.

Otro acuerdo con el Fideicomiso del $\mathrm{CH}$ fue darles permiso para que pudieran trabajar del 12 de diciembre al 12 de enero en los nuevos sitios asignados y en el resto de las calles del $\mathrm{CH}$ y sobre todo en Madero, ya que es una de las temporadas más fuertes del año. Así que, asumo que las restricciones y tolerancias dependen de los acuerdos políticos, ya que si de verdad estuviera prohibido cualquier tipo de manifestación artística en la calle, no hubieran tenido la concesión a finales de 2010. En todo este proceso, PRO DIANA A.C comenzaba a presionar a los artistas para que pagaran una cuota de \$50 por día para poder colocarse en el conflictivo espacio de Madero, la mayoría no cedió en ese momento, ya que al tener la concesión de las autoridades no tenían problemas para trabajar, aunque en ocasiones los seguían remitiendo al Juez Cívico 33 por obstrucción en vía pública.

\section{- Reunión realizada con el Fideicomiso del CH: 12 de enero de 2011}

El 12 de enero de 2011 comenzó la veda de los artistas callejeros y tuvieron reunión con el Fideicomiso del $\mathrm{CH}$, entre otros temas se trataron los intentos de cobro para el uso de la calle por parte de PRO DIANA A.C. y el balance de las actividades realizadas durante diciembre. Quiero aclarar que los artistas callejeros me entregaron algunas grabaciones de las reuniones con Fideicomiso, no tengo los nombres de las personas que intervienen, pero la información es verídica y considero que es la fuente directa para esta última parte del análisis:

"Se acercaron dos señoras a decirme que trabajaban en la calle Pimentel, que eran comerciantes, que pagando $\$ 100$, no necesitaba ningún permiso, que los policías se encargaban de todo. Yo no accedí a eso, porque creo que las cosas se tienen que hacer derechas, como estamos tratando que se hagan. ¿Pero cómo me dicen que las cosas se hacen derechas? si yo vengo un día y me dicen que es la reunión definitiva y que en un mes nos vamos a volver a reunir, yo no pude trabajar ni un día en el centro. Hubiera sido muy fácil decir: sí, te pago, pero no me parece." (Artista callejero, audio de reunión con Fideicomiso del CH, 12 de enero de 2011)

Por lo presentado en esa reunión, el tema de la A.C que quiere cobrar por los lugares en 
la calle, fue tratado por varios de los artistas, así que era una realidad conocida para el Fideicomiso del $\mathrm{CH}$, ya que en la misma reunión también se comentó la expulsión del "Azteca Plateado" de la calle Madero, y que como ellos dicen, no quiso alinearse con dicha asociación. Por lo tanto, tenemos un elemento más en la gestión de esta calle, el poder que sigue teniendo la familia Barrios sobre los espacios públicos del $\mathrm{CH}$. A lo que los artistas, en su momento, decidieron no pagar para colocarse en la calle, que si bien, pagando $\$ 50$ diarios tienen seguridad de poder trabajar, ya que dicha A.C hace la gestión con Programas Delegacionales y los policías de la calle, los artistas consideraron que era degradante caer en la "mafia de Barrios" como algunos dicen. Sobre el uso de la calle, otro artista planteó:

"Pagar va en contra de los acuerdos, pero si las autoridades no cumplen, yo tampoco cumplo. No es darle la espalda, la prueba es que estoy aquí, yo si estuve trabajando con estas personas, porque me convenía trabajar, venía por una lana. Porque los puntos que nos dieron, la verdad es que no sacaba. Hay veces que iba a otros lados tratando de trabajar y lo pude hacer. Si es bien bonito todo lo que se trató de hacer, pero la realidad es otra, ¿qué pasa?" (Artista callejero, audio de reunión con Fideicomiso del CH, 12 de enero de 2011)

Como lo comenté líneas atrás, el artista callejero del $\mathrm{CH}$ encuentra en las manifestaciones estéticas la forma de ganarse la vida, por lo tanto, no deja de ser un negocio. Aunque lo hacen con calidad, libertad creativa y soltura, la realidad es que es su medio de vida y tienen que trabajar, aún pagando a una A.C que no tiene interés por el arte, sino por el uso de sus espacios públicos, pero ha sido la forma en que muchos han podido seguir expresándose en las calles del $\mathrm{CH}$. La cuota de $\$ 50$ por día, lamentablemente, le ha dado una forma de trabajo a muchas personas, que encuentran en su bote la retribución por su esfuerzo físico y mental, que no han encontrado otra manera de expresarse y que en las calles encuentran el refugio para su creatividad. Sin embargo, si las calles son el espacio de la ciudadanía, pero tienes que pagar el costo por utilizarlas, algunos han caído en la lamentable forma de organización de esta calle, pagar por estar en este espacio público es una realidad tangible. Algunos artistas callejeros han propuesto pagar impuestos al Gobierno para poder colocarse en las calles del $\mathrm{CH}$, pero no ha habido respuesta al respecto. Por lo tanto, después de casi 4 años de negociaciones por el espacio público, luchando por el reconocimiento y la libertad creativa, a muchos nos les queda otra salida que pagar a una A.C para las minorías (como se autonombra dicha asociación). 
El Fidecomiso del CH en la reunión del 12 de enero de 2011 les dijo lo siguiente:

"Lamento que se hayan malinterpretado ciertos términos. Cuando les dijimos, si para salvar la temporada, el costo es darle dinero a estos mafiosos para salvarla, dénselos, se los dijimos derecho. Pero de eso a que haya habido una intención de vayan y denles, jamás les dijimos: vayan y cáiganle con un varo a los compas, ni jamás hemos aceptado un peso de ellos, eso lo quiero dejar muy clarito. Insisto, si les dijimos $\underline{\mathrm{Si} \text { el costo de salvar la temporada es que le caigan con una feria a }}$ estos cuates, aunque nos mordamos el orgullo, hay que dárselos, por sacar el chivo (subrayado mío). Estábamos conscientes del tipo de temporada que enfrentábamos, es una temporada particularmente delicada en el centro, todo el mundo anda buscando la chuleta, hay gastos, las fiestas, hay un consumismo exagerado, por eso necesitamos lana para la temporada, también necesitamos un varito, es parte de una cultura de la cual somos partícipes." (Representante del Fideicomiso del CH, audio de reunión con dicha institución, 12 de enero de 2011)

No sé qué persona del Fideicomiso es la que estuvo al frente de las reuniones, pero lo que queda claro es que ellos saben del poder político y social que tiene Alejandra Barrios y su familia, ya que proponer a los artistas que paguen la cuota que ella solicita, es porque se sabe que ella no va a dejar que nadie gestione ese espacio, así que queda alinearse o morir en el intento. Muchos artistas callejeros han decidido morir en el intento y ya no se colocan en las calles del $\mathrm{CH}$, cansados por la falta de apoyo, persecuciones de PRO DIANA A.C., las complicaciones de gestión, desgaste físico y mental, aunado a las tarifas por estar en espacio público, se convierte en un vía crucis ser parte del arte público en el CH. Las palabras del representante del Fideicomiso muestran el conocimiento que tiene de la problemática en Madero y la solución para salir del paso es que paguen por el uso de suelo del espacio público a una asociación que nada tiene que ver con el arte, pero si con el poder en el $\mathrm{CH}$. Aclaro nuevamente, la gran mayoría de los artistas callejeros ven esta actividad un medio de vida honrado, para entretener al público y contar con libertad, por lo tanto, el ganarse una moneda en las calles requiere del sacrificio (para muchos) de tener que pagar por $50 \mathrm{cms}^{2}$ para ofrecer un espectáculo a la gente que camina por estas calles.

Respecto a la asociación dirigida por Diana Barrios, el representante del Fideicomiso del CH explicó:

"Lo peor es la presencia del grupo de Diana Barrios, quiero compartir como vivimos desde el Gobierno esta situación. La lectura que le dio Diana Barrios a esta situación es que ellos son dueños de ese territorio, porque ahí vendían antes y como fueron objeto de una negociación política con el gobierno para vender en 
espacios cerrados, para que se liberaran esos espacios públicos, no estaban dispuestos a que esos espacios públicos tuvieran nuevos dueños [subrayado mío], por lo tanto, el hecho de que ellos se salieran con las botargas era para rescatar su espacio, ahora, el tema está en que el asunto planteado en esos términos, delante de nosotros no nos han dicho que cobran, ellos dicen que ustedes los buscan para que les den asesoría. Lamentablemente, es que el caso de ustedes estaba siendo utilizado para presionar al Gobierno, en el sentido de utilizar otros espacios. El $\mathrm{CH}$ no es nada más Madero, nos preocupa por supuesto, pero nos preocupaba mucho la Alameda, varios que nos pidieron instalarse en la Alameda, les dijimos si, pero en Juárez del otro lado, se llevaron a unos." (Representante del Fideicomiso del $\mathrm{CH}$, audio de reunión con dicha institución, 12 de enero de 2011)

Lo expuesto desde el Fideicomiso del CH muestra la claridad en la gestión, los espacios públicos que eran del comercio informal, aunque ellos ya no estén físicamente, siguen siendo de sus representantes, por medio del cobro de cuotas, la llegada de botargas (ex comerciantes ambulantes), pero lo importante es que es un secreto a voces, contra el cual parece no se puede hacer nada. Así como la Diputada Mendicuti les dijo que tenían que pagar, el representante del Fideicomiso del $\mathrm{CH}$ también asume que esa es la realidad de este espacio, de disfrute para unos, de arte y negocio para otros, pero a todo esto, ¿Dónde queda el arte, la creatividad? Se ha caído en una mercantilización desmedida, dirigida por personas que lo único que quieren es proteger su territorio, tomando como rehén al arte. Respecto a ser dueños de la calle, David Reyes, uno de los denominados coordinadores de la calle Madero (PRO DIANA A.C) me dijo en entrevista:

"Bueno, nosotros no somos dueños, no nos consideramos los dueños. Más bien, nosotros nos consideramos coordinadores para que la gente pueda trabajar. Nosotros vemos que estas personas están trabajando bien, no son conflictivos, nos apoyan. Buscamos que esa misma gente tenga el espacio para trabajar." (Entrevista con David Reyes, Coordinador de la calle, PRO DIANA A.C, 26 de enero de 2011)

Al parecer no se consideran dueños de la calle, pero es bien sabido que cobran por el uso del espacio público en diferentes calles del $\mathrm{CH}$, las autoridades también lo saben y lo asumen como el costo que se tuvo que pagar por quitar a los vendedores ambulantes del $\mathrm{CH}$. El costo ha sido alto, ya que son los encargados de dar espacios para manifestaciones artísticas, de las cuales no creo que tengan conocimiento estético, de comunicación o percepción, pero esta es la realidad desde la calle y las autoridades.

En esta reunión se concluyó que la veda para los artistas callejeros continuaría 
mientras se hicieran las gestiones pertinentes para sus actividades en espacios públicos, ya que no existe ley local, ni federal que prohíba estas actividades, pero tampoco que las fomente o que exija un trato diferenciado que el otorgado a los ambulantes, así que la relación con el ambulantaje sigue siendo una constante. En esta reunión se propuso hacer talleres de cultura urbana en el $\mathrm{CH}$, lo cual aplaudo, aunque cuestiono si eso ayudará a gestionar las actividades artísticas en sus espacios públicos, ya que el discurso es elocuente y convincente, pero la realidad de abusos, desprestigio y renta de espacios es con lo que se enfrentan día a día. En la reunión del 12 de enero de 2011 el representante del Fideicomiso comentó:

"Un elemento de balance para indicar, las áreas del Gobierno, del poder Ejecutivo de la ciudad con poder Legislativo, pocas veces podemos hacerlo juntos. Si derivado del taller salen propuestas que se ameriten legislaciones haremos lo que corresponde. Esta ocasión vamos juntos, es un elemento que hay que reconocer, el Diputado López Candido sería integrante de todo esto." (Representante del Fideicomiso del CH, audio de reunión con dicha institución, 12 de enero de 2011)

La propuesta desde el Fideicomiso del $\mathrm{CH}$ promueve lo que tanto se necesita en las políticas culturales: participación de los sectores involucrados, en este caso, también el reconocimiento a sus actividades y el apoyo para poder gestionar sus espacios, calidad y respeto hacia ellos. Sin embargo, a 6 meses de esa propuesta, no se ha promulgado una ley, ni mucho menos se han terminado los conflictos por la lucha del espacio público desde el arte, que como he mencionado, también es su forma de vida honesta, sufren las inclemencias del clima, políticas, asociaciones "dueñas" de espacios y por la falta de apoyo, lo cual genera conflictos internos y externos que son difíciles de superar.

\section{- Reunión realizada con el Fideicomiso del CH: 18 de enero de 2011}

Esta reunión no tuvo grandes cambios, se afirmó que la veda continuaría, que era necesario prepararlos en materia cultural, dándoles herramientas teóricas sobre arte y cultura, con lo cual coincido, pero ante la necesidad económica y de acuerdos claros, a los artistas no les resultó interesante la temática. Quizá esto marque más los conflictos entre los artistas con alguna preparación académica y los que no cuentan con ella. En esta reunión se intentó homologar definiciones de arte, cultura, $\mathrm{CH}$, su historia, UNESCO, etc. para que los artistas tuvieran herramientas básicas para realizar sus actividades. Sin embargo, ante la urgencia de contar con acuerdos concisos, la discusión teórica no surtió grandes efectos en los asistentes. 


\section{- Reunión realizada con el Fideicomiso del CH: 20 de enero de 2011}

Esta reunión es la última que tengo en audio, así que intentaré concluir con ella, ya que no hay más información al respecto. En dicha reunión se habló de los mecanismos que habían tenido para gestionar sus actividades en el $\mathrm{CH}$ : la entrega de credenciales de la Secretaría del Trabajo y la molestia que generaba en muchos no tenerlas. Sin embargo, uno de los artistas aclaró la credencial no nos va a hacer artistas (Artista callejero, audio de reunión con Fideicomiso del CH, 12 de enero de 2011). Lo cual me parece un punto relevante, el contar con esa acreditación no genera que se mejore la calidad o la afluencia del público, sin embargo, si genera cierta seguridad porque se supone que no pueden ser remitidos al Juez Cívico, aunque con todo y credencial pueden llegar a los separos. En esta reunión también se expresó la propuesta de que Filomeno Mata y Gante se hicieran corredores culturales (como lo presenté en el capítulo 1 de esta tesis). El representante del Fideicomiso del $\mathrm{CH}$ hizo una reflexión sobre las propuestas y la problemática:

"Anhelos: 1. Distinguirnos de los vendedores ambulantes. 2. Fortalecer nuestra identidad como colectivo artístico. 3. Fortalecer nuestra asociación. Petición: Salir a trabajar a partir de este fin de semana. Sugerencias: 1. Tomar como base las 14 credenciales expedidas en 2006, 2007 y 2008 y quienes no las tengan apoyarlos. 2. Fortalecer mecanismos de capacitación y formación. 3. Contar con espacio físico en el CH. 4. Tener presencia en los eventos que organiza el GDF. 5. Cubrir varias zonas del $\mathrm{CH}$ mediante la itinerancia e instituciones. 6. Organizar eventos propios: festivales, jornadas, carnavales, encuentros, etc. 7. Instaurar como plan piloto de manera oficial como corredores peatonales en Filomeno Mata y Gante. 8. Fortalecer la organización del gremio a través de la adopción de figuras asociativas legalmente constituidas." (Representante del Fideicomiso del $\mathrm{CH}$, audio de reunión con dicha institución, 20 de enero de 2011)

Lo presentado en esta última reunión es fundamental, ya que si se cumplieran los anhelos y las sugerencias no existirían problemas por el uso de los espacios públicos desde el arte. El poder distinguirse de los ambulantes debe ser elemento clave, ya que las actividades son diferentes, la reflexión generada en el público no se compara, el disfrute del espacio público cambia de atmósfera cuando ellos se colocan, se aprende arte e historia, por lo tanto, el que se distingan de los ambulantes es fundamental. Sin embargo, no puedo olvidar que la asociación que les sigue cobrando plaza para colocarse en Madero, depende claramente del ambulantaje, así que tener autonomía con el ambulantaje es complicado ante la necesidad de trabajo. De las sugerencias, el tema de las credenciales ya lo analicé y no me resta más que decir que, aunque las 
acreditaciones otorgadas por la Secretaría del Trabajo no autorizan automáticamente las labores en espacios públicos del $\mathrm{CH}$, su entrega generó un sinfín de conflictos internos que a la fecha han mermado algunas relaciones en el gremio. Las demás credenciales tampoco han marcado un gran cambio en sus actividades, ni en el respeto hacia ellas, pero si ha sido un avance en las negociaciones del implicado sistema de gestión en el CH. Capacitación y formación deberán ser fundamentales para mejorar sus ejecuciones. Sin embargo, ante la falta de oportunidades en otros sectores, algunos han encontrado en el arte una forma honrada de ganarse la vida, por lo que, la capacitación creo que se encuentra entre sus últimos deseos, ante la inminencia de tener sustento.

Contar con espacio físico en el $\mathrm{CH}$ es lo ideal, pero la realidad es otra, la gestión por los espacios va más allá de sus anhelos y de sus propuestas, ya que las mismas instituciones del $\mathrm{CH}$ asumen que existen "dueños” en algunas calles, así que es un problema más político que tendrán que resolver las instituciones competentes, aunque sigo cuestionando ¿En todo este conflicto dónde queda el arte y la creatividad? Pareciera que se ha perdido entre credenciales, puntos de acuerdo, reuniones y pagos por el espacio. Algunos, los menos, siguen yendo sin pagar, pero saben que el riesgo de que los corran por colocarse es mayor, así que la tensión en Madero es continua y el arte público ante los conflictos políticos por el espacio, se complica cada vez más.

El punto 4 sobre su presencia en eventos organizados por el GDF solamente se cumplió en 2010 cuando algunos de los artistas callejeros entrevistados estuvieron en el evento Prepa $\mathrm{Si}$, pero ha sido la única relación artística que han tenido con el GDF. Quiero pensar que aunque la reunión con el Fideicomiso del CH fue en enero de 2011, siguen analizando la problemática y si es posible los invitarán a colaborar en algún evento, pero hasta la fecha no ha sucedido.

Cubrir varias zonas del $\mathrm{CH}$ con manifestaciones artísticas itinerantes sigue siendo lejano, ya que como los artistas mencionan, con o sin credencial no tienen permitido expresarse en las calles del $\mathrm{CH}$. Otro de los anhelos tampoco se ha cumplido, según mis informantes, no se han realizado eventos que promuevan sus actividades, quizá otro tipo de expresiones si, pero el arte callejero sigue estando en el tintero de nuestras políticas 
culturales en el $\mathrm{CH}$. El plan piloto de corredor cultural para Filomeno Mata y Gante tampoco se ha llevado a cabo, supongo que requiere de tiempo de planeación y consulta o como muchas otras propuestas se ha quedado en las buenas intenciones. Este corredor cultural, como lo presenté en el capítulo del $\mathrm{CH}$ del DF es la confusión con los términos, remitiendo a lo cultural, para un arquitecto que ha realizado obras en el $\mathrm{CH}$ y trabaja en el GDF, un corredor cultural es donde vive gente y de preferencia artistas (como Regina), mientras que para los artistas se refiere a un espacio público donde se presenten diferentes manifestaciones artísticas. Así que este es uno de los tantos conflictos en el $\mathrm{CH}$. El contar con una asociación con figura jurídica es una realidad, tienen ES CULTURA VIVIENTE FUERA DE TIEMPO A.C, pero eso no ha logrado que su lucha por el espacio público tenga los resultados esperados, existen intereses internos en el gremio: unos por la calidad, otros por necesidad, conflictos políticos y económicos en el espacio público del $\mathrm{CH}$.

Sus actividades han sido constantes, por diversas calles del $\mathrm{CH}$, desde hace una década, su realidad es que continúan en una lucha que no tiene fin, donde la gestión desde diversas instituciones, con la Asamblea Legislativa, creando una A.C para tener figura jurídica, etc., han sido sólo algunos de los avances que han logrado, pero no se han podido resolver los problemas de raíz, su esfuerzo por lograr un trabajo digno por medio del arte, teniendo una vida honrada, otorgando al paseante un paisaje y una atmósfera fuera de su realidad, no bastan ante las presiones políticas y económicas en el espacio del $\mathrm{CH}$.

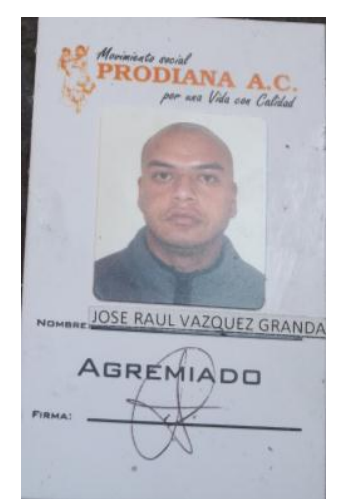

Documento proporcionado por Raúl Vázquez “La Muerte”. Marzo de 2011

La calle Madero se ha convertido en el bastión de PRO DIANA A.C (que ya entregó credenciales a sus agremiados), se considera dueña de la calle, pero también admito que ante la necesidad de ganarse el dinero de manera honrada, otorga espacios para que la gente pueda trabajar y expresarse de manera digna. Sin embargo, en todo este proceso se ha dejado fuera al arte, la creatividad y la libertad. Si el arte público está en las calles y no contiene solamente monumentos, ¿Cómo se logra la gestión entre el inmaculado patrimonio cultural tangible de Madero y los artistas callejeros? Es una 
pregunta que requiere muchas aristas de análisis, que no se pueden cerrar en el arte y la academia, sino a problemas internos por la lucha del espacio, por la entrada del ambulantaje al territorio del arte. También se deben considerar las instituciones externas, que como presenté en el capítulo del $\mathrm{CH}$ del DF, son diversas y con intereses diferentes, siempre en coordinación, pero con autonomía, por lo que la gestión de este espacio para el arte público es compleja. Las reglas de la calle son cero tolerancia para estas actividades, pero si la persona encargada de otorgar tolerancias decide que pueden hacerlo, se soluciona el problema del aglomeramiento de personas (principal argumento para no permitir sus actividades).

Asumo que algunas propuestas artísticas callejeras no pueden, ni deben competir con las políticas monumentalistas en Madero. Es necesario hacer una revisión sobre el peso que se otorga a cada una, ya que las manifestaciones callejeras han dotado de atmósferas, disfrute y conocimiento al público, que en las entrevistas realizadas a este sector no presentan quejas por la realización de estas actividades, quisieran que hubiera más y mejores. Por lo tanto, el visitante valora el paseo de esta remodelada calle Madero, así como las actividades artísticas presentadas en ella, algunos las comparan con las realizadas en Europa y otros simplemente dicen que les gusta llevar a sus hijos a que aprendan en la calle. ¿No es motivo suficiente para apoyar estas manifestaciones artísticas? A pesar de los intentos de diversas instituciones, en estos momentos, estos artistas están vedados en Madero, aún pagando su cuota, la tolerancia se ha quitado y su realidad es la búsqueda de un trabajo honrado o de un espacio donde expresar sus capacidades artísticas. Los intentos de gestión del espacio público para el arte no han tenido los resultados esperados, ya que el espacio en nuestro $\mathrm{CH}$ tiene un sinfín de aristas de análisis: algunos políticos, otros económicos, de seguridad, pero el arte parece que se ha quedado en el último eslabón de este espacio. Si bien, no todos los ejecutantes son artistas profesionales, encontraron en el arte público la forma de autoemplearse, con libertad creativa, de horarios y la satisfacción (emocional y económica) derivada de la calle, pero su historia no ha terminado de escribirse, estos espacios siguen en lucha y los artistas de la calle Madero buscan otros lugares para trabajar, mientras se resuelve su situación en esta calle con intereses y disputas constantes, con los edificios como testigo de la historia, de las luchas sociales y ahora de la disputa por el espacio público para el 
arte. $\mathrm{Si}$, el patrimonio inmaculado se ha convertido en vigilante de este sitio, que ha sufrido aglomeraciones, remisiones policíacas, conflictos internos entre los artistas, intromisión de ambulantes y acuerdos que no se han cumplido.

\section{Galería: Artistas de la calle Francisco I. Madero}

Gladys "Sacerdotisa Mexica

"Siento que para que el país avance debes de tomar en cuenta el arte. En muchos países, el arte urbano, las estatuas vivientes, los músicos son parte esencial."

Ana de Alba "Cantante de ópera

"El artista urbano puede tener o no preparación, pero debe de tener mucho carácter. En un escenario normal, las cosas están planeadas $[\ldots]$ pero aquí no se sabe: es un azar."
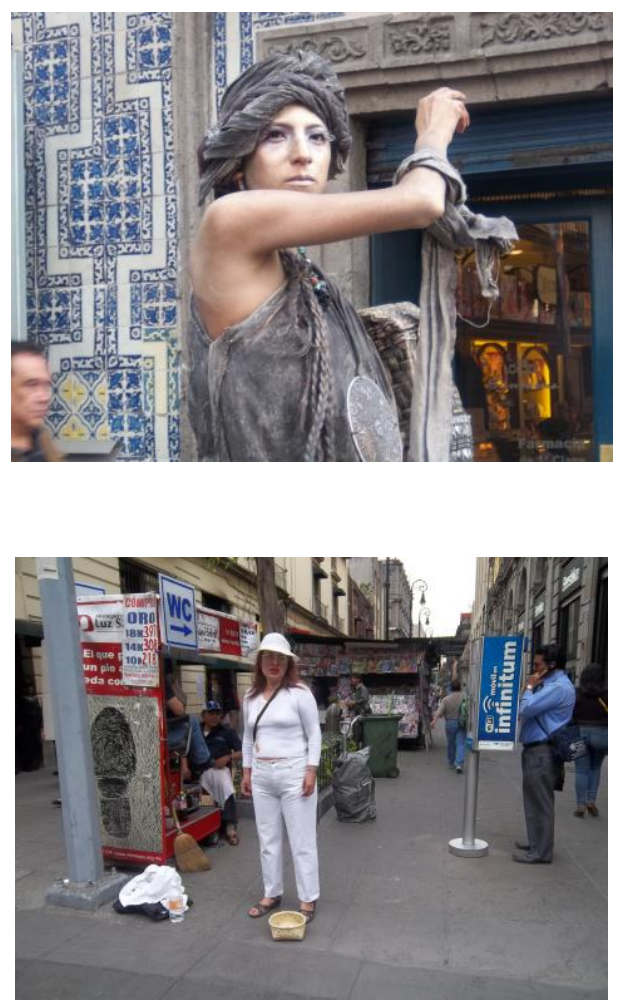

Ana Álvarez "Bruja
Wicca"
"El arte urbano es más
libre. De alguna manera,
no tiene reglas y se ofrece
a todo público [...]
Cuando la gente ve al
artista urbano, de alguna
manera empieza a tener
interés por el arte."

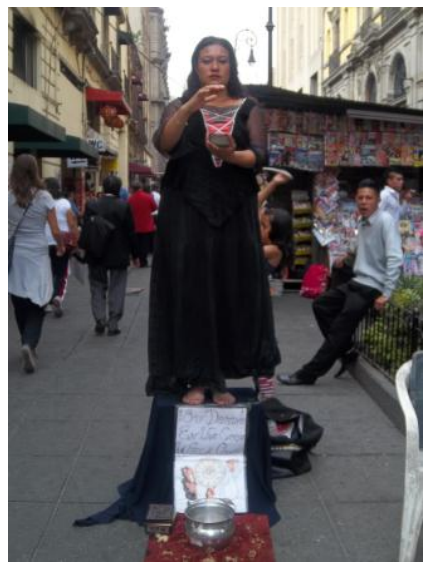


Sergio Sierra "Michael Jackson"

"El arte es una pequeña poesía de tu vida, tienes que ir construyéndolo, ir amándolo, ir sintiéndolo, para que te des cuenta que el arte es la vida misma."

Raúl Vázquez

"La Muerte" y "Cronos"

"Para hacer el trabajo es como todo artista, tienes que empezar con lo básico y la misma gente es la que te va puliendo el trabajo, porque aparte de ser tus patrones, son tus jueces."

Jesús "La Sombra"

"El arte lo puedes difundir donde sea, obviamente también lo hacemos con un fin [...] es mi oficio y la forma de mantener a mi familia."

Mario Peña "Watt" y "Caballero de las Puertas de la Percepción"

"Para mi ha sido la construcción de mi mismo, no algo de construir un personaje [...] intento darle algo a la gente, algo que los saque de su cotidianeidad."
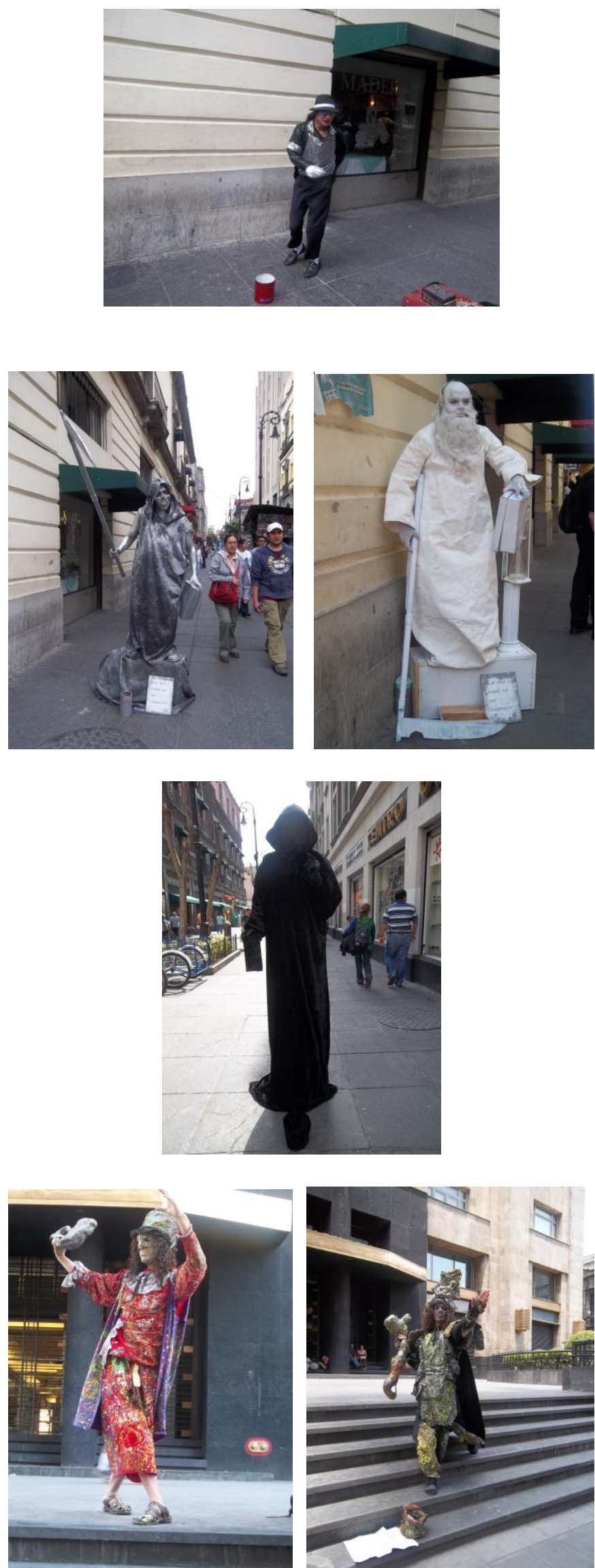
José Luis Carrillo

"El Soldado"

"Debes estar concentrado, no pensar mucho en las cosas, sacas lo que tienes adentro para dárselo a la gente."

Antonio Armengüal

"El obrero"

"Mi actividad es cultural $100 \%$, expreso que nuestra cultura es trabajadora. Pongo en alto este orgullo, para que aquellos que están arriba se den cuenta de que existimos y que tenemos que ser equitativos."

Eduardo Álvarez "Teatrero, malabarista" "Hay un desconocimiento de la capacidad del arte callejero para elevar el nivel cultural, el nivel de educación. Somos una piedrita en el zapato que el policía tiene la misión de ir a quitar."

Abraham Álvarez "Batman, Spider Man, Iron Man"

"No me gusta trabajar para nadie, soy una persona libre. Ví la libertad y capacidad para trabajar aquí y me gustó.”
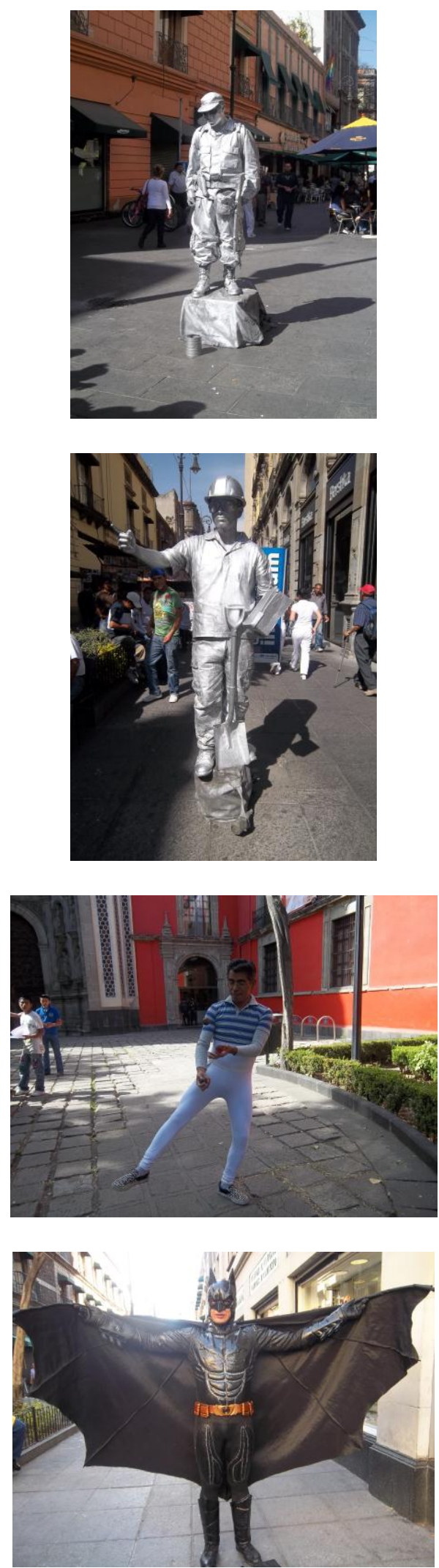
Itzel Díaz "Catrina"

"El $\mathrm{CH}$ es un lugar turístico, hay mucha cultura, los edificios son bonitos, hay que respetarlo. La gente viene a ver algo bueno, para eso se necesita creatividad y no ser ofensivos."

Julio Gómez "Minero", "Catrín" y "Sombrerero Loco"

"Yo creo que desde un principio, cuando alguien vio que aquí había varo buscó sus intereses y las causas se dejaron a un lado. Algunos buscamos mantener vivo el arte callejero, otros vieron que aquí había varo."

Jonathan Ríos "Azteca Dorado" y "Apache"

"El 2 de noviembre la gente se vino disfrazada. Algunos aprovecharon $\mathrm{y}$ dijeron: Él es artista, entonces yo también me visto y soy artista. Pero ellos no vieron toda la lucha que tuvimos por la calle de Madero."

Luis Miguel de la Cruz "Payaso Picolín"

"Abajo del maquillaje también sufrimos, sentimos; pero intentamos quitar el estrés de la gente que va pasando."
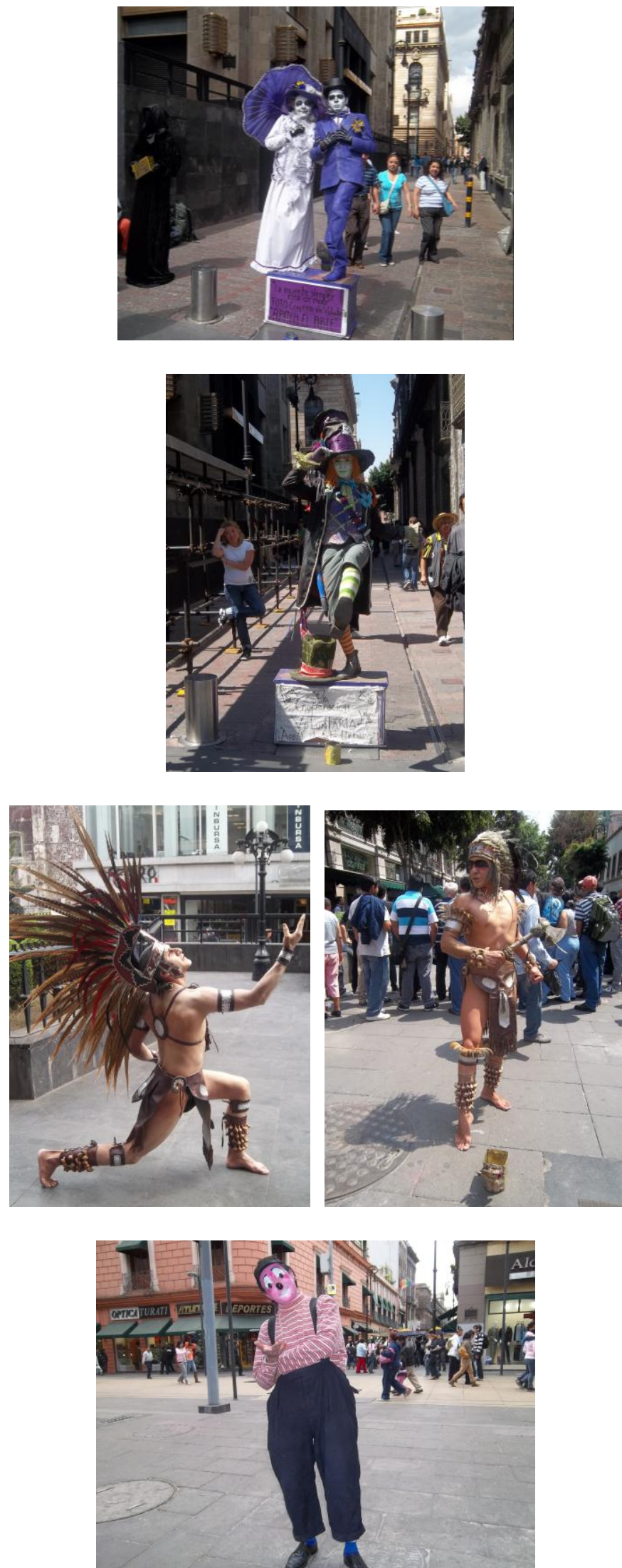
Juan Fonseca "Mago"

"No todo mundo se atreve a hacer magia en la calle, en pleno día. No es fácil enfrentar a un público que por donde quiera te está mirando."

Esteban Balkan "Músico" "Es una presión la mirada fija y cercana. A diferencia de las miradas múltiples en un gran escenario, que al fin de cuentas no sabes quien te está viendo [...] Disfrutas de otra manera."
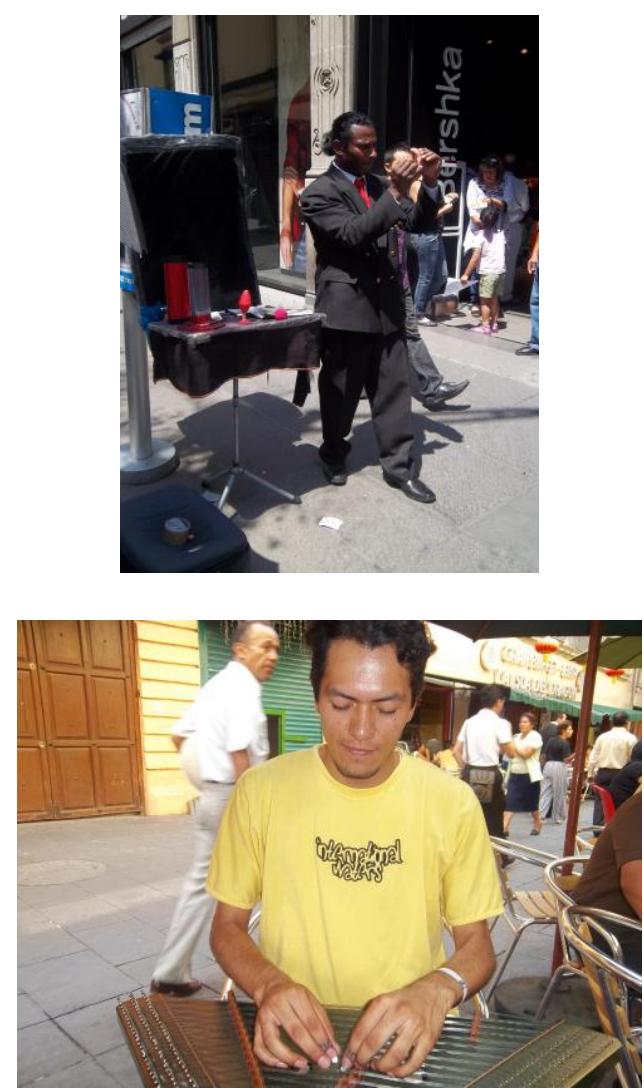


\section{Conclusiones.}

Cabe destacar que la hipótesis inicialmente planteada: La revitalización del Centro Histórico y en particular de la calle de Madero como espacio público con vasto patrimonio cultural, en donde se encuentra la cultura y la historia, deja de lado manifestaciones y expresiones que van más allá de la cultura y arte en foros cerrados y /o patrimoniales. ¿Cómo lograr encuentros entre arte urbano callejero (espacio público) y el patrimonio cultural en las políticas culturales del corredor Madero del Centro Histórico? Se demuestra a través de esta investigación, ya que las políticas culturales del CH de la Ciudad de México muestran grandes vacíos respecto al arte callejero de la calle de Madero, no cuentan con apoyo institucional para formación, difusión, ni para legitimar estas actividades como parte del desarrollo social de la ciudad. Sin embargo, las políticas culturales en este espacio, dan gran apoyo a la conservación del patrimonio cultural tangible, expresado en fachadas, monumentos y edificios emblemáticos (palabras de la Autoridad del $\mathrm{CH}$ ). Considero que el no contar con políticas culturales, que permitan el fortalecimiento de estas actividades artísticas, ha generado la incursión de personas que ven en estas manifestaciones exclusivamente una actividad lucrativa y no una expresión artística que genera desarrollo social en la población.

Respecto a los objetivos planteados, considero que se han cumplido ampliamente, ya que en esta investigación llevé a cabo un análisis de las políticas culturales en la revitalización del corredor Madero en el $\mathrm{CH}$ de la Ciudad de México, en donde el uso, percepción de arte y cultura en este espacio fueron elementos sustanciales en el desarrollo de esta tesis. En relación a este objetivo, presenté brevemente las políticas culturales en el $\mathrm{CH}$, analizando el apoyo que se da al arte desde diferentes instituciones, así como la visión que sobre ella tienen los encargados de los museos de esta calle, en donde el arte en foros cerrados, con estudios formales y trayectoria reconocida, son una constante, por lo tanto, la percepción del arte (en muchos casos) sigue siendo restrictiva para personas creativas como las que se presentan en la calle de Madero. Mostrando un elemento más para el conflicto latente del gremio artístico callejero. 
Como lo he presentado, los $\mathrm{CH}$ son sitios complejos, donde identidad, memoria, poder e intereses se mezclan y se dispersan en la toma de decisiones y en las acciones a desarrollar. Los $\mathrm{CH}$ no son sólo espacios históricos, en su momento eran la ciudad misma, con comercio, habitantes, templos, museos, etc., por lo que su gestión debe considerar un sinfín de aspectos, como los he presentado: su vinculación con la ciudad, con el turismo, con la globalización, con la memoria, con el patrimonio, etc. Pero no debemos caer en la protección al patrimonio monumental a ultranza, es importante considerar el arte y las expresiones culturales que nacen en el sustrato de estos espacios. Aunque, como mencionan los especialistas en $\mathrm{CH}$, el patrimonio cultural es donde se generan las relaciones sociales de apropiación, por lo tanto, no es de extrañar que se de tanto apoyo a la conservación y restauración del patrimonio tangible. Sin embargo, desde lo cultural, que genera esa lucha de significados en las políticas culturales deberá jugar un rol fundamental el arte, ya que las acciones hacia éste no son tan claras, ni duraderas como hacia el patrimonio cultural tangible, se están dejando de lado otras expresiones artístico culturales. Que si bien, en muchos casos, estas manifestaciones artísticas no cuentan con los recursos necesarios para presentarse en foros establecidos. $\mathrm{El} \mathrm{CH}$ se convierte en un gran escenario para comunicar, disfrutar y es una forma de vida que no daña el entorno, ni a la población residente, ni visitante. Sin embargo, después de exponer algunos elementos del entramado que contemplan los $\mathrm{CH}$, no cabe duda que su gestión urbana, social, económica, cultural y turística tiene distintas aristas para poder realizar acciones concretas al respecto.

Al realizar esta investigación en un espacio público del $\mathrm{CH}$ puedo darme cuenta del entramado institucional que existe, donde las reglas para el uso del espacio público son estrictas, no como en cualquier otra zona de la ciudad, ya que existe una regulación extrema, en donde priman los intereses políticos y económicos en la gestión de las calles. La hiper regulación del espacio público en el $\mathrm{CH}$ convierte a estos sitios en un paseo obligado para visitantes, donde las fachadas inmaculadas al paso del tiempo muestran la historia del país, pero donde las actividades artísticas en el espacio público son condenadas con regulaciones que los convierten en vendedores ambulantes, por lo tanto, no hay cabida para acuerdos que confieran derechos y obligaciones a los artistas callejeros, sino la condena por el uso de un espacio público restrictivo como el $\mathrm{CH}$ de la 
Ciudad de México.

Los conflictos no terminan, las formas de intervención son complejas y las posturas convergentes o divergentes por momentos; pero la revitalización de esta zona es una realidad. La dificultad de análisis de esta área y por lo tanto, de la gestión puede ser por la cantidad de instituciones implicadas en la toma de decisiones, que si bien, existe una Autoridad rectora, las propuestas y acciones no son unilaterales, sino en diálogo con otras instituciones, que quizá tengan otros objetivos u otros intereses, pero los resultados saltan a la vista. El conflicto que analizo en la calle Francisco I. Madero, no sé si responde a estos conflictos por intereses de cada instancia, de tipo comercial, de seguridad, de limpieza o de las posturas radicales de ambas partes, pero considero que es necesario presentar la complejidad que existe detrás de nuestro $\mathrm{CH}$ para poder analizar de manera clara el tema en cuestión: arte público (callejero) en la calle Madero.

Es importante mencionar que la historia de las expresiones artísticas en la calle no es un fenómeno moderno, comenzó en la historia Grecolatina, pasando por los juglares, los cuadros vivientes, etc., los cuales encontraron en su cuerpo y en la calle el paisaje para expresar el arte para todos. Aunque también debo destacar que la gestión del espacio público en otras ciudades del mundo donde se presentan estas manifestaciones artísticas varía, en el caso de estudio, los artistas callejeros han recorrido varias calles del $\mathrm{CH}$ y ante las posturas de rehabilitarlo, se han encontrado con la "limpieza" de los espacios públicos, en donde ellos, al igual que los comerciantes ambulantes, han sido quitados de sus calles de origen, los fueron alejando del gran espacio público por excelencia: el Zócalo y los fueron trasladando hacia Madero, por lo tanto, luchan por un territorio que ellos no escogieron, sino que les fue otorgado (de alguna manera). Sin embargo, existen diferentes conflictos en el gremio artístico, desde la lucha por definir si lo que hacen es arte o no, que como desarrollé en el capítulo 4, el arte se da por medio del uso de la creatividad y los mensajes a comunicar a través de expresiones estéticas. Pero la lucha por definir si sus actividades son artísticas es uno más de los conflictos internos, en donde se han visto agredidos estéticamente porque han incursionado en estas actividades ex vendedores ambulantes, que han encontrado en estas manifestaciones una forma de ganarse la vida, lo cual no discuto, pero dentro del gremio ha llegado a generar inconformidades. 
La gestión del espacio público para el arte ha sido compleja y no se ha llegado a acciones que favorezcan a los artistas callejeros, posiblemente por la rigidez de cada postura, ya que desde las instituciones de gobierno, las actividades realizadas por los artistas en la vía pública generan un caos que puede tornarse en un problema de protección civil, debido a la cantidad de gente que se aglomera en la calle para verlos. Los locatarios no los reciben con buenos ojos, ya que dicen que desde que la calle es peatonal, pareciera que todo está permitido y no les gusta que estén estas manifestaciones, supongo que porque no permiten la libre entrada a sus locales.

Los conflictos internos en el gremio artístico callejero de esta calle han provocado separaciones entre ellos, que como algunos dicen, de esta forma el Gobierno puede hacer lo que quiera, ya que si no están unidos no podrán defender su espacio, ni las actividades de los demás. Con el respaldo de algunas instituciones de gobierno han tenido avances en las negociaciones para el uso del espacio público, pero no ha sido una gestión constante que genere una política cultural de gran alcance, sino acuerdos que les permitan trabajar algunos días, esperando que no sean remitidos al Juez Cívico 33, pero no hay acuerdos reales que fomenten estas actividades, ni les han dado espacios adecuados, ya que también es una forma de vida para ellos, por lo tanto, si no está permitido que se coloquen en Madero, podrían gestionarles otros espacios en el $\mathrm{CH}$, pero sitios donde exista una oferta cultural amplia y afluencia de personas, ya que el arte requiere de mensajes y público a quien transmitírselos.

Las políticas culturales en el $\mathrm{CH}$, en este caso no han logrado desarrollar mecanismos de apoyo o desarrollo para estos artistas, que si bien, no todos cuentan con preparación profesional en arte, han encontrado en estas expresiones la forma de ganarse la vida honradamente, sin dañar al prójimo, generando entretenimiento y emociones en el público que los ve, a la gran mayoría les agrada el paseo por esta calle y el encuentro con hombres que parecen de piedra, lo cual provoca un acercamiento al arte desde otra latitud, sin grandes escenarios, ni distancias, sino con la cercanía que da la calle y el transitar en ella. Por lo tanto, aunque no tengan estudios profesionales en arte, es un medio de expresión y de vida que genera retroalimentación y disfrute con el público, el autoempleo encontrado en el arte es digno de destacar, ya que como mencionó un artista 
callejero ¿Quieren cirqueros o sicarios? Es una expresión fuerte, pero es una realidad en nuestro país, donde el desempleo y la formación académica frena a mucha gente a tener una actividad licita, en el arte podemos encontrar el autoempleo por medio del cuerpo, la creatividad y el entretenimiento sano para el público.

En la actualidad, se encuentran ante la disyuntiva de pagar el uso de suelo a una asociación que dirige ambulantes y apoya a las minorías en el $\mathrm{CH}$, porque no han encontrado otra salida para poder trabajar y ganarse una moneda honestamente. Aunque el espacio público es de todos, como expresión de la ciudadanía, en esta calle, dicho espacio cuenta con dueños, las autoridades lo saben y no han podido hacer nada al respecto, ya que existen diferentes intereses políticos y económicos en esta calle. Aunque dicha asociación hace las gestiones para que se coloquen los artistas callejeros en Madero, ellos no saben de arte, ni creo que sea de su interés, lo importante es cobrar la plaza a quienes quieran trabajar. Por lo que, desde mi punto de vista, se toma al arte como rehén de intereses económicos y políticos. Esta es la historia de los artistas callejeros de Madero, que sin voz y sin dañar a nadie, cada día intentan entretener al público, motivar el acercamiento al arte, a la reflexión y luchan por tener un espacio digno para expresarse y trabajar.

Se requieren políticas culturales, donde la participación de los diferentes sectores genere diálogo y acciones concretas, no solamente buenas intenciones, sino considerando la cultura y el arte como recursos de desarrollo humano y social. Para los artistas callejeros es una forma de vida honrada, disfrutando de la retroalimentación del público, es un empleo y una actividad creativa. Para los visitantes genera un acercamiento al arte, a la estética, a los espacios y al disfrute del tiempo libre. Sin embargo, la gestión de este espacio está implicada en negociaciones políticas y económicas, que poco tienen que ver con el arte y su desarrollo. Es necesario generar propuestas para que el arte público no cuente con las restricciones que han vivido estos artistas, que se tomen modelos exitosos de gestión, como en Europa, pero considerando las particularidades de nuestro $\mathrm{CH}$, donde los intereses políticos y económicos por el espacio público, parece que están por encima del arte. 


\section{Fuentes consultadas.}

Aguirre Beltrán, Gonzalo (1967). Regiones de refugio, INI, México.

Augé, Marc (1997). El viaje imposible. El turismo y sus imágenes. Gedisa, España.

Aura, Alejandro (2006) "La cultura como la dimensión central del desarrollo" en Políticas culturales en la Ciudad de México 1997-2005, Gobierno del Distrito Federal, Secretaría de Cultura, Ediciones del Basurero, México.

Berry, Steve (2003). La habitación de ámbar, La Factoría de Ideas, España.

Bonfil, Guillermo (2002). "De culturas populares y política cultural”. En Bonfil, Guillermo et al. Culturas populares y política cultural, CONACULTA, México.

Borja, Jordi y Muxi, Zaida (2000) El espacio público, ciudad y ciudadanía, s/e, Barcelona.

Bouchenaki, Mounir (2001). "Organismos internacionales e instrumentos jurídicos para la preservación de los centros históricos" en Fernando Carrión (Ed.) Centro históricos de América Latina y el Caribe, UNESCO, BID, Ministerio de Cultura y Comunicación de Francia, FLACSO Sede Ecuador, Quito.

Cantú, Rubén (2009) Centro histórico crítico. El ambiente sociourbano en la Ciudad de México, Plaza y Valdés, México.

Carrión, Fernando (2000). "Introducción: El gobierno de los centros históricos" en Fernando Carrión (ed.) Desarrollo cultural y gestión en centros históricos, FLACSO Sede Ecuador, Quito.

(2000). “Centro histórico: relación social, globalización y mitos” en Fernando Carrión (ed.) Desarrollo cultural y gestión en centros históricos, FLACSO 
Sede Ecuador, Quito.

(2001). "Medio siglo en el camino al tercer milenio: los centros históricos de América Latina" en Fernando Carrión (Ed.) Centro históricos de América Latina y el Caribe, UNESCO, BID, Ministerio de Cultura y Comunicación de Francia, FLACSO Sede Ecuador, Quito.

Carman, María (2006) Las trampas de la cultura: los intrusos y los nuevos usos del barrio Gardel, Paidós, Buenos Aires.

Celdrán, Pancracio (2010). Estatuas humanas. Arte en la calle, Subastas Siglo XXI, España.

Coulomb, René (2001). "El Centro Histórico de la Ciudad de México: del rescate patrimonial al desarrollo integral" en Carrión, Fernando (editor) Centros históricos de América Latina y el Caribe, UNESCO, Banco Interamericano de Desarrollo, Ministerio de Cultura y Comunicación de Francia, FLACSO Sede Ecuador, Quito.

Duhau, Emilio y Giglia, Angela (2008) Las reglas del desorden: habitar la metrópoli, Siglo XXI, UAM-A, México.

Ebrard, Marcelo (s/a). Programa General de Desarrollo del Distrito Federal 20072012, Gobierno del Distrito Federal, México.

Fox, Vicente (2001). "Instalación del Consejo Consultivo para el Rescate del Centro Histórico de la Ciudad de México”, Presidencia de la República, México. 14 de agosto.

(2003). "Segunda reunión del Consejo Consultivo para el Rescate del Centro Histórico”, Presidencia de la República, México, 29 de mayo.

Gallo, Rubén (2010). Las artes de la ciudad. Ensayos sobre la cultura visual de la capital, Fondo de Cultura Económica, México. 
Gamio, Manuel, (1960). Forjando Patria, Porrúa, México.

García Canclini, Néstor (ed.), (1987). Políticas culturales en América Latina, Grijalbo, México.

García Canclini, Néstor, (2002). Culturas populares en el capitalismo, Ed. Grijalbo, México.

García Canclini, Néstor (Coord.). (2004) Reabrir espacios públicos. Políticas culturales y ciudadanía, Plaza y Valdés, UAM- I, México.

(2008 a). Diferentes, desiguales y desconectados. Mapas de la interculturalidad, Gedisa, España. $3^{\text {a }}$ reimpresión.

García Canclini, Néstor y Ernesto Piedras (2008 b). Las industrias culturales y el desarrollo de México, Siglo XXI, FLACSO, México.

García Canclini, Néstor (2009). Culturas híbridas. Estrategias para entrar y salir de la modernidad, Random House Mondadori, México, $1^{\text {a }}$ edición en formato de Bolsillo

(2010). La sociedad sin relato. Antropología y estética de la inminencia, Katz Editores, Buenos Aires.

Gellner, Ernest, (1988), Naciones y nacionalismo, Alianza Editorial, México.

Gobierno del Distrito Federal (2004). Ley de cultura cívica del Distrito Federal. México.

(2007). “Acuerdo por el que se crea el órgano de apoyo a las actividades de la Jefatura de Gobierno en el Centro Histórico de la Ciudad de México, denominado Autoridad del Centro Histórico" en Gaceta oficial del Distrito Federal, Décima Séptima Época, No. 22-BIS, 22 de enero. 
Goldberg, Roselee (1988). Performance art, Ediciones Destino, Barcelona.

González, Luis (1947). Las calles de México I. Leyendas y sucedidos, Ediciones Botas, México.

Grimson, Alejandro (2008), "Cultura, globalización y sociedad”. Unidad de Enseñanza Aprendizaje I, Posgrado Virtual en Políticas Culturales y Gestión Cultural, CONACULTA, OEI, UAMI, México.

II Congreso Internacional de Arquitectos y Técnicos de Monumentos Históricos (1964). Carta de Venecia. Venecia.

Jesús Carrillo, Jorge J. (2000) "Plan Estratégico para la Regeneración y el Desarrollo Integral del Centro Histórico de la Ciudad de México" presentado en el Sexto Taller de Imagen Urbana en Ciudades Turísticas con Patrimonio Histórico, Campeche, 9 al 12 de febrero de 2000.

Mejía, Juan Luis (2009), “Apuntes sobre las políticas culturales en América Latina, 1987-2009” en Pensamiento Iberoamericano, 4, pp. 105-129.

Monsiváis, Carlos (2006). El Centro Histórico de la Ciudad de México, Artes Gráficas Palermo, Madrid.

(2010), Apocalipstick, Random House, México, $3^{\mathrm{a}}$ reimpresión.

Montero, Alma (2010), "Pasado y presente: la avenida Madero y los talleres de plateros" en Alicia Martínez (Coord.) Relatos de plata que fundieron nuestra historia, INAH, México.

Mutal, Sylvio (2001). "Ciudades y centros históricos de América Latina y el Caribe: 50 años de trayectoria (1950-1999) en Fernando Carrión (Ed.) Centros históricos de América Latina y el Caribe, UNESCO, BID, Ministerio de Cultura y Comunicación de Francia, FLACSO Sede Ecuador, Quito. 
Nivón, Eduardo, (2006). La política cultural. Temas, problemas y oportunidades, Consejo Nacional para la Cultura y las Artes, Colección Intersecciones, México.

(2008). "Políticas culturales en el tránsito de dos siglos" Unidad de Enseñanza Aprendizaje III. Posgrado Virtual en Políticas Culturales y Gestión Cultural. CONACULTA, OEI, UAMI, México.

Olea, Oscar (1980). El arte urbano. UNAM, México.

Presidencia de la República Mexicana (1975). Reglamento de Trabajadores no asalariados del Distrito Federal, México.

Remesar, A. (1997). Para una teoría del arte público. Proyectos y lenguajes escultóricos. s/e, s/l.

Rojas, Eduardo (2001) "El sector privado en la conservación del patrimonio urbano en América Latina y el Caribe: Lecciones de tres experiencias" en Carrión, Fernando (editor) Centros históricos de América Latina y el Caribe, UNESCO, Banco Interamericano de Desarrollo, Ministerio de Cultura y Comunicación de Francia, FLACSO - Ecuador, Ecuador.

Sánchez Vázquez, Adolfo (1967) Las ideas estéticas de Marx, Ediciones ERA, México.

Secretaría de Desarrollo Urbano y Vivienda. Subdirección de Imagen Institucional y Difusión (2010) “Se inaugura el corredor peatonal Francisco I. Madero”. 18 de octubre.

Teixeira, José Antonio (2008). “Cultura y Sociedad. Unidad de Enseñanza Aprendizaje II, Posgrado Virtual en Políticas Culturales y Gestión Cultural, CONACULTA, OEI, UAMI, México.

Tresserras, Jordi (2004). "La tematización cultural de las ciudades como estrategia de 
desarrollo a través del turismo" en Portal Iberoamericano de Gestión Cultural.

Tylor, B. Edward (1975), "La ciencia de la cultura" en Kahn, JS. Comp. El concepto de cultura: textos fundamentales, Anagrama, España.

UNESCO, (1982). "Conferencia Mundial sobre Políticas Culturales”. Declaración de México.

While, Aidan (2003). "Locating Art Worlds: London and the Making of Young Britisk Art”, en Area, Vol. 35, No. 3, Septiembre, pp.251-263.

Young, James (2006). “Art, Authenticity and Appropriation” en Frontiers of Philosophy in China, Vol. 1, No. 3. Septiembre. pp.455-476.

Yúdice, George, (2002). El recurso de la cultura. Uso de la cultura en la era global, Gedisa, Barcelona.

(2005). "Cultura y Desarrollo: Análisis y consecuencias" en Seminario: La cultura como factor de desarrollo, Chile, Universidad de Chile. (2010), Nueva Guía del Centro Histórico de México, México, Travesía

Editores.

\section{Revistas electrónicas:}

Job, Vanessa (2009). "Poco a poco más estudiantes en el Centro Histórico" en Kilómetro cero (kmcero) Noticias del Centro Histórico de la Ciudad de México, Fideicomiso del Centro Histórico de la Ciudad de México, Febrero, no.7, pp.1, 4-5.

Ortega, Sandra (2010) “2010, el Centro celebrará cambiando" en Kilómetro cero (kmcero) Noticias del Centro Histórico de la Ciudad de México, Fideicomiso del Centro Histórico de la Ciudad de México, Enero, número 18, p.1.

Ruvalcaba, Patricia (2009). "Enorme, el potencial turístico del Centro Histórico” en 
Kilómetro cero (kmcero) Noticias del Centro Histórico de la Ciudad de México, Fideicomiso del Centro Histórico de la Ciudad de México, Marzo, no. 8, pp. 1, 4-6.

Zamorano, Regina (2011) "Espacio público: nueva cara del Centro" en Kilómetro cero (kmcero) Noticias del Centro Histórico de la Ciudad de México, Fideicomiso del Centro Histórico de la Ciudad de México, Febrero, número 31, pp. 1, 4-6.

\section{Información electrónica}

http://www.fundacioncentrohistorico.com.mx/

http://www.centrohistorico.df.gob.mx/fideicomiso/

http://www.autoridadcentrohistorico.df.gob.mx/index.php/la-ach

http://www.milenio.com/node/628272

http://bicentenario.com.mx/?p=10951

http://www.noticiasdetuciudad.df.gob.mx/?p=9897

http://www.accionglobalmexico.org/doc/centroespanol.pdf

\section{Entrevistas realizadas en campo:}

Transcripción de reunión de artistas callejeros de Madero con Fideicomiso del Centro Histórico. (12 de enero de 2011).

Transcripción de reunión de artistas callejeros de Madero con Fideicomiso del Centro Histórico. (18 de enero de 2011).

Entrevista con Gladys “Sacerdotisa Mexica”. Estatua viviente. (19 de enero de 2011).

Transcripción de reunión de artistas callejeros de Madero con Fideicomiso del Centro Histórico. (20 de enero de 2011).

Entrevista con Víctor Romero. Empleado de tienda. (20 de enero de 2011).

Entrevista con Ana de Alba "Cantante de ópera". (20 de enero de 2011).

Entrevista con Ana Álvarez "Bruja wicca" (Personaje). (23 de enero de 2011).

Entrevista con Sergio Sierra "Michael Jackson” (Personaje). (23 de enero de 2011).

Entrevista con Raúl Vázquez “La Muerte” (Estatua viviente). (23 de enero de 2011).

Entrevista con Jesús "La sombra”. (23 de enero de 2011). 
Entrevista con Jorge Baena "Charro cantor" (Estatua viviente). (23 de enero de 2011).

Entrevista con Mario Peña "Watt" (Performance y estatua viviente). (25 de enero de 2011).

Entrevista con José Luis Carrillo "El Soldado (Estatua viviente). (26 de enero de 2011).

Entrevista con David Reyes. Encargado de la calle Madero. PRO DIANA A.C. (26 de enero de 2011).

Entrevista con Antonio Armengüal "El obrero" (Estatua viviente). (26 de enero de 2011).

Entrevista con Rubén Mazariegos. Segundo Oficial de la Corporación Policía Auxiliar del DF. (28 de enero de 2011).

Entrevista con Eduardo Álvarez. "Teatrero, bailarín, cirquero, malabarista”. (28 de enero de 2011).

Entrevista con Abraham Álvarez. "Batman”, "Spider Man”, “Iron Man”. (Personaje). (28 de enero de 2011).

Entrevista con Itzel Díaz. "Catrina” (Estatua viviente). (28 de enero de 2011).

Entrevista con Julio Gómez. "Catrín", "Minero" y "Sombrerero Loco" (Estatua viviente). (28 de enero de 2011).

Entrevista con Jonathan Ríos. "Azteca Dorado" (Estatua viviente). (28 de enero de 2011).

Entrevista con Moisés Rosas. Organillero de la calle Madero. (1 de febrero de 2011).

Entrevista con Luis Miguel de la Cruz. "Payaso Picolín”. (3 de febrero de 2011).

Entrevista con Salomón Masliah. Dueño de dos tiendas Santa Clara y frutería Di Frutetto en Madero. (16 de marzo de 2011).

Entrevista con Enrique Fuentes. Dueño de Librería Madero. (24 de marzo de 2011).

Entrevista con Francisco Chávez. Empleado de tienda. (24 de marzo de 2011).

Entrevista con Irma García. Usuaria y trabajadora del CH. (29 de marzo de 2011).

Entrevista con arquitecto Ricardo Jaral. Coordinador Ejecutivo de Conservación del Espacio Público. Autoridad del CH. (5 de abril de 2011).

Entrevista con Juan Fonseca "Mago". (5 de abril de 2011).

Entrevista con Diputado Arturo López Candido. Vicepresidente de la Comisión de 
Cultura y Presidente de la Comisión de Asuntos Laborales y Previsión Social (Asamblea Legislativa del DF). (6 de abril de 2011).

Entrevista con Fabiola Bernal. Secretaria del Diputado López Candido. (6 de abril de 2011).

Entrevista con Sergio Ortiz. Comunicación y Relaciones Públicas del Museo del Estanquillo. Colecciones Carlos Monsiváis. (7 de abril de 2011).

Entrevista con Noemí Ortega. Limpieza de la calle Madero. (7 de abril de 2011).

Entrevista con Sandra Ortega. Directora de la publicación Kmcero. (11 de abril de 2011).

Entrevista con Anabelí Contreras. Jefa de Unidad de Difusión del Fideicomiso del CH. (15 de abril de 2011).

Visitante 1: Teresa, Nuria, Alfonso. (San Luis Potosí). (19 de abril de 2011).

Visitante 2: Angeles. (Iztapalapa). (19 de abril de 2011).

Visitante 3: Francisco y Judith. (México y Canadá). (19 de abril de 2011).

Visitante 4: Ceferina Conde. (Santa María La Ribera). (21 de abril de 2011).

Visitante 5: Violeta Tapia. (Toluca). (21 de abril de 2011).

Visitante 6: Jessica Rodríguez. (Azcapotzalco). (21 de abril de 2011).

Visitante 7: María de Jesús. (Tlalnepantla). (21 de abril de 2011).

Visitante 8: Beatriz. (Tecamac). (21 de abril de 2011).

Visitante 9: Javier Cortés. (Centro). (21 de abril de 2011).

Visitante 10: Jorge Urquidi. (Morelia). (22 de abril de 2011).

Visitante 11: Ernesto. (22 de abril de 2011).

Entrevista con Gilberto Ramírez. Comunicación interna y casa de cultura Banamex. Fomento Cultural Banamex. (25 de abril de 2011).

Visitante 12: Alma Ortíz (Unidad CTM). (26 de abril de 2011).

Entrevista con Esteban Balkan. Músico profesional y callejero por motivación. (24 de mayo de 2011).

Entrevista con Alejandro Sánchez. Habitante del CH. (26 de mayo de 2011).

Entrevista con arquitecto Alejandro Martínez. Director de Proyectos 
Sustentables de la Secretaría de Obras y Servicios del Gobierno del DF. (20 de junio de 2011). 


\section{anil \\ Casa abierta al tiempo}

\section{UNIVERSIDAD AUTÓNOMA METROPOLITANA}

UNIDAD IZTAPALAPA

\section{DIVISIÓN DE CIENCIAS SOCIALES Y HUMANIDADES}

\section{POSGRADO EN CIENCIAS ANTROPOLÓGICAS}

\section{Caminando por el arte y la cultura en la calle Francisco I. Madero} del Centro Histórico de la Ciudad de México.

\section{Ginna Alexandra Zabre Santamaría}

\section{Tesina de Maestría en Ciencias Antropológicas}

Directora: Dra. Alba Elena Ávila González

Asesores: Dr. Miguel Ángel Aguilar Díaz

México, D.F.

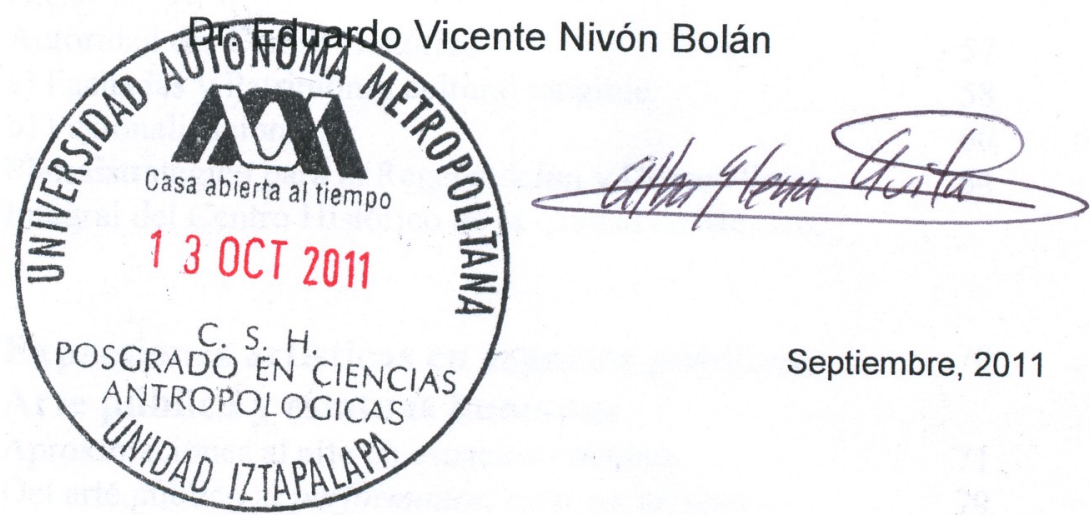

